WSRC-TR-2001-00037

Revision 0

\title{
FORCE REDUCTION FACTORS FOR THE STRUCTURAL DESIGN AND EVALUATION OF FACILITIES CONTAINING NUCLEAR AND HAZARDOUS MATERIALS (U)
}

March 13, 2001

Structural Mechanics

Westinghouse Savannah River Company

Savannah River Site

Aiken, SC 29808

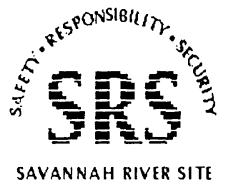

Does Not Contain Unclassified Controlled Nuclear Information

Reviewing Official: $\quad J \cdot R \cdot J v S H I$ Date: $04 / 23 / 01$ 
Revision 0

\section{FORCE REDUCTION FACTORS FOR THE STRUCTURAL DESIGN AND EVALUATION OF FACILITIES CONTAINING NUCLEAR AND HAZARDOUS MATERIALS (U)}

March 13, 2001

Structural Mechanics

Westinghouse Savannah River Company

Savannah River Site

Aiken, SC 29808

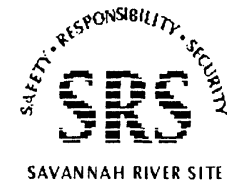


WSRC-TR-2001-00037

Revision 0

\section{FORCE REDUCTION FACTORS FOR THE STRUCTURAL DESIGN AND EVALUATION OF FACILITIES CONTAINING NUCLEAR AND HAZARDOUS MATERIALS (U)}

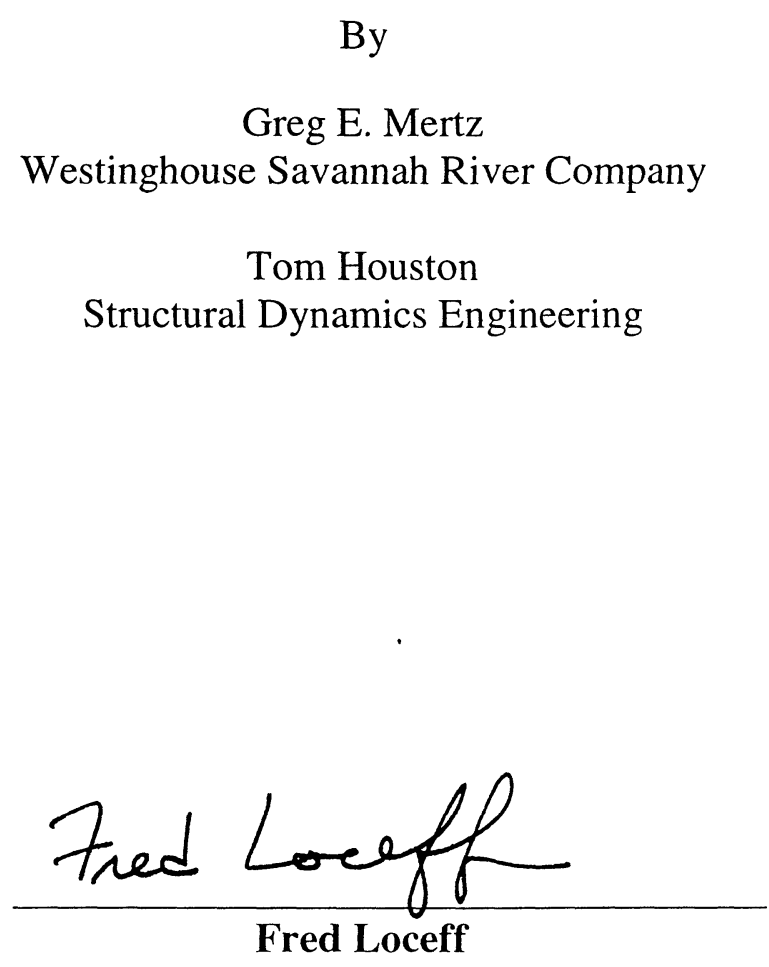

Approved by:

Fred Loceff 


\section{DISCLAIMER}

This report was prepared as an account of work sponsored by an agency of the United States Government. Neither the United States Government nor any agency thereof, nor any of their employees, makes any warranty, express or implied, or assumes any legal liability or responsibility for the accuracy, completeness, or usefulness of any information, apparatus, product or process disclosed, or represents that its use would not infringe privately owned rights. Reference herein to any specific commercial product, process or service by trade name, trademark, manufacturer, or otherwise does not necessarily constitute or imply its endorsement, recommendation, or favoring by the United States Government or any agency thereof. The views and opinions of authors expressed herein do not necessarily state or reflect those of the United States Government or any agency thereof.

This report has been reproduced directly from the best available copy.

Available for sale to the public, in paper, from: U.S. Department of Commerce, National Technical Information Service, 5285 Port Royal Road, Springfield, VA 22161

phone: (800) 553-6847

fax: (703) 605-6900

email: orders@ntis.fedworld.gov

online ordering: http://www.ntis.gov/ordering.htm

Available electronically at http://www.doe.gov/bridge

Available for a processing fee to U.S. Department of Energy and its contractors, in paper, from: U.S. Department of Energy, Office of Scientific and Technical Information, P.O. Box 62, Oak Ridge, TN 37831-0062

phone: (865)576-8401

fax: (865)576-5728

email: reports@adonis.osti.gov 
Force Reduction Factors for the Structural Design and Evaluation of Facilities Containing Nuclear and Hazardous Materials

Summary

The seismic analysis of building frame systems is often performed using structural models that represent the elastic behavior and can capture the elastic response of the structure. Inelastic, or non-linear behavior, in real structures can provide an inelastic energy absorption capacity that reduces the demand on the building from that predicted using the elastic models. Building codes account for this reduction in demand by permitting the use of an " $R$ " factor to significantly reduce the seismic demand used in design. These factors are developed primarily from testing, judgment and experience related to the performance of buildings in past earthquakes and also include a large contribution for presumed over-strength. DOE-STD-1020, used extensively for design of facilities containing hazardous and nuclear material, permits a smaller reduction factor, $F_{\mu}$, which does not credit over-strength in the building system. Neither of the " $R$ " nor " $F_{\mu}$," factors explicitly consider frequency dependence or the effects of higher modes on the reduction in demand due to inelastic behavior.

Extensive work in developing and summarizing allowable distortion and ductility data for elements has been performed over the past decade. Much of this work has been summarized in FEMA documents, FEMA-273 and FEMA-274. Additional studies, sponsored in part by the Applied Technology Council (ATC), has provided substantial information relating the nonlinear behavior of multi-degree of freedom systems, like that found in real structures, to the response of idealized non-linear single degree of freedom systems. The availability of this data allows a closer examination of the contribution of the inelastic energy absorption capacity to force reduction factors.

This report examines significant contributions to inelastic behavior of common building systems and develops frequency dependent force reduction factors that may be used with the results from linear elastic analyses models. Element ductilities that are consistent with a number of limit states, or damage states, are selected, the frequency dependence of demand reduction factors to system ductility is examined, and the relationships between system ductility and the corresponding story and element ductility associated with a given system ductility are established. These contributions are used to develop composite force reduction factors, $F_{\mu}$, for use with elastic analysis of building structures. These frequency dependent reduction factors are developed for generic allowable element ductilities for six models that characterize a wide range of structural system behavior. These generic factors are applied to structural systems typical of those found in facilities containing nuclear and hazardous materials. 
Force Reduction Factors for the Structural Design and Evaluation of Facilities

Containing Nuclear and Hazardous Materials

WSRC-TR-2001-00037

Page iv

\section{Table of Contents}

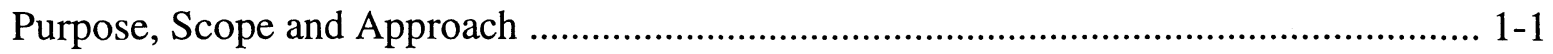

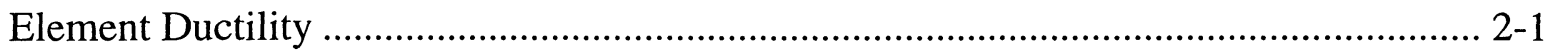

Frequency Dependence of the SDOF Force Reduction Factor ................................... 3-1

Relationship Between Element, Story and System Ductilities ................................... 4-1

Force Reduction Factors for Structural Design and Evaluation ................................... 5-1

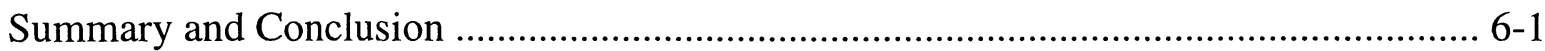

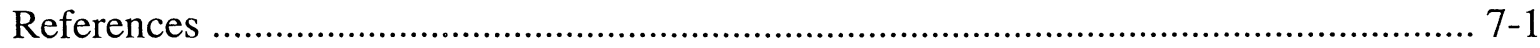

Appendices

A - Span to Depth Ratios as an Indication of Reinforced Concrete Beam Shear ........... A-1

B - Inelastic Energy Absorption Factor for Weak Story Structures .............................. B-1 
Force Reduction Factors for the Structural Design and Evaluation of Facilities Containing Nuclear and Hazardous Materials

\subsection{Purpose, Scope and Approach}

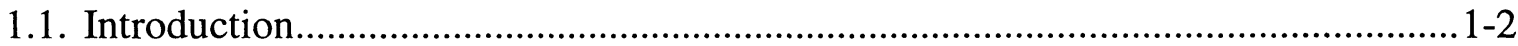

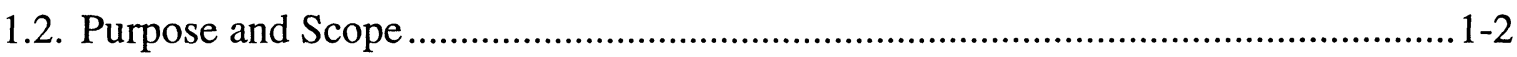

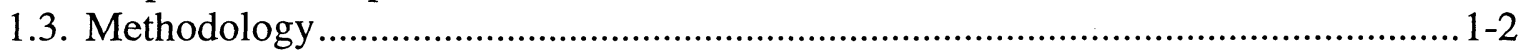

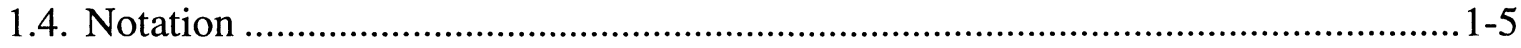




\section{Force Reduction Factors for the Structural Design and Evaluation of Facilities Containing Nuclear and Hazardous Materials

\subsection{Introduction}

The engineering community has known for some time that ductile structures are better at resisting seismic loads than elastic structures. Building codes for conventional structures recognize the benefits of ductile construction and allow for design using a reduced seismic base shear to reflect the beneficial effects of ductile behavior. This reduced base shear is calculated using force reduction factors. However, building codes for conventional structures are primarily concerned with preventing the loss of human life and allow significant structural damage. This level of damage may not be appropriate for facilities containing nuclear or other hazardous materials. For example, it may be desirable to limit the seismic damage in a nuclear confinement structure to hairline cracks while a Category 2 structure could suffer appreciable damage as long as it did not collapse on a Category 1 structure. Thus, an appropriate set of design rules for a nuclear structure would allow for various force reduction factors dependant on the amount of damage that is acceptable. This acceptable damage level defines the limit state. This document summarizes and applies data published in the literature over the past two decades to develop force reduction factors that are appropriate for facilities containing nuclear or other hazardous materials.

\subsection{Purpose and Scope}

The purpose of this document is to (1) propose a methodology to develop a seismic force reduction factor, $\mathrm{F} \mu$, for facilities containing nuclear or other hazardous materials as function of the limit state; (2) develop force reduction factors that are generically applicable to building systems, and (3)apply this methodology to reinforced concrete and structural steel building systems which are commonly used in these facilities.

The authors have had the privilege of participating on an ASCE sub-committee, that is developing performance based structural acceptance criteria for nuclear structures. This subcommittee has developed four structural limit states ranging from essentially elastic behavior to moderate structural damage. The element ductilities and force reduction factors proposed in this document are calibrated to fit these limit states although the generic force reduction factor relationships are also applicable to other limit states.

\subsection{Methodology}

This set of proposed $\mathrm{F} \mu$ factors is developed utilizing the information available in the literature and, through permitting larger force reduction factors for qualitatively more reliable structures, is intended to encourage the use of more reliable building systems. Consistent with the goals of model building codes, the use of good detailing practice is encouraged through allowing higher $\mathrm{F} \mu$, while low reliability configurations are discouraged by decreasing or disallowing the use of a $\mathrm{F} \mu$ in design. Thus, force reduction factors are developed for reinforced concrete moment frames, reinforced concrete shear wall structures, steel moment resisting frames and steel braced frames. 
A force reduction factor, $\mathrm{R}$, that accounts for both the overstrength and the inelastic energy absorption of the structural system is used in the model building codes. Overstrength in a building system can be quantified using a pushover analysis or estimated from existing analyses of similar structures. Pushover analyses are not usually performed as part of the design process and the.use of existing analyses to estimate overstrength is problematic for nuclear facilities. Thus, the overstrength factor is omitted from the force reduction factors proposed here. The overstrength factor in typical nonnuclear commercial building frames ranges from 2 to 3.5 and represents about one-half of the $\mathrm{R}$ factor used in building codes [ATC-2, 1974].

Inelastic energy absorption factors, $\mathrm{F}_{\mu}$, have been extensively studied. The element ductility, amount of strain hardening, shape of the hysteresis loops, building frequency, supporting soil type, and the influence of higher modes (SDOF vs. MDOF) affect $F_{\mu}$. The following sections:

(1) develop element ductilities, $\mu_{\text {element }}$, that are correlated to desired performance or limit state;

(2) relate frequency dependence, secondary effects of strain hardening, hysteresis loop shape and soil type to the force reduction factor for a SDOF system, F $\mu$;

(3) develop relationships between the ductility of MDOF and SDOF systems; and

(4) combine items 1, 2 and 3 to yield force reduction factors, $F \mu$, for design and evaluation.

These four steps are described below, developed in Sections 2-5 and are shown schematically in Figure 1.1.

First, acceptable damage for different limit states is defined for each type of element. Four limit states are used in this document that range from moderate damage in Limit State A (LS-A) to essentially elastic behavior in LS-D. Intermediate limit states consist of LS-C which corresponds to immediate occupancy and LS-B which is defined as halfway between LS-A and LS-C. Story displacements or element rotations associated with each limit state are selected based on the average element behavior, as shown in Figure 1.2. The element is conservatively assumed to have an elasto-plastic behavior with a yield point at the nominal code capacity and an allowable inelastic deformation corresponding to the appropriate limit state displacement. Element ductilities for each limit state are derived on this assumption. The limit state definition and selection of these ductilities is discussed in Section 2.

The inelastic response of different SDOF systems to various ground motions have been extensively studied. Flexural structural systems are represented by hysteresis models having full stable hysteresis loops while structural systems dominated by shear deformation or diagonal brace buckling are represented by pinched hysteresis models. Relationships developed by several researchers are examined in Section 3 and force reduction factors for a SDOF system, F $\mu$ s, are determined considering structural system type, system frequency and element ductility. 
Force Reduction Factors for the Structural Design and Evaluation of Facilities Containing Nuclear and Hazardous Materials

- Element Test Data
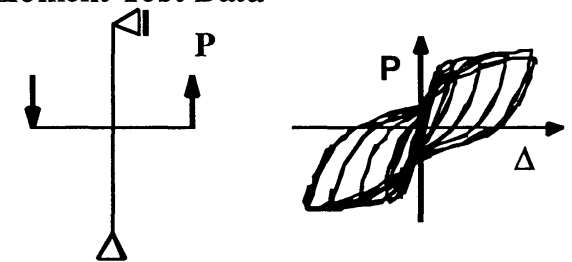

$\Rightarrow \quad$ Allowab le Element Ductility,
$\mu$ element

- SDOF Nonlinear Response S tudies
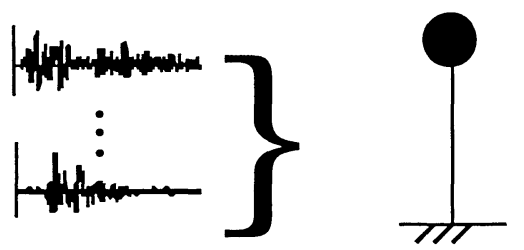

Frequency Dependant SDOF

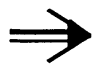

Force Reduction Factor, $\mathrm{F} \mu \mathrm{s}(\mathrm{f})$

- MDOF Nonlinear Res pons e Studies
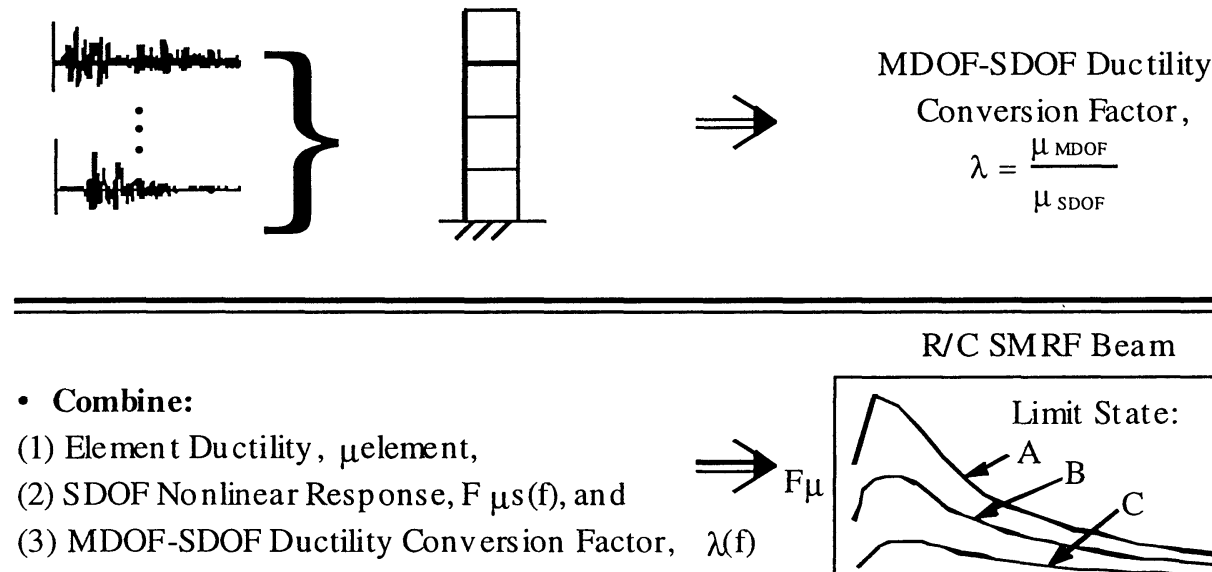

R/C SMRF Beam

- Combine:

(1) Element Ductility, $\mu$ element,

(3) MDOF-SDOF Ductility Conversion Factor, $\lambda(\mathrm{f})$

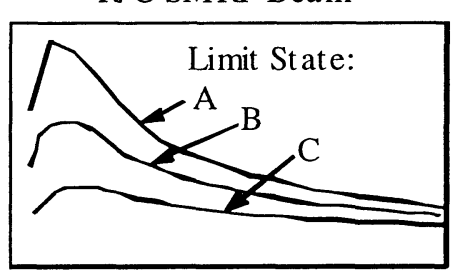

Frequency, $f$

Figure 1.1 F $\mu$ Development

Single degree of freedom models neglect the contribution of higher modes and the relationship between component and global ductility. For some structures these factors may be important, especially at lower frequencies. Relationships between the response of multiple degree of freedom (MDOF) systems and single degree of freedom (SDOF) systems for each of the structural framing types are developed in Section 4.

The allowable element ductility developed in Section 2; modified to account for MDOF effects in Section 4 are used to develop frequency dependent $F \mu$ 's for elements used in each of the building types. The resulting frequency dependent $F \mu$ values are described in Section 5. Conservative, frequency independent, $F \mu$ factors for each type of framing 
Force Reduction Factors for the Structural Design and Evaluation of Facilities Containing Nuclear and Hazardous Materials

WSRC-TR-2001-00037

Page1-5

system are selected based on building frequencies representative of that typically found in facilities containing nuclear material or other hazardous materials.

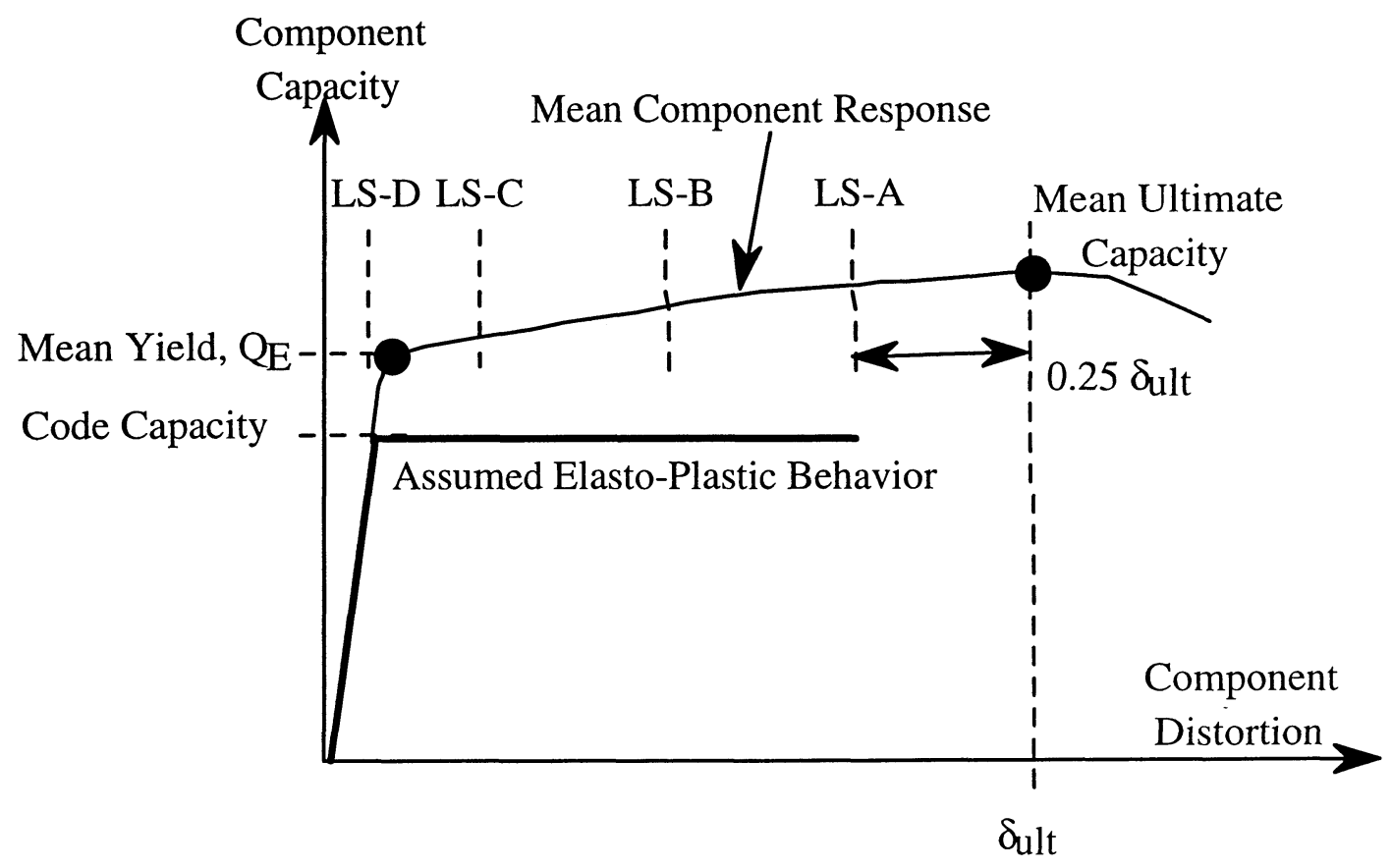

Figure 1.1 Typical Load-Deformation Curve and Limit States

\subsection{Notation}

$\alpha=$ strain hardening ratio or the ratio of post yield stiffness to the elastic stiffness;

$\alpha \mathrm{ki}=$ post yield stiffness of element $\mathrm{i}$;

$\beta=$ viscous damping ratio;

$\beta \mathrm{e}=$ effective damping in the structural system;

$\beta_{\mathrm{H}}=$ hysteretic damping in the structural system;

$\delta_{\phi \mathrm{Fn}}=$ elastically computed displacement at the nominal code capacity limit;

$\delta_{\phi \mathrm{V} n}=$ elastically computed displacement for shear controlled walls at the nominal code capacity limit;

$\delta_{\mathrm{A}}=$ element deformations corresponding to the limit state A;

$\delta_{\mathrm{B}}=$ element deformations corresponding to the limit state B;

$\delta_{\mathrm{C}}=$ element deformations corresponding to the limit state $\mathrm{C}$;

$\delta_{\mathrm{f}}=$ deformation prior to complete loss of strength;

$\delta_{\mathrm{i}}=$ displacement for limit state $\mathrm{i}$;

$\delta_{\text {ult }}=$ displacement at the ultimate load;

$\bar{\delta}_{u l t}=$ mean value of ultimate deformation, $\delta_{\mathrm{ult}}$; 


\section{Force Reduction Factors for the Structural Design and Evaluation of Facilities Containing Nuclear and Hazardous Materials}

$\delta_{\text {FEMA-273 "Collapse }}=$ element deformation corresponding to the FEMA 273 collapse prevention Prevention" limit state;

$\delta_{\text {FEMA-273 "Immediate }}=$ element deformation corresponding to the FEMA 273 Immediate Occupancy" Occupancy limit state;

$\delta_{\text {FEMA-273 "Life Safty" }}=$ element deformation corresponding to the FEMA 273 life safety limit state;

$\delta_{\mathrm{Y}}=$ yield displacement;

$\bar{\delta}_{\mathrm{Y}}=$ mean yield displacement;

$\Delta 1=$ spring yield displacement of first spring in two spring system;

$\Delta 2$ = spring yield displacement of second spring in two spring system;

$\Delta=$ displacement;

$\Delta \mathrm{s}=$ system displacement;

$\Delta \mathrm{y}=$ member yield displacement;

$\phi \mathrm{Fn}=$ nominal code capacity;

$\phi \mathrm{Mn}=$ nominal code moment capacity;

$\phi \mathrm{Vn}=$ nominal code shear capacity;

$\phi=$ strength reduction factor specified by building codes;

$\Phi=$ coefficient used to compute force reduction factors of SDOF systems, a function of site classification (rock, soft soil, alluvium);

$\kappa_{\mathrm{FSW}}=$ ratio of MDOF base shear to SDOF base shear for a Flexural Shear Wall (FSW);

$\kappa=$ ratio of MDOF to SDOF base shear at a constant ductility;

$\lambda_{\mathrm{BF}}=$ ductility modification factor for braced frames;

$\lambda_{\mathrm{CH}}=$ ductility modification factor for frames where hinges form in the columns;

$\lambda_{\text {Reed }}=$ ductility modification factor for frames with a single weak story;

$\lambda_{\text {ws }}=$ ductility modification factor for frames with a weak story;

$\lambda=$ ratio of MDOF to SDOF ductility at a constant base shear;

$\lambda_{\mathrm{BH}}=$ ductility modification factor for frames where hinges form in the beams;

$\rho=$ ratio of tension reinforcement;

$\rho^{\prime}=$ ratio of compression reinforcement;

$\rho_{\mathrm{BAL}}=$ reinforcement ratio producing balanced strain conditions;

$\mu 1=$ ductility of the first spring in two spring system;

$\mu 2=$ ductility of the second spring in two spring system;

$\mu=$ ductility;

$\mu \mathrm{e}=$ effective ductility;

$\mu_{\text {element }}=$ element ductility;

$\mu_{\mathrm{i}},=$ ductility for limit state $\mathrm{i}$;

$\mu_{i}^{\prime}=$ ductility based on the mean yield displacement, $\bar{\delta}_{Y}$;

$\mu \mathrm{s}=$ system ductility;

$\mu_{\mathrm{A}}=$ ductility for Limit State A;

$\mu_{\mathrm{B}}=$ ductility for Limit State B;

$\mu_{\mathrm{C}}=$ ductility for Limit State $\mathrm{C}$; 


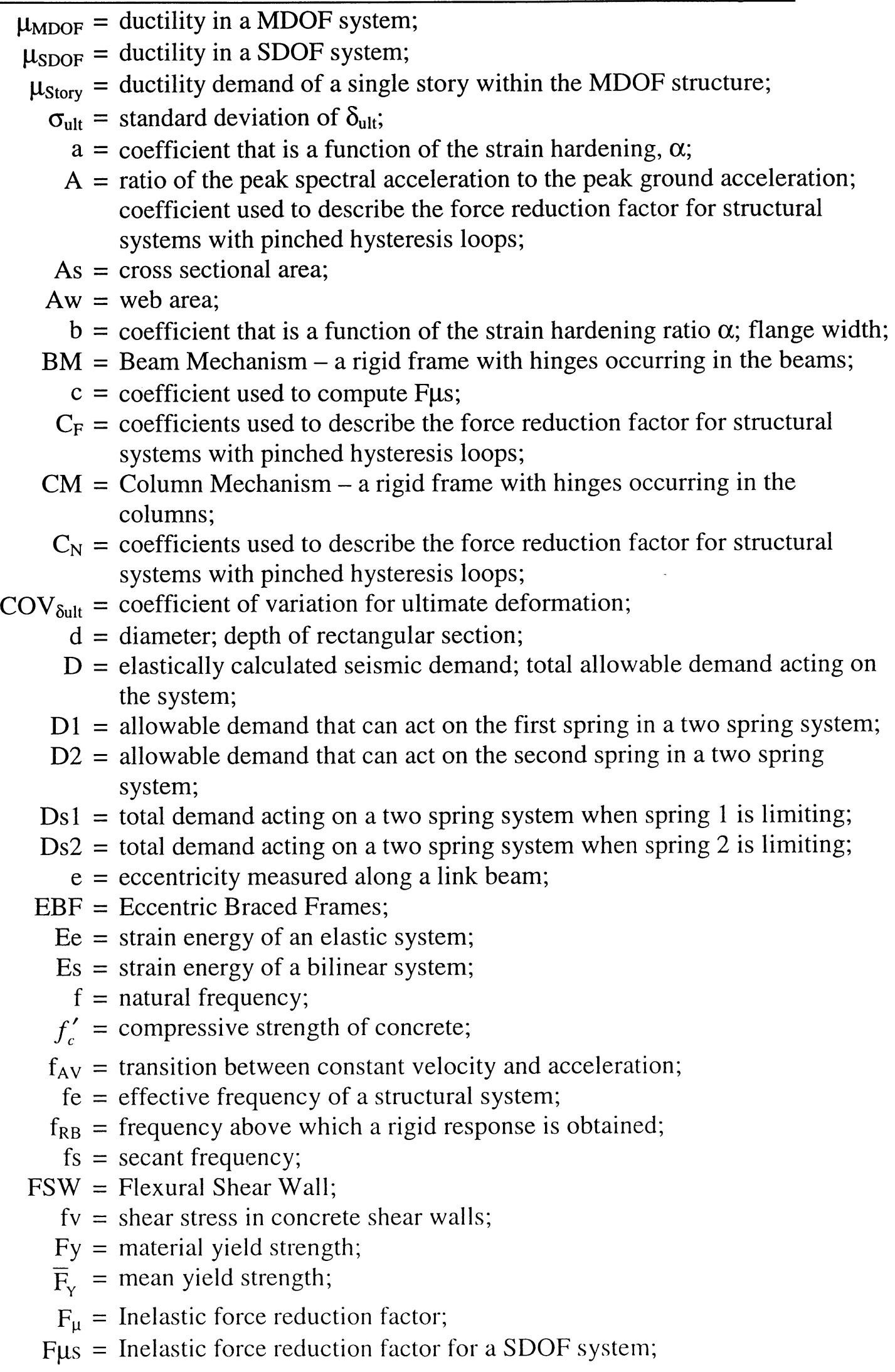


Force Reduction Factors for the Structural Design and Evaluation of Facilities Containing Nuclear and Hazardous Materials

$\overline{\mathrm{F}} \mu \mathrm{s}=$ the mean value of the SDOF force reduction factor;

$\mathrm{g}=$ acceleration due to gravity;

$\mathrm{h}=$ height of wall; depth of section;

$\mathrm{H}=$ height;

$\mathrm{hz}, \mathrm{Hz}=$ hertz;

$\mathrm{IBC}=$ International Building Code;

IMRF = Intermediate Moment Resisting Frames;

$\mathrm{k}=$ location of the weak story, numbered up from the base;

$\mathrm{K}=$ stiffness of elastic region of a pushover curve;

$\mathrm{ki}=$ elastic stiffness of spring;

1 = span;

LS-A = Limit State A;

LS-B = Limit State B;

LS-C = Limit State C;

LS-D = Limit State D;

$\mathrm{lw}=$ wall length;

MDOF = multi-degree of freedom system;

$m_{\text {FEMA-273 "Collapse }}=$ force reduction factor provided in FEMA 273 for the collapse prevention

Prevention" limit state;

$\mathrm{m}_{\text {FEMA-273 "Immediate }}=$ force reduction factor provided in FEMA 273 for the Immediate

Occupancy" Occupancy limit state;

m $_{\text {FEMA-273 "Life Safety" }}=$ force reduction factor provided in FEMA 273 for the life safety limit state;

$\mathrm{m}_{\mathrm{i}}=$ force reduction factor provided in FEMA 273 at limit state $\mathrm{i}$;

$\mathrm{n}=$ number of stories in a multistory system;

OCBF = Ordinary Concentric Braced Frames;

OMRF = Ordinary Moment Resisting Frames;

$\mathrm{P}=$ applied load on a cantilever beam; axial load in beam or column;

$\mathrm{P} 1$ = capacity of the first spring in two spring system;

$\mathrm{P} 2$ = capacity of the second spring in two spring system;

$\mathrm{Pa}=$ load at the first change in stiffness in a backbone curve;

$\mathrm{PGA}=$ peak ground acceleration;

$\mathrm{Pi}=$ capacity of the element $\mathrm{I}$;

Py = yield force;

$\mathrm{R}=$ factor used by model building codes to reduce seismic demand which includes both $F \mu$ and overstrength and is typically defined at the life safety limit state;

$\mathrm{s}=$ strain hardening ratio;

$\mathrm{Sa}=$ spectral acceleration;

SDOF = Single Degree-of-Freedom;

SMRF = Special Moment Resisting Frames;

$\mathrm{T}=$ period of a structure $(\mathrm{sec})$;

$\mathrm{t}=$ thickness;

$\mathrm{T}_{\mathrm{D}}=$ duration of strong motion;

$\mathrm{t}_{\mathrm{f}}=$ flange thickness; 
Force Reduction Factors for the Structural Design and Evaluation of Facilities

Containing Nuclear and Hazardous Materials

WSRC-TR-2001-00037

Page1-9

$\mathrm{Tg}=$ predominant period of the site which corresponds to the period of peak spectral velocity;

$\mathrm{UBC}=$ Uniform Building Code;

$\mathrm{V}_{\mathrm{MDOF}}=$ shear in a MDOF system;

$\mathrm{Vs}=$ shear demand;

$\overline{\mathrm{V}}_{\mathrm{Y}}=$ mean shear capacity of reinforced concrete shear walls;

$\mathrm{V}_{\mathrm{SDOF}}=$ shear in a SDOF system;

$\mathrm{w}=$ width;

$\mathrm{WS}=$ Weak Story - a rigid frame with inelastic deformation concentrated into a weak story;

$\mathrm{Z}=$ plastic section modulus. 
Force Reduction Factors for the Structural Design and Evaluation of Facilities

\subsection{Element Ductility}

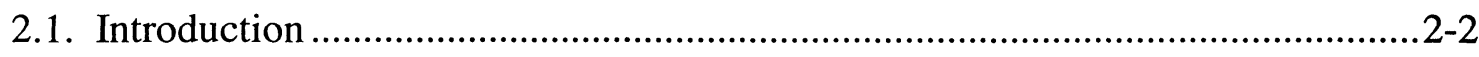

2.2. Limit States ........................................................................................... 2-2

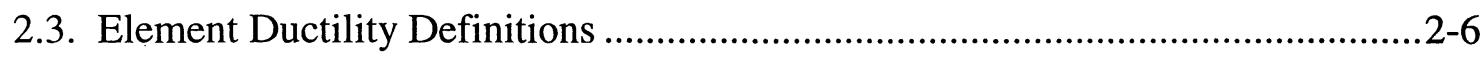

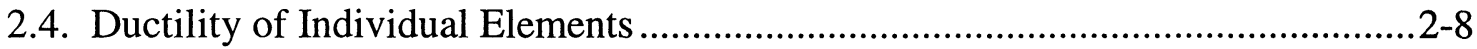

2.4.1. Reinforced Concrete Frames ....................................................................2-8

2.4.2. Concrete Shear Walls .......................................................................... 2-12

2.4.3. Steel Moment Resisting Frames..........................................................2-16

2.4.4. Steel Braced Frame ..........................................................................2-18 


\section{Force Reduction Factors for the Structural Design and Evaluation of Facilities Containing Nuclear and Hazardous Materials WSRC-TR-2001-00037}

\subsection{Introduction}

Element ductilities are developed in this section for four different limit states ranging from essentially elastic behavior to moderate permanent distortion associated with moderate damage. Each limit state represents a different level of seismic deformation and it is anticipated that the user will identify an acceptable deformation level for a particular structure and utilize the ductility corresponding to the acceptable deformation. Ductilities are developed on the element level rather than the structure level because failure of any given element to meet a given limit state is a function of the deformation demands placed on that element.

In this document an element is defined as the portion of a structural member in the primary seismic load path that undergoes inelastic deformation. Examples of elements include:

- the plastic hinge region at the end of a beam or column;

- the hinge region of either shear or bending controlled shear walls;

- the entire length of a brace element that buckles; and

- the plastic hinge region of a link beam in an eccentrically braced frame.

Secondary elements are elements that have inelastic deformation, but the resistance of these elements is not included in the seismic load path. A rigid moment frame that resist gravity loads in shear wall structure subject to lateral seismic loads consist of secondary elements because the shear walls, designed to resist $100 \%$ of the lateral seismic load, are the primary lateral load path. Note that this same gravity frame is the primary load path for vertical seismic loads. The deformation limits developed in this report are applicable for both primary and secondary elements. However, the limit state for secondary members may be less restrictive than the limit state for primary members.

Element ductilities are derived from element ductilities, deformation limits and force reduction factors provided in FEMA 273. FEMA-273 utilizes mean element capacities while the approach used in this document is based on code capacities. Thus, the FEMA273 element data is modified to account for the difference between mean and code capacities. Element ductilities are developed for reinforced concrete moment frame, reinforced concrete shear wall, steel moment frame, and steel braced frame systems.

\subsection{Limit States}

Permissible member ductilities are based upon the four limit states described in Table 2.1, and shown on the typical element load-deformation curve in Figure 2.1. The overall deformation in a redundant structure is typically less than the deformation in the element with the largest demand to capacity ratio. Thus, the maximum element deformations in Figure 2-1 are likely to be larger than the overall structural damage in Table 2.1. Note that Table 2.1 contains limit state descriptions from the perspective of the entire structure 


\section{Force Reduction Factors for the Structural Design and Evaluation of Facilities Containing Nuclear and Hazardous Materials

while the load deformation curve in Figure 2.1 is for a single, limiting element. The four limits states are:

- Limit State D (LS-D) corresponds to the element's deformation at the nominal code capacity, $\phi \mathrm{Fn}(\phi \mathrm{Mn}, \phi \mathrm{Vn}$, etc...) and represents essentially elastic behavior. The ductility for Limit State $D$ is always unity, $\mu_{D}=1$, and this limit state is not discussed further.

- Limit State C (LS-C) corresponds to minor inelastic deformation in the element and is consistent with the "Immediate Occupancy" limit state in FEMA-273. This limit state corresponds to the mean deformation at which visible, permanent deformation in the element occurs. This limit state corresponds to minor hairline cracking in concrete elements and minor local yielding or minor buckling in steel members.

- Limit State A (LS-A) is the element deformation that is generally exceeded.by roughly $84 \%$ (mean less one standard deviation) of the deformations corresponding to the ultimate strength, $\delta_{\text {ult }}$. Assuming a coefficient of variation for ultimate deformation, $\mathrm{COV}_{\delta \text { ult }}$, of 0.25 then $\sigma_{\text {ult }}=\operatorname{COV}_{\text {dult }} \bar{\delta}_{\text {ult }}=0.25 \bar{\delta}_{\text {ult }}$ where $\sigma_{\text {ult }}$ is the standard deviation of $\delta_{\text {ult }}$ and $\bar{\delta}_{u l t}$ is the mean value of $\delta_{\text {ult. }}$ Then, the element deformation associated with limit state $\mathrm{A}, \delta_{\mathrm{A}}$, is

$\delta_{A}=\bar{\delta}_{u l t}-\sigma_{u l t}=\bar{\delta}_{u l t}-0.25 \bar{\delta}_{u l t}=0.75 \bar{\delta}_{u l t}$

Thus the deformation at Limit State A is consistent with the FEMA-273 "Life Safety" limit state. The R values used in IBC-2000 are also based on a "Life Safety" limit state. Therefore, the deformation at Limit State A would be expected to be consistent with the IBC-2000 deformation. However, the $\mathrm{R}$ values contain a system over strength factor that is not considered in the development of $F_{\mu}$. Thus, the deformation of a structure designed to Limit State A will be less than the deformation of the same structure designed to the IBC-2000 "Life Safety" limit state.

This limit state is associated with limited yielding in reinforced concrete beams without crushing and minor cracking of shear walls. Steel elements are expected to have element distortions associated with minor yielding and buckling. These element deformations are described further below.

- Limit State B (LS-B) is an intermediate limit state between Limit States A and C.

$\delta_{B}=\frac{\delta_{A}+\delta_{C}}{2}$ 
In addition to the Immediate Occupancy and Life Safety limit states, FEMA-273 also has a "Collapse Prevention" limit state, which permits deformations corresponding to the lesser of $\bar{\delta}_{u l t}$ and $75 \% \delta_{\mathrm{f}}$ as shown in Figure 2.2, where $\delta_{\mathrm{f}}$ corresponds to the deformation prior to complete loss of strength. The FEMA-273 "Collapse Prevention" limit state would result in more deformation than in Limit State A and, for ductile elements, represents the mean estimate of $\bar{\delta}_{u l t}$.

The parameters used to define ductility in this document are defined and deformations and ductilities corresponding to these limit states are developed for individual steel and concrete elements in the following sections.

Table 2.1 Structure Limit States

\begin{tabular}{|l|l|l|l|l|}
\hline Limit State & LS-A & LS-B & LS-C & LS-D \\
\hline Description & $\begin{array}{l}\text { Moderate } \\
\text { Permanent } \\
\text { Distortion }\end{array}$ & $\begin{array}{l}\text { Minor } \\
\text { Permanent } \\
\text { Distortion }\end{array}$ & $\begin{array}{l}\text { Limited } \\
\text { Permanent } \\
\text { Distortion }\end{array}$ & $\begin{array}{l}\text { Essentially } \\
\text { Elastic } \\
\text { Behavior }\end{array}$ \\
\hline $\begin{array}{l}\text { Overall } \\
\text { Damage }\end{array}$ & Moderate & Minor & Light & Very Light \\
\hline $\begin{array}{l}\text { General } \\
\text { Structure }\end{array}$ & $\begin{array}{l}\text { Some residual } \\
\text { strength and } \\
\text { stiffness left in } \\
\text { all stories. } \\
\text { Gravity-load- } \\
\text { bearing elements } \\
\text { function. No out- } \\
\text { of-plane failure } \\
\text { of walls. Some } \\
\text { permanent drift. }\end{array}$ & $\begin{array}{l}\text { Residual } \\
\text { strength and } \\
\text { stiffness left in } \\
\text { all stories. Some } \\
\text { local yielding. } \\
\text { Limited } \\
\text { permanent drift. }\end{array}$ & $\begin{array}{l}\text { No visible } \\
\text { permanent drift. } \\
\text { Structure } \\
\text { substantially } \\
\text { retains original } \\
\text { strength and } \\
\text { stiffness. Minor } \\
\text { cracking of } \\
\text { structural } \\
\text { elements. }\end{array}$ & $\begin{array}{l}\text { No permanent } \\
\text { drift; structure } \\
\text { substantially } \\
\text { retains original } \\
\text { strength and } \\
\text { stiffness. Minor } \\
\text { cracking of } \\
\text { structural } \\
\text { elements. }\end{array}$ \\
\hline
\end{tabular}


Force Reduction Factors for the Structural Design and Evaluation of Facilities Containing Nuclear and Hazardous Materials

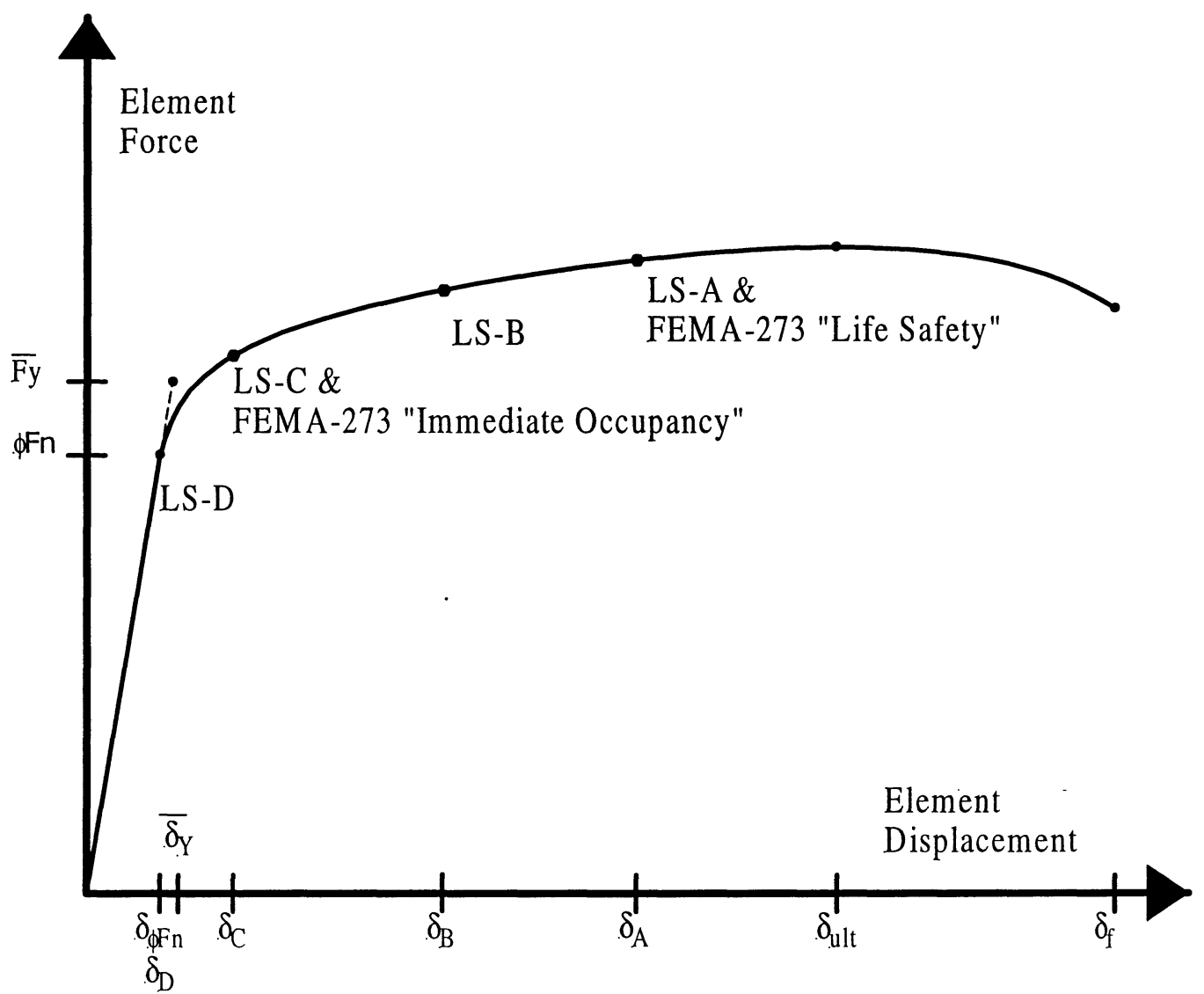

Figure 2.1 Typical Element Load-Deformation Curve and Limit States
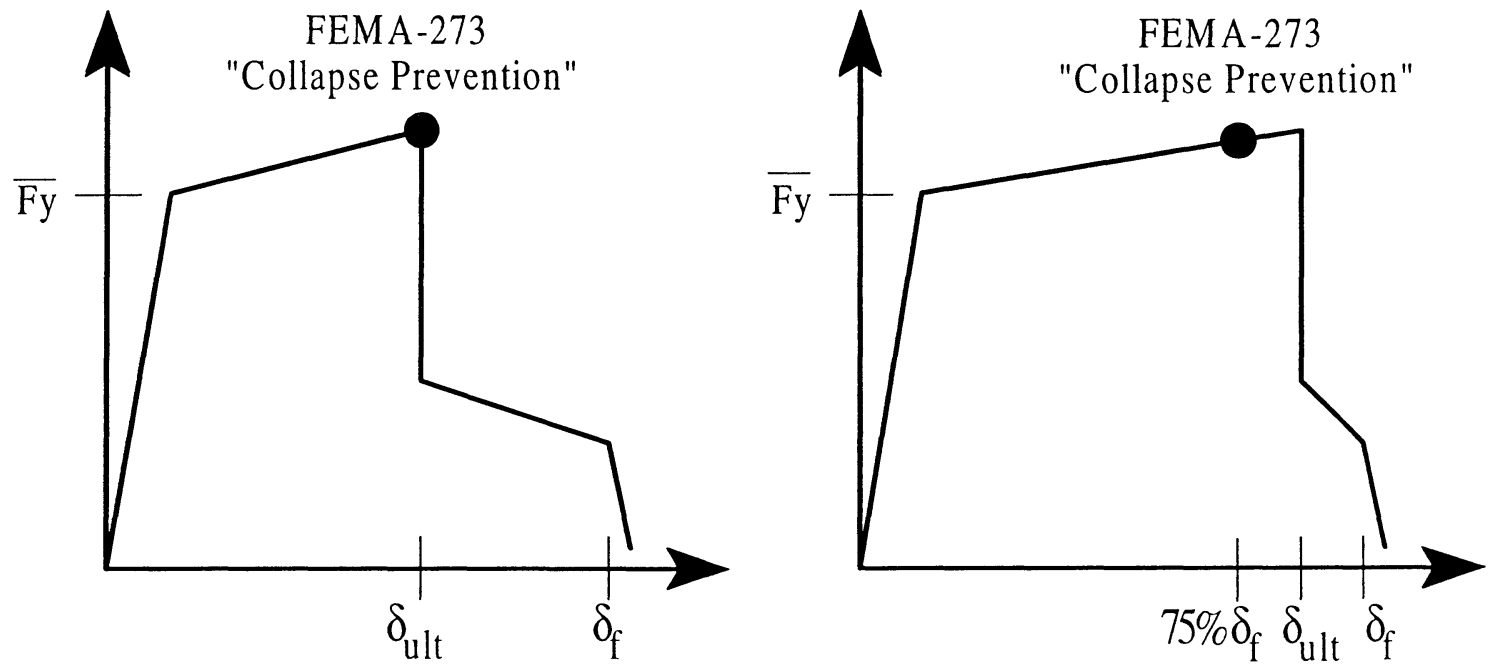

Figure 2.2 FEMA-273 Collapse Prevention Limit State 


\section{Force Reduction Factors for the Structural Design and Evaluation of Facilities Containing Nuclear and Hazardous Materials WSRC-TR-2001-00037}

Page 2-6

\subsection{Element Ductility Definitions}

Ductility is defined as the ratio of the maximum displacement to the yield displacement. However, differences in the assumed yield point lead to inconsistent ductility definitions. FEMA-273 has an extensive collection of component ductilities and force reduction factors, $\mathrm{m}$, that are based on mean yield capacities. The ductility definition used in this document is defined below and is related to the FEMA-273 ductility and force reduction factor. This relationship is used in subsequent sections to convert the FEMA-273 component data for use in this document.

In this document, the ductility for limit state $\mathrm{i}, \mu_{\mathrm{i}}$, is defined as the ratio of the displacement for limit state $\mathrm{i}, \delta_{\mathrm{i}}$, to the elastically computed displacement, $\delta_{\phi \mathrm{Fn}}$, at the nominal code capacity, $\phi \mathrm{Fn},(\phi \mathrm{Mn}, \phi \mathrm{Vn}, \ldots)$

$$
\mu_{i}=\frac{\delta_{i}}{\delta_{\phi F n}}
$$

The mean yield strength, $\bar{F}_{Y}$, is assumed to be $125 \%$ of the nominal code capacity, $\phi F n$. This $125 \%$ difference corresponds to removing the $\phi$ factor $(\phi=0.9)$ and conservatively ${ }^{1}$ taking the mean material strength as $115 \%$ of the minimum specified strength.

$$
\bar{F}_{Y}=1.15 \frac{\phi F n}{0.9} \approx 1.25 \phi F n
$$

Assuming that the member response is elastic below the mean yield strength, a mean yield strength equal to $125 \%$ of the nominal code capacity also results in the mean yield displacement, $\bar{\delta}_{Y}$, equal to $125 \%$ of the displacement corresponding to the nominal code capacity, $\delta_{\phi \mathrm{Fn}}$

$$
\bar{\delta}_{Y}=1.25 \delta_{\phi F n}
$$

FEMA-273, Section 2.13, defines the force reduction factor at limit state $\mathrm{i}, \mathrm{m}_{\mathrm{i}}$, as

\footnotetext{
${ }^{1}$ FEMA-273 is based on the expected capacities for deformation controlled elements. For steel members the expected capacity is calculated using the expected (mean) yield strength and code capacities with $\phi$ taken as unity. Currently, the expected yield strength of structural steels is 115 to $130 \%$ of the specified minimum yield strength depending on steel grade [SAC Seismic Design Criteria for New Moment-Resisting Steel Frame Construction, 50\% Draft, January 1999].
}

As a default value for concrete elements, the tensile yield strength for longitudinal reinforcement in FEMA-273 is taken as $125 \%$ times the nominal yield strength and ACI 318 may be used to calculate strengths, provided that the strength reduction factor, $\phi$ is taken as unity. 
$m_{i}=0.75 \frac{\delta_{i}}{\delta_{Y}}=0.75 \mu_{i}^{\prime}$

Where $\delta_{\mathrm{i}}$, is the displacement for limit state $\mathrm{i}, \bar{\delta}_{Y}$ is the mean yield displacement and $\mu_{i}^{\prime}$ is the ductility based on the mean yield displacement, $\bar{\delta}_{Y}$.

In Section 3 of this document, the elastic force reduction factor for low frequency structures is shown to be approximately equal to the ductility, $\mu$. The reduction of $m_{i}$ to $0.75 \mu_{i}^{\prime}$ in Equation 2-6 introduces a conservative bias in low frequency structures. At higher frequencies, the force reduction factor in Section 3 is shown to be less than the ductility, and use of $0.75 \mu_{i}^{\prime}$ for a force reduction factor may not be conservative ${ }^{2}$. The $\mathrm{F} \mu$ force reduction factors developed in Section 3 explicitly account for frequency dependency and the use of $0.75 \mu$ would be redundant. Therefore, the ductility based on the mean yield displacement at Limit State i, $\mu_{i}^{\prime}$, can be derived from the FEMA-273 "m" factor by

$\mu_{i}^{\prime}=\frac{\delta_{i}}{\bar{\delta}_{Y}}=\frac{4}{3} m$

or the maximum displacement for limit state $i$ is

$\delta_{i}=\frac{4}{3} m \bar{\delta}_{Y}$

Substituting Equations 2-5 and 2-8 into Equation 2-3 and simplifying yields

$\mu_{i}=\frac{\delta_{i}}{\delta_{\phi F n}}=\frac{4 / 3 m_{i}\left(1.25 \delta_{\phi F n}\right)}{\delta_{\phi F n}}=1.67 m_{i}$

Thus, the ductility for limit state $i$, defined in this document as the ratio of the maximum displacement for limit state $\mathrm{i}, \delta_{\mathrm{i}}$, to the elastically computed displacement, $\delta_{\phi \mathrm{Fn}}$, at the nominal code capacity, $\phi F n$, and the ductility is 1.67 times the FEMA-273 force reduction factor, $\mathrm{m}$, for limit state $\mathrm{i}$.

\footnotetext{
${ }^{2}$ In the constant acceleration range where the force reduction factor is $\sqrt{2 \mu-1}$, then the approximation of $3 / 4 \mu_{i}^{\prime}$ is conservative for ductilities less than 3 and unconservative for ductilities greater than 3 .
} 
Force Reduction Factors for the Structural Design and Evaluation of Facilities

Containing Nuclear and Hazardous Materials

Combining Equation 2-9 with the limit states from the previous section yields the ductility for Limit State $\mathrm{C}, \mu_{\mathrm{C}}$,

$\mu_{\mathrm{C}}=1.67 \mathrm{~m}_{\text {FEMA 273"Immediate Occupancy" }}$

Similarly, the ductility for Limit State $\mathrm{A}, \mu_{\mathrm{A}}$

$\mu_{A}=1.67 m_{\text {FEMA 273"Life Safety" }}$

and the ductility for Limit State $B, \mu_{B}$

$\mu_{B}=\frac{\mu_{A}+\mu_{C}}{2}$

Element deformations corresponding to the limit states are

$$
\begin{aligned}
& \delta_{\mathrm{C}}=\delta_{\mathrm{FEMA} 273 " \text { Immediate Occupancy" }} \\
& \delta_{\mathrm{A}}=\delta_{\mathrm{FEMA} 273 " \text { Life Safety" }} \\
& \delta_{B}=\frac{\delta_{A}+\delta_{C}}{2}
\end{aligned}
$$

\subsection{Ductility of Individual Elements}

The ductilities permitted in elements correspond to the desired performance, or limit state, of the structure. Ductilities for elements in reinforced concrete (R/C) frames, steel moment frames, steel braced frames and $\mathrm{R} / \mathrm{C}$ shear walls are developed for Limit States $\mathrm{A}, \mathrm{B}$, and $\mathrm{C}$.

\subsubsection{Reinforced Concrete Frames}

The level of permissible non-linear behavior in reinforced concrete elements corresponds to the desired performance level of the structure. Performance levels for two limit states, LS-A and LS-C, are used to develop allowable levels of non-linear behavior for reinforced concrete moment frames and thus the magnitude of ductility permitted for each limit state. These limits for performance, and associated building drifts, are described in Table 2.2. 
Force Reduction Factors for the Structural Design and Evaluation of Facilities

Containing Nuclear and Hazardous Materials

WSRC-TR-2001-00037

Page 2-9

Table 2.2 Limit State for Elements in Reinforced Concrete Frames

\begin{tabular}{|l|l|l|}
\hline Limit State & LS-A & LS-C \\
\hline $\begin{array}{l}\text { R/C Moment } \\
\text { Resisting Frame } \\
\text { Damage }\end{array}$ & $\begin{array}{l}\text { Extensive damage to beams. } \\
\text { Spalling of cover and shear } \\
\text { cracking (<1/8 inch) in ductile } \\
\text { columns. Spalling of cover in } \\
\text { nonductile columns. Joint } \\
\text { cracks less than } 1 / 8 \text { inch. }\end{array}$ & $\begin{array}{l}\text { Minor hairline cracking. } \\
\text { Limited yielding possible at a } \\
\text { few locations. No crushing } \\
\text { (concrete strains below 0.003) }\end{array}$ \\
\hline $\begin{array}{l}\text { Structure Drift } \\
\text { drift }\end{array}$ & $\begin{array}{l}1 \% \text { transient drift; } \\
\text { no visible permanent drift. }\end{array}$ \\
\hline
\end{tabular}

Allowable deformations corresponding to limit states LS-A and LS-C are a function of both detailing and load condition. Joint detailing, including both the development of reinforcement and the amount of confinement provided, affects the displacement capacity of an element as follows:

- Joints with inadequate development have degrading hysteresis loops as the bar slips, while joints with adequate development have large stable hysteresis loops.

- Confinement is typically provided by transverse reinforcement and increases both the crushing ductility and shear ductility of the element.

- Poorly confined beams can have pinched hysteresis loops due to shear deformation.

- Similarly, the ductility of poorly confined columns is limited by either crushing or shear mechanisms.

Balanced reinforcing affects the size and shape of the hysteresis loops. Members with symmetrical reinforcing tend to form large, stable loops while those with grossly unsymmetrical reinforcing do not.

The level of applied shear and axial load also affects the displacement capacity of concrete elements. Members with low shear form large stable hysteresis loops while members with high shear tend to have pinched hysteresis loops. In addition, members with large axial load fail prematurely by crushing of the concrete. Generally, ductility decreases as the axial load is increased.

Permissible plastic rotations are developed using Equations 2-13 to 2-15 and ductilities are developed using Equations 2-10 to 2-12 with the deformation limits and $m$ values based on the values provided in FEMA-273, Chapter 6 . The permissible plastic rotations and corresponding ductilities are a function of (1) detailing; (2) shear stress; and (3) axial stress. Reinforced concrete frames are designated as Ordinary Moment Resisting Frames (OMRF), Intermediate Moment Resisting Frames (IMRF), or Special Moment Resisting Frames (SMRF), with separate detailing requirements for each frame type. Judgment is used to assess the shear and axial stress levels that are appropriate for concrete frames used in nuclear facilities. 
Force Reduction Factors for the Structural Design and Evaluation of Facilities Containing Nuclear and Hazardous Materials

Frames resisting lateral loads in new nuclear construction should be built in accordance with Chapter 21 of ACI 349-97 and would classify these frames as Special Moment Resisting Frames. IMRF and ORMF are not recommended for new nuclear construction and the values for these frame types are included to assist in the evaluation of existing nuclear facilities.

The member ductilities selected for each frame category are shown in Table $2.3 \mathrm{a}$ and the corresponding rotations are shown in Table $2.3 \mathrm{~b}$. The basis for selection of the member ductilities of the concrete components for each frame category is summarized below. The applicability of the values in these tables is provided in following the next paragraphs.

Table 2.3a Member Flexural Ductilities for Reinforced Concrete Frames

\begin{tabular}{|c|c|c|c|c|}
\cline { 3 - 5 } \multicolumn{2}{c|}{} & \multicolumn{3}{c|}{ Limit State } \\
\hline \multirow{3}{*}{ Element } & Frame Type & LS-A & LS-B & LS-C \\
\hline \multirow{3}{*}{ Beams $15 \leq \ell / \mathrm{h}$} & SMRF & 10 & 6.5 & 3.25 \\
\cline { 2 - 5 } & IMRF & 5 & 4 & 3.25 \\
\cline { 2 - 5 } & OMRF & 5 & 4 & 3.25 \\
\hline \multirow{3}{*}{ Columns } & SMRF & 5 & 4.25 & 3.25 \\
\cline { 2 - 5 } & IMRF & 3.75 & 3.5 & 3.25 \\
\cline { 2 - 5 } & OMRF & 3.25 & 2.25 & 1.25 \\
\cline { 2 - 5 } & SMRF & 2.5 & 2.25 & 1.75 \\
\cline { 2 - 5 } & IMRF & 1.75 & 1.5 & 1.25 \\
\hline
\end{tabular}

Note: Linear interpolation is recommended for beams with $10<\% / \mathrm{h}<15$.

Table 2.3b Plastic Rotation for Reinforced Concrete Frames (radians)

\begin{tabular}{|c|c|c|c|c|}
\hline & & \multicolumn{3}{|c|}{ Limit State } \\
\hline Element & Frame Type & LS-A & LS-B & LS-C \\
\hline \multirow{3}{*}{ Beams $15 \leq \mathrm{e} / \mathrm{h}$} & SMRF & 0.02 & 0.01 & 0.005 \\
\cline { 2 - 5 } & IMRF & 0.01 & 0.0075 & 0.005 \\
\cline { 2 - 5 } & OMRF & 0.01 & 0.0075 & 0.005 \\
\hline \multirow{3}{*}{ Beams $/ \mathrm{h} \leq 10$} & SMRF & 0.01 & 0.0075 & 0.005 \\
\cline { 2 - 5 } & IMRF & 0.075 & 0.006 & 0.005 \\
\cline { 2 - 5 } & OMRF & 0.005 & 0.0025 & 0.0 \\
\hline \multirow{3}{*}{ Columns } & SMRF & 0.005 & 0.0025 & 0.0 \\
\cline { 2 - 5 } & IMRF & 0.0 & 0.0 & 0.0 \\
\cline { 2 - 5 } & OMRF & 0.0 & 0.0 & 0.0 \\
\hline
\end{tabular}

Note: Linear interpolation is recommended for beams with $10<1 / 1<15$. 


\section{Force Reduction Factors for the Structural Design and Evaluation of Facilities Containing Nuclear and Hazardous Materials}

\section{Special Moment Resisting Frames (SMRF)}

Member rotations and ductilities developed for Special Moment Resisting Frames (SMRF) are based on:

- Members comply with the ACI-349 Chapter 21 Seismic Detailing requirements,

- Symmetric reinforcement such that $\frac{\rho-\rho^{\prime}}{\rho_{b a l}} \leq 0$,

- Transverse reinforcing with a spacing less than $d / 3$ in plastic hinge regions and Vs $>$ $75 \% \mathrm{Vu}$ for components with a ductility greater than 3 ,

- As shown in Appendix A, beams with a span to depth ratio greater than $15, \ell / h \geq 15$, have shear stresses less than $3 \sqrt{f^{\prime} c}$ while beams with a span to depth ratio less than $10, \ell / \mathrm{h} \leq 10$, may have a shear stress greater than $6 \sqrt{f^{\prime} c}$,

- Columns are assumed to have a shear stress greater than $6 \sqrt{f c}$, and

- Columns are assumed to have a axial load greater $0.4 \mathrm{f}$ 'c but less than $70 \%$ of the concentric axial load capacity.

Note that the ductility for a column with an axial stress greater than $40 \% \mathrm{f}^{\prime} \mathrm{c}$ is about $50 \%$ of the ductility for a column with an axial stress less than $10 \% \mathrm{f}$ 'c. Thus, the assumed axial stresses result in conservative predictions of ductility.

The ductility for the Life Safety limit state for columns in FEMA-273 is conservatively set equal to the ductility for Immediate Occupancy, while the corresponding allowable rotations for Immediate Occupancy, Life Safety and Collapse Prevention are 0.0, 0.005 and 0.010 respectively. This bias in the FEMA-273 Life Safety ductility is removed by redefining the Life Safety ductility as $75 \%$ of the Collapse Prevention ductility (Equation $2-1)$. This is consistent with Section 2.13 of FEMA-273 which defines $\delta_{\text {FEMA-273 "Life Safety" }}$

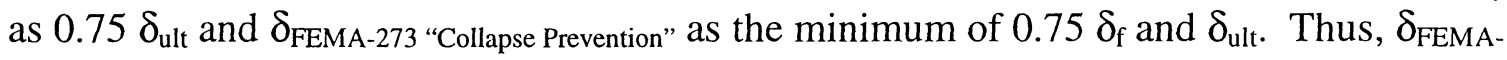

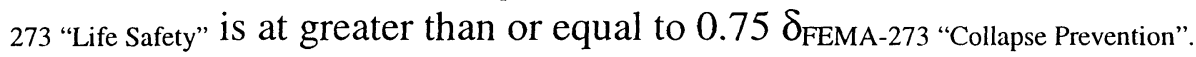

\section{Intermediate Moment Resisting Frames (IMRF)}

Member rotations and ductilities for Intermediate Moment Resisting Frames (IMRF) are included for the evaluation of existing structures. These values are based on:

- Members comply with the ACI-318 Chapter 21 Seismic Detailing requirements ${ }^{3}$ for moment frames in regions of moderate seismicity.

- Unsymmetric reinforcement such that $\frac{\rho-\rho^{\prime}}{\rho_{\text {bal }}}>0.5$. However, symmetric reinforcing is allowed and will have better performance than unsymmetrically reinforced sections.

3 ACI-349 Chapter 21 does not recognize intermediate moment frames, nor does it recognize moment frames in regions of moderate seismicity. 
- Transverse reinforcing with a spacing less than $\mathrm{d} / 3$ in plastic hinge regions and Vs $>$ $75 \% \mathrm{Vu}$ for components with a ductility greater than 3 ,

- Columns are assumed to have a shear stress greater than $6 \sqrt{f^{\prime} c}$, and

- Columns are assumed to have a axial load greater $0.4 \mathrm{f}$ 'c but less than $70 \%$ of the concentric axial load capacity.

The ductility for the Life Safety limit state for beams with high shear $(/ / 1 \leq 10)$ in FEMA273 is conservatively equal to the ductility for Immediate Occupancy, while the corresponding allowable rotations for Immediate Occupancy, Life Safety and Collapse Prevention are $0.005,0.005$ and 0.010 respectively. This bias in the FEMA-273 life safety ductility is removed by using Equation 2-1 to define the permissible ductility, resulting in a slight increase in beam ductility.

The FEMA 273 m value for columns corresponding to the Immediate Occupancy limit state is unity. Only $125 \%$ of the $\mathrm{m}$ value are used for the element ductility rather than the value in Equation 2-10. The 125\% increase reflects the difference between the nominal code capacity and the mean yield strength. This approach conservatively assumes that the maximum allowable column displacement for Limit State $\mathrm{C}$ is $\bar{\delta}_{Y}$.

\section{Ordinary Moment Resisting Frames (OMRF)}

Member rotations and ductilities for Ordinary Moment Resisting Frames (OMRF) are included for the evaluation of existing structures. These values are based on:

- Members comply with ACI-349, excluding Chapter 21, Seismic Detailing requirements,

- Beams are assumed to have unsymmetrical reinforcing and non-conforming stirrups.

- Columns are assumed to have an axial stress greater than $0.4 \mathrm{f}$ 'c, non-conforming ties and a shear stress greater than $6 \sqrt{f^{\prime} c}$.

The FEMA $273 \mathrm{~m}$ value corresponding to Immediate Occupancy beams is unity. As described for IMRF systems, $125 \%$ of the $m$ value is used for the element ductility rather than the value in Equation 2-10. The 125\% increase reflects the difference between the nominal code capacity and the mean yield strength. Similarly, the FEMA-273 m value corresponding to limit states for both Life Safety and Immediate Occupancy columns is unity, thus $125 \%$ of the $\mathrm{m}$ value is used for the element ductility for Limit State A.

\subsubsection{Concrete Shear Walls}

Performance levels for limit state LS-A and limit state LS-C are used to develop allowable levels of non-linear deformation for bending controlled and shear controlled structural walls and thus the magnitude of the ductility permitted for each limit state. These limit states, and associated structure deformations, are described in Table 2.4. 


\section{Force Reduction Factors for the Structural Design and Evaluation of Facilities Containing Nuclear and Hazardous Materials .}

Table 2.4 Limit State for Reinforced Concrete Shear Wall Structures

\begin{tabular}{|c|c|c|}
\hline Limit State & LS-A & LS-C \\
\hline $\begin{array}{l}\text { R/C Shear Wall } \\
\text { Damage }\end{array}$ & $\begin{array}{l}\text { Some boundary element } \\
\text { distress, including limited } \\
\text { buckling of reinforcement. } \\
\text { Some sliding of joints. Damage } \\
\text { around openings. Some } \\
\text { crushing and flexural cracking. } \\
\text { Coupling beams have extensive } \\
\text { shear and flexural cracks; some } \\
\text { crushing, but concrete } \\
\text { generally remains in place. }\end{array}$ & $\begin{array}{l}\text { Minor hairline cracking of } \\
\text { walls, with cracks less than } \\
1 / 16 \text { " wide. Coupling beams } \\
\text { experience cracks less than } \\
\text { 1/8" wide. }\end{array}$ \\
\hline $\begin{array}{l}\text { Structure Drift - } \\
\text { Bending Controlled }\end{array}$ & $\begin{array}{l}1 \% \text { transient; } 0.5 \% \text { permanent } \\
\text { drift }\end{array}$ & $\begin{array}{l}0.5 \% \text { transient drift; } \\
\text { no visible permanent drift. }\end{array}$ \\
\hline $\begin{array}{l}\text { Structure Drift - } \\
\text { Shear Controlled }\end{array}$ & $\begin{array}{l}0.75 \% \text { transient; } 0.4 \% \\
\text { permanent drift }\end{array}$ & $\begin{array}{l}0.5 \% \text { transient drift; } \\
\text { no visible permanent drift. }\end{array}$ \\
\hline
\end{tabular}

The allowable deformation corresponding to each limit state is a function of wall geometry (aspect ratio) and detailing. The aspect ratio (height/width) of a wall typically determines whether the behavior is dominated by shear or bending. The displacements of walls with large aspect ratios are dominated by bending deformation, while the displacements of low-rise walls are dominated by shear deformation. Generally, bending deformation results in larger allowable displacements than shear deformation and bending hysteresis loops tend to be large stable loops while shear hysteresis loops tend to be pinched and dissipate less energy than the bending loops.

In walls subject to overturning moment, one edge of the wall is in compression. In bending dominated walls this compression can be significant. Similar to columns, the compressive ductility of the boundary element is dependent on the confining reinforcement in the boundary element. Inadequate boundary element confinement can allow the compression element to crush at low compressive strain, reducing the allowable rotation and ductility of the wall. ACI 349, Chapter 21, does not require boundary elements for low rise shear walls, $\mathrm{h} / \mathrm{lw}<2$, because the compression load in these walls does not limit the wall's capacity.

Tensile and compressive stresses are present in the web of a shear wall on diagonal axes. The shear strength of lightly reinforced shear walls is limited by yielding of the web reinforcing that crosses tensile cracks. If additional web reinforcing is added, the tensile yield is suppressed and large compressive stresses develop on the perpendicular diagonal axis. In some walls the capacity is limited by crushing of the web along this axis, and the web crushing mechanism is less ductile than the tensile yielding mechanism.

Additionally, similar to columns, walls with low axial load are more ductile than walls with large axial load. 


\section{Force Reduction Factors for the Structural Design and Evaluation of Facilities Containing Nuclear and Hazardous Materials}

WSRC-TR-2001-00037

Page 2-14

The ductilities in Table 2.5 for LS-A and LS-C are based on FEMA-273 ductilities for the Life Safety and Immediate Occupancy limit states for shear walls dominated by bending deformation. These ductilities are based on:

- Shear walls comply with the ACI-349 Chapter 21 Seismic Detailing requirements,

- Less than $0.10 \mathrm{f}$ 'c axial stress,

- Symmetric reinforcing, and

- Confined boundary elements.

The ductilities in Table 2.5 for LS-C and LS-A are based on FEMA-273 ductilities for Immediate Occupancy and NUREG/CR-6104 deformation data for shear walls dominated by shear deformation. These ductilities are based on:

- Shear walls comply with the ACI-349 Chapter 21 Seismic Detailing requirements,

- Less than $0.15 \mathrm{f}$ 'c axial stress,

- Symmetric reinforcing, and

- Shear stress less than or equal to $6 \sqrt{f^{\prime} c}$.

ACI 318 specifies a $\phi$ factor for shear controlled walls of 0.60 whereas a $\phi$ factor of 0.90 was assumed in the development of Equation 2.11. Thus, Equation 2.11 could be modified for shear controlled walls:

$\mu_{A}=1.67 \frac{\phi=0.9}{\phi=0.6} m_{\text {FEMA 273"Life Safety" }}=2.5 m_{\text {FEMA 273"Life Safety" }}$

Which yields a limit state A ductility of $\mu_{\mathrm{A}}=2.5(2)=5$.

Table 2.5a Shear Wall Ductilities for In-Plane Forces

\begin{tabular}{|r|r|r|r|}
\hline Limit State & LS-A & LS-B & LS-C \\
\hline $\begin{array}{r}\text { Bending Controlled } \\
f v>6 \sqrt{f^{\prime} c}\end{array}$ & 5 & 4 & 3.25 \\
\hline $\begin{array}{r}\text { Bending Controlled } \\
f v<3 \sqrt{f^{\prime} c}\end{array}$ & 6.75 & 5 & 3.25 \\
\hline Shear Controlled & 5 & 4 & 3.25 \\
\hline
\end{tabular}

Note: Use linear interpolation between shear stresses of $3 \sqrt{f^{\prime} c}$ and $6 \sqrt{f^{\prime} c}$. 


\section{Force Reduction Factors for the Structural Design and Evaluation of Facilities Containing Nuclear and Hazardous Materials

Table 2.5b Shear Wall Acceptable Drift (\%) or Chord Rotation (radians)

\begin{tabular}{|r|r|r|r|}
\hline Limit State & \multicolumn{1}{|c|}{ LS-A } & \multicolumn{1}{c|}{ LS-B } & \multicolumn{1}{c|}{ LS-C } \\
\hline $\begin{array}{r}\text { Bending Controlled } \\
f v>6 \sqrt{f^{\prime} c}\end{array}$ & 0.008 & 0.006 & 0.004 \\
\hline $\begin{array}{r}\text { Bending Controlled } \\
f v<3 \sqrt{f^{\prime} c}\end{array}$ & 0.010 & 0.008 & 0.005 \\
\hline Shear Controlled & 0.0075 & 0.006 & 0.004 \\
\hline
\end{tabular}

Note: Use linear interpolation between shear stresses of $3 \sqrt{f^{\prime} c}$ and $6 \sqrt{f^{\prime} c}$.

NUREG/CR-6104 contains a statistical evaluation of low-rise $(\mathrm{h} / \mathrm{w} \leq 1)$ shear wall drift data, summarized in Table 2.6. Capacities less than $100 \%$ correspond to the post-ultimate capacity portion of the load-deflection backbone curve. Of interest in Table 2.6 are the $0.72 \%$ and $1.84 \%$ median drifts at the ultimate capacity and $50 \%$ post-ultimate capacity. FEMA-273 provides comparable drifts ${ }^{4}$ of $0.75 \%$ and $1.5 \%$ at the ultimate capacity and $40 \%$ of the post-ultimate capacity for shear dominated walls. Thus, the shear wall drift data used by FEMA-273 and NUREG/CR-6104 for the ultimate capacity is consistent $(0.72 \%$ vs. $0.75 \%)$. FEMA-273 has slightly lower drifts for the post-ultimate load case (1.5\% vs. $1.84 \%)$.

For shear controlled walls, the mean capacity, $\bar{V}_{Y}$, is about $190 \%$ of the nominal code capacity, $\phi \mathrm{Vn}$. This $190 \%$ difference corresponds to removing the shear controlled shear wall $\phi$ factor $(\phi=0.6)$ and conservatively taking a $15 \%$ difference between the mean material strength and the minimum specified strength.

$\bar{V}_{Y}=1.15 \frac{\phi V n}{0.6} \approx 1.90 \phi V n$

Conversely, the nominal design strength is at least $52 \%(=1 / 1.9)$ of the ultimate capacity. At $60 \%$ of the ultimate capacity, $84 \%$ of the walls have a drift greater than 0.0097 , which could be assigned to $\delta_{\mathrm{A}}$. However $\delta_{\mathrm{A}}$ is conservatively limited to 0.0075 . From Table 2.5 at a deformation of 0.004 the shear controlled wall has a ductility of 3.25 . From Equation $2-3, \delta_{\phi V_{n}}$ is $0.004 / 3.25=0.0012$. Substituting $\delta_{\mathrm{A}}$ and $\delta_{\phi V_{n}}$ back into Equation 2-3 yields $\mu_{\mathrm{A}}=\frac{.0075}{.0012}=6.25$ which is greater than the value of $\mu_{\mathrm{A}}=5$ in Table 2.5. Thus, the shear controlled ductility for Limit State A in Table 2.5 is conservative. 
Force Reduction Factors for the Structural Design and Evaluation of Facilities Containing Nuclear and Hazardous Materials

Table 2.6 Summary of Shear Wall Drift Statistics [NUREG/CR-6104] Aspect Ratio $\leq 1$

\begin{tabular}{|c|c|c|c|}
\hline $\begin{array}{c}\text { Fraction of } \\
\text { Ultimate Load }\end{array}$ & $\begin{array}{c}\text { Median } \\
\text { Drift }\end{array}$ & $\begin{array}{c}\text { Logarithmic } \\
\text { Standard Deviation }\end{array}$ & $84 \%$ Drift \\
\hline $100 \%$ & 0.0072 & 0.373 & 0.0050 \\
\hline $90 \%$ & 0.0100 & 0.437 & 0.0065 \\
\hline $80 \%$ & 0.0124 & 0.452 & 0.0079 \\
\hline $70 \%$ & 0.0148 & 0.464 & 0.0093 \\
\hline $60 \%$ & 0.0164 & 0.524 & 0.0097 \\
\hline $50 \%$ & 0.0184 & 0.566 & 0.0104 \\
\hline
\end{tabular}

\subsubsection{Steel Moment Resisting Frames}

Steel moment resisting frames are categorized as special, intermediate and ordinary moment frames. Special Moment Resisting Frames (SMRF) provide the highest level of ductility while Ordinary Moment Resisting Frames (ORMF) provide the lowest level. The third class of structural frame is provided for moderate levels of ductility and is referred to as an Intermediate Moment Resisting Frame (IMRF). AISC Provisions for Structural Steel Buildings force hinge formation to occur in the beams, not in the connection or column, for SMRF and IMRF systems. Furthermore, the AISC provisions specify plastic rotation capacities of $0.03,0.02$ and 0.01 radians for special, intermediate and ordinary moment frames respectively at the "Life Safety" limit state.

Since the rotation capacity required for beam-column connections in IMRF systems is $2 / 3$ of that for the SMRF system, the allowable member ductility for components within an IMRF system are taken as $2 / 3$ of that computed for the SMRF system. The detailing requirements for OMRF's are much less restrictive than that for the IMRF and SMRF systems resulting in elements, which are more susceptible to local buckling. However the connections are still required to demonstrate a minimum rotation ductility of $1 / 3$ of that for the SMRF system.

Performance descriptions for Limit States A and $\mathrm{C}$ for steel moment resisting frames are contained in Table 2.7. The allowable distortion corresponding to each limit state is a function of:

- Local buckling of elements which causes strain concentrations and reduces the allowable global deformation,

- Axial load, which reduces the element ductility due to buckling, and

- Connection ductility which may limit frame ductility. 
Force Reduction Factors for the Structural Design and Evaluation of Facilities Containing Nuclear and Hazardous Materials

WSRC-TR-2001-00037

Page 2-17

Table 2.7 Limit State for Steel Moment Frames

\begin{tabular}{|l|l|l|}
\hline Limit State & LS-A & LS-C \\
\hline $\begin{array}{l}\text { Steel Moment } \\
\text { Frame Damage }\end{array}$ & $\begin{array}{l}\text { Hinges form. Local buckling of } \\
\text { some beam elements. Severe } \\
\text { joint distortion; isolated } \\
\text { moment connection fractures, } \\
\text { but shear connections remain } \\
\text { intact. A few elements may } \\
\text { experience partial fracture. }\end{array}$ & $\begin{array}{l}\text { Minor local yielding at a few } \\
\text { places. No fractures. Minor } \\
\text { buckling and distortion of } \\
\text { members. }\end{array}$ \\
\hline Structure Drift & $\begin{array}{l}3 \% \text { transient drift; } \\
1 \% \text { permanent drift }\end{array}$ & $\begin{array}{l}1 \% \text { transient drift; } \\
\text { no visible permanent drift. }\end{array}$ \\
\hline
\end{tabular}

Member ductilities, which are dependent on axial load, slenderness ratio and connection type for the limit states in Table 2.7 are summarized in FEMA-273. These values are used to develop component ductilities for elements and connections, shown in Table 2.8, for SMRF and IMRF systems. Note that the connections for SMRF and IMRF systems are designed to exceed the capacity of the connecting element.

Table 2.8a Member Ductilities for Steel Moment Resisting Frames

\begin{tabular}{|c|c|c|c|c|}
\hline & & \multicolumn{3}{|c|}{ Limit State } \\
\hline \multirow{2}{*}{ Element } & Frame Type & LS-A & LS-B & LS-C \\
\hline \multirow{2}{*}{$\begin{array}{c}\text { Beams, } \\
\text { Columns }\end{array} / \mathrm{Py}<0.2$} & SMRF & 10 & 5.5 & 3.25 \\
\cline { 2 - 5 } & IMRF & 6.75 & 5 & 3.25 \\
\cline { 2 - 5 } & OMRF & 3.25 & 2.25 & 1.25 \\
\hline \multirow{2}{*}{$\begin{array}{c}\text { Columns } \\
0.2<{ }_{\mathrm{Py}} \leq 0.5\end{array}$} & SMRF & $15\left(1-1.7^{\mathrm{P}} / \mathrm{Py}\right)$ & $8.1-12.7^{\mathrm{P}} / \mathrm{Py}$ & 1.25 \\
\cline { 2 - 5 } & IMRF & $10\left(1-1.7^{\mathrm{P}} / \mathrm{Py}\right)$ & $5.6-8.5^{\mathrm{P}} / \mathrm{Py}$ & 1.25 \\
\cline { 2 - 5 } & OMRF & 1.25 & 1.25 & 1.25 \\
\hline
\end{tabular}

Table 2.8b Nonlinear Member Rotation Limits for Steel Moment Resisting Frames

\begin{tabular}{|c|c|c|c|c|}
\hline & & \multicolumn{3}{|c|}{ Limit State } \\
\hline Element & Frame Type & LS-A & LS-B & LS-C \\
\hline \multirow{3}{*}{$\begin{array}{c}\text { Beams, } \\
\text { Columns }{ }^{\mathrm{P}} / \mathrm{Py}<0.2\end{array}$} & SMRF & 0.03 & 0.017 & 0.004 \\
\hline & IMRF & 0.02 & 0.012 & 0.004 \\
\hline & OMRF & 0.01 & 0.007 & 0.004 \\
\hline \multirow{3}{*}{$\begin{array}{c}\text { Columns } \\
0.2<<^{\mathrm{P}} / \mathrm{Py} \leq 0.5\end{array}$} & SMRF & $0.042\left(1-1.7^{\mathrm{P}} / \mathrm{Py}\right)$ & $0.023-0.036 \mathrm{P} / \mathrm{Py}$ & 0.004 \\
\hline & IMRF & $0.028\left(1-1.7^{\mathrm{P}} / \mathrm{Py}\right)$ & $0.016-0.024 \mathrm{P} / \mathrm{Py}$ & 0.004 \\
\hline & OMRF & 0. & 0. & 0. \\
\hline
\end{tabular}


Where $P$ is the applied axial load, Py is the axial yield load, Py=As Fy

As is the cross sectional area, and

Fy is the yield stress.

The ductilities shown in Table 2.8 are based on the following assumptions, consistent with the requirements of AISC Seismic Provisions for Structural Steel Buildings.

- Moment frames comply with the AISC Seismic Detailing requirements.

- SMRF frames use compact steel sections with projecting compression elements meeting the slenderness ratio limit $\frac{b}{2 t_{f}} \leq \frac{52}{\sqrt{F y}}$, where $\mathrm{b}$ and $\mathrm{t}_{\mathrm{f}}$ are the flange width and thickness and Fy is the material yield strength.

- IMRF frames use compact steel sections with projecting compression elements meeting the slenderness ratio limit $\frac{\mathrm{b}}{2 \mathrm{t}_{\mathrm{f}}} \leq \frac{65}{\sqrt{\mathrm{Fy}}}$.

- OMRF frames use compact steel sections with projecting compression elements meeting the slenderness ratio limit $\frac{b}{2 t_{f}} \leq \frac{95}{\sqrt{F y}}$. However, FEMA-273 rotations and ductilities are based on $\frac{b}{2 t_{f}} \geq \frac{95}{\sqrt{F y}}$.

- Beams and columns have sufficient lateral support and are capable of developing their full plastic moment without lateral-torsional buckling.

- The rotational ductility of columns is based on the magnitude of axial load,

$$
\mathrm{P} / \mathrm{Py} \leq 0.5 \text {. }
$$

FEMA 273 does provide ductilities that correspond to IMRF. However, given the AISC rotation capacities of $0.03,0.02$ and 0.01 radians for SMRF, IMRF and OMRF then IMRF ductilities are interpolated from SMRF and ORMF ductilities

\subsubsection{Steel Braced Frame}

Descriptions of Limit States A and C behaviors for steel braced frames are provided in Table 2.9. The allowable distortion corresponding to each limit state is a function of the type of brace used. 
Table 2.9 Limit State for Steel Braced Frames

\begin{tabular}{|l|l|l|}
\hline Limit State & LS-A & LS-C \\
\hline $\begin{array}{l}\text { Steel Braced Frame } \\
\text { Damage }\end{array}$ & $\begin{array}{l}\text { Many braces yield or buckle } \\
\text { but do not totally fail. Many } \\
\text { connections may fail. }\end{array}$ & $\begin{array}{l}\text { Minor yielding or buckling of } \\
\text { braces. }\end{array}$ \\
\hline Building Drift & $\begin{array}{l}1.5 \% \text { transient drift; } \\
0.5 \% \text { permanent drift }\end{array}$ & $\begin{array}{l}0.5 \% \text { transient drift; } \\
\text { negligible permanent drift. }\end{array}$ \\
\hline
\end{tabular}

FEMA-273 provides a source of member ductilities which are dependent on axial load, slenderness ratio and connection type for the limit states in Table 2.9. Ductilities for Braced Frames, shown in Table 2.10, are based on:

- Concentric braced frames comply with the AISC Seismic Detailing requirements for Ordinary Concentric Braced Frames and eccentric braced frames comply with the appropriate AISC requirements.

- The capacity of concentric braced frames is limited by member buckling of diagonal brace elements.

- The capacity of eccentric braced frames is limited by the link beam yielding in bending or shear. The link beam has three or more web stiffeners. Brace elements of an eccentric braced frame have a capacity greater than the link beam.

- Columns or chords of braced frames are assumed to be capable of resisting the maximum force that can be delivered.

- Connections are assumed to carry $125 \%$ of the brace strength in compression and $125 \%$ of the brace yield strength.

- Rectangular cold-formed tubes have unstiffened compression elements with $\frac{d}{t} \leq \frac{90}{\sqrt{\text { Fy }}}$

- Circular hollow tubes have diameter to thickness ratios of $\frac{d}{\mathrm{t}} \leq \frac{1500}{\mathrm{Fy}}$. 
Force Reduction Factors for the Structural Design and Evaluation of Facilities

Containing Nuclear and Hazardous Materials

WSRC-TR-2001-00037

Page 2-20

Table 2.10 Member Ductilities for Braced Steel Frames

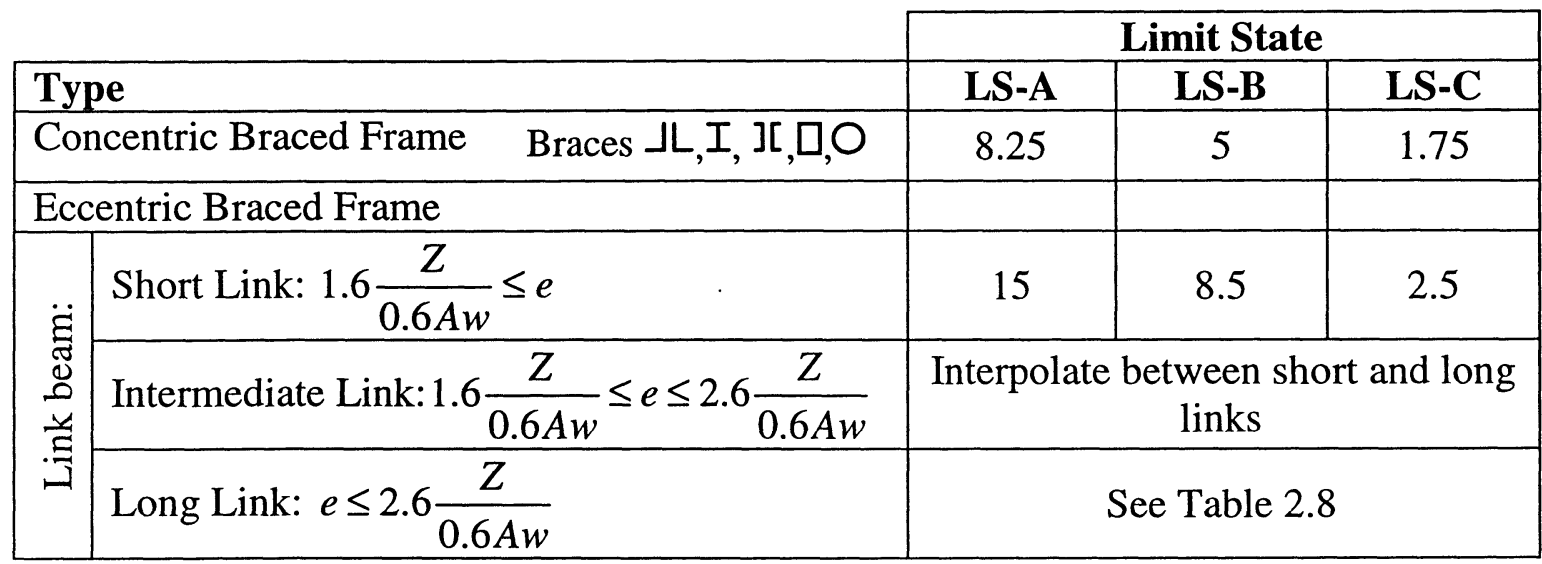

Where $\mathrm{Z}$ is the plastic section modulus,

Aw is the web area, and

$\mathrm{e}$ is the eccentricity measured along the link beam.

The nonlinear deformation limits for braced steel frame elements are the ductilities in

Table 2.10 times the yield displacement, or

$\delta_{i}=\mu_{i} \delta_{\phi F n}$ 
Force Reduction Factors for the Structural Design and Evaluation of Facilities Containing Nuclear and Hazardous Materials

\subsection{Frequency Dependence of the SDOF Force Reduction Factor}

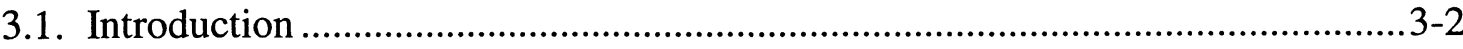

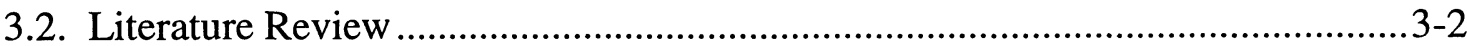

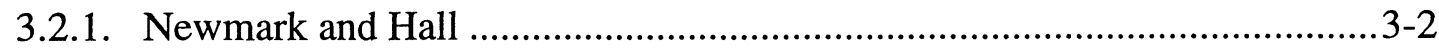

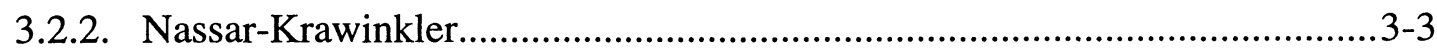

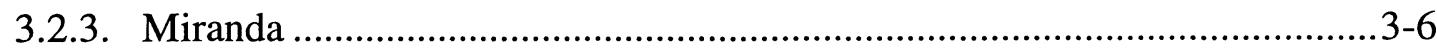

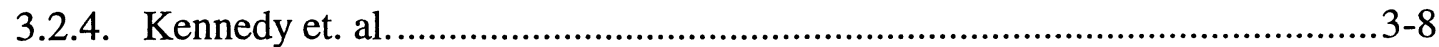

3.3. Consequences Of Using A Constant Force Reduction Factor............................3-12

3.3.1. Rigid Frames .....................................................................................

3.3.2. Braced Frames and Shear Wall Structures ...............................................3-13

3.4. Simplified Frequency Dependent Force Reduction Factor ............................. 3-14 


\section{Force Reduction Factors for the Structural Design and Evaluation of Facilities Containing Nuclear and Hazardous Materials

\subsection{Introduction}

The demand reduction factor, $\mathrm{F}_{\mu}$, is defined as the ratio of the elastic base shear to the base shear computed considering non-linear behavior. In this section, studies utilizing Single Degree-of-Freedom (SDOF) models with elastic-plastic, and bilinear and pinched hysteresis models are utilized to evaluate the frequency dependence of F $\mu$ for a SDOF system, F $\mu$ s.

The base shear in a SDOF structure is proportional to the spectral acceleration. Thus, the force reduction factor for a SDOF structure, F $\mu$ s, is also equal to the ratio of the elastic spectral acceleration to the inelastic spectral acceleration.

\subsection{Literature Review}

Miranda [1994] provides an extensive summary of F $\mu$ s studies considering various input time histories, soil conditions, damping, strain hardening and statistical treatments of the results. This section is based on Miranda's paper and summarizes studies by NewmarkHall, Nassar-Krawinkler, and Miranda. Additional studies by Kennedy et. al. [1984] evaluate the effect of pinched hysteresis loops on F $\mu$ s. The results in this section are expressed in terms of frequency, instead of period, to emphasize the frequency range of interest for nuclear structures.

\subsubsection{Newmark and Hall}

Newmark and Hall [1987] developed nonlinear response spectra based on the $1940 \mathrm{El}$ Centro ground motion using elasto-plastic hysteresis models. They observed that for low frequencies, the displacements of an inelastic system are approximately equal to the displacements of an elastic system and that F $\mu$ s in this range is approximately equal to $\mu$. In the constant acceleration portion of the spectra, they observed that the total energy in an inelastic structure is similar to the total energy in an elastic structure, resulting in $\mathrm{F} \mu \mathrm{s}=\sqrt{2 \mu-1}$. For rigid structures $\mathrm{F} \mu \mathrm{s}$ is one regardless of the ductility.

The Newmark-Hall median inelastic velocity response spectra for $5 \%$ viscous damping is shown in Figure 3.1 for ductilities of 2, 4, 6 and 8 along with an elastic response spectra $(\mu=1) . F \mu$ is the ratio of the elastic spectral acceleration to the inelastic spectral acceleration and is shown in Figure 3.2. In the constant displacement and constant velocity regime, below $1.5-2 \mathrm{hz}$ in Figure 3.2, F $\mu \mathrm{s}=\mu$. In the constant acceleration regime $F \mu s=\sqrt{2 \mu-1}$, which, depending on the ductility, is between 2-3.5 and 8-9 hz. $\mathrm{F} \mu \mathrm{s}=1$ in the rigid range which is above $33 \mathrm{hz}$. The different regions are joined by transition zones. 
Force Reduction Factors for the Structural Design and Evaluation of Facilities Containing Nuclear and Hazardous Materials

WSRC-TR-2001-00037

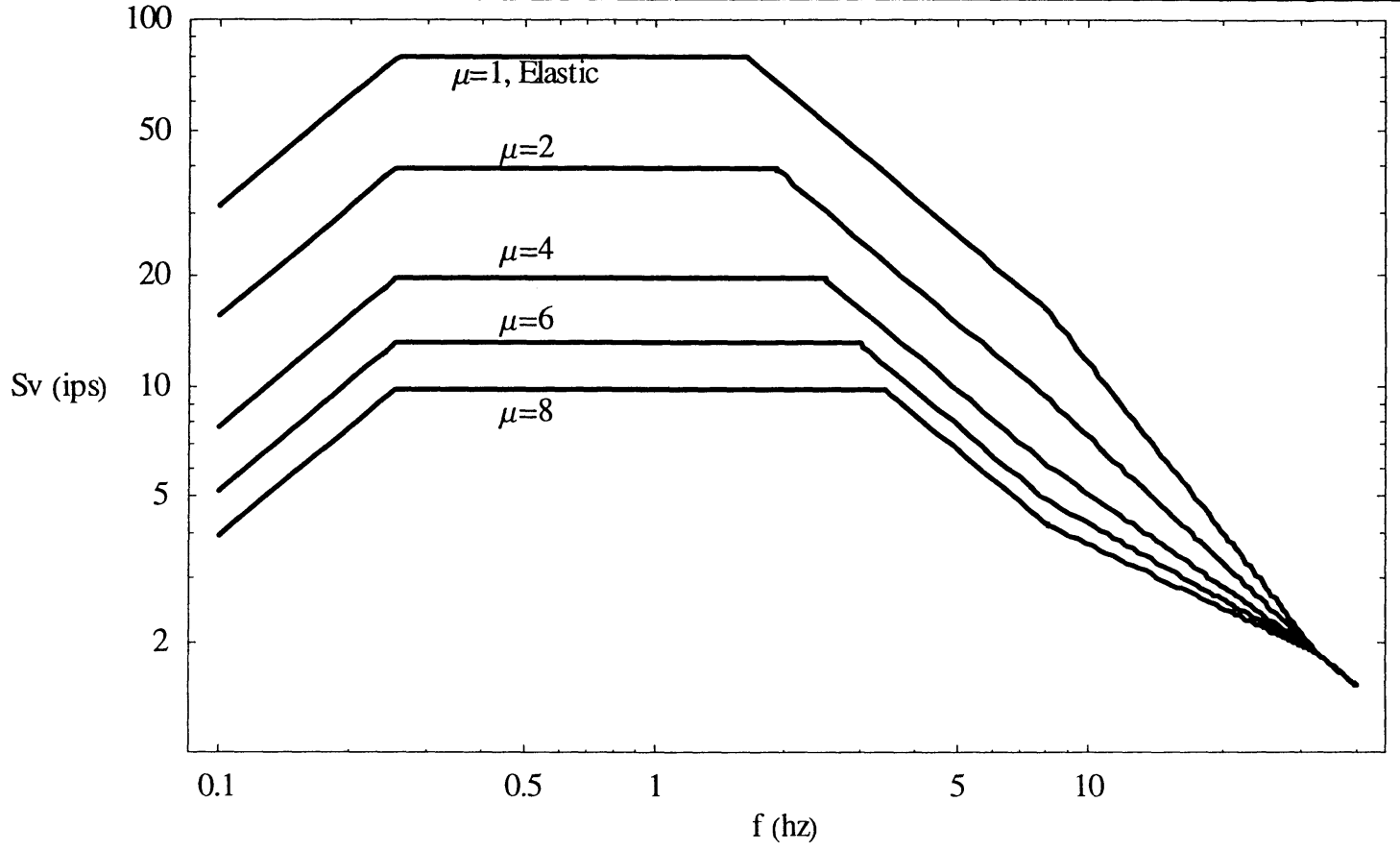

Figure 3.1 Newmark - Hall Median Inelastic Acceleration Response Spectra $1 \mathrm{~g}$ PGA, $5 \%$ Viscous Damping, $\mu=2,4,6$ and 8

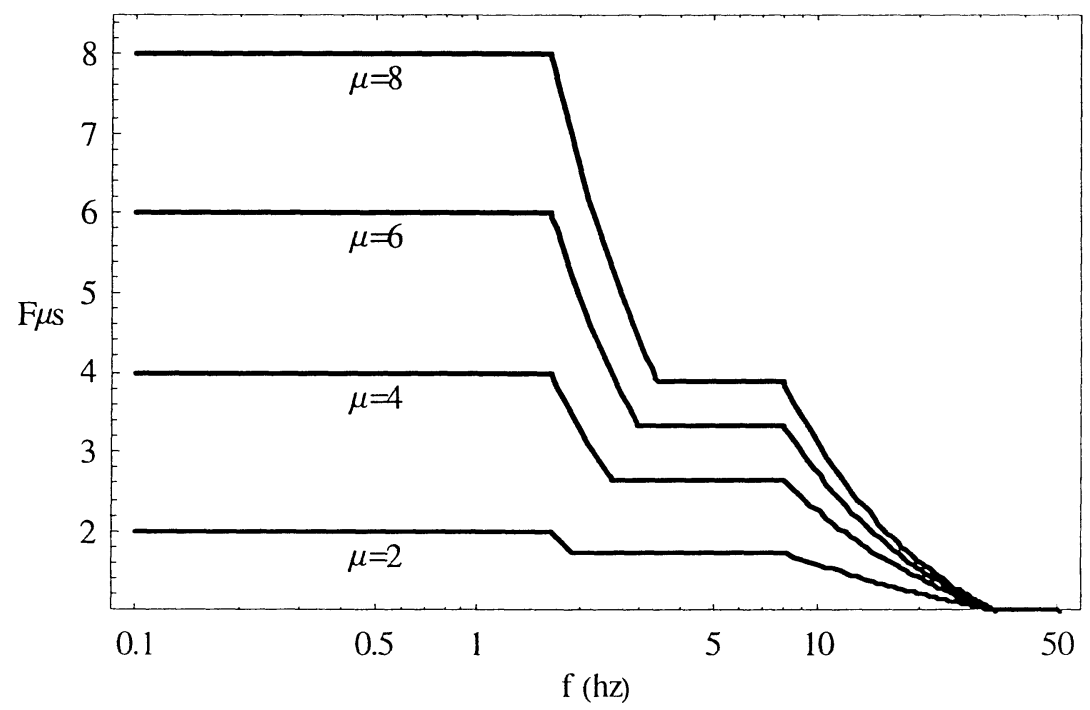

Figure 3.2 F $\mu$ s Based on Newmark-Hall Inelastic Response Spectra, $\mu=2,4,6$ and 8

\subsubsection{Nassar-Krawinkler}

Nassar and Krawinkler [1991] developed mean F $\mu$ s for both elasto-plastic and bilinear hysteresis models with different amounts of strain hardening using 15 western US ground motions for structures with natural frequencies between 0.25 and $10 \mathrm{hz}$. Their relationship for F $\mu$ s is 
Force Reduction Factors for the Structural Design and Evaluation of Facilities Containing Nuclear and Hazardous Materials

$\mathrm{F} \mu \mathrm{s}=(\mathrm{c}(\mu-1)+1)^{1 / \mathrm{c}}$

Where $c=\frac{T^{a}}{1+T^{a}}+\frac{b}{T}$,

$\mathrm{T}$ is the period,

$\alpha$ is a measure of strain hardening and is defined as the ratio of the post yield stiffness to the elastic stiffness, and the coefficients $a$ and $b$ are functions of the strain hardening.

$\begin{array}{ccc}\alpha & \mathbf{a} & \mathbf{b} \\ 0.00 & 1.00 & 0.42 \\ 0.02 & 1.00 & 0.37 \\ 0.10 & 0.80 & 0.29\end{array}$

Functions for the mean F $\mu$ s for elasto-plastic and bilinear hysteresis models are shown in Figure 3.3 for ductilities of 2 and 6. At $\mu=2$ the effect of strain hardening on $F \mu$ s is minor. For larger ductilities, strain hardening increases F $\mu$ s. At a ductility of six, F $\mu$ s, for $10 \%$ strain hardening system is $25 \%$ larger than $F \mu$ s for an elasto plastic system in the $3-6 \mathrm{hz}$ range.

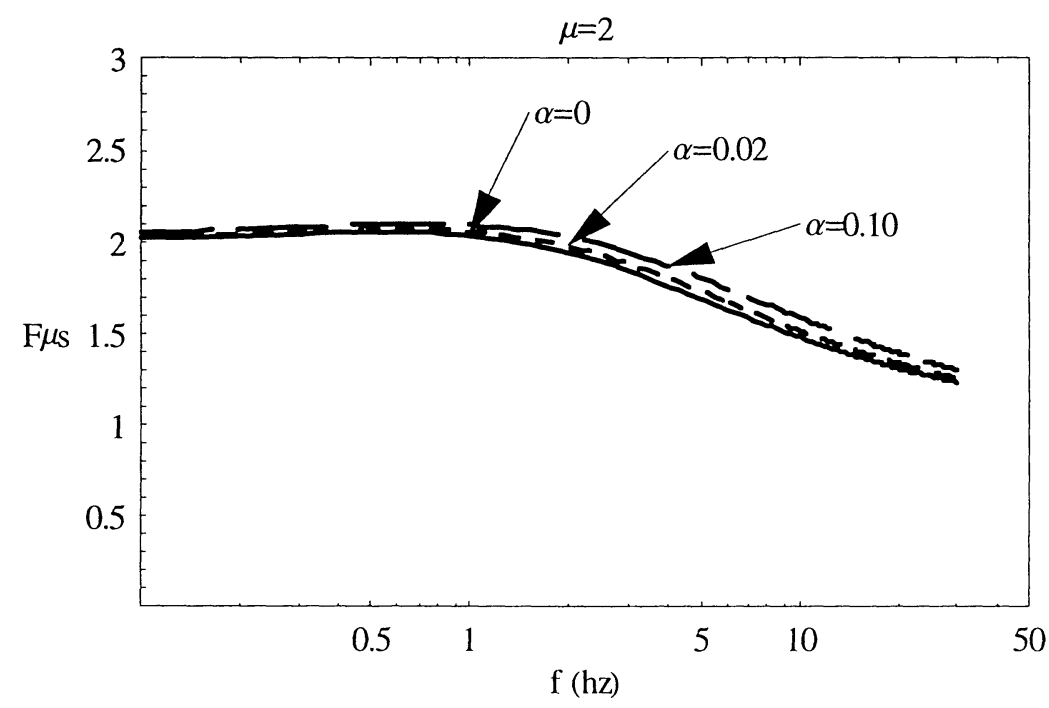

Figure 3.3a Nassar-Krawinkler $F \mu$ s for $\mu=2$

Elasto-Plastic $(\alpha=0)$ and Bilinear Hysteresis Models $(\alpha=0.02,0.10)$ 


\section{Force Reduction Factors for the Structural Design and Evaluation of Facilities}

Containing Nuclear and Hazardous Materials

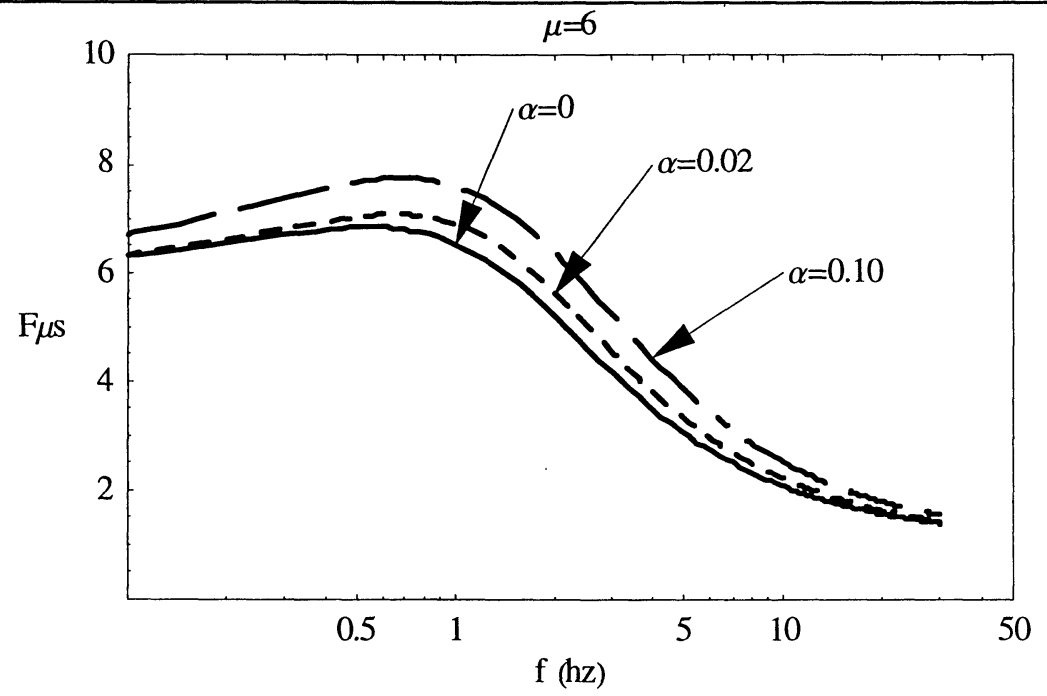

Figure 3.3b Nassar-Krawinkler F $\mu$ s for $\mu=6$

Elasto-Plastic $(\alpha=0)$ and Bilinear Hysteresis Models $(\alpha=0.02,0.10)$

Mean Fus are shown in Figure 3.4 for elasto-plastic systems with ductilities ranging from 2 to 8. As indicated in Figure 3.3, the influence of strain hardening on F $\mu$ s is small compared to the influence of frequency on Fus.

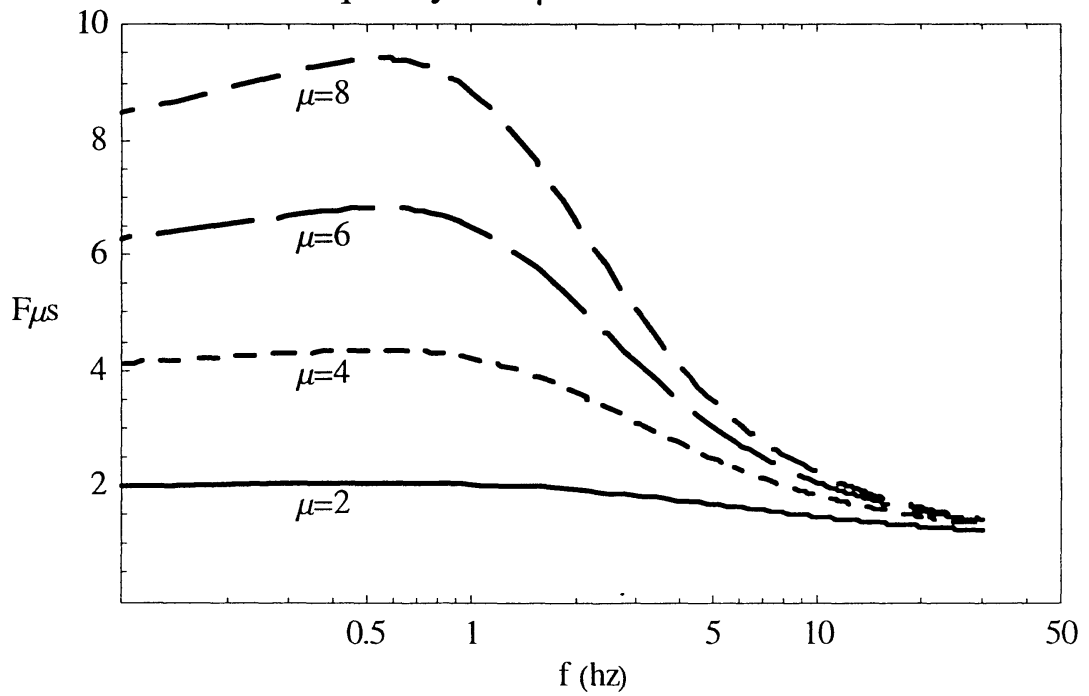

Figure 3.4 Nassar-Krawinkler F $\mu$ s for Elasto-Plastic Systems

Nassar and Krawinkler also evaluated the effect of degrading stiffness hysteresis models and observed that the differences in F $\mu$ s between the bilinear and degrading stiffness (Clough) models are usually small. For elasto-plastic systems with frequencies less than 2 hz Nassar and Krawinkler report that the degrading stiffness system actually had a larger F $\mu$ s than the elasto-plastic system. The variations in F $\mu$ s due to strain hardening and stiffness degradation are much less than the variation due to frequency. 


\section{Force Reduction Factors for the Structural Design and Evaluation of Facilities Containing Nuclear and Hazardous Materials}

Nassar and Krawinkler included an evaluation of the influence of epicentral distance and concluded that F $\mu$ s was not very sensitive to epicentral distance.

Nassar and Krawinkler F $\mu$ s, for a ductility of six, are compared to Newmark-Hall F $\mu$ s in. Figure 3.5. Overall, the results of these two studies are generally consistent. Below $5 \mathrm{hz}$, Newmark-Hall have lower F $\mu$ s than Nassar-Krawinkler. Between 5 and 20 hz, NassarKrawinkler have lower F $\mu$ s than Newmark-Hall. At $7 \mathrm{hz}$, the Nassar-Krawinkler F $\mu$ s is about $3 / 4$ of the Newmark-Hall Fus. These differences are smaller at lower ductilities.

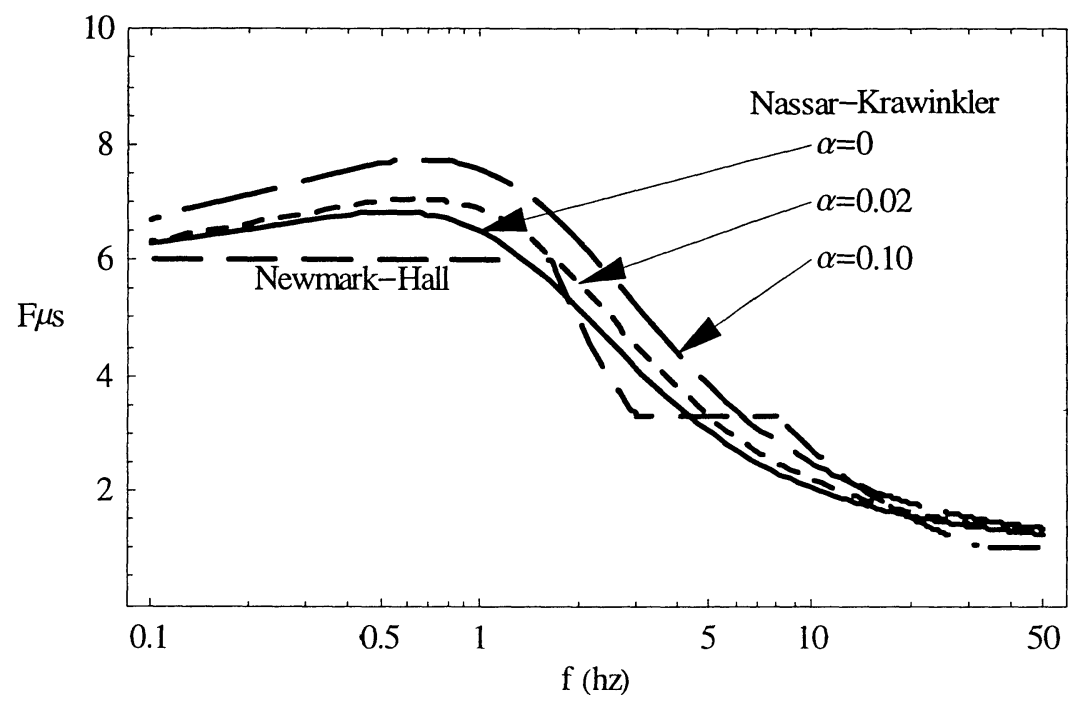

Figure 3.5 Comparison of Nassar-Krawinkler and Newmark-Hall F $\mu s, \mu=6$

\subsubsection{Miranda}

Miranda [1994] developed nonlinear response spectra based on 124 recorded ground motion representing a wide range of soil conditions. Soil conditions were classified into three broad groups as (1) rock; (2) alluvium; and (3) soft soil sites. Mean Fus were developed for each soil site using a bilinear hysteresis model with $5 \%$ damping. The Miranda expression for F $\mu$ s is

$\mathrm{F} \mu \mathrm{s}=\frac{\mu-1}{\Phi}+1$

Where

$$
\begin{array}{ll}
\Phi=1+\frac{1}{10 \mathrm{~T}-\mu \mathrm{T}}-\frac{1}{2 \mathrm{~T}} \operatorname{Exp}\left(-\frac{3}{2}\left(\operatorname{Ln}(\mathrm{T})-\frac{3}{5}\right)^{2}\right) & \text { for rock sites, } \\
\Phi=1+\frac{1}{12 \mathrm{~T}-\mu \mathrm{T}}-\frac{2}{5 \mathrm{~T}} \operatorname{Exp}\left(-2\left(\operatorname{Ln}(\mathrm{T})-\frac{1}{5}\right)^{2}\right) & \text { for alluvium sites, and }
\end{array}
$$




\section{Force Reduction Factors for the Structural Design and Evaluation of Facilities Containing Nuclear and Hazardous Materials}

$$
\Phi=1+\frac{T g}{3 T}-\frac{3 T g}{4 T} \operatorname{Exp}\left(-3\left(\operatorname{Ln}\left(\frac{T}{T g}\right)-\frac{1}{4}\right)^{2}\right) \quad \text { for soft soil sites. }
$$

where $\mathrm{Tg}$ is the predominant period of the site which corresponds to the period of peak spectral velocity.

F $\mu$ for rock, alluvium and soft soil (assuming Tg is 1 second) are shown in Figure 3.6, for ductilities of 2, 4 and 6. F $\mu$ s for the three soil types converge at both low and high frequencies. Note that the variation in F $\mu$ s with frequency is stronger than the variation in F $\mu$ s with soil type. Increasing Tg from 1 second to 1.5 second shifts the peak of the soft soil response from about $0.85 \mathrm{hz}$ to $0.56 \mathrm{hz}$, however, the magnitude of the peak is essentially the same for both values of $\mathrm{Tg}$.

Miranda also studied the influence of earthquake magnitude and epicentral distance and concluded that these parameters have a negligible effect on F $\mu$ s.

The Miranda F $\mu$ s are compared the Newmark-Hall F $\mu$ s in Figure 3.7, these two methods yield compatible results. Overall, the Newmark-Hall Fus are within the range of soil types studied by Miranda except around $1 \mathrm{hz}$ where Miranda predicts larger F $\mu$ s. Note that the mean of the 3 soil types in Figure 3.7 are similar to the Nassar-Krawinkler, $\alpha=0$, F $\mu$ s in Figure 3.5.

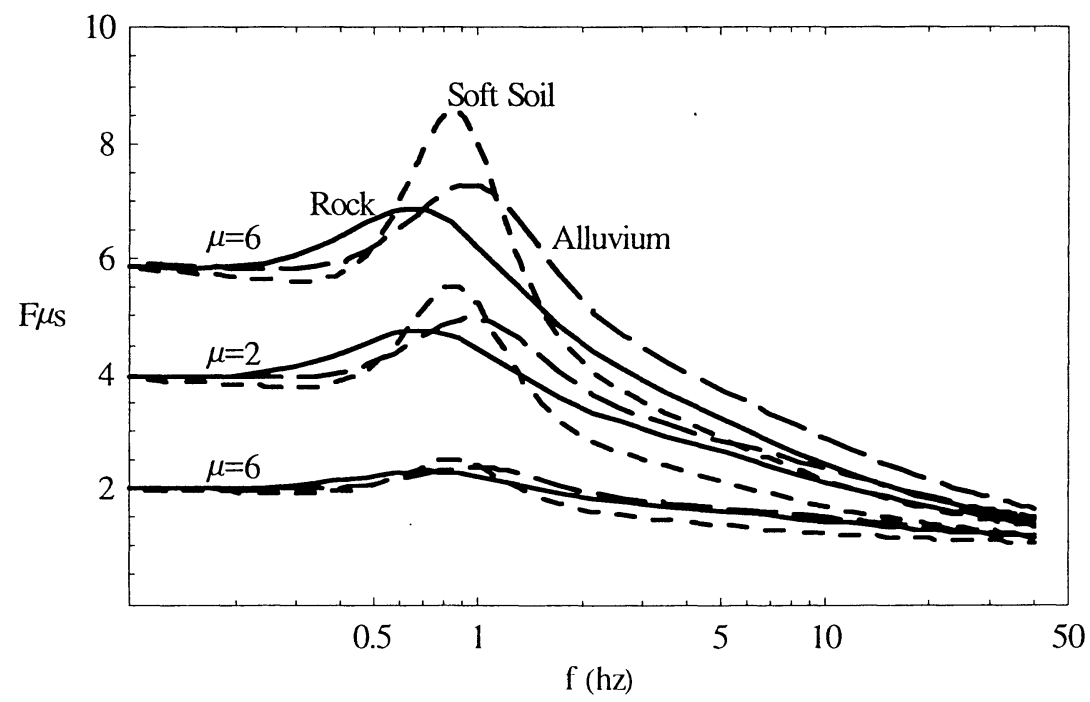

Figure 3.6 Miranda F $\mu$ s for Rock, Alluvium and Soft Soil $\mu=2,4,6$ 
Force Reduction Factors for the Structural Design and Evaluation of Facilities Containing Nuclear and Hazardous Materials

WSRC-TR-2001-00037

Page 3-8

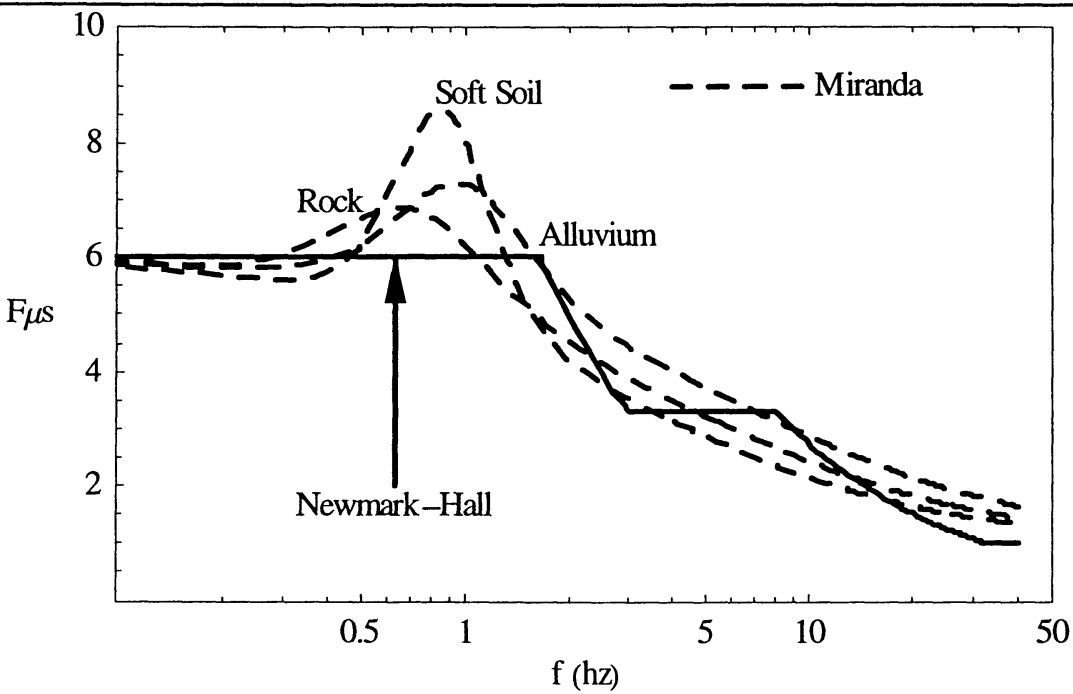

Figure 3.7 Comparison of Miranda and Newmark-Hall F $\mu \mathrm{s}, \mu=6$

\subsubsection{Kennedy et. al.}

Kennedy, Short, Merz and Tokarz [1984] determined the nonlinear response of four shear wall structures using a pinched hysteresis model at ductilities of 1.85 and 4.27. The shear wall structures were representative of nuclear facilities with natural frequencies between 2.14 and $8.54 \mathrm{hz}$. Eleven natural ground motions of varying duration were used as seismic input along with an artificial time history representing the Regulatory Guide 1.60 spectra.

Over the range of natural frequencies studied, structures with pinched hysteresis loops were observed to dissipate less energy than structures with full hysteresis loops, and for a given ground motion and capacity, structures with pinched hysteresis loops typically have larger ductility demands. The ductility demand was observed to be strongly influenced by the length of the time history, with the ductility demand increasing with the duration of strong motion.

Mean F $\mu$ s were developed using an effective frequency, fe, and damping, $\beta \mathrm{e}$,

$$
F \mu s=\mu\left(\frac{f e}{f}\right)^{2} \frac{S a(f, \beta)}{S a(f e, \beta e)}
$$

Where $\mathrm{Sa}(\mathrm{f}, \beta)$ is the elastic spectral acceleration

$f$ is the elastic natural frequency,

$\beta$ is the viscous damping ratio, $\beta=0.07$,

$\mathrm{Sa}(\mathrm{fe}, \mathrm{Be})$ is the effective spectral acceleration

$$
f e=f\left((1-A)+A \frac{f s}{f}\right) \text {, }
$$


Force Reduction Factors for the Structural Design and Evaluation of Facilities

Containing Nuclear and Hazardous Materials

WSRC-TR-2001-00037

Page 3-9

fs is a secant frequency, $\mathrm{fs}=\mathrm{f} \sqrt{\frac{1+\mathrm{s}(\mu-1)}{\mu}}$,

$s$ is the strain hardening ratio, $s=0.10$,

$\mathrm{A}=\mathrm{C}_{\mathrm{F}}\left(1-\frac{\mathrm{fs}}{\mathrm{f}}\right) \leq 0.85$,

$\beta \mathrm{e}=\left(\frac{\mathrm{fs}}{\mathrm{fe}}\right)^{2}\left(\beta+\beta_{\mathrm{H}}\right)$,

$\beta_{\mathrm{H}}$ is the hysteretic damping, $\beta_{\mathrm{H}}=\mathrm{C}_{\mathrm{N}}\left(1-\frac{\mathrm{fs}}{\mathrm{f}}\right)$, and

coefficients $C_{F}$ and $C_{N}$ were chosen to minimize the error between the preceding simple formula for $\mathrm{F} \mu \mathrm{s}$ and the nonlinear analysis results and are:

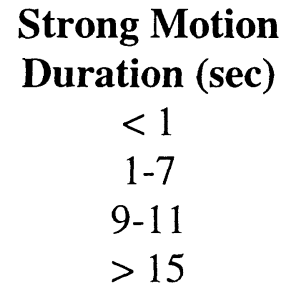

\section{Number of Strong Nonlinear Cycles}

1

2

3

4
$\mathbf{C}_{\mathbf{F}}$

1.5

1.9

2.3

2.7
$\mathbf{C}_{\mathbf{N}}$

0.30

0.15

0.11

0.11

Note that $C_{F}$ and $C_{N}$ were fit to the above equations with $s=0.10$ and $\beta=0.07$, and these values should be used with these expressions. The authors state most structures have a strain hardening ratio between $3 \%$ and $15 \%$, and that $10 \%$ is reasonable for shear walls with $1 \%$ reinforcing that are typical in nuclear facilities. Additionally, a parametric study was used to demonstrate that $F \mu$ for shear walls is relatively insensitive to strain hardening ratio's between $3 \%$ and $15 \%$ [Kennedy 1984].

The viscous damping formulation used to determine $C_{F}$ and $C_{N}$ was proportional to the tangent modulus of the wall to avoid double counting the hysteretic energy dissipation within the inelastic range. Thus, when the structure loads on the backbone curve beyond the yield point the viscous damping is $s \beta=0.1 \times 7 \%=0.7 \%$. The total effective damping is shown in Figure 3.8 for various levels of ductility. Note that the effective damping for ground motions greater than 7 seconds is less than $9.5 \%$, while the effective damping for all ground motions greater than 1 seconds is less than $11 \%$. The short records have one strong nonlinear cycle per second, while the long records have less than $3 / 7=.4$ to $4 / 15=.07$ strong nonlinear cycle per second. Thus, the longer records spend less time in strong nonlinear cycles and consequently have smaller effective damping ratios. 
Force Reduction Factors for the Structural Design and Evaluation of Facilities Containing Nuclear and Hazardous Materials

WSRC-TR-2001-00037

Page 3-10

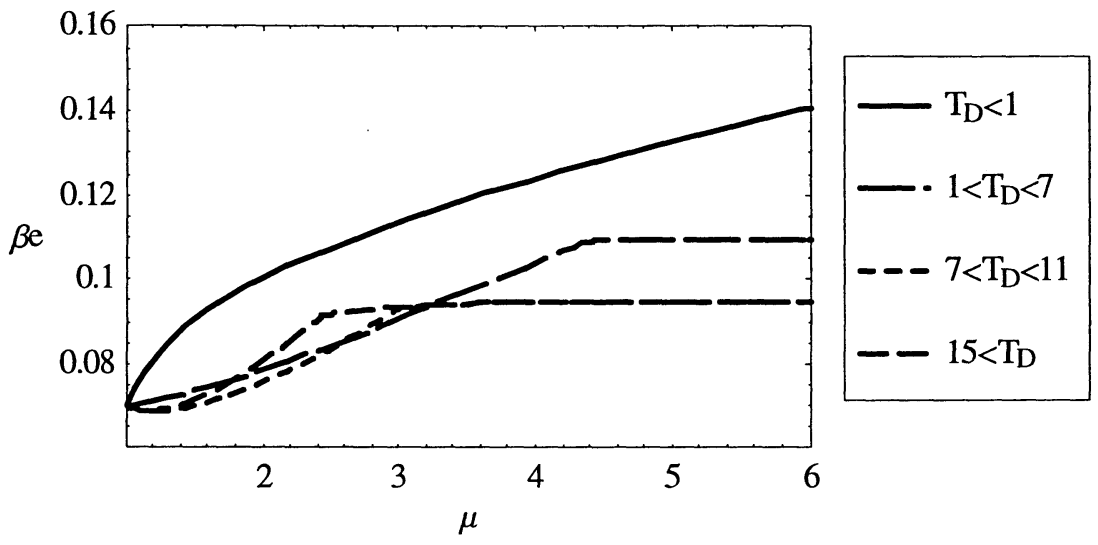

Figure 3.8 Effective Damping, $\log (\beta e)$

The ratio of effective frequency to elastic frequency is shown in Figure 3.9. Note that a ductility of 3 corresponds to a $30 \%$ drop in effective frequency or a $50 \%$ drop in effective stiffness.

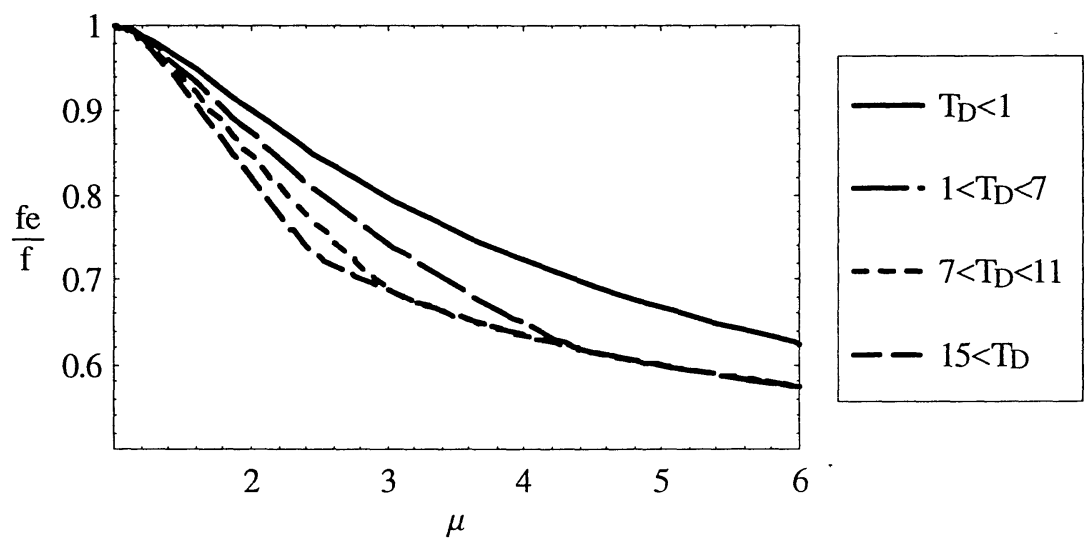

Figure 3.9 Effective Frequency, fe

Newmark and Hall estimate the mean spectral acceleration in the constant acceleration range as

$\mathrm{Sa}=3.21-0.68 \log (\beta)$

where the damping, $\log (\beta)$, is expressed in percent. As long as both the elastic frequency and effective frequency remain in the constant acceleration range, the ratio of spectral accelerations can be stated as:

$\frac{\mathrm{Sa}(\mathrm{f}, \beta)}{\mathrm{Sa}(\mathrm{fe}, \beta \mathrm{e})}=\frac{3.21-0.68 \log (\beta)}{3.21-0.68 \log (\beta \mathrm{e})}$ 
The influence of ground motion duration on F $\mu$ s is shown in Figure 3.10, when both $\mathrm{f}$ and fe remain in the constant acceleration range. F $\mu$ s decreases as the duration of the ground motion increases. However, the difference in F $\mu$ s between the 9-11 and $>15$ second ground motion is small. Facilities containing nuclear materials are typically analyzed for strong ground motions with long durations. Thus, $\mathrm{CF}=2.7$ and $\mathrm{CN}=0.11$ are recommended. Other values may be used for shorter ground motions.

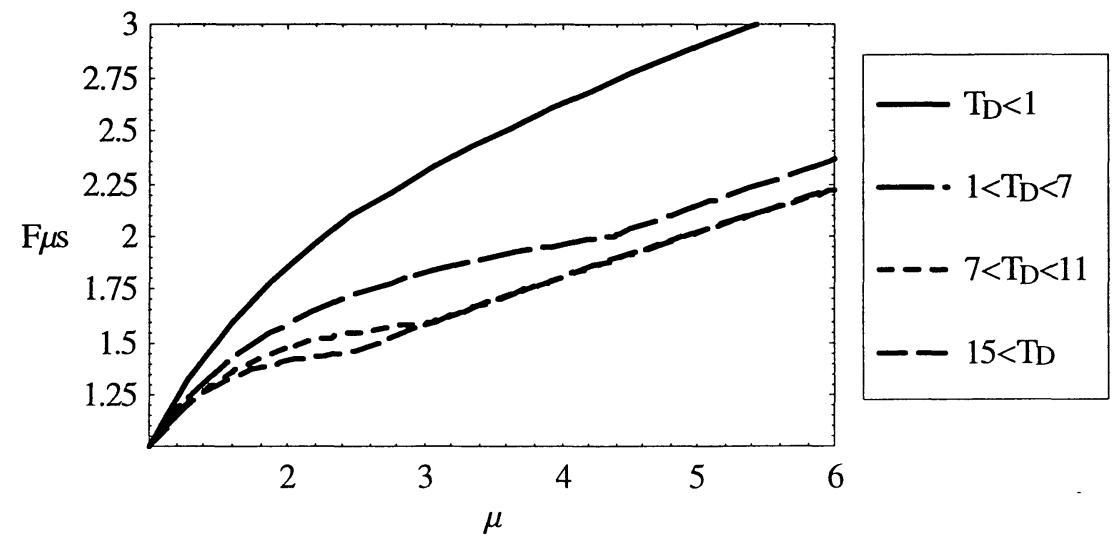

Figure 3.10 F $\mu$ s vs. $\mu$ For Various Length Ground Motion in the Constant Acceleration Region

Inelastic response spectra are shown in Figure 3.11 for pinched structural systems. In the constant acceleration range F $\mu$ s is solely dependant on ductility. Below 2 to $3 \mathrm{hz}$, the effective frequency falls in to the constant velocity portion of the spectra resulting in additional reductions in response. Recall that the numerical studies only covered the range between 1 and $10 \mathrm{hz}$. Interpolation was used to construct the response spectra between 10 and $33 \mathrm{hz}$.

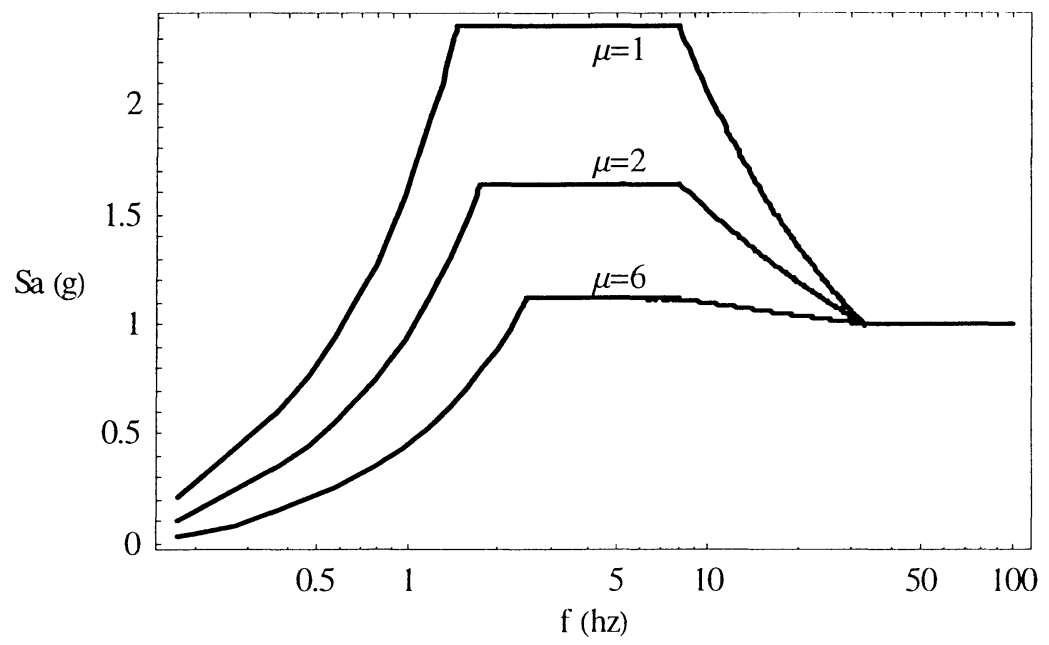

Figure 3.11 Inelastic Response Spectra for Pinched Structural Systems 


\section{Force Reduction Factors for the Structural Design and Evaluation of Facilities Containing Nuclear and Hazardous Materials}

\subsection{Consequences Of Using A Constant Force Reduction Factor}

\subsubsection{Rigid Frames}

Current building codes commonly use a frequency independent value of F $\mu$ s, and neglect the reduction in spectral acceleration for frequencies higher than the peak of the spectra. In Figure 3.12 the elastic spectra divided by the ductility, referred to as the 'design' spectra, is compared to the Newmark-Hall inelastic response spectra. For a ductility of 2 the design spectra and inelastic response spectra compare favorably with a difference of less than $15 \%$. At a ductility of 6 the inelastic response spectra is almost twice of the design spectra between 2 and $8 \mathrm{hz}$ and almost three time the design spectra for rigid structures.

A comparison of these two spectra for ductility's between 2 and 8, summarized in Table 3.1, indicates that for frequencies above $2 \mathrm{hz}$, the design spectra is increasingly unconservative with increasing ductility. In Table 2.1 for $\mu=8$ and $5 \mathrm{hz}$, The NewmarkHall spectral acceleration is more than twice the design acceleration.

Note that rigid frames typically have large ductilities, and for conventional construction, rigid frames seldom have frequencies above $2 \mathrm{hz}$. The 'design' spectra in this range matches the inelastic response spectra. Thus, for conventional construction the common design method of dividing the entire spectrum by a constant reduction factor yields rational results. However, for special structures such as short-stiff rigid frames with a high natural frequency the conventional design method can lead to unconservative results.

The frequency dependency of F $\mu$ s should be explicitly considered to obtain a high degree of reliability for non-conventional facilities containing nuclear materials.

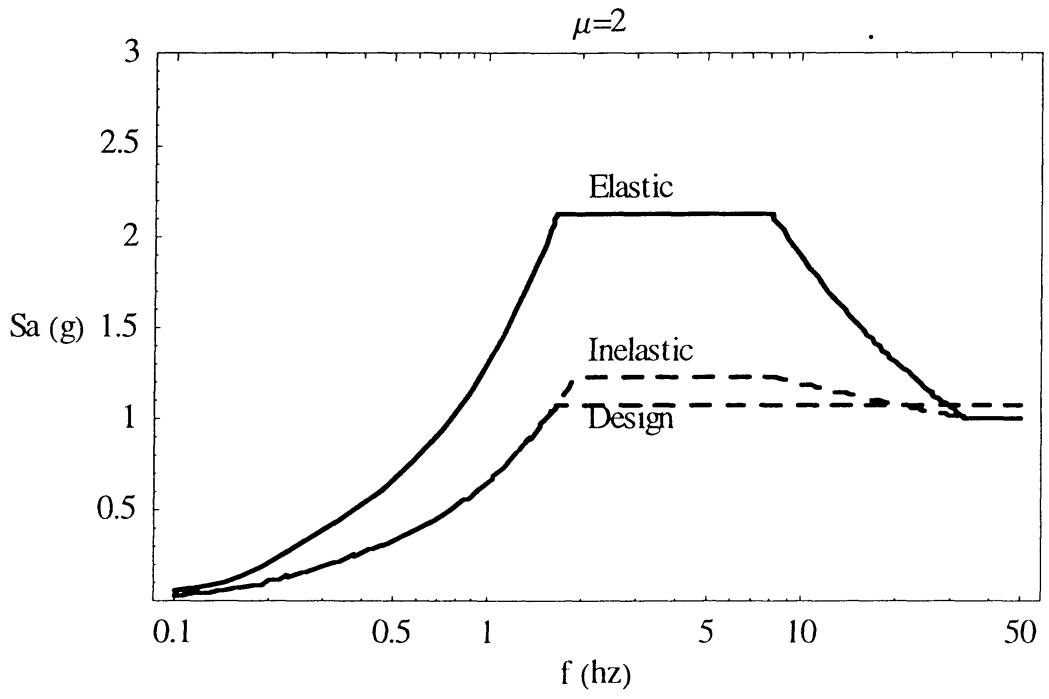

Figure 3.12a Comparison of Newmark-Hall Inelastic Spectra and Design Spectra, $\mu=2$ 
Force Reduction Factors for the Structural Design and Evaluation of Facilities Containing Nuclear and Hazardous Materials

WSRC-TR-2001-00037

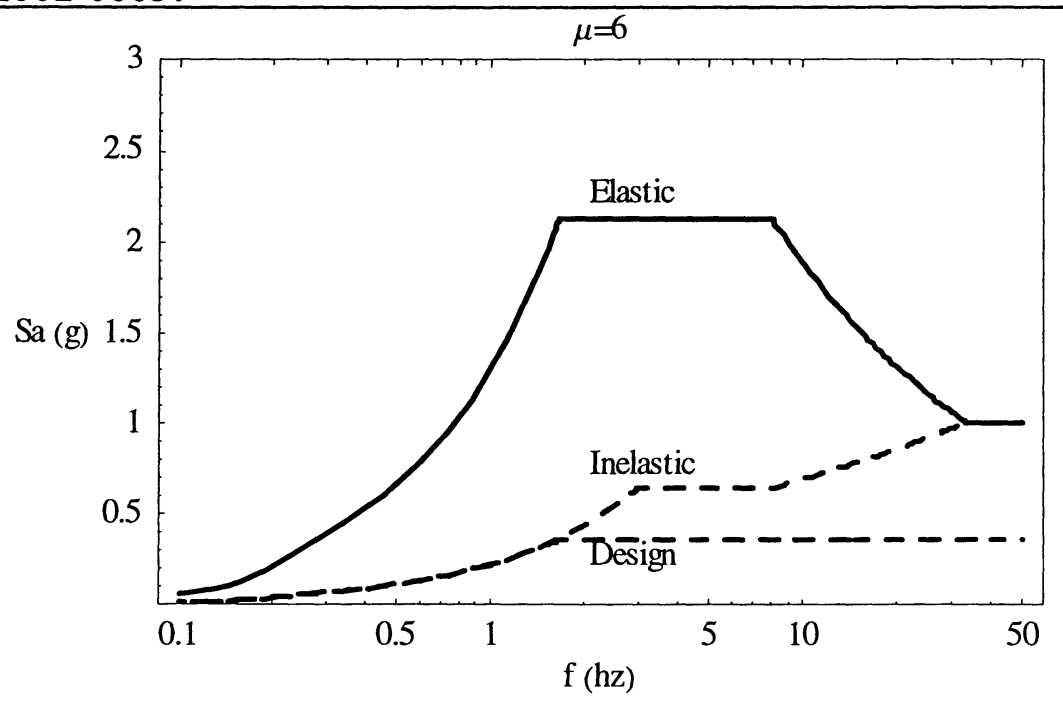

Page 3-13

Table 3.1 Comparison of Inelastic and Design Spectra

\begin{tabular}{cccc} 
Frequency & $<\mathbf{2 ~ h z}$ & $\mathbf{2 - 8} \mathbf{~ h z}$ & $>\mathbf{3 3} \mathbf{~ h z}$ \\
$\frac{\text { InelasticSa }}{\text { ElasticSa }}$ & $\frac{1}{\mu}$ & $\frac{1}{\sqrt{2 \mu-1}}$ & 1.0 \\
Design Sa & $\frac{1}{\mu}$ & $\frac{1}{\mu}$ & $\frac{\mathrm{A}}{\mu}$ \\
$\frac{\text { ElasticSa }}{\text { InelasticSa }}$ & 1.0 & $\frac{\mu}{\sqrt{2 \mu-1}}$ & $\frac{\mu}{\mathrm{A}}$ \\
\hline Design Sa & & 1.15 & 0.94 \\
$\mu=2$ & 1.0 & 1.51 & 1.88 \\
$\mu=4$ & 1.0 & 1.81 & 2.83 \\
$\mu=6$ & 1.0 & 2.06 & 3.77 \\
$\mu=8$ & 1.0 & &
\end{tabular}

Where $\mathrm{A}$ is the ratio of the peak spectral acceleration to the peak ground acceleration. $A=2.12$ for a $5 \%$ damped mean spectra [Newmark, 1987].

\subsubsection{Braced Frames and Shear Wall Structures}

The force reduction factors developed by Kennedy et. al. are a function of the response spectra at both the initial and effective frequencies, and have an inherent frequency dependence. However, the Newmark-Hall elastic response spectra, shown in Figure 3.11, was used to demonstrate the pinched F $\mu$ s has a constant acceleration between 2 and $8 \mathrm{hz}$. Thus, the spectral values at both the initial and the effective frequency were equal and an 


\section{Force Reduction Factors for the Structural Design and Evaluation of Facilities Containing Nuclear and Hazardous Materials}

important component of F $\mu$ s, shifting the frequency of the system off the peak spectral demand, was not observed.

Real ground motions are seldom as broad and never as smooth as the Newmark-Hall design response spectra. The mean F $\mu$ s, $(\bar{F} \mu s)$, calculated [Kennedy 1984] for 11 recorded ground motions varied from $\overline{\mathrm{F}} \mu \mathrm{s}=1.8$ at $8.5 \mathrm{hz}$ to $\overline{\mathrm{F}} \mu \mathrm{s}=3.41$ at $2.1 \mathrm{hz}$ for $\mu=4.27$, while the calculated force reduction factor using the smooth spectra is 1.8 . Thus, the use of a smooth broad design spectra introduces a conservative bias in the F $\mu$ s for structures with pinched hysteresis models.

\subsection{Simplified Frequency Dependent Force Reduction Factor}

The following simplified frequency dependent F $\mu$ s is proposed for structures with full hysteresis loops to reflect the reduction in F $\mu$ s at higher frequencies.

$$
F \mu s= \begin{cases}\mu & f \leq 1 h z \\ \mu^{1-\operatorname{Ln}(f) / \operatorname{Ln}(30)} & 1 h z<f \leq 30 h z \\ 1.0 & 30 h z<f\end{cases}
$$

F $\mu$ s is simply a straight line on a log-log plot between $(1 \mathrm{hz}, \mathrm{F} \mu \mathrm{s}=\mu)$ and $(30 \mathrm{hz}, \mathrm{F} \mu \mathrm{s}=1)$ and is shown in Figure 3.13.

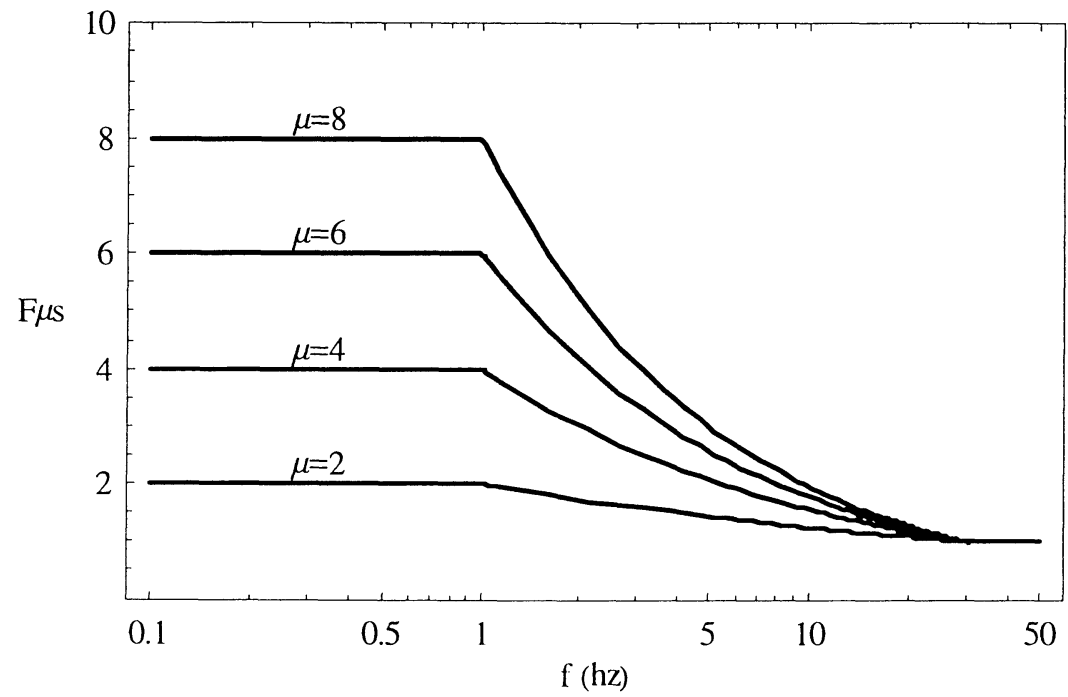

Figure 3.13 Proposed Frequency Dependant F $\mu$ s

The proposed F $\mu$ s are compared to F $\mu$ s by Newmark-Hall, Nassar-Krawinkler and Miranda for $\mu=2$ and 6 in Figure 3.14. The proposed F $\mu$ s capture the important aspects of frequency dependence but do not include strain hardening nor soil effects. For design, the proposed F $\mu$ s are biased to the conservative side of the reference F $\mu$ s. 


\section{Force Reduction Factors for the Structural Design and Evaluation of Facilities}

Containing Nuclear and Hazardous Materials

Recognizing that the studies by Newmark-Hall, Nassar-Krawinkler and Miaranda are heavily influenced by western earthquakes, Equation 3-6 can be generalized to address earthquakes with other spectral shapes. For western earthquakes the transition between constant velocity and acceleration ranges occurs between 1 and 2 hertz. Denote this frequency as $f_{A V}$ and recognize that $f_{A V}$ was rounded down to 1 hertz to provide a lower bound to the studies as seen in Figure 3.14. Similarly, western earthquakes typically have a rigid response above 33 hertz. Similarly, denote this frequency as $f_{R B}$ and recognize that it is rounded down to 30 hertz to provide a lower bound to the studies as seen in Figure 3.14. Thus, the generalized force reduction factor is postulated to be

$F \mu S= \begin{cases}\mu & \mathrm{f} \leq \mathrm{f}_{\mathrm{AV}} \\ \mu^{1-\operatorname{Ln}(\mathrm{f}) / \mathrm{Ln}(\mathrm{fRB})} & \mathrm{f}_{\mathrm{AV}}<\mathrm{f} \leq \mathrm{f}_{\mathrm{RB}} \\ 1.0 & \mathrm{f}_{\mathrm{RB}}<\mathrm{f}\end{cases}$

where $f_{A V}$ is slightly less than the frequency between the constant velocity and acceleration range; and

$f_{R B}$ is slightly less than the rigid body frequency. 
Force Reduction Factors for the Structural Design and Evaluation of Facilities Containing Nuclear and Hazardous Materials

WSRC-TR-2001-00037

Page 3-16
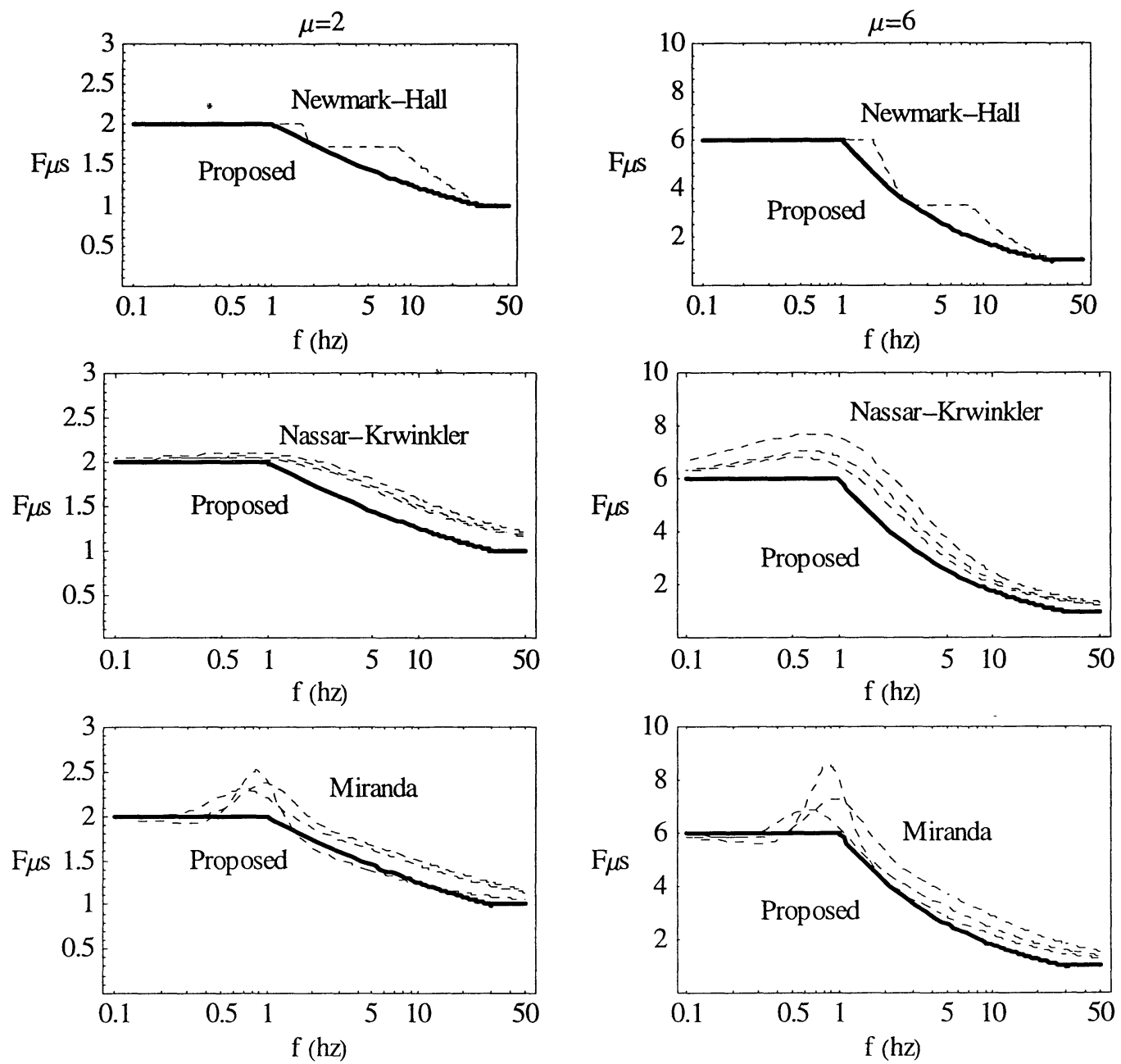

Figure 3.14 Fus Comparison 


\subsection{Relationship Between Element, Story and System Ductilities}

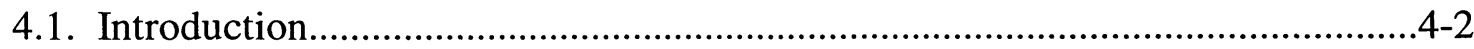

4.2. Single-Element, Single Degree of Freedom Structures ........................................4-2

4.3. Multiple-Element, Single Degree of Freedom Structures ......................................4-3

4.3.1. Structural Model and Backbone Curves.......................................................4-3

4.3.2. Ductility Relationships ……………………….........................................4-7

4.3.3. Application of Force Reduction Factors ………..........................................4-8

4.3.3.1. Low Frequency Systems ......................................................................4-9

4.3.3.2. Mid-Range Frequency Systems .......................................................4-13

4.3.3.3. Application to Dual Systems ............................................................4-17

4.3.4. Summary for Multiple-Element Single Degree of Freedom Structures......4-18

4.4. Multiple Degree of Freedom Structures.......................................................... 4-20

4.4.1. Moment Frames..................................................................................4-22

4.4.1.1. Beam Hinge - Strong Column, Weak Beam Moment Frames .............4-23

4.4.1.2. Column Hinge - Weak Column, Strong Beam Moment Frames..........4-24

4.4.1.3. Weak Story Rigid Frames ................................................................... 4-27

4.4.2. Shear Walls .......................................................................................... 4-30

4.4.2.1. Shear Dominated Shear Walls.............................................................4-31

4.4.2.2. Flexural Shear Walls .......................................................................4-31

4.4.3. Braced Frames.................................................................................... 4-34

4.4.4. Summary for Multiple Degree of Freedom Structures................................... 4-35 
Force Reduction Factors for the Structural Design and Evaluation of Facilities Containing Nuclear and Hazardous Materials

WSRC-TR-2001-00037

Page 4-2

\subsection{Introduction}

In Section 3 mean frequency dependant relationships between $F_{\mu}$ and ductility, $\mu$, were developed for single-element, single degree-of-freedom systems. The ductility for these single degree-of-freedom systems was denoted F $\mu$ s to delineate it from the F $\mu$ used for multiple degree-of-freedom structures.

Ductility relationships for multiple-element, single degree-of-freedom structures are developed in this section. These relationships are used to demonstrate that the F $\mu \mathrm{s}$ relationships for single elements developed in Section 3 are generally applicable for multiple element structures.

Additionally, dynamic analyses of multiple degree-of-freedom systems are reviewed to determine the amplification of element ductility and the reduction in effective $F \mu$ due to multi-mode effects. Separate ductility amplifications and effective $F \mu$ reductions are developed for moment frames with beam mechanisms, moment frames with column mechanisms, structures with weak stories, shear walls and braced frames. These ductility amplification factors and effective $F_{\mu}$ factors are used in Section 5 to account for multi degree-of-freedom effects in the convolution of allowable element ductilities with the force reduction factor based on a single degree-of-freedom structures, $F_{\mu s}$.

\subsection{Single-Element, Single Degree of Freedom Structures}

A cantilever beam is shown in Figure 4.1 with a length, $\mathrm{H}$, an applied load, $\mathrm{P}$ and a tip displacement of $\Delta$. For this structure the tip displacement represents the element, story and structure displacement.
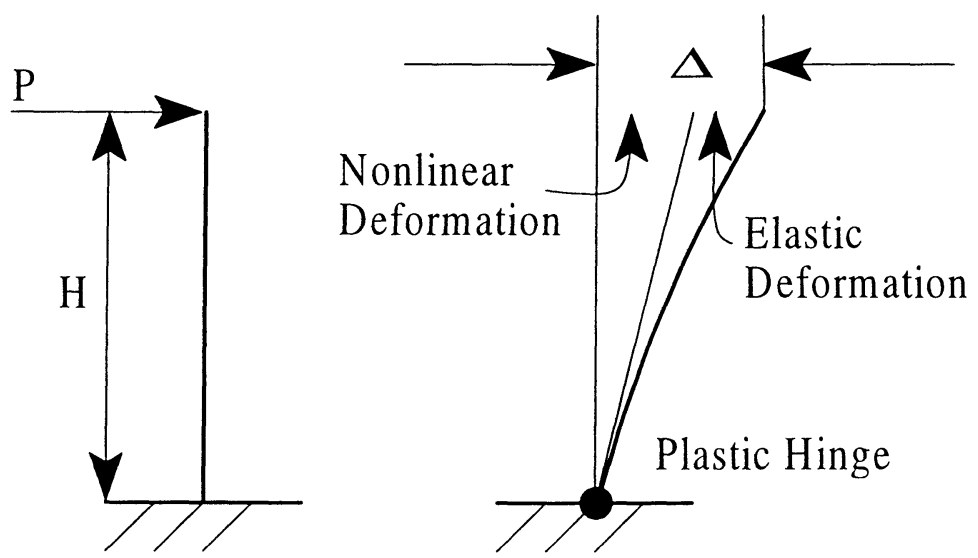

Figure 4.1 Single Degree of Freedom System

A pushover curve, normalized to the member yield force, Py, for the single degree of freedom structure is shown in Figure 4.2. The pushover curve has an elastic region 
with a stiffness of $\mathrm{K}=\mathrm{Py} / \Delta \mathrm{y}$, and a post yield stiffness of $\alpha \mathrm{K}$, where $\Delta y$ is the member yield displacement and $\alpha$ is the strain hardening coefficient. Ductility, $\mu$ is defined as the ratio of total displacement, $\Delta$, to the yield displacement, $\mu=\Delta / \Delta y$. Since the total displacement for the element, story and structure of the model in Figure 4.1 are equal, then the element, story and structure ductility are also equal.

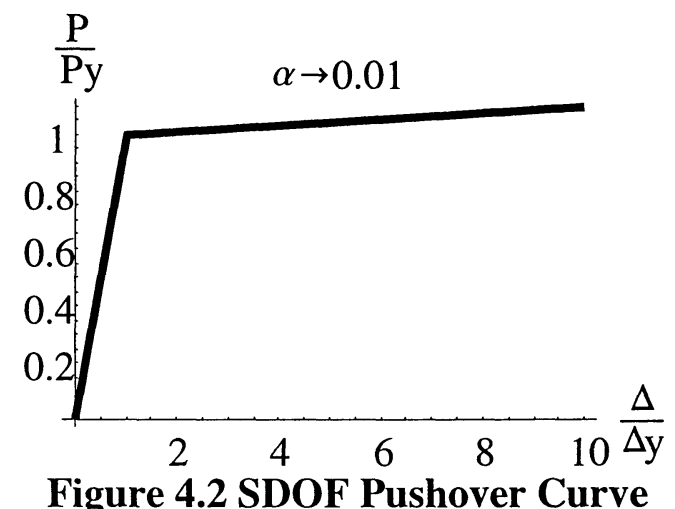

The model shown in Figure 4.1 and the pushover curve in Figure 4.2 were used in Section 3 to develop mean SDOF frequency dependant relationships between F $\mu$ s and ductility, $\mu$. This model is typical for simple shear wall structures, single story buildings, and cantilevered commodity supports.

\subsection{Multiple-Element, Single Degree of Freedom Structures}

\subsubsection{Structural Model and Backbone Curves}

Consider the one story (one degree-of-freedom) structure shown in Figure 4.3 which has two columns with unequal stiffness and strength. This structure can be represented by the two spring model shown in Figure 4.4. Each spring has a yield point, $(\Delta \mathrm{i}, \mathrm{Pi})$, which defines that spring's elastic stiffness $k i=P i / \Delta i$ and a post yield stiffness of $\alpha$ ki. Choose Spring 1 as the spring which has the smaller yield displacement, $\Delta 1 \leq \Delta 2$. Thus, regardless of strength or stiffness Spring 1 always yields first.

For this model, the structure's displacement is equal to the story's displacement, thus the story and structure ductilities are identical. For simplicity, the story and structure are referred to as the system in this subsection. Note that the system displacement is equal to the displacement of each element. However, since the two elements can yield at different displacements their ductilities may not be equal, nor are either of the element ductilities necessarily equal to the system ductility. 
Force Reduction Factors for the Structural Design and Evaluation of Facilities Containing Nuclear and Hazardous Materials

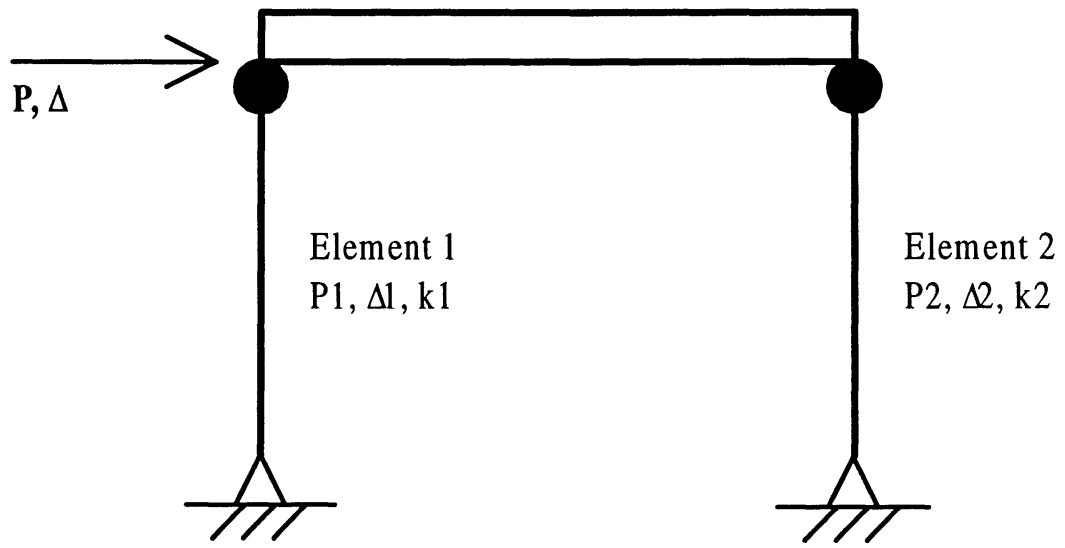

Figure 4.3 Two Column Shear Building

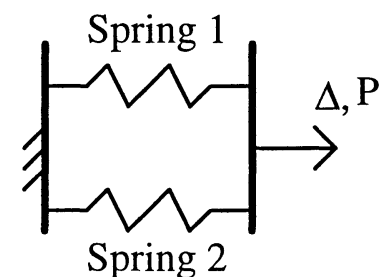

Figure 4.4 Two Spring SDOF Model

Typical backbone curves for the two spring system with varying spring strengths and yield displacements (ie. stiffness) are shown in Figure 4.5, assuming a post yield stiffness of $1 \%$ the elastic stiffness $(\alpha=0.01)$. Let the system yield force, Py, be the sum of the two spring yield forces. Expressing the spring yield strengths as a ratio of P1 to P2, Py becomes

$\mathrm{Py}=\mathrm{P} 1+\mathrm{P} 2={ }^{\mathrm{P}} 1 / \mathrm{P} 2 \mathrm{P} 2+\mathrm{P} 2=(\mathrm{P} 1 / \mathrm{P} 2+1) \mathrm{P} 2$

The first change in the system's stiffness corresponds to yielding of Spring 1 while the second change in the system's stiffness corresponds to yielding of Spring 2. The total force in the system at the first change in stiffness, $\mathrm{Pa}$, is

$\mathrm{Pa}=\mathrm{P} 1+\mathrm{k} 2 \Delta 1=\mathrm{P} 1+{ }^{\mathrm{P}} 2 / \Delta 2 \Delta 1=(\mathrm{P} 1 / \mathrm{P} 2+\Delta 1 / \Delta 2) \mathrm{P} 2$

Normalizing $\mathrm{Pa}$ with respect to the system yield force, $\mathrm{Py}$, yields

$\frac{\mathrm{Pa}}{\mathrm{Py}}=\frac{(\mathrm{P} 1 / \mathrm{P} 2+\Delta 1 / \Delta 2) \mathrm{P} 2}{(1+\mathrm{P} 1 / \mathrm{P} 2) \mathrm{P} 2}=\frac{(\mathrm{P} 1 / \mathrm{P} 2+\Delta 1 / \Delta 2)}{(1+\mathrm{P} 1 / \mathrm{P} 2)}$

which is shown in Figure 4.6. Generally, ${ }^{\mathrm{Pa}} / \mathrm{Py}$ decreases as $\mathrm{Pl} / \mathrm{P} 2$ and ${ }^{\Delta 1} / \Delta_{2}$ decrease. 
Force Reduction Factors for the Structural Design and Evaluation of Facilities Containing Nuclear and Hazardous Materials

Individual load deformation curves for the two springs are also shown in Figure 4.5. The strength of Spring 1 is varied from $50 \%$ to $200 \%$ of the strength of Spring 2 while the yield displacement of Spring 1 is varied from $50 \%$ to $100 \%$ of Spring 2, resulting in Spring 1 stiffness variations of between $50 \%$ and $400 \%$ of Spring 2's stiffness.
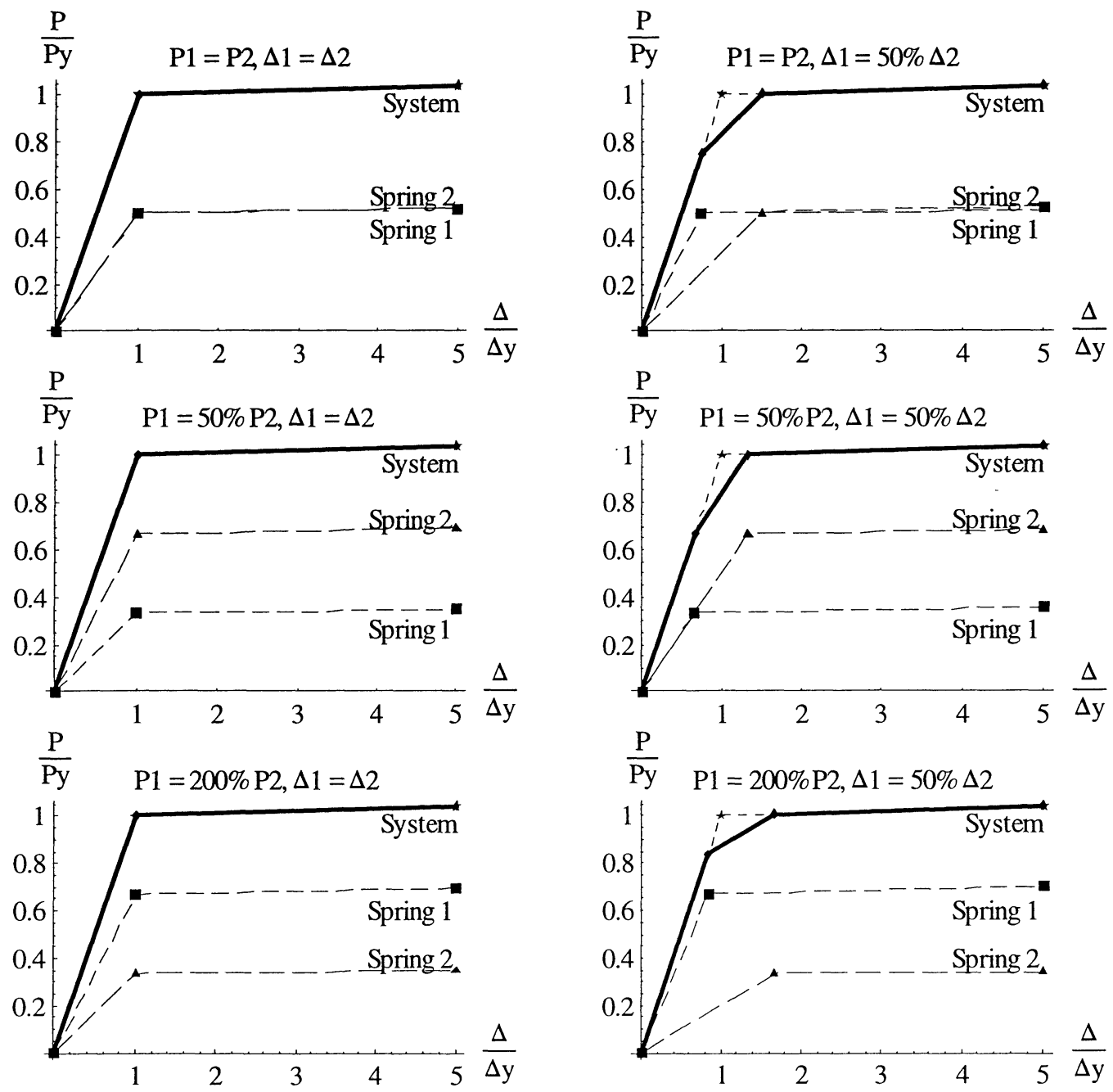

Figure 4.5 Typical Backbone Curves 


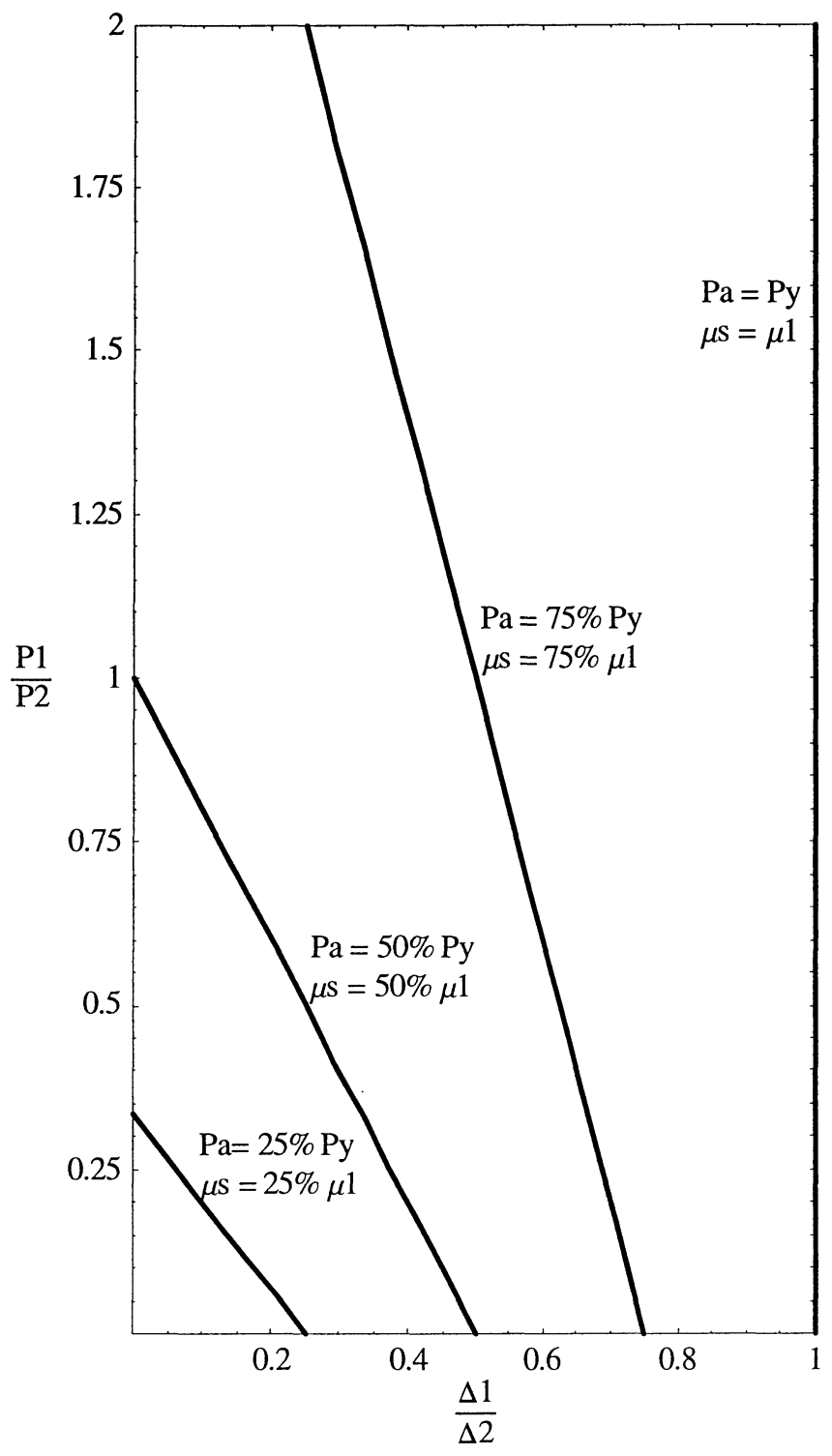

Figure 4.6 System Capacity at First Stiffness Change, Pa, and System Ductility

Additionally, superimposed on each backbone curve is an idealized system curve with a yield strength of Py and yield displacement of $\Delta y$. Note that the system stiffness, $K$, is the sum of the elastic stiffness of both springs.

$$
\mathrm{K}=\mathrm{k} 1+\mathrm{k} 2=\frac{\mathrm{P} 1}{\Delta 1}+\frac{\mathrm{P} 2}{\Delta 2}=\frac{\mathrm{P} 1 / \mathrm{P} 2 \mathrm{P} 2}{\Delta 1 / \Delta 2 \Delta 2}+\frac{\mathrm{P} 2}{\Delta 2}=\frac{\mathrm{P} 1 / \mathrm{P} 2+\Delta 1 / \Delta 2}{\Delta 1 / \Delta 2} \frac{\mathrm{P} 2}{\Delta 2}
$$

The system yield displacement is the yield force divided by the elastic stiffness, or 


$$
\Delta y=\frac{\mathrm{Py}}{\mathrm{K}}=\frac{\Delta 1 / \Delta 2}{\mathrm{P} 1 / \mathrm{P} 2+\Delta 1 / \Delta 2} \frac{\Delta 2}{\mathrm{P} 2}(\mathrm{P} 1 / \mathrm{P} 2+1) \mathrm{P} 2=\frac{\Delta 1 / \Delta 2(\mathrm{P} 1 / \mathrm{P} 2+1)}{\mathrm{P} 1 / \mathrm{P} 2+\Delta 1 / \Delta 2} \Delta 2 \quad \text { or } \quad \Delta y=\frac{(\mathrm{P} 1 / \mathrm{P} 2+1)}{\mathrm{P} 1 / \mathrm{P} 2+\Delta 1 / \Delta 2} \Delta 1
$$

\subsubsection{Ductility Relationships}

Relationships between element and story/structure ductility are developed in this section. The system ductility, $\mu \mathrm{s}$, given a displacement of $\Delta \mathrm{s}$ is

$$
\mu \mathrm{s}=\frac{\Delta \mathrm{s}}{\Delta \mathrm{y}}
$$

Conversely, the system displacement given the system ductility is

$$
\Delta \mathrm{s}=\mu \mathrm{s} \Delta \mathrm{y}=\mu \mathrm{s} \frac{(\mathrm{P} 1 / \mathrm{P} 2+1)}{\mathrm{P} 1 / \mathrm{P} 2+\Delta 1 / \Delta 2} \Delta 1
$$

Similarly, the ductility of Spring $1, \mu 1$, is

$$
\mu 1=\frac{\Delta s}{\Delta 1}=\frac{\mu s \frac{(\mathrm{P} 1 / \mathrm{P} 2+1)}{\mathrm{P} 1 / \mathrm{P} 2+\Delta 1 / \Delta 2} \Delta 1}{\Delta 1}=\frac{\mathrm{P} 1 / \mathrm{P} 2+1}{\mathrm{P} 1 / \mathrm{P} 2+\Delta 1 / \Delta 2} \mu \mathrm{s} \quad \text { or } \quad \mu s=\frac{\mathrm{P} 1 / \mathrm{P} 2+\Delta 1 / \Delta 2}{\mathrm{P} 1 / \mathrm{P} 2+1} \mu 1
$$

Thus, the ratio of the system ductility to the ductility of Spring 1 is

$$
\frac{\mu \mathrm{s}}{\mu 1}=\frac{\mathrm{P} 1 / \mathrm{P} 2+\Delta 1 / \Delta 2}{(\mathrm{P} 1 / \mathrm{P} 2+1)}
$$

which is equal to $\mathrm{Pa} / \mathrm{Py}$, Equation 4-3, and is also shown in Figure 4.6. Therefore, the lower the first change in stiffness, $\mathrm{Pa}$, the larger the disparity between system ductility and the ductility of the first yield element. The system ductility is shown to be greater than $50 \%$ of Spring 1's ductility for most structures and greater than $50 \%$ of Spring 1's ductility for all structures with either $\mathrm{P} 1>\mathrm{P} 2$ or $\Delta 1>50 \% \Delta 2$.

The ratio of Spring 1 to system ductilities is shown to be less than 1.5 for most of the structures with ${ }^{\mathrm{P} 1} / \mathrm{P}_{2} \leq 2$ and less than 1.5 for all structures with $\mathrm{Pl} / \mathrm{P} 2>2$.

Large differences between the ductility of Spring 1 and the system ductility occurs for small values of $\mathrm{Pl} / \mathrm{P}_{2}$ and $\Delta 1 / \Delta 2$. Figure 4.7 is the backbone curve for such a structure with a Spring 1 ductility that is four times the system ductility ( $\mu s=25 \% \mu 1)$. Given the frame in Figure 4.3, a reinforced concrete structure with $\mu \mathrm{s}=0.25 \mu 1$ would have one column with $0.5 \%$ reinforcing and the other, same size, column with about $4 \%$ reinforcing. Differences in reinforcing this large are certainly atypical for moment frames. Similarly, 


\section{Force Reduction Factors for the Structural Design and Evaluation of Facilities Containing Nuclear and Hazardous Materials

the yield displacement for different elements in braced frames typically to not have large variations, nor does the yield displacement in shear walls. Thus, typical structures would not be expected to have differences in ductility this large. Note that mixing shear walls or braced frames with moment frames, or dual systems, can have large variations in $\Delta 1 / \Delta 2$. The effect of dual systems on element demand are addressed separately below.

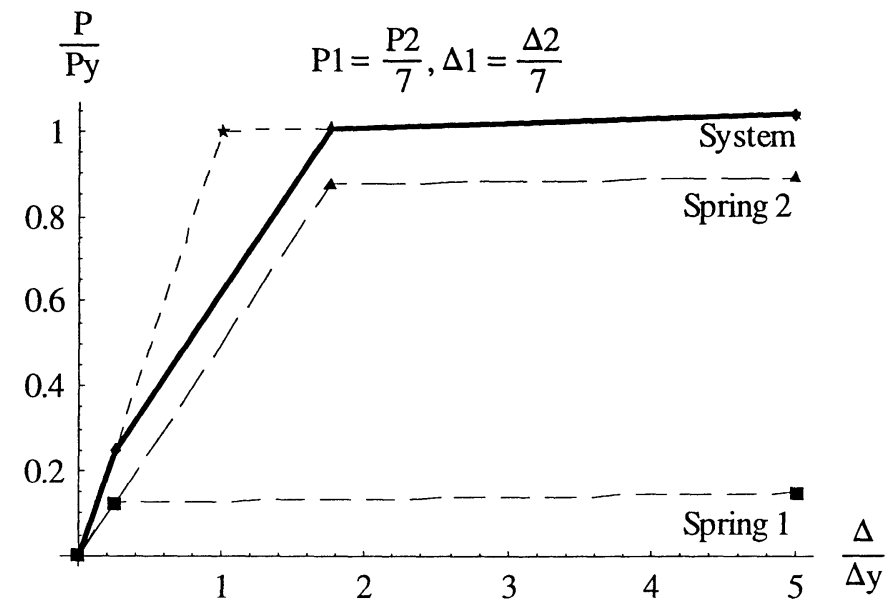

Figure 4.7 Backbone Curve for $\mu s=25 \% \mu 1$ Structure

The ductility of Spring $2, \mu 2$, is

$\mu 2=\frac{\Delta s}{\Delta 2}=\frac{\mu \mathrm{s} \frac{\Delta 1 / \Delta 2(\mathrm{P} 1 / \mathrm{P} 2+1)}{\mathrm{P} 1 / \mathrm{P} 2+\Delta 1 / \Delta 2} \Delta 2}{\Delta 2}=\frac{\Delta 1 / \Delta 2(\mathrm{P} 1 / \mathrm{P} 2+1)}{\mathrm{P} 1 / \mathrm{P} 2+\Delta 1 / \Delta 2} \mu \mathrm{s}=\Delta 1 / \Delta 2 \mu 1$

Comparing Equations 4-9 and 4-10 we note that, for springs with unequal yield displacement and $\Delta 1<\Delta 2$ that $\mu 1>\mu s>\mu 2$.

Therefore it is shown that the element ductility may not necessarily be equal to the system ductility. The influence that this difference in element ductility has on the seismic demand to capacity ratio is evaluated in the following section.

\subsubsection{Application of Force Reduction Factors}

In Section 3 it was shown that the inelastic force reduction factor, $\mathrm{F} \mu$, for a single degree-of-freedom system with a single, well-defined, yield point is a function of the element ductility, which is equal to the system ductility. For a system with multiple elements, the ductility of each element may not be equal to the system ductility. Seismic capacity based on system strength and system ductility, is compared to the seismic capacity based on element strength and element ductility in the following section. For the single degree of freedom system, with a single well defined yield point, the 
elastically calculated seismic demand, D, is divided by $\mathrm{F} \mu$ and set less than or equal to the system capacity, Py.

$\frac{\mathrm{D}}{\mathrm{F} \mu_{\text {System }}} \leq \mathrm{Py}$

\subsubsection{Low Frequency Systems}

As seen in Section 2, for low frequency systems, both the elastic and inelastic structures have about the same displacement and the force reduction factor is approximated by the ductility, $F \mu \cong \mu$. For the multi-element system in Figure 4.4, the allowable system displacement is limited by the smaller of $\mu 1 \Delta 1$ and $\mu 2 \Delta 2$. Assume, temporarily, that Spring 1 is limiting with an allowable ductility of $\mu 1$. Then, the allowable demand that can act on Spring 1, D1, is

$$
\mathrm{D} 1=\mathrm{F} \mu(\mu 1) \mathrm{P} 1=\mu 1 \mathrm{P} 1
$$

The elastically calculated demand acting on Spring 1, D1, is shown in Figure 4.8 along with the demand acting on Spring 2, D2, and the demand acting on the entire structure, D.

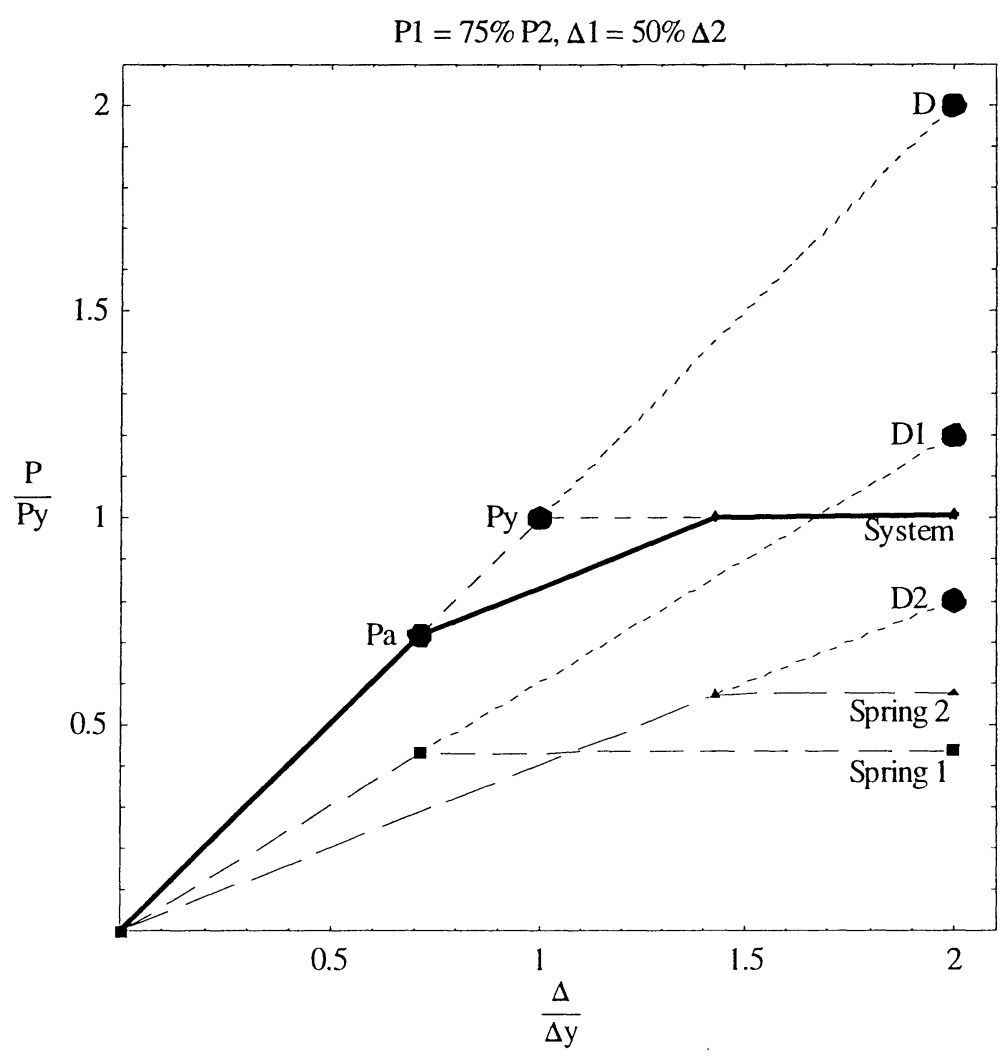

Figure 4.8 System and Element Demands 
The total allowable demand acting on the system, D, when Spring 1 has a demand of D1 is determined by stiffness ratios of the elements

$$
\mathrm{D}=\frac{\mathrm{K}}{\mathrm{k} 1} \mathrm{D} 1=\frac{\frac{\mathrm{P} 1 / \mathrm{P} 2+\Delta 1 / \Delta 2}{\Delta 1 / \Delta 2} \frac{\mathrm{P} 2}{\Delta 2}}{\mathrm{P} 1 / \Delta 1} \mu 1 \mathrm{P} 1=\frac{\mathrm{P} 1 / \mathrm{P} 2+\Delta 1 / \Delta 2}{\mathrm{P} 1 / \mathrm{P} 2} \mu 1 \mathrm{P} 1 / \mathrm{P} 2 \mathrm{P} 2=(\mathrm{P} 1 / \mathrm{P} 2+\Delta 1 / \Delta 2) \mu 1 \mathrm{P} 2
$$

Since the ductility of Spring 1 is known, then the system ductility is also known and the total allowable demand acting on the idealized bilinear system is

$$
\mathrm{D}=\mathrm{Py} F \mu(\mu \mathrm{s})=(\mathrm{P} 1 / \mathrm{P} 2+1) \mathrm{P} 2 \mu \mathrm{s}=(\mathrm{P} 1 / \mathrm{P} 2+1) \mathrm{P} 2 \frac{\mathrm{P} 1 / \mathrm{P} 2+\Delta 1 / \Delta 2}{\mathrm{P} 1 / \mathrm{P} 2+1} \mu 1=(\mathrm{P} 1 / \mathrm{P} 2+\Delta 1 / \Delta 2) \mu 1 \mathrm{P} 2
$$

which is equal to the total allowable demand acting on the system based on Spring 1's ductility shown in Equation 4-13. Thus, the allowable demand acting on a system is equal whether the demand is based on Spring 1, with Spring 1's ductility or on the idealized bilinear system, using the system's capacity, Py, and the systems ductility, $\mu$ s.

Assume that Spring 2 has a lower allowable displacement, $\mu 2 \Delta 2$, than Spring 1 . The allowable demand that can act on Spring 2, D2, is

$$
\mathrm{D} 2=\mathrm{F} \mu(\mu 2) \mathrm{P} 2=\mu 2 \mathrm{P} 2
$$

And, the total allowable demand acting on the system, D, when Spring 2 has a demand of D2 is

$$
\mathrm{D}=\frac{\mathrm{K}}{\mathrm{k} 2} \mathrm{D} 2=\frac{\frac{\mathrm{P} 1 / \mathrm{P} 2+\Delta 1 / \Delta 2}{\Delta 1 / \Delta 2} \frac{\mathrm{P} 2}{\Delta 2}}{\mathrm{P} 2 / \Delta 2} \mu 2 \mathrm{P} 2=\frac{\mathrm{P} 1 / \mathrm{P} 2+\Delta 1 / \Delta 2}{\Delta 1 / \Delta 2} \mu 2 \mathrm{P} 2
$$

Since the ductility of Spring 2 is known, then the system ductility is also known and the total allowable demand acting on the system is

$$
\mathrm{D}=\mathrm{Py} F \mu(\mu \mathrm{s})=(\mathrm{P} 1 / \mathrm{P} 2+1) \mathrm{P} 2 \mu \mathrm{s}=(\mathrm{P} 1 / \mathrm{P} 2+1) \mathrm{P} 2 \frac{\mathrm{P} 1 / \mathrm{P} 2+\Delta 1 / \Delta 2}{\Delta 1 / \Delta 2(\mathrm{P} 1 / \mathrm{P} 2+1)} \mu 2=\frac{\mathrm{P} 1 / \mathrm{P} 2+\Delta 1 / \Delta 2}{\Delta 1 / \Delta 2} \mu 2 \mathrm{P} 2
$$

which is equal to the total demand acting on the system based on Spring 2's ductility shown in Equation 4-16.

Thus, regardless of which element is limiting, the allowable demand acting on a system is equal whether the demand is based on the limiting spring with the limiting spring's ductility or on the system, using the system's capacity and ductility. 


\section{Force Reduction Factors for the Structural Design and Evaluation of Facilities Containing Nuclear and Hazardous Materials}

Yet, another approach is to evaluate the elastic demand based on the system's capacity at first yield, $\mathrm{Pa}$, using an effective ductility, $\mu$ e, for Spring 1 . The maximum system displacement is limited by the minimum value of $\mu \mathrm{i} \Delta \mathrm{i}$. Converting the maximum system displacement into an equivalent ductility for Spring 1 yields,

$\mu \mathrm{e}=\frac{\operatorname{Min}[\mu \mathrm{i} \Delta \mathrm{i}]}{\Delta 1}$

Assume that Spring 1 limits the system's allowable displacement and $\mu \mathrm{e}=\mu 1$. Then, in this approach the allowable demand that can act on the system is

$\mathrm{D}=\mathrm{F} \mu(\mu \mathrm{e}) \mathrm{Pa}=\mu 1(\mathrm{P} 1 / \mathrm{P} 2+\Delta 1 / \Delta 2) \mathrm{P} 2$

which is equal to the demand based on Spring 1 and the demand based on the system when Spring 1 is limiting as shown in Equations 4-13 and 4-14.

This is shown schematically in Figure 4.9 where the psudo system has a capacity of $\mathrm{Pa}$ and a ductility of $\mu 1$. This formulation assumes that Spring 2 yields at the same yield displacement as Spring 1, as shown in Figure 4.9 by the Psudo Spring 2 load deformation curve.

If Spring 2 limits the system's allowable displacement, then $\mu \mathrm{e}=\Delta 2 / \Delta 1 \mu 2$, and the allowable demand that can act on the system is

$\mathrm{D}=\mathrm{F} \mu(\mu \mathrm{e}) \mathrm{Pa}=\frac{\mu 2 \Delta 2}{\Delta 1}(\mathrm{P} 1 / \mathrm{P} 2+\Delta 1 / \Delta 2) \mathrm{P} 2=\frac{\mathrm{P} 1 / \mathrm{P} 2+\Delta 1 / \Delta 2}{\Delta 1 / \Delta 2} \mu 2 \mathrm{P} 2$

which is equal to the demand based on Spring 2 and the demand based on the system when Spring 2 is limiting as shown in Equations 4-16 and 4-17.

Design rules can be used to simplify the implementation of this approach. These rules would assure a minimum allowable ductility for all the elements in a given structural system or assure that elements with inherently lower ductility have limited yield displacement. Then, an effective ductility could be assigned to the system. This approach is used by both UBC-97 and IBC-2000 building codes. 
Page 4-12

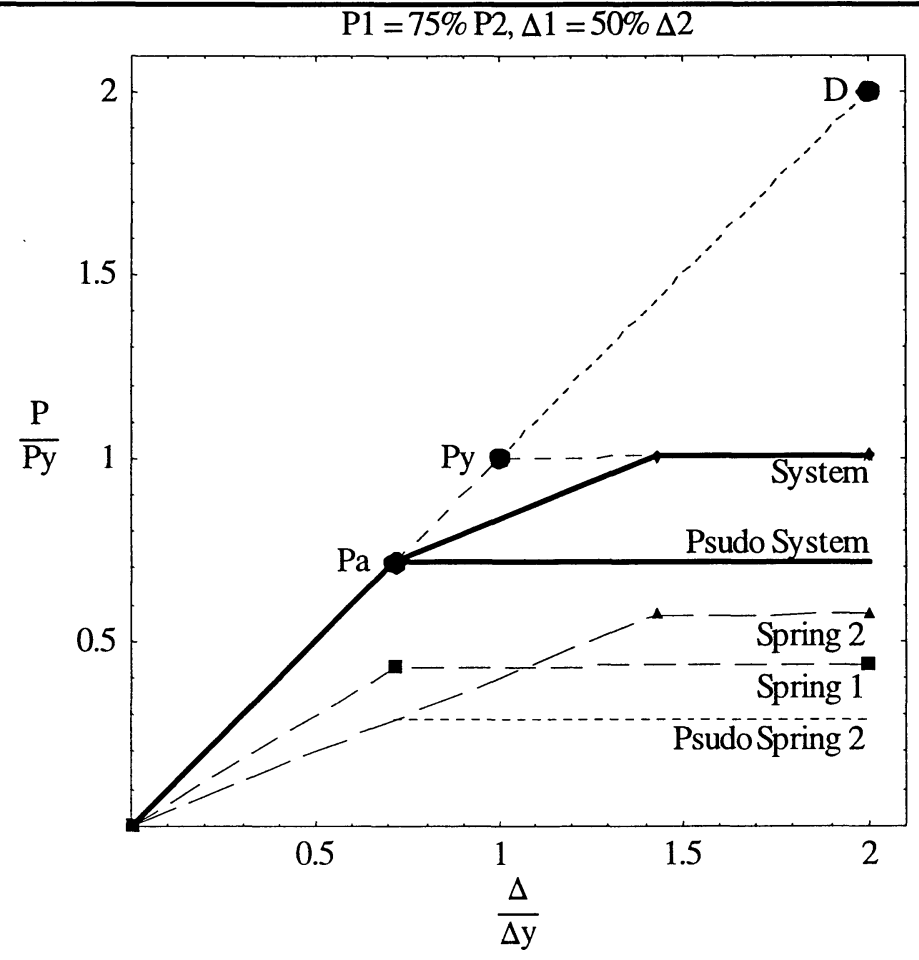

Figure 4.9 Psudo-System Backbone Curve

For low frequencies structures where $F \mu \cong \mu$, the following three approaches are shown to be equivalent in evaluating $\frac{\mathrm{D}}{\mathrm{F} \mu} \leq \mathrm{C}$

1. The inelastic force reduction factor is applied with the system ductility using the system yield point as the capacity. This approach would requires developing the system capacity, Py, and converting the element ductilities in Section 1 into system ductilities, $\mu \mathrm{s}$. This conversion can be achieved using Figure 4.6.

2. The inelastic force reduction factor is applied with the allowable ductility for each individual element using that element's individual capacity. This approach allows the direct use of element ductilities from Section 2 and each elements capacity, Pi.

3. The inelastic force reduction factor is applied using an effective ductility and the system capacity at first yield $(\mathrm{Pa})$. This approach would require either (1) calculating the effective ductility; or (2) assigning an effective ductility to a structural system and developing design rules to assure that that ductility can be met by all of the elements. 


\subsubsection{Mid-Range Frequency Systems}

The energy dissipated by an elastic and inelastic systems are approximately equal, for midrange frequency systems, which yields $F \mu \cong \sqrt{2 \mu-1}$ for a bilinear system. Assuming that the same relationship also holds for the system in Figure 4.4, then the allowable demand acting on Spring 1, D1, with ductility $\mu 1$, is

$\mathrm{D} 1=\mathrm{P} 1 \mathrm{~F} \mu(\mu 1)=\mathrm{P} 1 \sqrt{2 \mu 1-1}=\mathrm{P} 1 \mathrm{P} 2 \sqrt{2 \mu 1-1} \mathrm{P} 2$

The corresponding allowable demand acting on the entire system when Spring 1 is limiting, Ds 1, is

$\mathrm{Ds} 1=\frac{\mathrm{K}}{\mathrm{k} 1} \mathrm{D} 1=\frac{\frac{\mathrm{P} 1 / \mathrm{P} 2+\Delta 1 / \Delta 2}{\Delta 1 / \Delta 2} \frac{\mathrm{P} 2}{\Delta 2}}{\mathrm{P} 1 / \Delta 1} \mathrm{P} 1 / \mathrm{P} 2 \sqrt{2 \mu 1-1} \mathrm{P} 2=(\mathrm{P} 1 / \mathrm{P} 2+\Delta 1 / \Delta 2) \sqrt{2 \mu 1-1} \mathrm{P} 2$

Similarly, the allowable elastic demand acting on the idealized system, D, can be calculated by

$$
\mathrm{D}=\mathrm{Py} F \mu(\mu \mathrm{s})=(1+\mathrm{P} 1 / \mathrm{P} 2) \sqrt{2 \mu \mathrm{s}-1} \mathrm{P} 2
$$

Since the displacements of both springs and the structure are equal then the ductility $\mu$ s can be expressed as a function of $\mu 1$ as given in Figure 4.6.

The allowable demands, Ds1 and D are compared in Figure 4.10. Note that Ds 1 is always less than $\mathrm{D}$ which indicates that the allowable demand, based on the ductility, $\mu 1$, and strength, P1 of Spring 1 is less than the allowable demand based on the idealized elastic system's ductility, $\mu \mathrm{s}$, and strength, Py. Thus, the use of $\mathrm{P} 1 \sqrt{2 \mu 1-1}$ to calculate seismic demand in the frequency range is conservative.

As shown in the figures, this degree of conservatism becomes more pronounced as the ductility increases and for small values of ${ }^{\mathrm{P} 1} / \mathrm{P} 2$ and ${ }^{\Delta 1} / \Delta 2$. For most structures the difference between Ds1 and D is less than $20 \%$. 

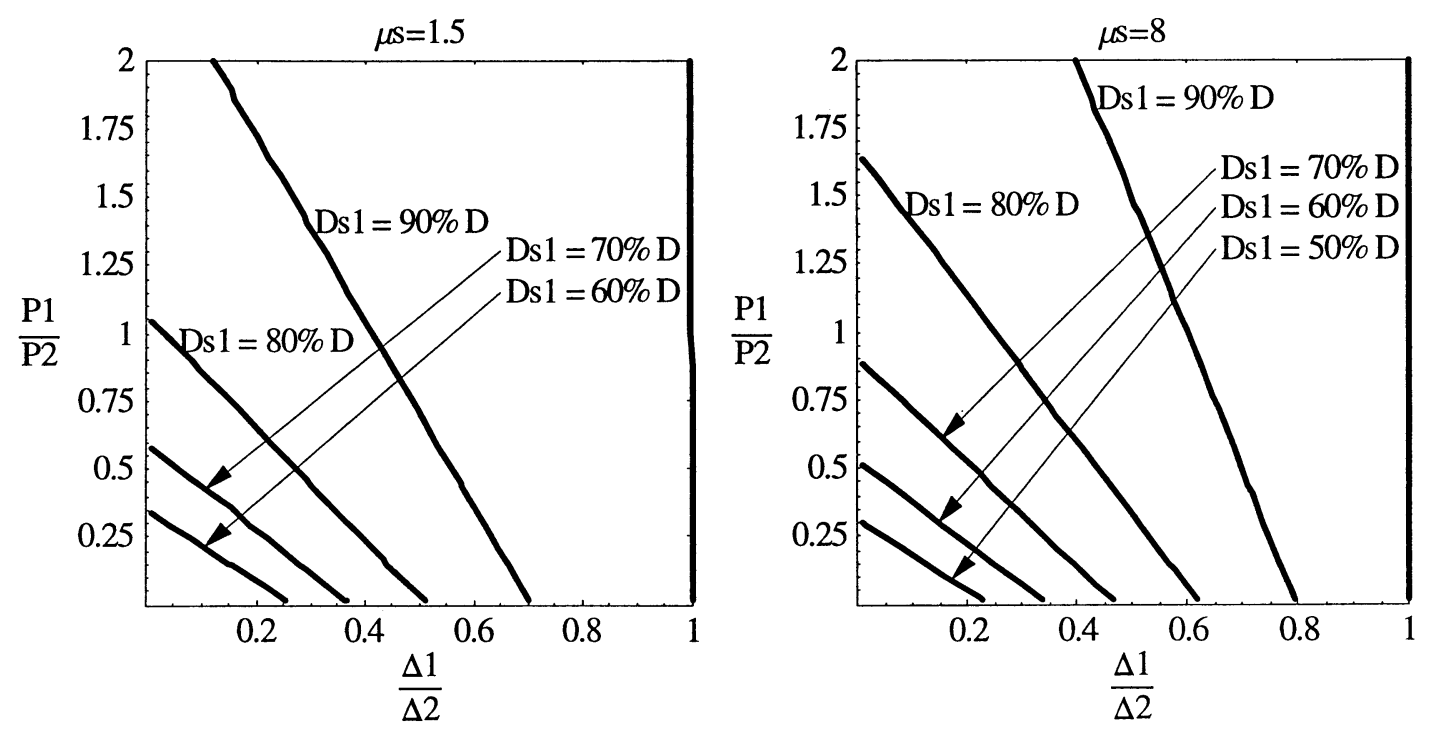

Figure 4.10 Comparison of Total Elastic Demand Based on Element 1 and the Idealized Elasto-Plastic System

As seen by the example in Figure 4.11, the idealized bilinear system dissipates more energy than the sum of the two springs. Recall that $F \mu=\sqrt{2 \mu s-1}$ is derived by setting the strain energy of the bilinear system, Es, equal to the strain energy of the elastic system, Ee, where

$\mathrm{Es}=\frac{\mathrm{Py} \Delta \mathrm{y}}{2}+\mathrm{Py}(\mu \mathrm{s} \Delta \mathrm{y}-\Delta \mathrm{y})=\frac{\operatorname{Py} \Delta \mathrm{y}}{2}(2 \mu \mathrm{s}-1)$

and

$\mathrm{Ee}=\frac{\mathrm{D} \frac{\mathrm{D} \Delta \mathrm{y}}{\mathrm{Py}}}{2}=\frac{\mathrm{D}^{2} \Delta \mathrm{y}}{2 \mathrm{Py}}$

Setting Es equal to Ee yields

$\mathrm{Es}=\frac{\mathrm{Py} \Delta \mathrm{y}}{2}(2 \mu \mathrm{s}-1)=\mathrm{Ee}=\frac{\mathrm{D}^{2} \Delta \mathrm{y}}{2 \mathrm{Py}} \Rightarrow \frac{\mathrm{D}}{\mathrm{Py}}=\sqrt{2 \mu \mathrm{s}-1}$

To compensate for the excess energy dissipation of the idealized bilinear system, shown in Figure 4.11, the sum of the element strain energies is substituted for Es and the demand on the idealized elastic system is

Es $=\sum$ Element Strain Enrgy $=E e=\frac{D^{2} \Delta y}{2 P y} \Rightarrow D=\sqrt{\frac{2 P y \sum \text { Element Strain Energy }}{\Delta y}}$ 


\section{Force Reduction Factors for the Structural Design and Evaluation of Facilities Containing Nuclear and Hazardous Materials}

As before, the system demands, Ds1 and D are compared in Figure 4.12. Note that Ds1 is still less than D which indicates that the allowable demand, based on the ductility, $\mu 1$, and strength, P1 of Spring 1 is less than the allowable demand based on the system's ductility, $\mu \mathrm{s}$, and total strain energy. Thus, the use of $\mathrm{P} 1 \sqrt{2 \mu 1-1}$ to calculate seismic demand is still conservative.

Comparing Figures 4.10 and 4.12, the effect of removing the unconservative strain energy absorbed by the idealized bilinear system was to reduce the magnitude of conservativism.
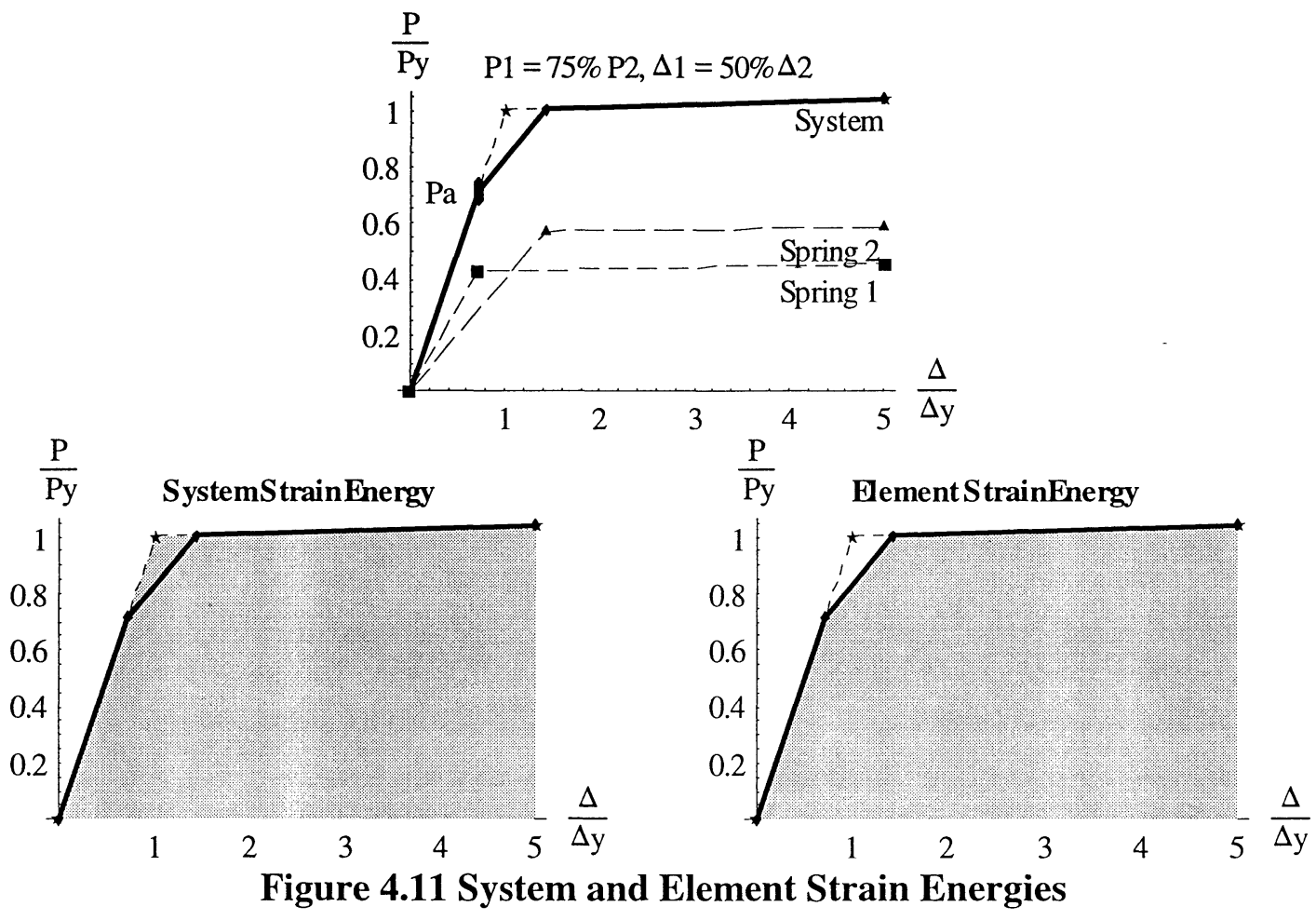


\section{Force Reduction Factors for the Structural Design and Evaluation of Facilities
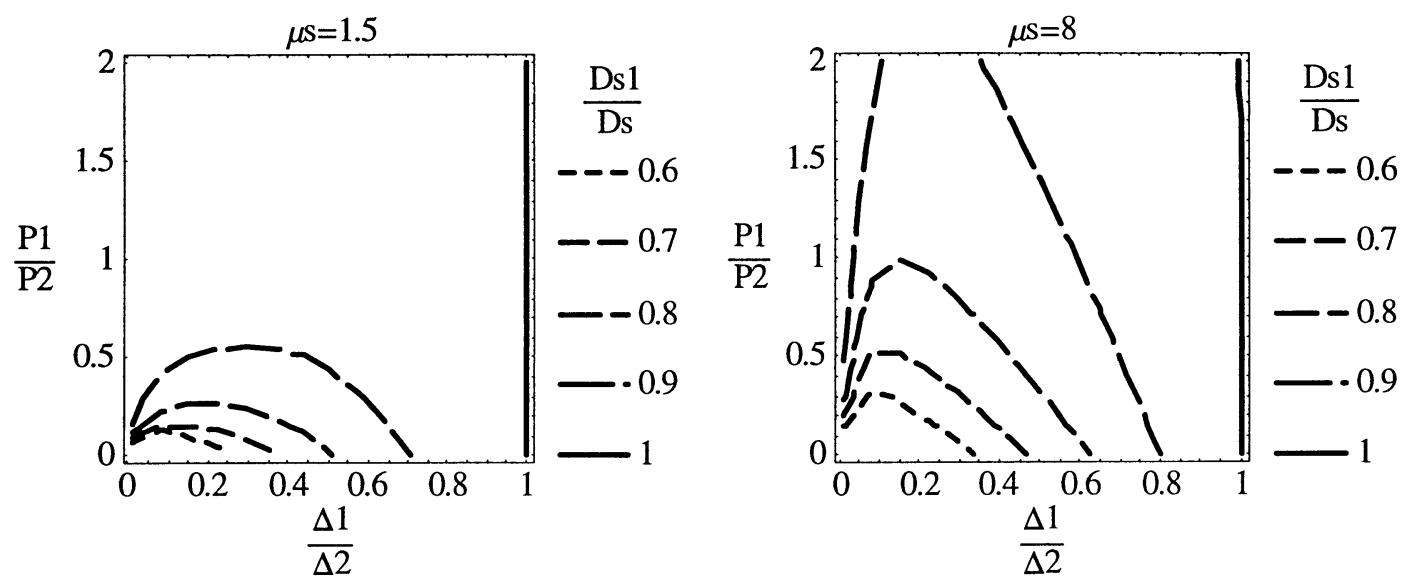

Figure 4.12 Comparison of Total Elastic Demand Based on Element 1 and the System Strain Energy

Consider the allowable demand acting on Spring 2, D2, with ductility $\mu 2$,

$\mathrm{D} 2=\mathrm{P} 2 \mathrm{~F} \mu(\mu 2)=\mathrm{P} 2 \sqrt{2 \mu 2-1}$

And, the corresponding allowable demand acting on the entire structure when Spring 2 is limiting, Ds2, is

$\mathrm{Ds} 2=\frac{\mathrm{K}}{\mathrm{k} 2} \mathrm{D} 2=\frac{\frac{\mathrm{P} 1 / \mathrm{P} 2+\Delta 1 / \Delta 2}{\Delta 1 / \Delta 2} \frac{\mathrm{P} 2}{\Delta 2}}{\mathrm{P} 2 / \Delta 2} \sqrt{2 \mu 1-1} \mathrm{P} 2=\frac{\mathrm{P} 1 / \mathrm{P} 2+\Delta 1 / \Delta 2}{\Delta 1 / \Delta 2} \sqrt{2 \mu 1-1} \mathrm{P} 2$

As before, the allowable elastic demand acting on the idealized system, D, is calculated by including the total strain energy. Since the displacements of both springs and the structure are equal then the ductility $\mu$ s can be expressed as a function of $\mu 1=\Delta_{1} 1 / \Delta_{2} \mu 2$ using Figure 4.6.

The allowable system demands, Ds2 and D are compared in Figure 4.13. Note that Ds2 is always greater than $\mathrm{D}$ which indicates that the allowable demand, based on the ductility, $\mu 2$, and strength, P2 of Spring 2 is greater than the allowable demand based on the system's ductility, $\mu \mathrm{s}$, and strain energy. Recall that the ductility for Spring 1 is limiting for structures with $\Delta 1 \mu 1<\Delta 2 \mu 2$ and the over-prediction of allowable demand by Spring 2 is moot for these structures.

However, if $\Delta 1 \mu 1>\Delta 2 \mu 2$ then Spring 2 is limiting and the results predicted by Spring 2 are unconservative. The degree of unconservatism becomes more pronounced as the ductility increases and for small values of ${ }^{\Delta 1} / \Delta_{2}$ and large values of ${ }^{\mathrm{P} 1} / \mathrm{P} 2$. This condition would arise if Spring 1 is relatively strong and stiff with a large ductility while Spring 2 is relatively weak and flexible with low ductilities. As an example, Spring 1 could 


\section{Force Reduction Factors for the Structural Design and Evaluation of Facilities Containing Nuclear and Hazardous Materials

represent a special moment frame while Spring 2 would represent a curtain wall. The standard practice in these situations is to neglect the seismic resistance of the weaker element.
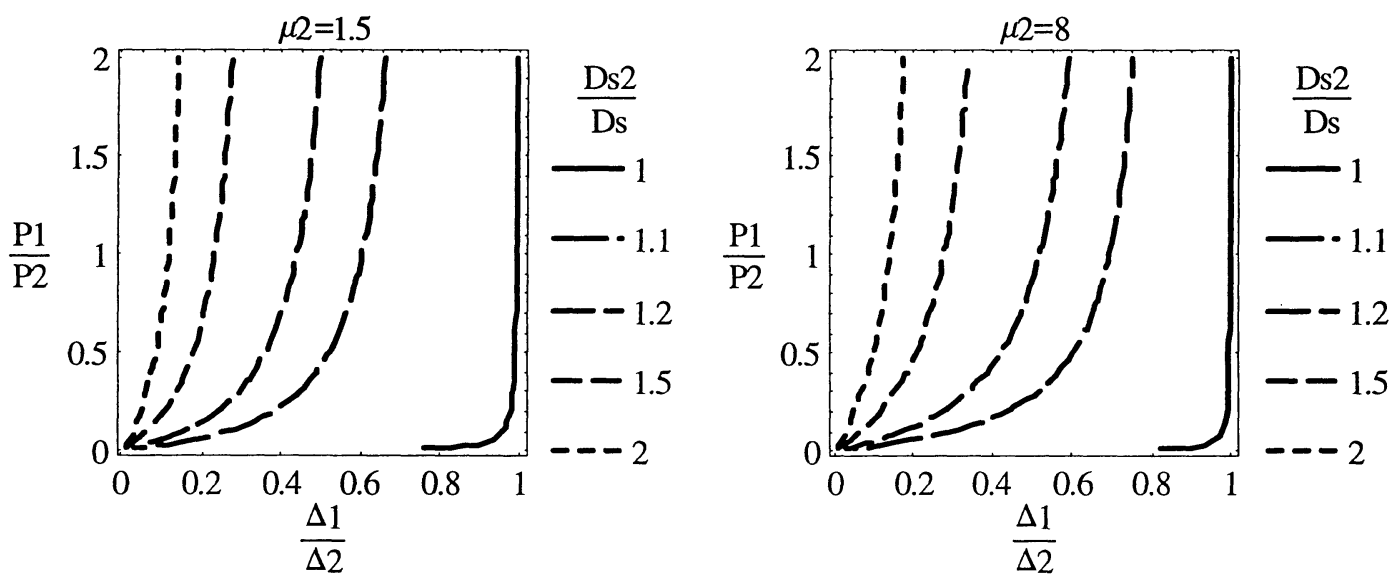

Figure 4.13 Comparison of Total Elastic Demand Based on Element 1 and the System Strain Energy

For mid-range frequency structures where $F \mu \cong \sqrt{2 \mu-1}$, the following two approaches are shown to be comparable in evaluating $\frac{\mathrm{D}}{\mathrm{F} \mu} \leq \mathrm{C}$

1. The inelastic force reduction factor is applied with the system ductility using the total strain energy in the system. This approach would requires developing the total strain energy in the system and converting the element ductilities in Section 1 into system ductilities, $\mu$ s.

2. The inelastic force reduction factor is applied with the allowable ductility for each individual element using that element's individual capacity. This approach allows the direct use of element ductilities from Section 2. This approach is conservative if $\Delta 1 \mu 1<\Delta 2 \mu 2$ as shown in Figure 4.12 and is unconservative if $\Delta 1 \mu 1>\Delta 2 \mu 2$ as shown in Figure 4.13.

\subsubsection{Application to Dual Systems}

Dual systems comprised of shear walls combined with moment frames or braced frames combined with moment frames typically have a fundamental mode in the mid-frequency range and the use of $F \mu \cong \sqrt{2 \mu-1}$ in this range is appropriate. In dual systems, the braced frames or shear walls yield at lower displacements than the moment frames. As seen in Section 2, the ductility of shear walls is typically less than the ductility of moment frames, Thus, $\Delta 1 \mu 1<\Delta 2 \mu 2$ for dual systems and Figure 4.12 is usually applicable. 


\section{Force Reduction Factors for the Structural Design and Evaluation of Facilities Containing Nuclear and Hazardous Materials}

The yield drift in a shear controlled wall can be estimated several ways. The first is to assume as yield strength of 4 to $6 \sqrt{f^{\prime} c}$ and divide by the shear modulus which yields story drift ratios between $1 / 4000$ and $1 / 1000$ depending on the assumed Poisson's ratio and degree of cracking. The second method to estimate yield deformation is to divide the allowable drift in Section 2 by the element ductilities which, for LS-A, yields a story drift ratio of $1 / 700$. Similarly, the yield displacement of a braced frame is estimated by assuming a 0.002 yield strain on a bracing element inclined $30^{\circ}$ to $60^{\circ}$ which yields drift ratios between $1 / 600$ and $1 / 1000$. Assuming that the frame is designed with an elastic drift ratio of $1 / 200$, then dual systems have $\Delta 1 / \Delta 2$ between 0.05 and 0.30 .

In dual systems the moment frame is proportioned for at least $25 \%$ of the base shear and the load in the braced frame or shear wall is proportioned based on the relative stiffness. Assuming that the strength of the braced frame or shear wall varies from $75 \%$ to $100 \%$ of

the base shear yield, then ${ }^{\mathrm{P} 1} / \mathrm{P} 2$ ranges between 3 and 4 . Extrapolating from Figure 4.12 indicates that allowable demand in typical dual systems with $\Delta 1 \mu 1<\Delta 2 \mu 2$ is less than $10 \%$ conservative.

It is possible to combine a concentric braced frame, which has a LS-A ductility of 8, with an ordinary moment frame, which, if controlled by column mechanisms can have a LS-A ductility of 1.25. For this case it is possible that $\Delta 1 \mu 1>\Delta 2 \mu 2$ and the allowable demand would be unconservative as indicated in Figure 4.13. This condition is avoided in the UBC-97 and IBC-2000 building codes by requiring special moment frames with high ductility for use in dual systems.

\subsubsection{Summary for Multiple-Element Single Degree of Freedom Structures}

Ductility relationships for multiple-element, single degree-of-freedom structures were developed for the structure in Figure 4.3 as idealized in Figure 4.4. In structures with elements having unequal element yield displacements the element which yields first will have a larger ductility than the structure. For low frequency structures, the allowable demand acting on the structure is identical whether the demand is calculated using (1) an effective system yield with system ductility; or (2) the individual yield and corresponding ductility for each element. For mid-frequency structures, the total allowable demand calculated using a system yield with system ductility is greater than the allowable demand calculated using the first element yield and corresponding ductility provided $\mu 1 \Delta 1<\mu 2 \Delta 2$. All regular structures that the authors are familiar with meet this criterion.

The structure depicted in Figure 4.3 as idealized in Figure 4.4 can be used to represent many structures which are dominated by a single degree-of-freedom response. For example, relocating the portal frame hinges to the beam, as shown in Figure 4.14, would yield backbone curves similar to Figure 4.5 as hinge 1 yields first due to negative moment and then hinge 2 reverses and yields due to positive moment. Thus, the 
conclusions of this study in this section also apply to the frame in Figure 4.14, and many other structures whose response can be described primarily by its fundamental mode.

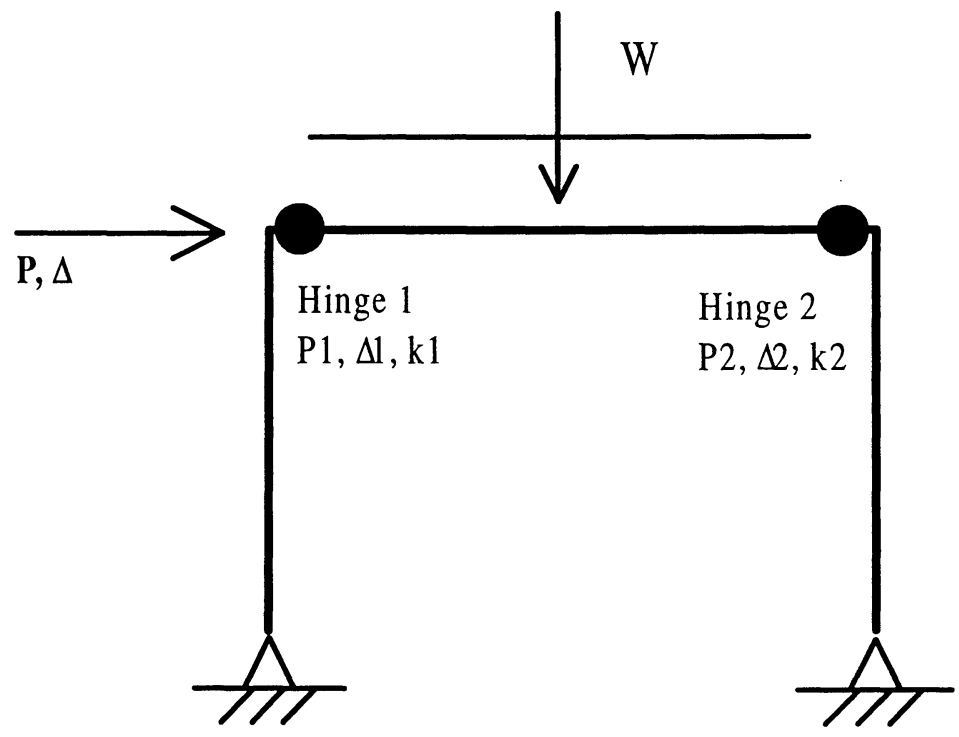

Figure 4.14 Portal Frame with Beam Mechanism

\subsection{Multiple Degree of Freedom Structures}

To this point, the discussion of the force reduction factor assumes that the response of a structure can be idealized as a single degree of freedom (SDOF) system, as characterized by a pushover analysis. However, typical structures are often multi-degree of freedom (MDOF) systems. These systems generally have higher modes that can increase the ductility demand in individual elements over that predicted by single degree of freedom models.

In addition, real structures are often constructed such that "geometric" non-uniformities exist in capacity, element yield point, and relative stiffness of individual elements. The previous sections established that the presence of "geometric" non-uniformities in single degree-of-freedom structures generally does not affect the overall magnitude of the force reduction factor. However, using the behavior of single degree of freedom systems to predict element demands neglects the increase in element demands that may be caused by (1) the presence of higher modes; and (2) concentration of the structure's ductility demand in a limited number of elements.

This effect can be stated as follows: If the multi-degree of freedom system is designed for the same base shear as the corresponding first mode single degree of freedom system,

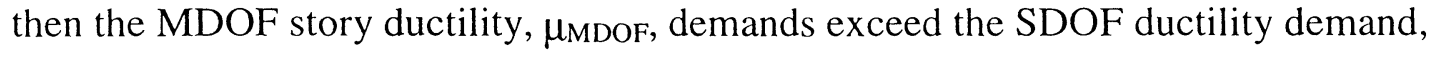

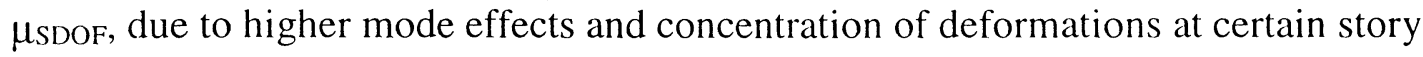
levels [Nassar, Krawinkler, 1991]. The ratio of $\mu_{\mathrm{MDOF}}$ to $\mu_{\mathrm{SDOF}}$ is a ductility modification factor, $\lambda$ 


$$
\lambda=\frac{\mu_{\mathrm{MDOF}}}{\mu_{\mathrm{SDOF}}}
$$

This relationship is shown schematically in Figure 4.15. Using this ductility modification factor, the force reduction factor for an element in a MDOF system becomes

$$
\mathrm{F} \mu=\mathrm{F} \mu \mathrm{s}\left(\frac{\mu_{\text {element }}}{\lambda}\right)
$$

where $\mu_{\text {element }}$ is the allowable element ductility and F $\mu$ s represents the SDOF force modification factor.

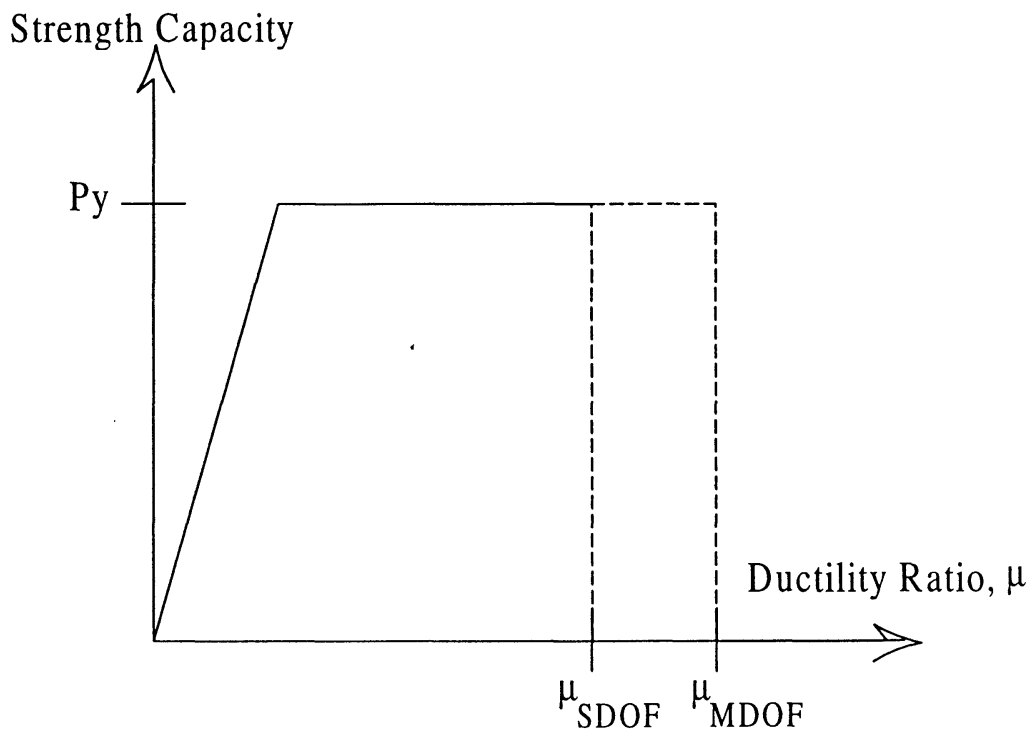

Figure 4.15 Increase in Inter-Story Ductility Demand to Achieve Equal Base Shear Demands in MDOF and SDOF Systems

An alternative approach to account for MDOF effects is to increase the strength capacity of the MDOF systems until the ductility of the SDOF and MDOF systems are equal, as shown schematically in Figure 4.16. The ratio of strengths $V_{\text {MDOF }}$ to $V_{\text {SDOF }}$, is a force modification factor, $\kappa$,

$$
\kappa=\frac{\mathrm{V}_{\mathrm{MDOF}}}{\mathrm{V}_{\mathrm{SDOF}}}
$$

Using this force modification factor, the force reduction factor for an element in a MDOF system becomes 
$\mathrm{F} \mu=\frac{\mathrm{F} \mu \mathrm{s}\left(\mu_{\text {element }}\right)}{\kappa}$

Note that in the constant displacement and velocity regimes where, $F \mu s \cong \mu$ the ductility and force reduction factors are equal, $\lambda \cong \kappa$.

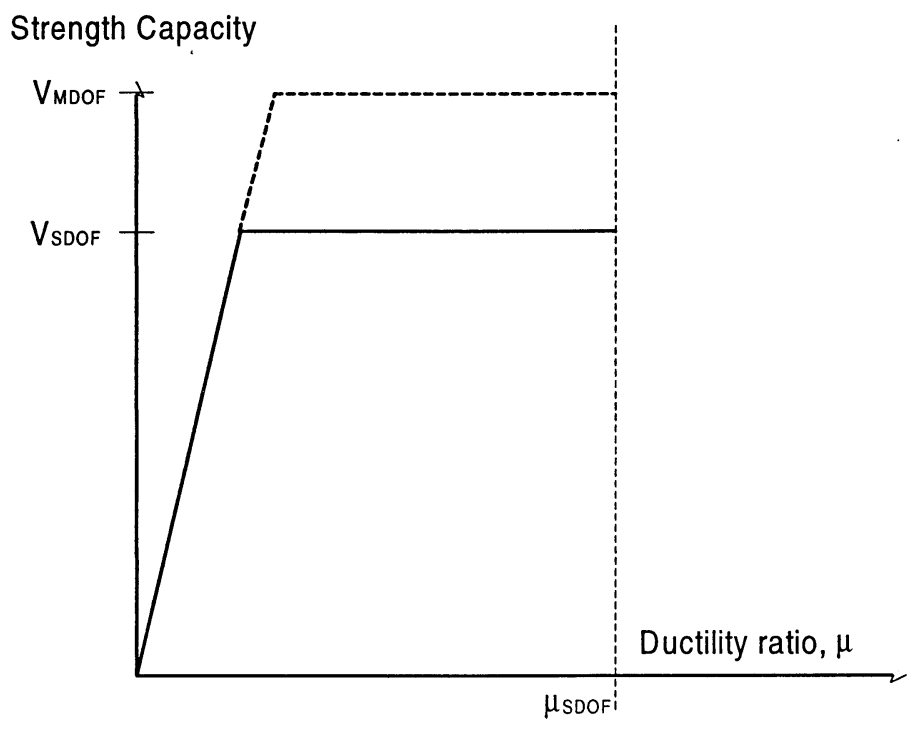

Figure 4.16 Increase in Strength Capacity to Achieve Equal Ductility Demands in MDOF and SDOF Systems

The approach shown in Figure 4.15 is used to develop an effective ductility for use with the relationships for SDOF systems to estimate element demand reduction factors. The approach shown in Figure 4.16 can be used to decrease the demand reduction factor computed for SDOF systems directly. Thus data that describes the increase in element ductility demand over that for SDOF systems, $\lambda$, and data that describes the increase in strength demand in MDOF systems over SDOF systems, $\kappa$, can be used to make appropriate adjustments to the predicted demand reduction factor computed for SDOF systems described in Section 3.

The structural system types addressed in this report are typical of those used in the construction of nuclear facilities and are described in Section 2. The systems addressed include moment frames, braced frames, and wall systems. Two types of wall system behavior is evaluated; a bending deformation mode and a shear deformation mode.

\subsubsection{Moment Frames}

Plastic hinges can occur in different locations in moment frame systems depending upon the proportioning of the members in the frame system; specifically the relative strength of beams vs. columns and relative story to story strength. Three different types of moment 
Force Reduction Factors for the Structural Design and Evaluation of Facilities Containing Nuclear and Hazardous Materials

WSRC-TR-2001-00037

Page 4-22

Plastic hinges can occur in different locations in moment frame systems depending upon the proportioning of the members in the frame system; specifically the relative strength of beams vs. columns and relative story to story strength. Three different types of moment frame systems are evaluated to develop functions that account for the higher demands in the MDOF system than that predicted in the SDOF system. These moment frame systems are:

- Beam Hinge (BH) Moment Frames: These frames have strong columns and weak beams and plastic hinges can only form in the beams. These types of frames are typical of special moment resisting frames where the design codes require that the column strength be greater than that of the beam.

- Column Hinge (CH) Moment Frames: These frames have weak columns and strong beams and can only form plastic hinges in columns, with some distribution of ductility demand (plastic hinge rotation) at multiple floor levels in the structure. These frames are representative of ordinary moment resisting frames where design codes permit column strengths to be less than that of the connecting beams.

- Weak Story (WS) Moment Frames: In these systems, hinges form in one story, focusing most or all of the nonlinear behavior into the weak story. These systems may exist in nuclear facilities where the lower floors have large openings for access.

The seismic demand in moment frame systems were studied extensively by Nassar and Krawinkler [1991], and Seneviratna and Krawinkler [1993], summarized in ATC-19 and ATC-34. In these studies, the ductility demands of MDOF structures are compared to the ductility demands predicted by SDOF models and the resulting $\lambda$ are used in Equation 4-31 to incorporate higher mode effects as well as focusing of the ductility demand into a single story for some frame types.

\subsubsection{Beam Hinge - Strong Column, Weak Beam Moment Frames}

Beam Hinge $(\mathrm{BH})$ moment frames with strong columns and weak beams are representative of (1) steel intermediate and special moment resisting frames designed in accordance with the "AISC Seismic Provisions for Structural Steel Buildings,";

(2) concrete frames resisting lateral seismic loads designed in accordance with Chapter 21 of ACI-349-97; and (3) concrete frames in regions of high seismicity resisting lateral seismic loads designed in accordance with Chapter 21 of ACI-318-99. Each of these design codes require that the sum of the column strength framing into a joint be greater than the sum of the beam strengths, which forces the plastic hinges to form in the beams.

The frame model used by Krawinkler, et. al. to evaluate this type of system is a regular, two dimensional, single bay frame shown in Figure 4.17. Plasticity is concentrated at the ends of the members with no yielding occurring within the members. The elastic stiffness of this frame is tuned such that the hinges develop simultaneously under the 1988 UBC equivalent static lateral load pattern, and the structure has a bilinear response (roof drift to base shear). The strength of the SDOF model is adjusted to match the bilinear pushover response of the MDOF system. 


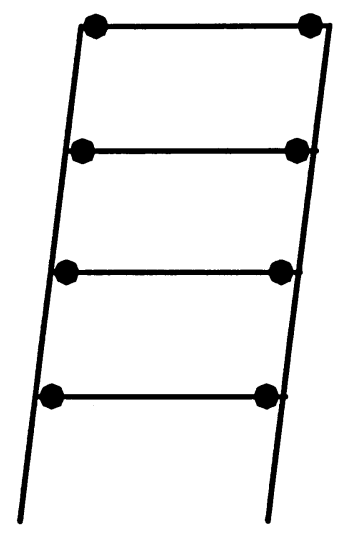

\section{Figure 4.17 Beam Hinge Moment Frame}

The MDOF effect for this framing systems is obtained by comparing the largest ductility demand from the individual beam hinges to that of the SDOF system. Multiple structures are investigated for a range of ductilities and building frequencies. Two sets of ground motions were considered; each set consist of an ensemble of 15 different ground motions with mean spectra similar to the UBC (ATC-3) design spectra. Mean ductility ratios for each set of ground motions are averaged.

The ratio of MDOF element ductility demands to SDOF ductility demand, $\lambda$, are frequency dependent, especially in the low frequency region, as shown in Figure 4.18. The relations plotted for SDOF ductilities of 2,4 , and 8 , indicate that $\lambda$ is not very sensitive to the SDOF ductility. For frequencies above $1.5 \mathrm{hz}$ the ductility demand in a MDOF structure is actually less than the ductility demand in a SDOF structure because all of the MDOF structure's mass does not participate in the first mode as assumed in the SDOF model. A ductility demand modification function for beam hinge system, $\lambda_{\mathrm{BH}}$, that represents the data in Figure 4.18 is

$\lambda_{\text {Bн }}=\mathrm{e}^{-0.54 \ln \mathrm{f}+0.18} \geq 0.85$

A lower bound of 0.85 is used for $\lambda_{\mathrm{BH}}$ because there is little data for moment frames above $2 \mathrm{hz}$. This function is used in Equation 4-31 to modify the element ductility to be used with the SDOF relationships provided in Section 3.

\subsubsection{Column Hinge - Weak Column, Strong Beam Moment Frames}

Column Hinge $(\mathrm{CH})$ frames with weak columns and strong beams are representative of (1) steel ordinary moment resisting frames designed in accordance with the "AISC Seismic Provisions for Structural Steel Buildings;" (2) concrete frames in regions of moderate seismicity resisting lateral seismic loads designed in accordance with Chapter 21 of ACI-318-99; (3) and frames not proportioned to resist lateral seismic loads. In these frames, the sum of the column strengths framing into a joint is not required to be 
Force Reduction Factors for the Structural Design and Evaluation of Facilities Containing Nuclear and Hazardous Materials

element ductility demands to system ductility demand are frequency dependent, especially in the low frequency region. These ratios are plotted for target ductilities of 2 , 4, and 8 and are shown in Figure 4.20. As shown, the MDOF to SDOF ratio is both frequency dependent and sensitive to the SDOF ductility. Thus, for column hinge systems, $\lambda_{\mathrm{CH}}$ is developed for different SDOF ductilities

$\begin{array}{cc}\mu_{\text {SDOF }} & \lambda_{\text {CH }} \\ 1 & 1.0 \\ 2 & \mathrm{e}^{-0.32 \ln \mathrm{f}+0.34} \geq 1.0 \\ 4 & \mathrm{e}^{-0.41 \ln \mathrm{f}+0.72} \geq 1.0 \\ 8 & \mathrm{e}^{-0.44 \ln \mathrm{f}+0.83} \geq 1.0\end{array}$

Interpolate between $\mu_{\mathrm{SDOF}}=1,2,4$ and 8 for intermediate values of ductility. This function is used in Equation 4-31 to modify the element ductility to be used with the SDOF relationships provided in Section 3.

Note that data in Figure 4.20 only covered the frequency range between 0.5 and $4 \mathrm{hz}$, which is adequate for most rigid frames below 20 stories. At $0.5 \mathrm{hz}$ the data's trend is not conservatively represented by Equation 4-35. However, the equation is acceptable for use here as rigid frame nuclear structures are shorter than 20 stories.

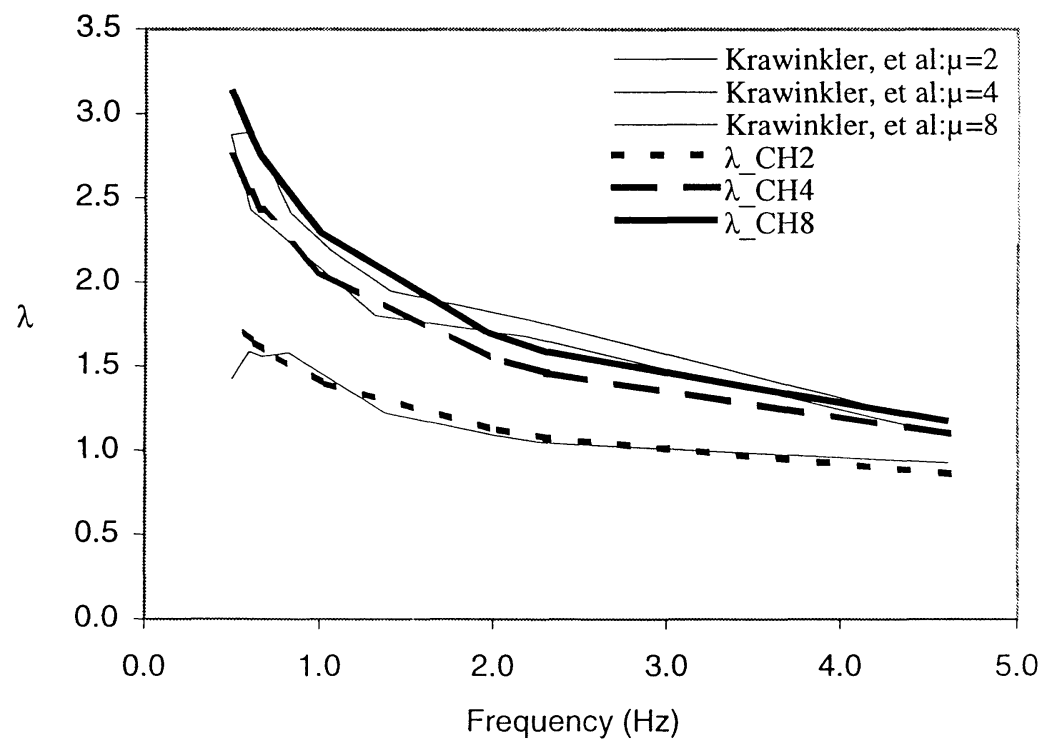

Figure 4.20 Ductility Demand Modification Factors, $\lambda$, for CH Systems 
Force Reduction Factors for the Structural Design and Evaluation of Facilities

\subsubsection{Weak Story Rigid Frames}

Weak stories can be found in lower floors of buildings where large openings are provided for operation, access and egress. These systems were included in studies by Krawinkler, et. al. The frame model used is similar to that for the column hinge model, except that the hinges are located only at each end of the first story columns, as shown in Figure 4.21. The strength and stiffness of this model are tuned as described for the two previous models.

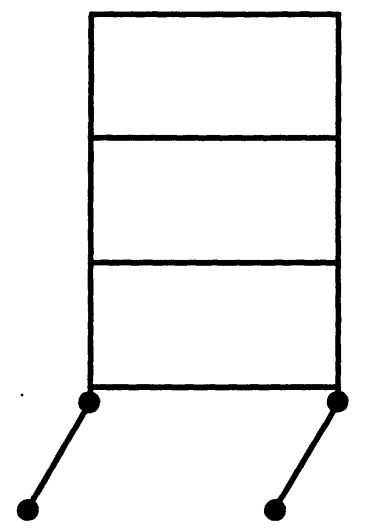

\section{Figure 4.21 Weak Story (WS) Rigid Frame}

The MDOF effect for this framing system is obtained by comparing the maximum ductility demand in the first floor column hinges to that of the SDOF system, for a range of SDOF ductilities and building frequencies. Like the previous frame models, $\lambda$, is frequency dependent, especially in the low frequency region. These ratios are plotted for SDOF ductilities of 2, 4, and 8 in Figure 4.22. As shown, the MDOF to SDOF effect is both frequency dependent and ductility dependant, thus, for weak story moment frames, $\lambda_{\text {ws }}$ is developed for different ductilities

$\begin{array}{cc}\mu_{\text {SDOF }} & \lambda_{\text {WS }} \\ 1 & 1.0 \\ 2 & \mathrm{e}^{-0.72 \ln \mathrm{f}+1.11} \geq 1.0 \\ 4 & \mathrm{e}^{-0.87 \ln \mathrm{f}+1.52} \geq 1.0 \\ 8 & \mathrm{e}^{-0.88 \ln \mathrm{f}+1.6} \geq 1.0\end{array}$

Interpolate Equation 4-36 between $\mu_{\mathrm{SDOF}}=1,2,4$ and 8 for intermediate values of ductility. This function is used in Equation 4-31 to modify the element ductility to be used with the SDOF relationships provided in Section 3.

The difference between MDOF and SDOF response is much larger for the weak story moment frame than the beam hinge or column hinge moment frames because most of the ductility demand is concentrated into a single story. 


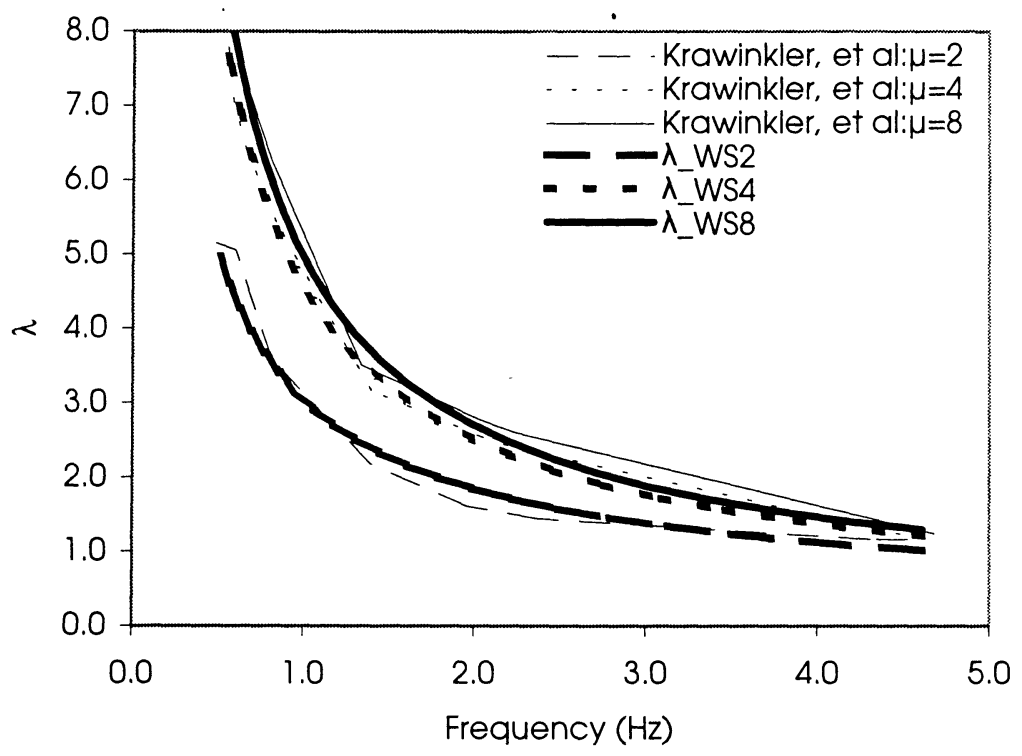

Figure 4.22 Ductility Demand Modification Factors, $\lambda$, for WS Systems

It is observed that, for weak story structures, the ductility demand is focused in a single, weak story. Another approach, proposed by Reed, as discussed in Appendix B, examines the first mode response of a structure with all of the ductility concentrated in a single weak story. The structure's ductility is calculated using a weighted average of the inelastic displacements divided by a weighted average of the elastic displacements at yield. Reed expresses the ductility of an equivalent SDOF structure, $\mu_{\text {SDOF, }}$ as a function of the ductility demand in the weak story, $\mu_{\text {Story, }}$

$\mu_{\mathrm{SDOF}}=1+2\left(\mu_{\text {Story }}-1\right) \frac{\mathrm{n}-\mathrm{k}+1}{\mathrm{n}(\mathrm{n}+1)}$

where $\mathrm{n}$ is the number of stories in the system

$\mathrm{k}$ is the location of the weak story, numbered up from the base.

Note that $\mu_{\text {Story }}$ is the ductility demand in the MDOF structure. Substituting into Equation 4-30 yields

$$
\lambda_{\text {Reed }}=\frac{\mu_{\mathrm{MDOF}}}{\mu_{\mathrm{SDOF}}}=\frac{\mu_{\text {Story }}}{1+2\left(\mu_{\mathrm{Story}}-1\right) \frac{\mathrm{n}-\mathrm{k}+1}{\mathrm{n}(\mathrm{n}+1)}}
$$




\section{Force Reduction Factors for the Structural Design and Evaluation of Facilities Containing Nuclear and Hazardous Materials

For the special case of a weak story in the first floor, $\mathrm{k}=1$, Equation 4-38 yields

$$
\lambda_{\text {Reed }}=\frac{(n+1) \mu_{\text {Story }}}{n-1+2 \mu_{\text {Story }}}
$$

Reed's approach is compared to the frames studied by Krawinkler et. al. in Figure 4.23, using Krawinkler's assumed frequency for different structures.

$\begin{array}{cc}\text { Number of Stories } & \text { Frequency (hz) } \\ 2 & \approx 4.5 \\ 5 & \approx 2.5 \\ 10 & \approx 1.5 \\ 20 & \approx 1 \\ 30 & \approx 0.75 \\ 40 & \approx 0.5\end{array}$

For frequencies above 1-2 hz the two approaches agree quite well. Below 1-2 hz the frames are above the 10 to 20 story range and higher mode effects become important. Moment frames with more than 5 floors are rare in nuclear facilities.

Another observation from Figure 4.23 is that the two curves diverge at higher frequencies for low ductilities, and at slightly lower frequencies for higher ductilities. Perhaps this is because the MDOF effects are larger at low ductilities than at high ductilities.

Supporting the point is the reduced difference between these two approaches in the low frequency range for high ducilities.

The relationships for weak story structures focus the entire non-linear behavior, and thus the entire ductility demand, into a single story. As such, and as shown by comparison of Figure 4.22 to Figures 4.18 and 4.20 , this method provides a conservative prediction of the ductility demand. Thus, for systems which have, or are assumed to have, a nonuniform distribution of strength, as defined by $\mathrm{D} / \mathrm{C}$ ratios that vary widely from story to story, Equation 4-36 represents a conservative estimate of the MDOF effects.

Alternately, Equation 4-38 or 4-39 may be used for structures with frequencies above 1 to $2 \mathrm{hz}$. 
Force Reduction Factors for the Structural Design and Evaluation of Facilities Containing Nuclear and Hazardous Materials
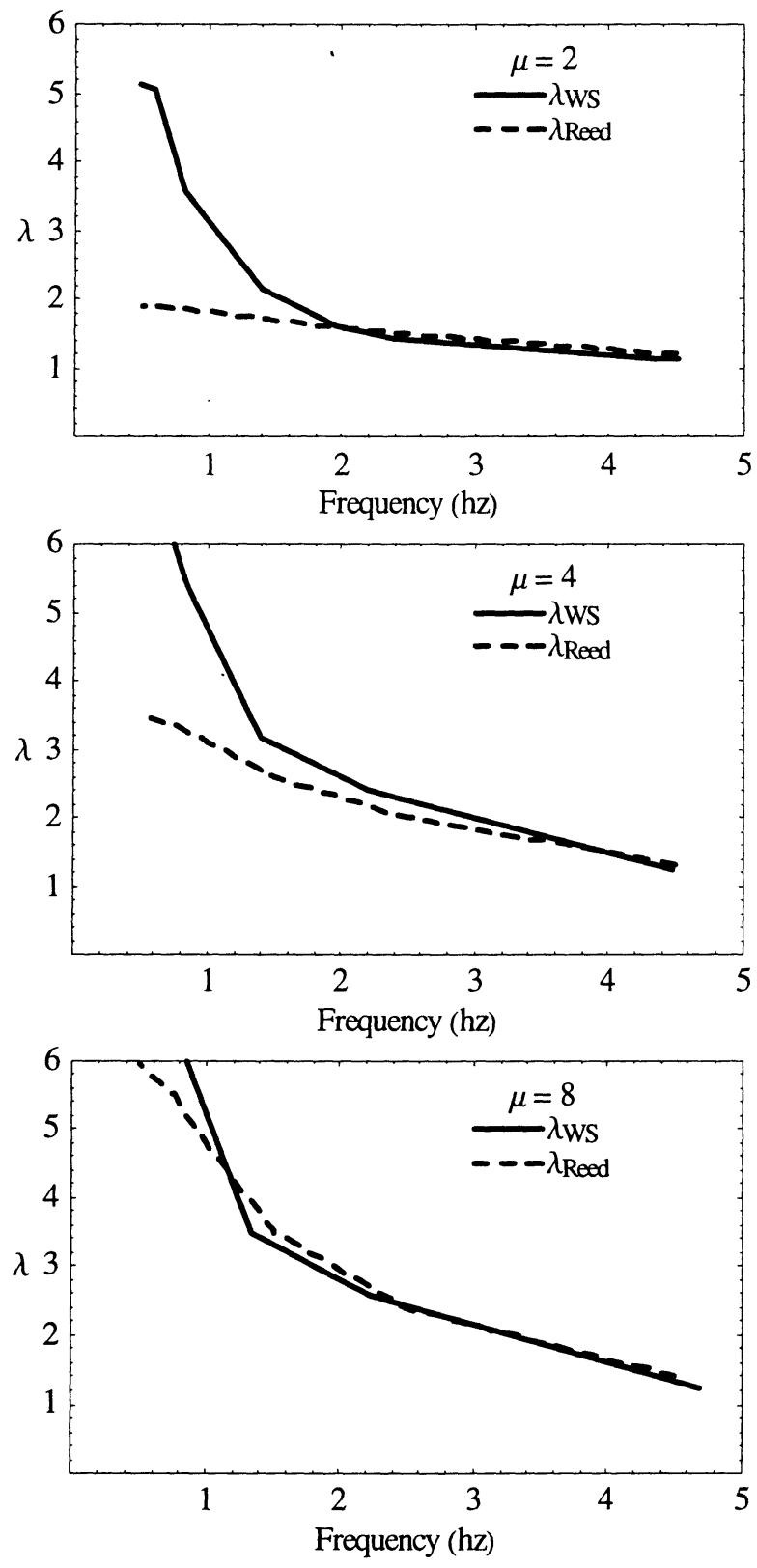

Figure 4.23 Comparison of $\lambda_{w s}$ and $\lambda_{\text {Reed }}$

\subsubsection{Shear Walls}

Deformation of structural wall systems can be characterized as occurring in either a bending mode or a shear mode. ACI-349 implies that walls with height to width ratios less than 2 are dominated by shear while taller walls are dominated by flexural. 
Force Reduction Factors for the Structural Design and Evaluation of Facilities Containing Nuclear and Hazardous Materials

\subsubsection{Shear Dominated Shear Walls}

Shear walls with a shear mode response have low aspect ratios, thus the higher mode effects will not be significant and no increase in the predicted demand from the SDOF model, Section 3, will be needed to adequately predict the force reduction factor. Thus, for shear controlled shear walls, $\lambda=\kappa=1$.

\subsubsection{Flexural Shear Walls}

Walls with bending mode deformations generally have a mechanism in which a hinge forms at the base of the structure. The MDOF response of flexural shear walls has been studied by Seneviratna and Krawinkler [1993], who provide relationships between the strength demand in the MDOF system to that which occurs in the equivalent SDOF system, $\kappa$. These studies are.used to develop functions that relate the element demand in the MDOF system to the demand predicted by the SDOF system and the resulting $\mathrm{K}$ are used in Equation 4-33.

The bending wall models used by Seneviratna and Krawinkler are developed to restrict the inelastic response to overturning moments that lead to plastic hinging and prevent shear failures. These models are MDOF vertical cantilever structures with equal masses lumped at each 12 foot story level. Structures with 2, 5, 10, 20, 30, and 40 stories are studied with corresponding frequencies of $4.5,2.3,1.4,0.8,0.6$, and 0.5 hertz.

These MDOF beam models were adjusted such that the first mode of the MDOF model is consistent with the SDOF system. Each of these models was subjected to three sets of ground motions, similar to the beam hinge moment frame, from which elastic and inelastic responses were calculated. The mean amplification of base shear in flexural shear wall buildings due to MDOF effects was extracted from this data and is shown in Figures $4.24,4.25$, and 4.26 for SDOF ductility ratios of 1, 2, 3 and 8 .

Although shear wall structures used in nuclear facilities typically have frequencies greater than 2 hertz, below $2 \mathrm{~Hz}$, the base shear in the MDOF system increases sharply with decreasing frequency, and this frequency dependent behavior should be considered. As shown in Figures 4.24, 4.25, and 4.26, for structures above about $2 \mathrm{~Hz}$, a constant amplification can be used to account for amplification of base shear due to MDOF effects. In this frequency range, base shear demand is increased by $20 \%$ to $40 \%$ for system ductilities of 2 and 3 and by about $70 \%$ for a system ductility of 8 . The ratio of the MDOF base shear to the SDOF base shear for a Flexural Shear Wall (FSW), $\kappa_{F S W}$ is 
Force Reduction Factors for the Structural Design and Evaluation of Facilities Containing Nuclear and Hazardous Materials

WSRC-TR-2001-00037

Page 4-31

$\begin{array}{cc}\mu_{\text {SDOF }} & \kappa_{\text {FSW }} \\ 1 & 1.0 \\ 2 & \mathrm{e}^{-1.65 \ln \mathrm{f}+0.19} \geq 1.2 \\ 3 & \mathrm{e}^{-0.8 \ln \mathrm{f}+0.78}>1.4 \\ 8 & \mathrm{e}^{-1.1 \ln \mathrm{f}+1.4}>1.7\end{array}$

Interpolate $\lambda_{\text {FSW }}$ for intermediate values of ductility. This function is used in Equation 433 to modify the demand computed using the SDOF relationships provided in Section 3.

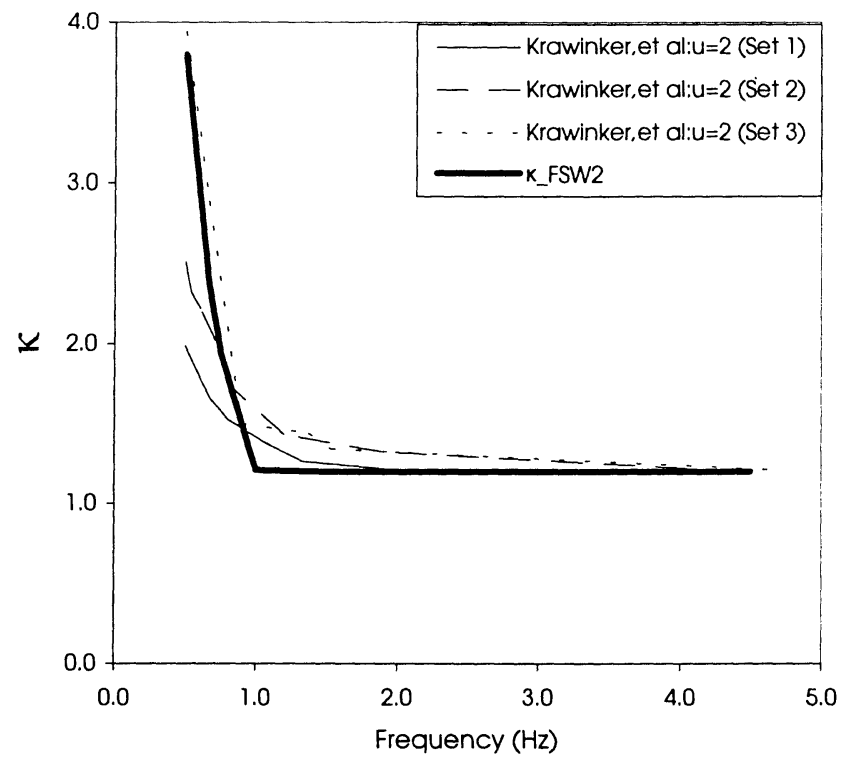

Figure 4.24 Demand Modification Factor, $\kappa$, for Flexural Shear Walls: $\mu=2$ 
Force Reduction Factors for the Structural Design and Evaluation of Facilities Containing Nuclear and Hazardous Materials

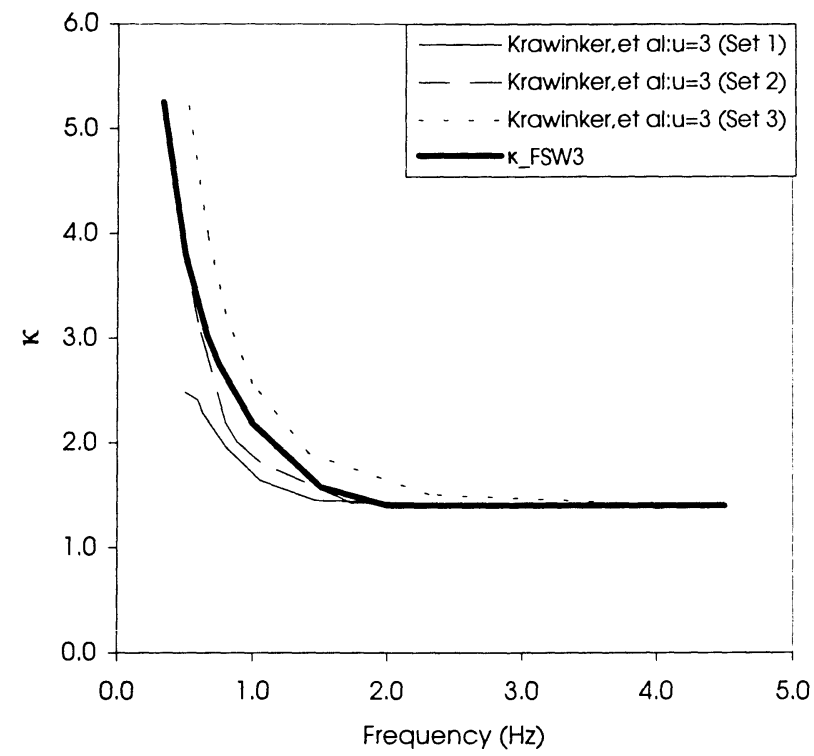

Figure 4.25 Demand Modification Factor, $\kappa$, for Flexural Shear Walls: $\mu=3$

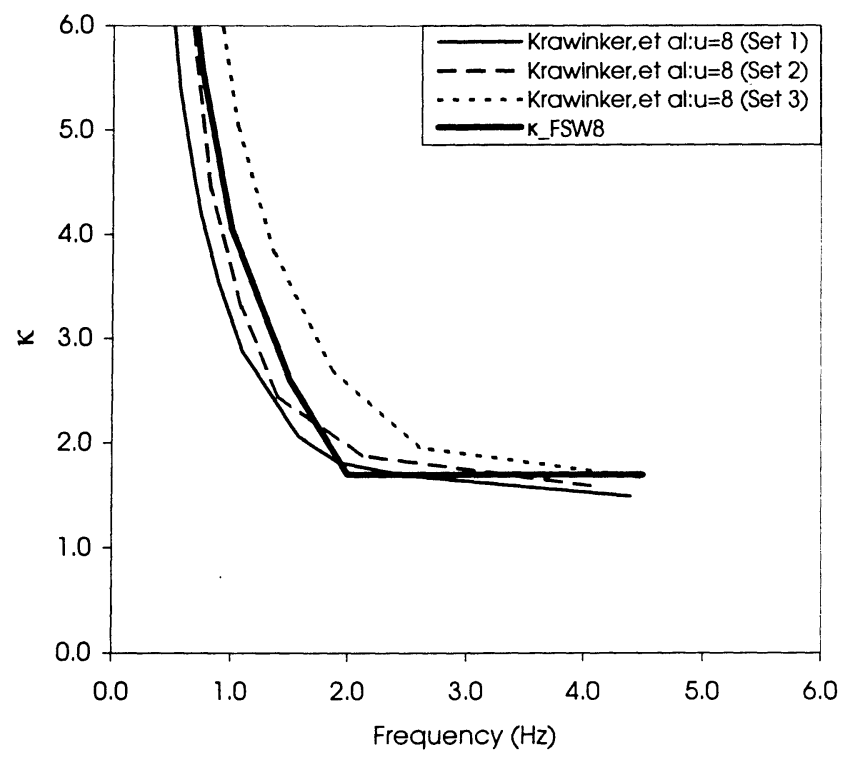

Figure 4.26 Demand Modification Factor, $\kappa$, for Flexural Shear Walls: $\mu=8$ 


\subsubsection{Braced Frames}

Braced frame structures consist of either a concentric and eccentric vertical truss and are used to resist seismic forces in a building system. Concentric braced frames consist of members subjected primarily to axial forces. The diagonal bracing elements of concentric braced frames buckle in compression and yield in tension. Load-deformation plots for concentric braced frames have pinched hysteresis loops. Eccentric braced frames are diagonally braced frames in which at least one end of each brace frames into a link beam a short distance from a beam-column joint or from another diagonal brace. The link beam is the only element that yields, and can yield in either a shear or bending mode. Eccentric braced frames typically have large stable hysteresis loops. The difference in hysteretic behavior for these two frame types is addressed by choosing different SDOF models corresponding to the appropriate energy dissipation. However, the MDOF effects for these two frame types is assumed to be similar.

The higher mode effects on demands of braced frames has not been addressed generally in the literature. Osteraas and Krawinkler (1990) performed a limited study of the response of braced frame and perimeter moment frames using bilinear models and suites of representative earthquakes as input to non-linear models. These studies describe the relationship between local and global ductility associated with the "geometric" nonuniformities inherent in braced frame systems but not the effects of higher mode contributions nor the effect of focusing the ductility demand in a limited number of stories. Thus, an alternative approach is needed to account for the MDOF effects in braced frames.

The seismic force distribution has larger bracing loads in the lower stories of the structure. In braced frames the same bracing elements are typically used over several stories, if not the entire structure. Thus, the bracing elements in the first story, and every story where the bracing members change size are apt to have high demand to capacity ratio's. The proposed approach conservatively assumes that a weak story develops in a single floor and thus the ductility demand of the system is focused in a single floor.

Since braced frames in nuclear structures are typically above $2 \mathrm{hz}$, the equivalent ductility demand for braced frames is computed using Equation 4-38. This approach accounts for both the location of the bracing panel in the building (story number), and the total number of stories in the building. However, it is always conservative to assume that the soft story is on the first floor, and Equation 4-39 is used to represent the relationship between MDOF and SDOF ductilities.

$\lambda_{\mathrm{BF}}=\frac{(\mathrm{n}+1) \mu_{\text {Story }}}{\mathrm{n}-1+2 \mu_{\text {Story }}}$ 
Force Reduction Factors for the Structural Design and Evaluation of Facilities Containing Nuclear and Hazardous Materials

This function is used in Equation 4-31 to modify the element ductility to be used with the SDOF relationships provided in Section 3.

\subsubsection{Summary for Multiple Degree of Freedom Structures}

Relationships were developed in this section to relate either the ductility demand, $\lambda$, or base shear, $\kappa$, of SDOF structures to MDOF structures. These factors consider the in element demands that may be caused by (1) the presence of higher modes; and (2) concentration of the structures ductility demand in a limited number of elements. These factors are summarized for the different structural systems below.

\section{Structural System}

Beam Hinge Moment Frame

Column Hinge Moment Frame

Weak Story Moment Frame

Shear Dominated Shear Walls

Flexural Dominated Shear Walls

Eccentric and Concentric Braced Frames
F $\mu$ Equation

4-31

4-31

4-31

4-31

4-33

4-31

\section{$\lambda$ or $\kappa$ Equation}

4-34

4-35

4-36

$\lambda=1$

4-40

4-41 
Force Reduction Factors for the Structural Design and Evaluation of Facilities

Containing Nuclear and Hazardous Materials

\subsection{Force Reduction Factors for Structural Design and Evaluation}

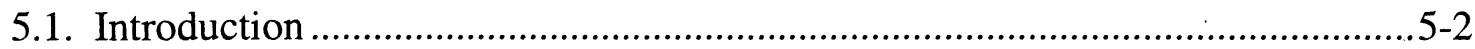

5.2. Convolution of Element Ductilities, SDOF $\mathrm{F}_{\mu} \mathrm{s}$, and MDOF Effects ................5-2

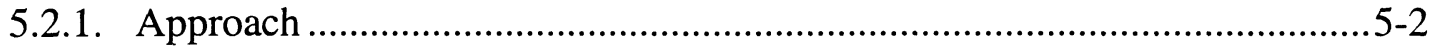

5.3. Application to Facilities Containing Nuclear and Hazardous Materials........... 5-11

5.3.1. Reinforced Concrete Special Moment Resisting Frames (R/C-SMRF) .............................................................................5-11

5.3.2. Reinforced Concrete Intermediate Moment Resisting Frames (R/C-IMRF)

5.3.3. Reinforced Concrete Ordinary Moment Resisting Frames $(\mathrm{R} / \mathrm{C}-\mathrm{OMRF})$

5.3.4. Tall Reinforced Concrete Shear Walls.......................................................5-26

5.3.5. Short Reinforced Concrete Shear Walls..................................................5-28

5.3.6. Steel Special Moment Resisting Frames (Steel-SMRF) ..........................5-29

5.3.7. Steel Intermediate Moment Resisting Frames (Steel-IMRF)....................5-32

5.3.8. Steel Ordinary Moment Resisting Frames (Steel-OMRF) .........................5-36

5.3.9. Steel Ordinary Concentric Braced Frames (Steel-OCBF) .........................5-39

5.3.10. Steel Eccentric Braced Frames (Steel-EBF) ........................................5-40 


\section{Force Reduction Factors for the Structural Design and Evaluation of Facilities Containing Nuclear and Hazardous Materials WSRC-TR-2001-00037

\subsection{Introduction}

Force reduction factors are developed for frame and shear wall structures considering the ductility capacity of the elements making up the structure, the effects of ductility on demand for SDOF systems, and the differences between demands in MDOF and SDOF systems. These three effects significantly affect the force reduction factors and are convolved to obtain frequency dependent relationships for F $\mu$. The use of these curves may be too cumbersome to use as a design tool. One simplification is to identify reasonable frequency ranges for given structural systems and select a constant $F_{\mu}$ appropriate for the selected range. For example, if we think that concrete rigid frames used in nuclear facilities have an upper bound frequency of about $3 \mathrm{~Hz}$, then a constant, conservative $\mathrm{F}_{\mu}$ can be chosen.

\subsection{Convolution of Element Ductilities, SDOF $F_{\mu} s$, and MDOF Effects}

\subsubsection{Approach}

Functions that describe the relationship between element ductility, frequency, and $F \mu$ are developed using the equations developed in Sections 3 and 4 that describe the SDOF behavior and MDOF effects. Given an allowable element ductility, these convolved functions can be used directly to obtain the force reduction factor appropriate for the expected behavior of a structural framing system.

Six models are used in this document to describe the characteristic behavior of structural systems; 1) moment frame systems with hinges forming in the beams, 2) moment frame systems with hinges forming in columns, 3) moment frame systems with hinges forming in a single story, 4) a bending mode vertical cantilever system, 5) a shear mode system with pinched hysteresis loops, and 6) an eccentric braced frame system. In addition, the behavior of the non-moment frame systems, models $4-6$, can be adjusted to account for behavior associated with the formation of a weak story.

\section{Moment Frames}

The behavior of moment frame systems is described by three models; a beam hinge model, a column hinge model, and a weak story model. The force reduction functions for these models are developed using Equation 3-6 to describe the SDOF behavior, and Equation 4-31 to compute the appropriate allowable effective system ductility, $\frac{\mu_{\text {element }}}{\lambda}$, used with Equation 3-6. $\lambda$ is computed for each of the three models using equations 4-34, 4-35, and 4-36.

Frequency dependent functions relating element ductility to $F \mu$ are provided in Figures $5.1,5.2$, and 5.3 for each category of moment frame systems listed above. The functions 
Force Reduction Factors for the Structural Design and Evaluation of Facilities Containing Nuclear and Hazardous Materials

WSRC-TR-2001-00037

Page 5-3

for moment resisting frames generally follow the shape of the SDOF response, Equation $3-6$, above frequencies of about $1 / 2 \mathrm{~Hz}$. Below this frequency, the higher mode effects increase dramatically, resulting in the steep reduction in $\mathrm{F} \mu$ with decreasing frequencies.

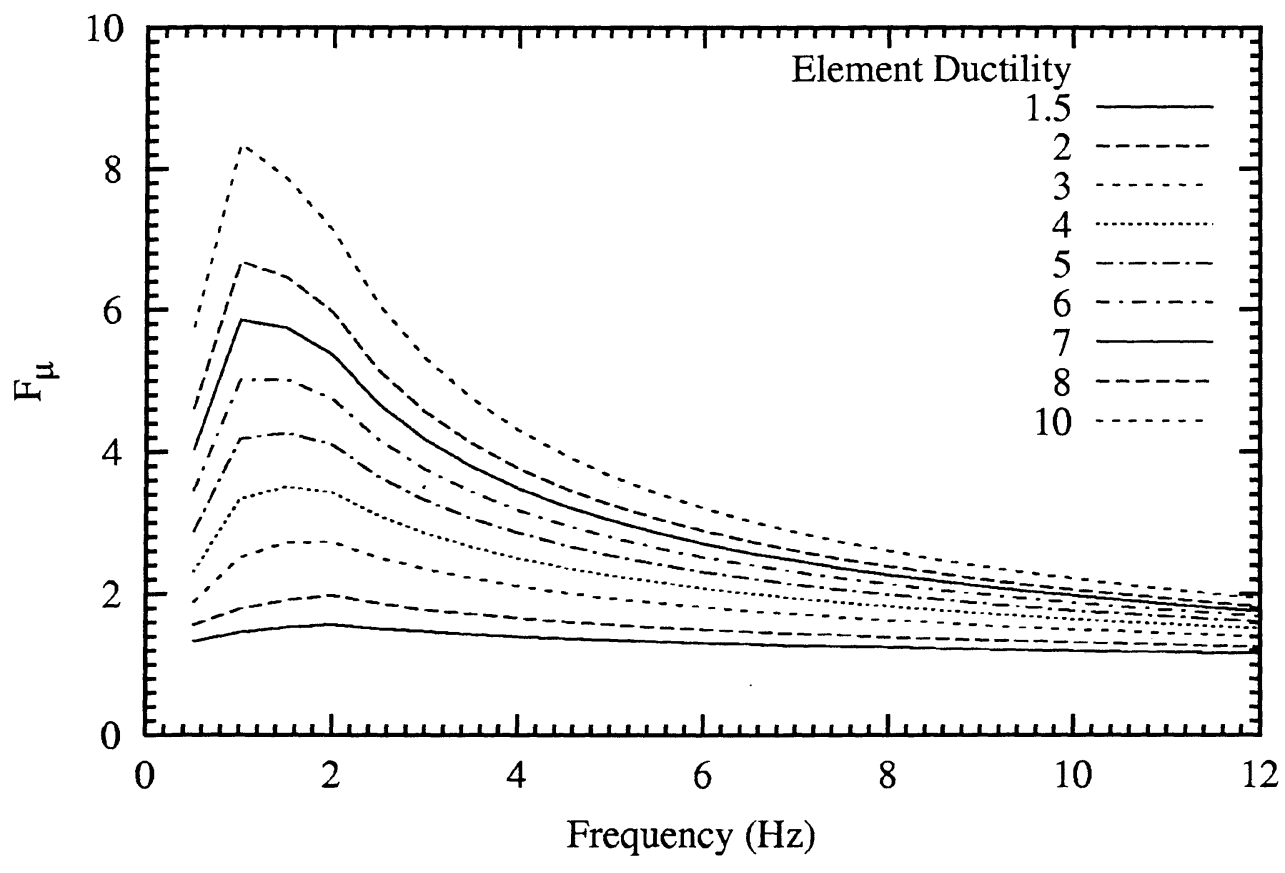

Figure 5.1 F $\mu$ for Element Ductilities in Moment Resisting Frames with Beam Hinges 
Force Reduction Factors for the Structural Design and Evaluation of Facilities Containing Nuclear and Hazardous Materials

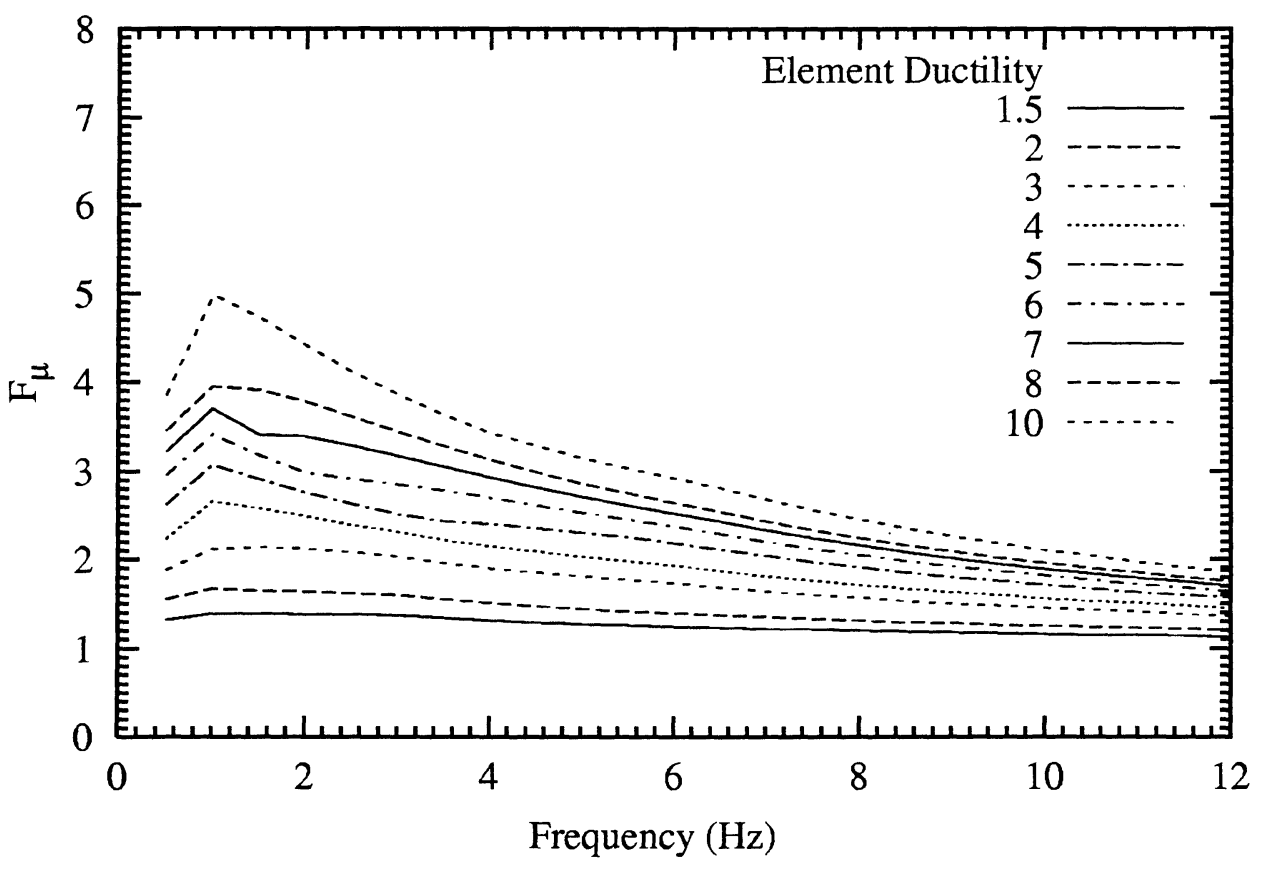

Figure 5.2 F $\mu$ for Element Ductilities in Moment Resisting Frames with Column Hinges

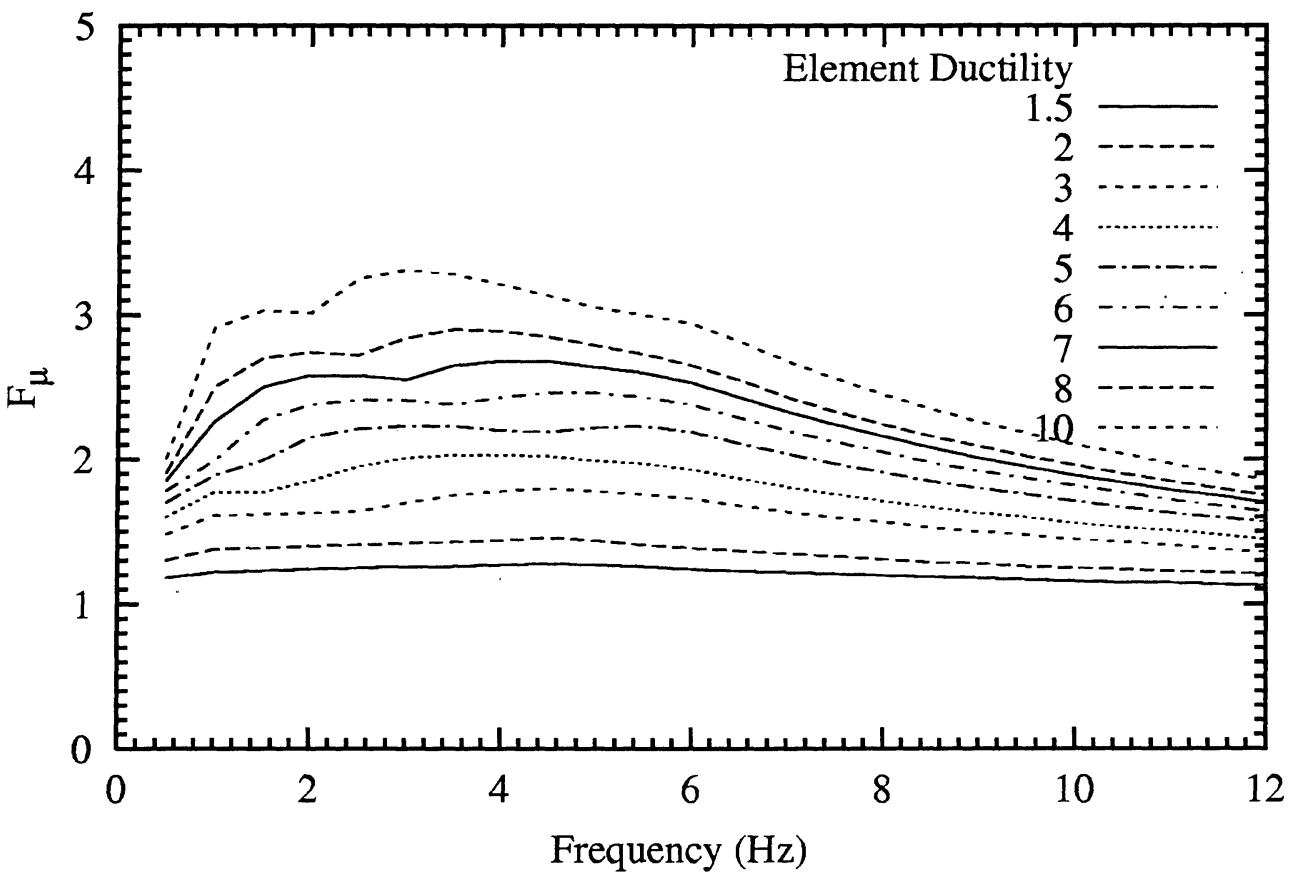

Figure 5.3 F $\mu$ for Element Ductilities in Moment Resisting Frames with Weak Story 


\section{Force Reduction Factors for the Structural Design and Evaluation of Facilities Containing Nuclear and Hazardous Materials

Force reduction factors for moment frame models are shown versus period in Figures 5.4, 5.5 , and 5.6 for ductilities of 2,4 , and 6 , respectively.

At lower ductilities, Figure 5.4, the force reduction factors predicted by the beam hinge model exceed that predicted by the SDOF model at periods below about 0.75 seconds. At higher periods (lower frequencies) the higher mode effects begin to have a significant contribution to the demand and the resulting force reduction factor is reduced. At higher ductilities, the beam hinge model becomes very similar to that predicted by the SDOF model for periods below about $0.8 \mathrm{sec}$ (above about $1.25 \mathrm{~Hz}$ ). As indicated in Figures 5.4 through 5.6, and as expected, the maximum $F \mu$ values for systems with hinges forming in the columns and in a weak story are substantially less than those for the SDOF and beam hinge systems. Thus the force reduction factors developed in this document will reward the desired Beam Hinge behavior by permitting lower seismic design demands.

With the exception of the beam hinge model at low ductilities, the $\mathrm{F} \mu$ values never reach that predicted by the SDOF system, and are usually significantly reduced.

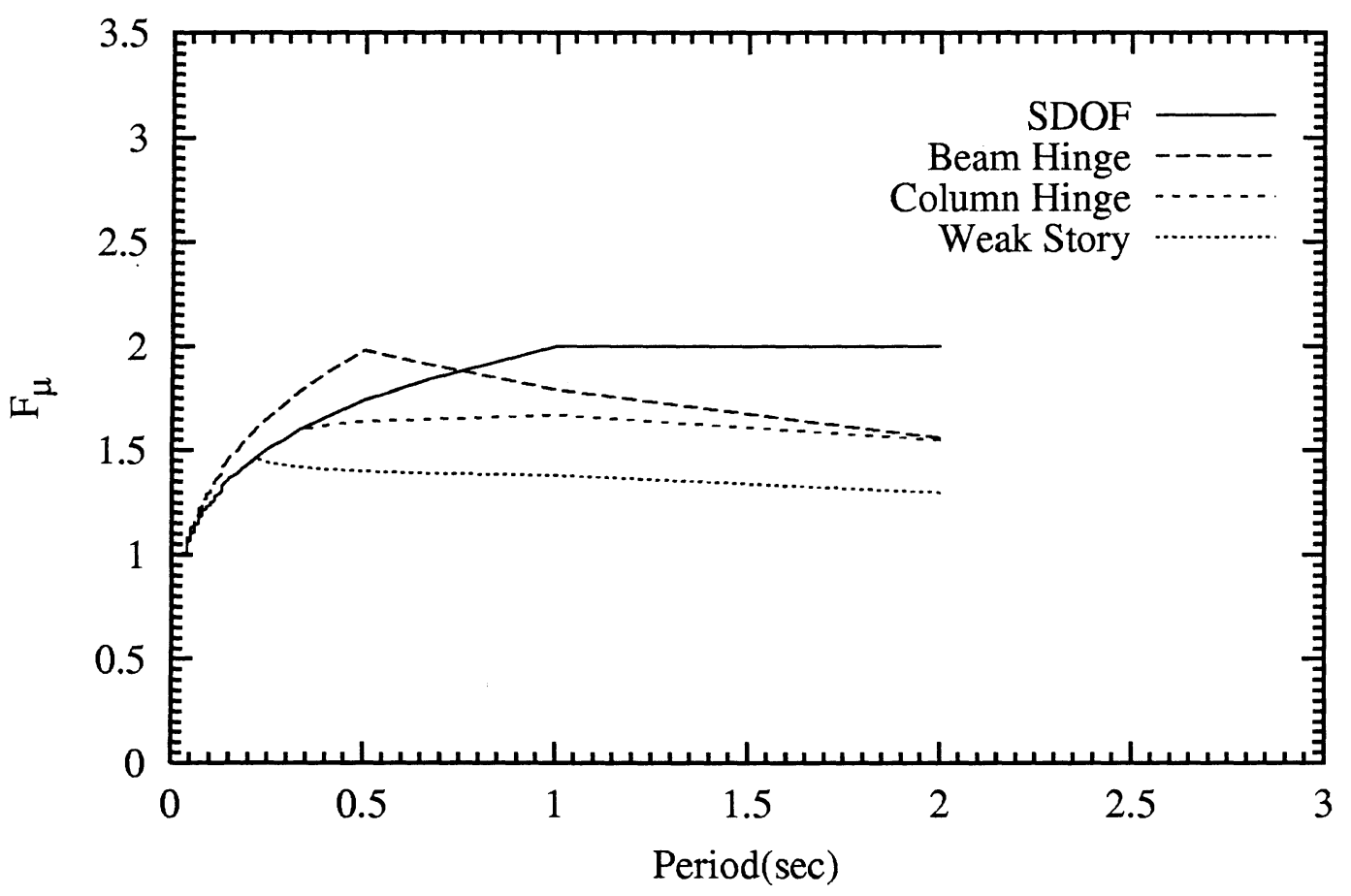

Figure 5.4 Force Reduction Factors for Element Ductility $=2$ 
Force Reduction Factors for the Structural Design and Evaluation of Facilities Containing Nuclear and Hazardous Materials

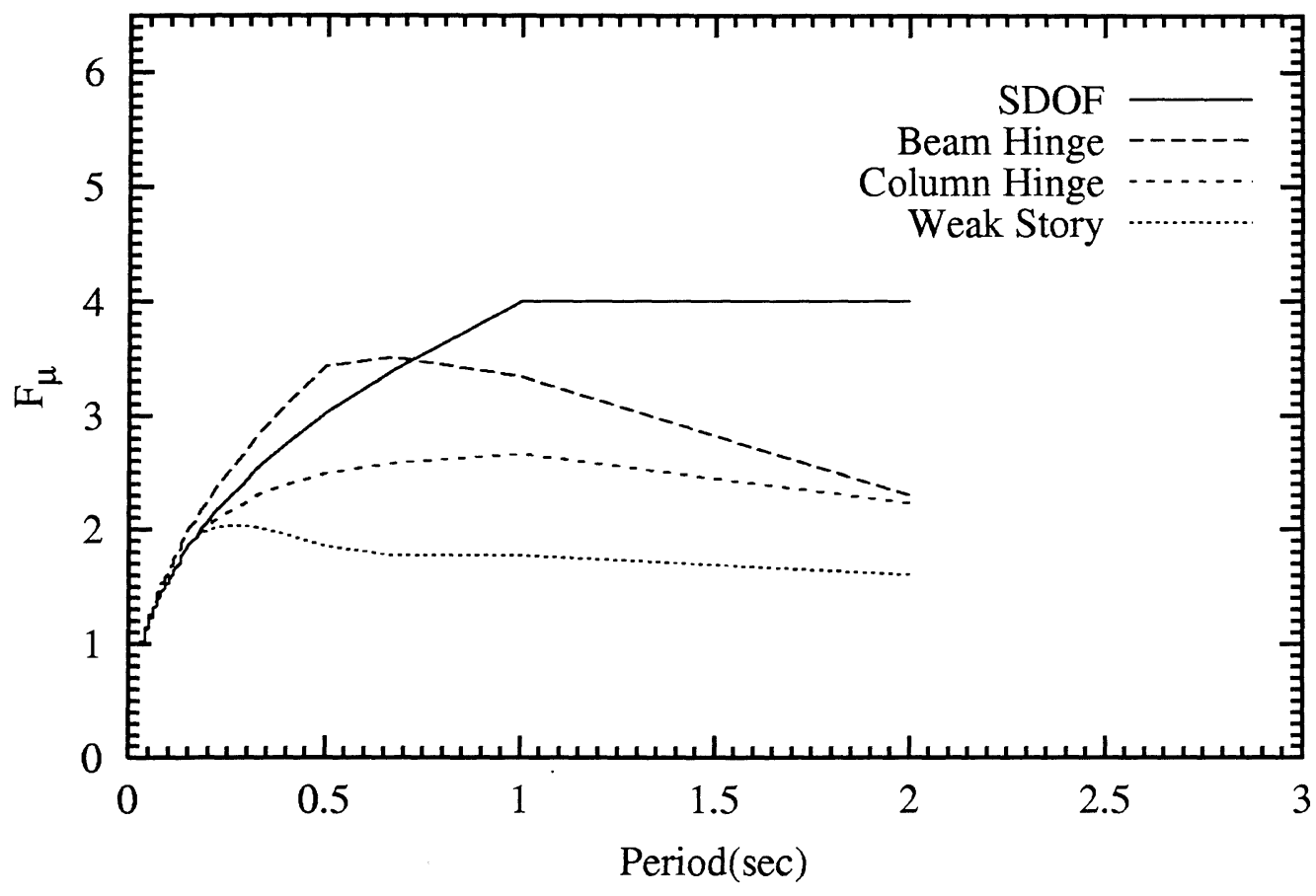

Figure 5.5 Force Reduction Factors for Element Ductility $=4$

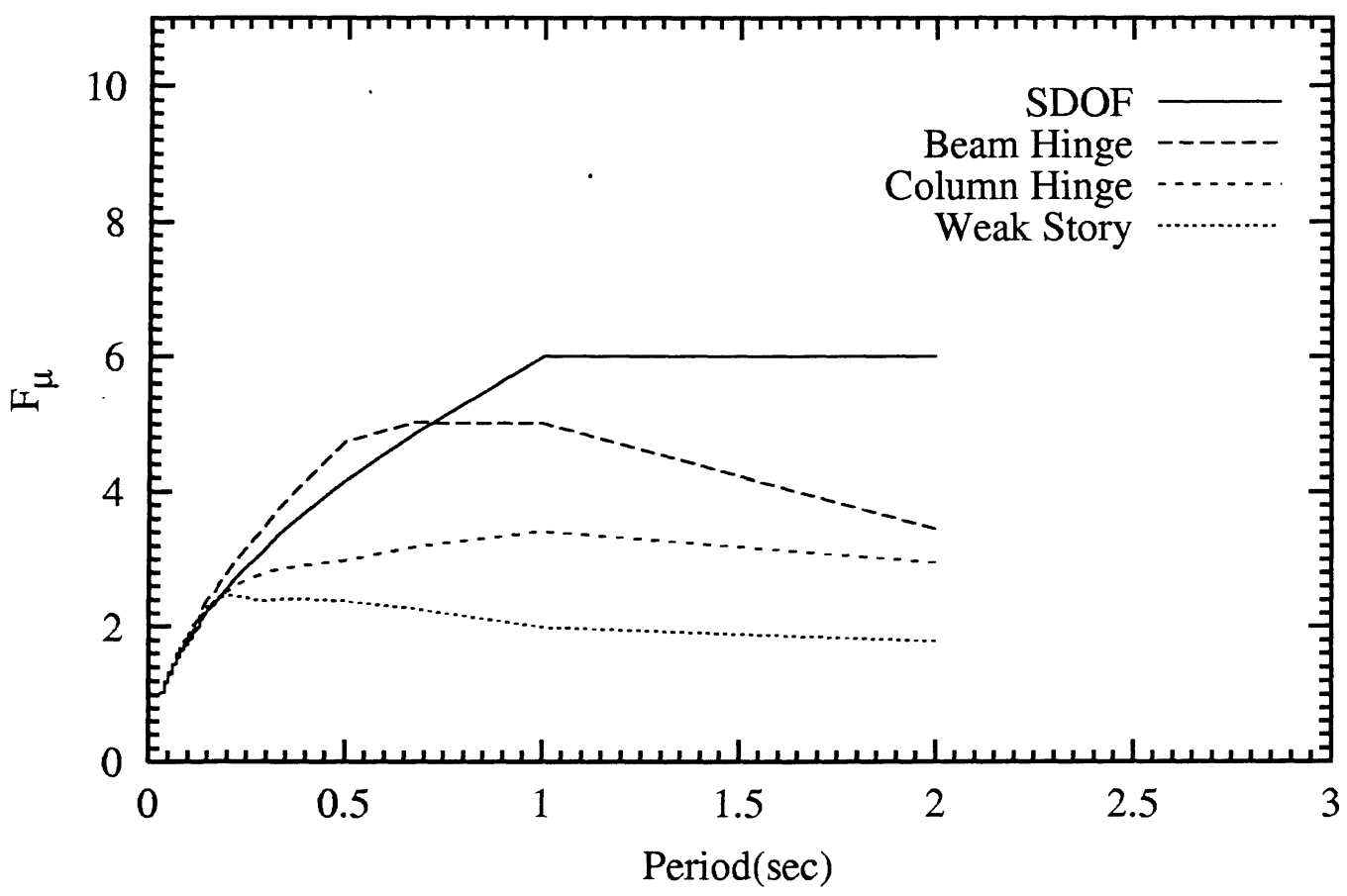

Figure 5.6 Force Reduction Factors for Element Ducility $=6$ 


\section{Force Reduction Factors for the Structural Design and Evaluation of Facilities Containing Nuclear and Hazardous Materials

\section{Bending Shear Walls}

The force reduction factors for bending wall systems, walls with height to width ratios greater than 2, are described by Equation 4-33, where the force reduction factor computed using Equation 3-6 and the resulting force reduction factor is modified by $\kappa . \kappa$ for bending wall systems is computed using Equation 4-40. Frequency dependent force reduction factors, $\mathrm{F} \mu$, relating element ductility to $\mathrm{F} \mu$ are provided in Figure 5.7.

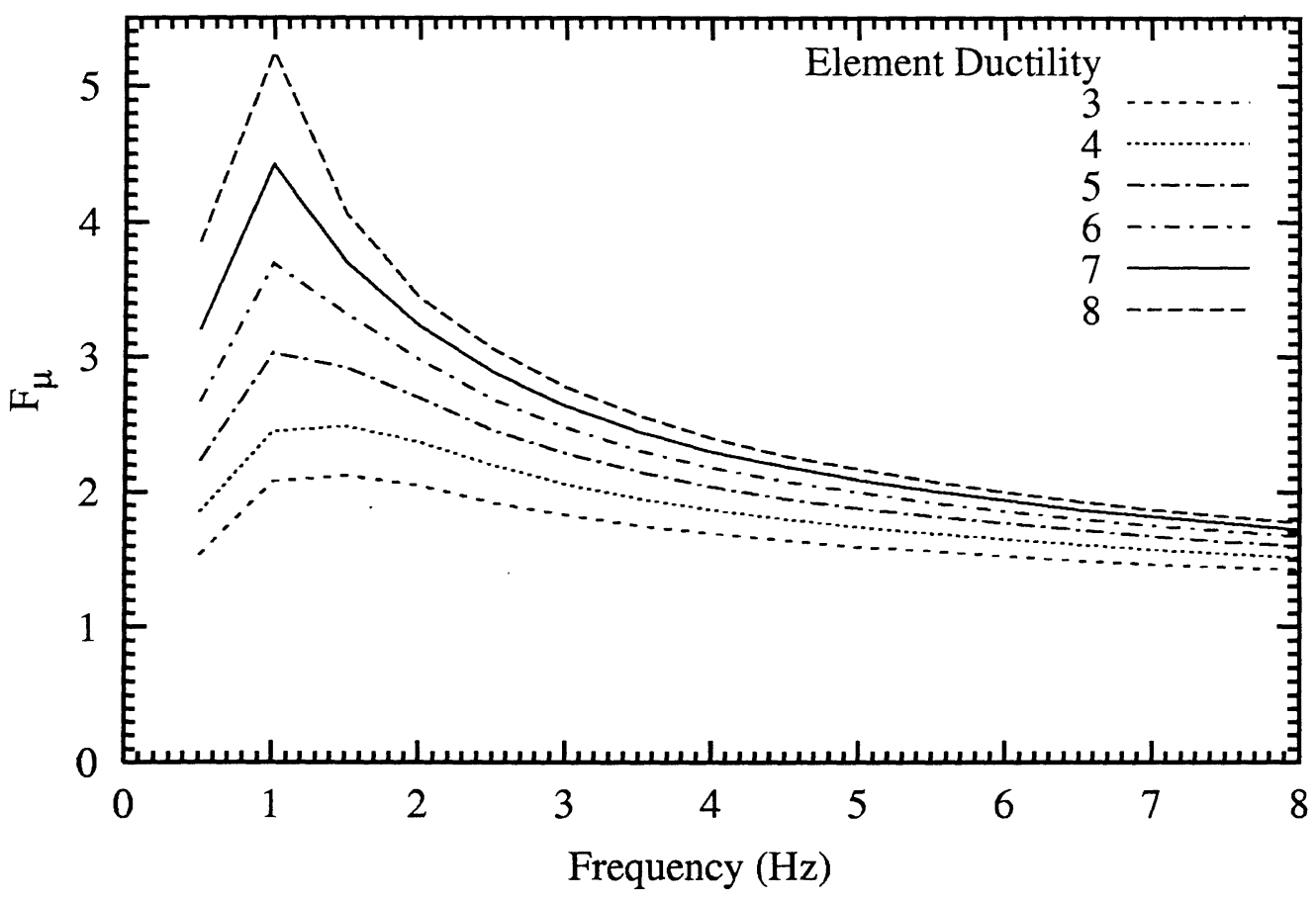

Figure 5.7 F $\mu$ for Element Ductilities in Bending Shear Wall Structures

\section{Structures With Pinched Hysteresis Loops}

Systems which respond primarily in a shear mode, such as low-rise shear walls and braced frames, have pinched hysteresis loops. Their response is related more closely to the number of stories and is significantly influenced by the effect of the pinched hysteresis behavior than to a direct frequency dependency. The effective force reduction factor for these systems, given an effective system ductility, can be obtained using Equation 3-3. This relationship between the effective system ductility and F $\mu$ is shown in Figure 5.8.

Often the behavior of shear wall systems can be considered as a single, full building ' height wall. In'these cases, the force reduction values shown in Figure 5.7 and Figure 5.8 are appropriate. However, when a substantial difference in the strength between stories 
Force Reduction Factors for the Structural Design and Evaluation of Facilities Containing Nuclear and Hazardous Materials

exists, then the building response may be either a bending mode with a hinge formation at the base of the wall or a shear mode with distortion of the weak story. These behaviors are shown schematically in Figures 5.9 for taller bending mode walls and Figure 5.10 for low rise shear walls.

If the response of the structure is a hinge formation in the weaker floor, the force reduction factors can be computed using the relationships developed in Section 3 for bending shear walls. However, if a weak story develops, the ductility demand will be focused into the weak story. This increase in ductility demand is accounted for by assuming that all of the nonlinear behavior in the system occurs in the weak story and Equation 4-38 is used to calculate $\lambda$. The resulting change in the force reduction factors for walls responding in a shear mode is shown in Figure 5.11 for 3 to 9 story buildings.

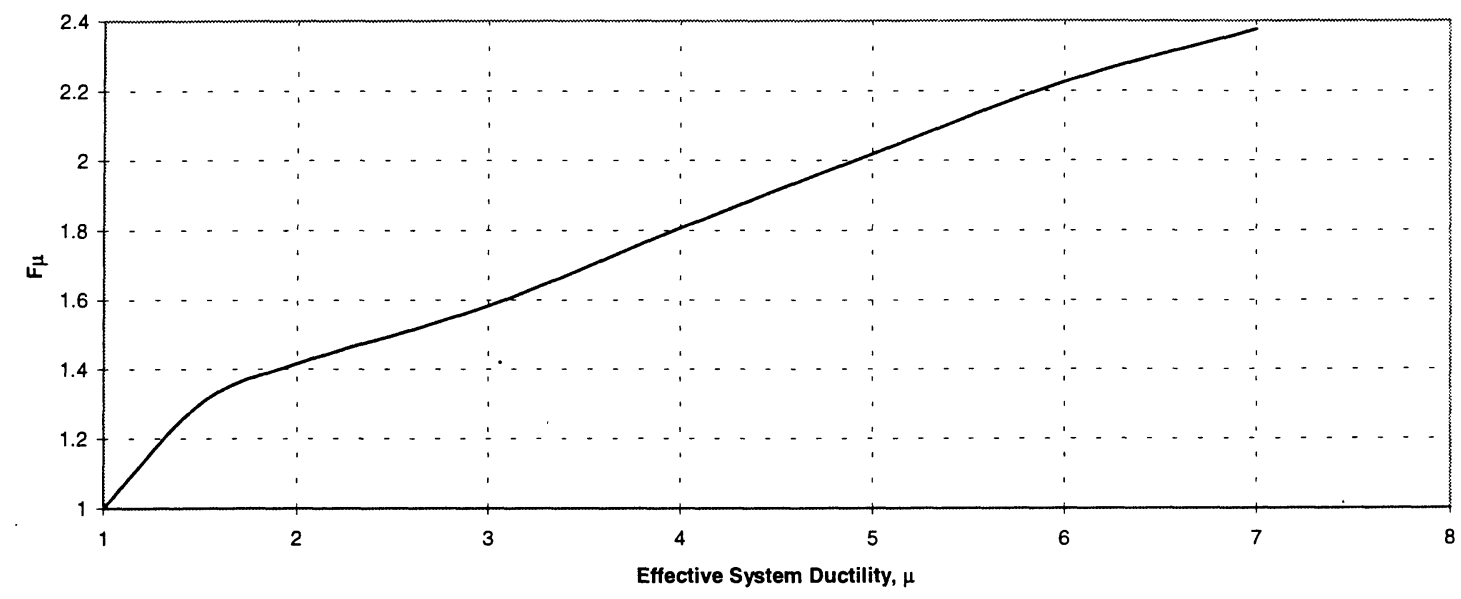

Figure 5.8 F $\mu$ vs. Effective System Ductility 
Force Reduction Factors for the Structural Design and Evaluation of Facilities Containing Nuclear and Hazardous Materials
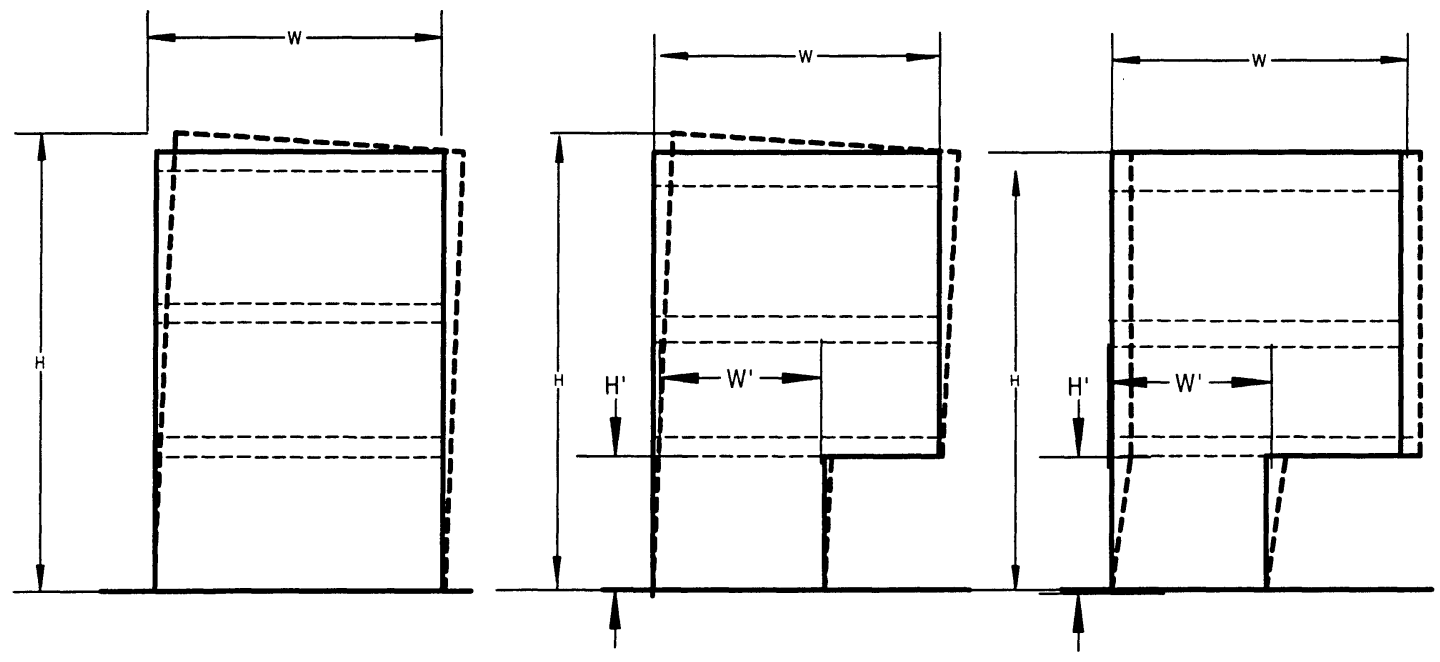

Figure 5.9 Bending Wall Structures and Bending Wall Weak Story Behavior

The allowable force reduction factor for the element described by $\mathrm{H}^{\prime}$ and $\mathrm{W}$ ' in Figure 5.9 and 5.10 is developed based upon whether the expected response of the element is in a shear or bending mode. A reasonable basis for selecting the behavior model, consistent with the ACI 349 definition of low rise shear walls, is to limit bending mode behavior to wall with ratios of $(\mathrm{M} / \mathrm{V}) * \mathrm{~W}^{\prime}$ greater than 2 , where $\mathrm{M}$ is the element overturning moment, $\mathrm{V}$ is the element shear, and $\mathrm{W}^{\prime}$ is the element width.
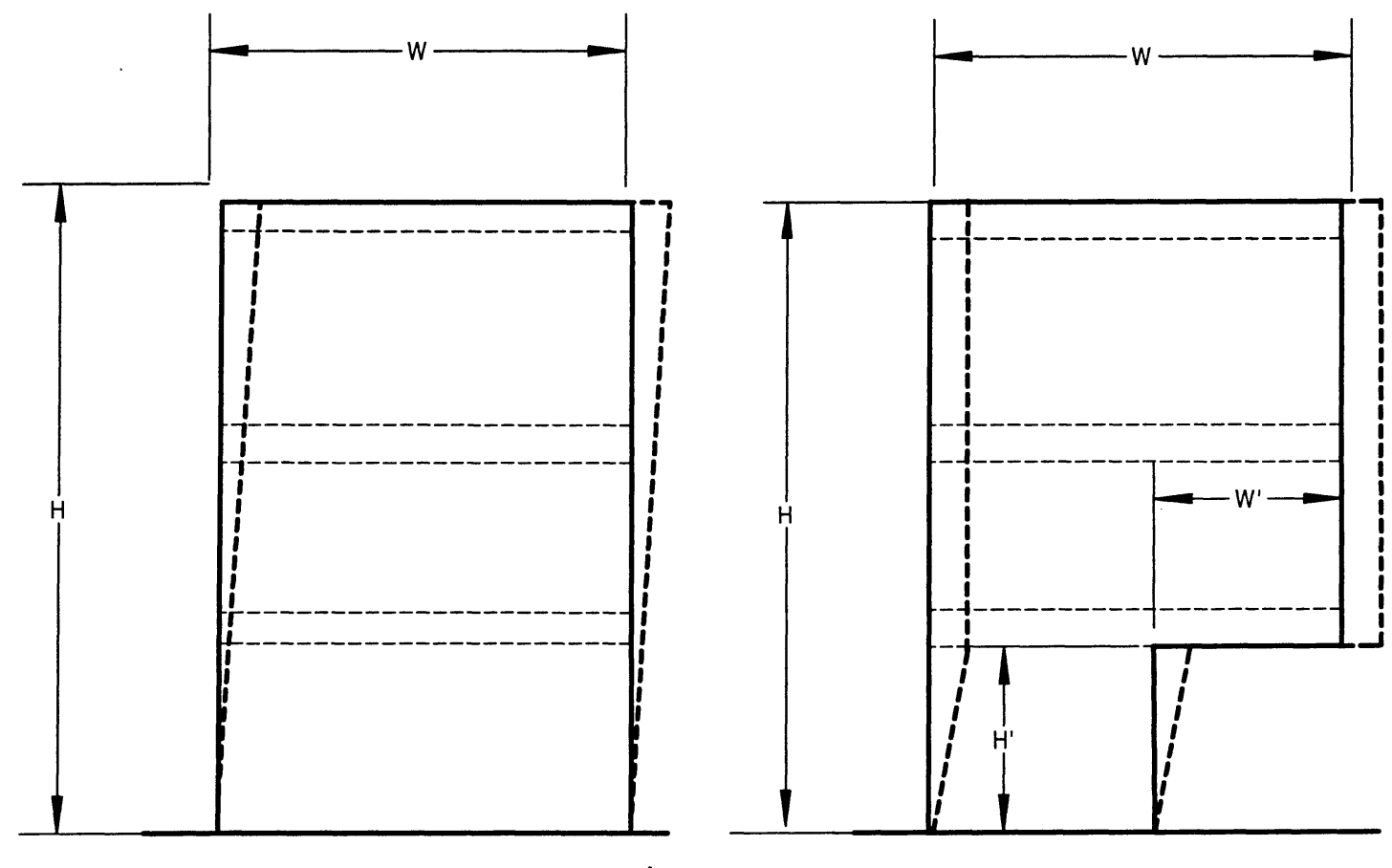

Figure 5.10 Shear Wall Structures and Weak Story Behavior 


\section{Force Reduction Factors for the Structural Design and Evaluation of Facilities}

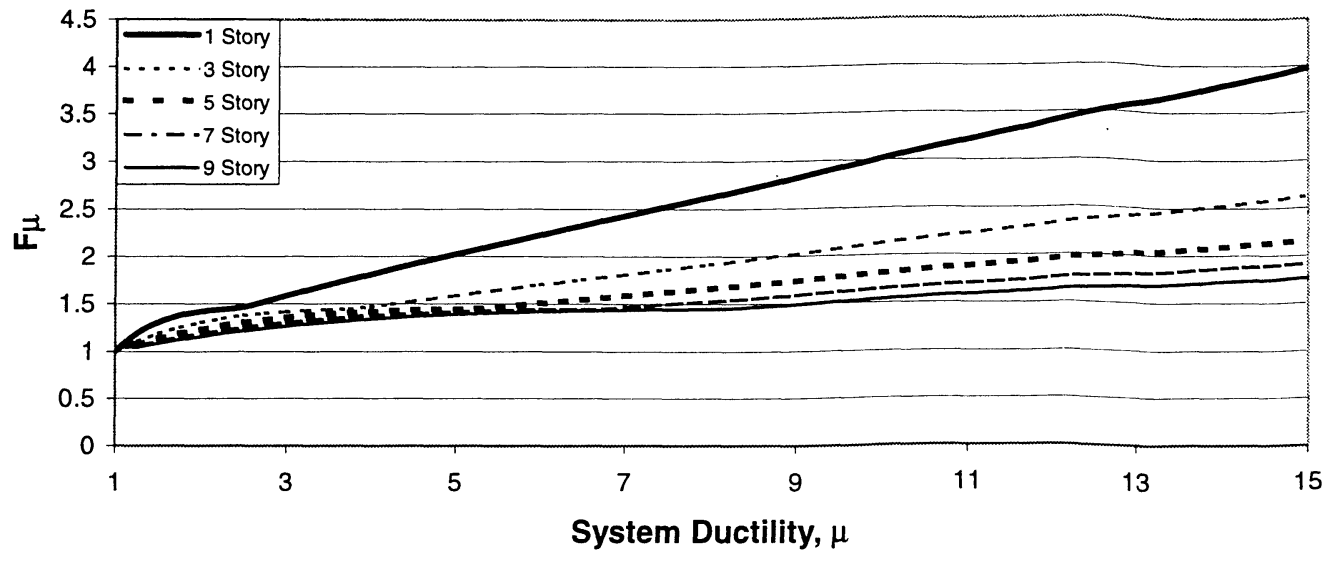

Figure 5.11 Effect of Number of Stories for Shear Mode Structures with Pinched Hysteresis Loops

\section{Concentric Braced Frames}

The behavior of concentric braced frame systems is similar to the model used for low rise shear walls. However, given the tendency to use similar sizes for the diagonal bracing over several story heights, it is assumed that a weak story will form at the first story and at each story where the bracing configuration or size changes. Thus, Equation 4-38 is used to compute $\lambda$ and Equation 4-31 is used in conjunction with Figures 5.8 and 5.11 to establish the allowable force reduction factor for concentric braced frame systems.

\section{Eccentric Braced Frames}

Eccentric braced frames have full hysteresis loops when subjected to cyclic loading, therefore their behavior in terms of story ductility demand, is similar to that for moment frame systems, which also have full hysteresis loops (Equation 3-6). However, once a hinge forms in the link beam in any story, it is likely that "weak story" behavior will occur. Thus, the force reduction factors for these systems are computed using Equation 438 to obtain an effective system ductility and Equation 4-31 combined with Equation 3-6 to obtain an allowable $\mathrm{F} \mu$. The resulting, frequency and story number dependent, force reduction factors for eccentric braced frames are of the form shown in Figure 5.12. 
Force Reduction Factors for the Structural Design and Evaluation of Facilities Containing Nuclear and Hazardous Materials

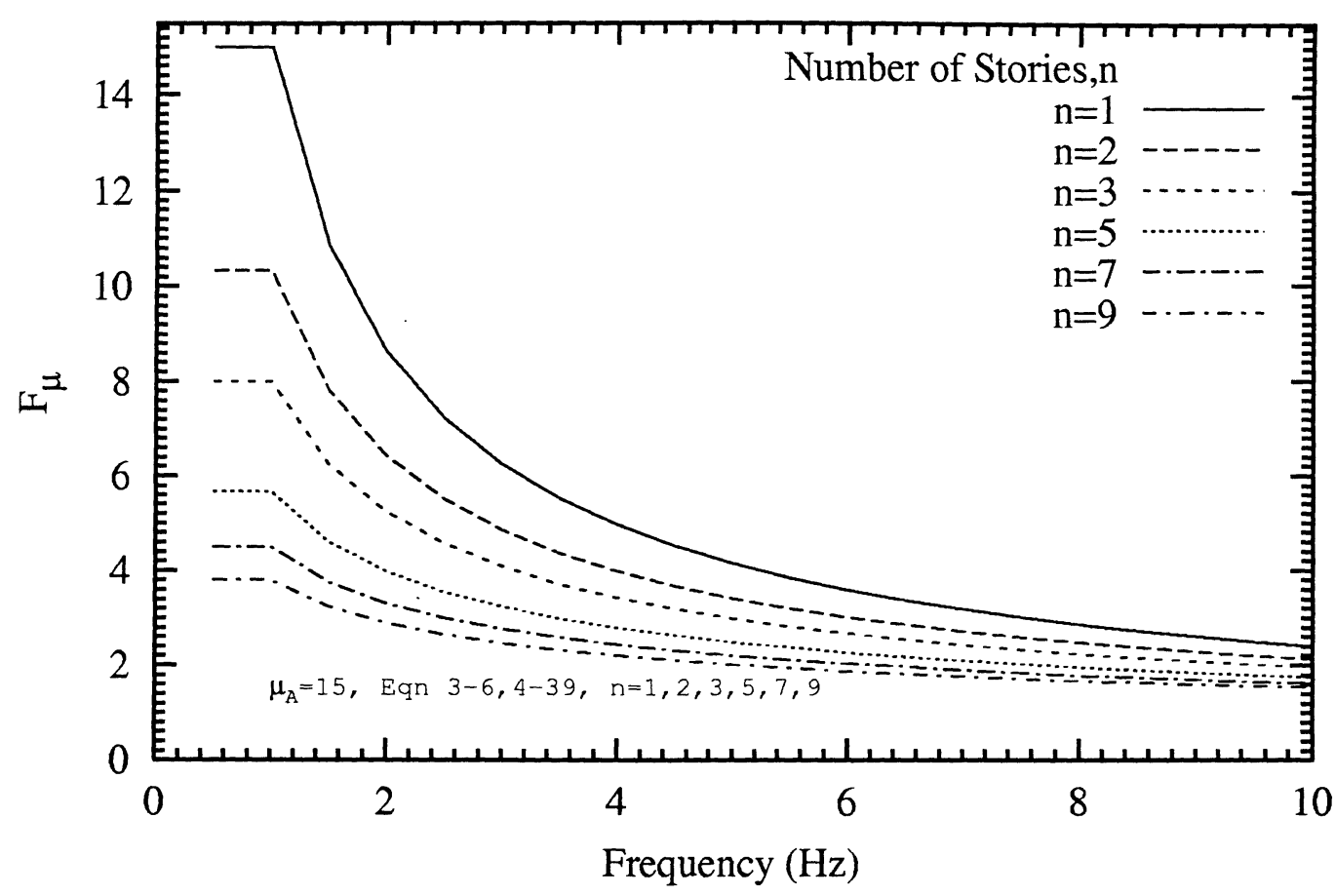

Figure 5.12 F $\mu$ for Eccentric Braced Frames.

\subsection{Application to Facilities Containing Nuclear and Hazardous Materials}

The F $\mu$ methodology developed in the preceding section is applied to reinforced concrete and steel structures common in nuclear facilities.

\subsubsection{Reinforced Concrete Special Moment Resisting Frames (R/C-SMRF)}

The ACI 349-97 Chapter 21 detailing requirements for moment frames resisting seismic loads forces hinges to form in the beams by proportioning the sum of column strengths to be greater than the sum of beam strengths. Similar requirements in ACI 318-99 Chapter 21 force Beam Hinges $(\mathrm{BH})$ for moment frames in regions of high seismicity. In moment frames with beam hinges, the MDOF force reduction factor, $F \mu$, is related to the SDOF force reduction factor, F $\mu$ s by a form of Equation 4-31 or

$$
F \mu=F \mu s\left(\frac{\mu_{\text {element }}}{\lambda_{\text {BH }}}\right)
$$




\section{Force Reduction Factors for the Structural Design and Evaluation of Facilities Containing Nuclear and Hazardous Materials}

where $\mu_{\text {element }}$ is the allowable element ductility for members in a reinforced concrete SMRF given in Table 2.3, or

\begin{tabular}{|r|c|c|c|c|}
\cline { 3 - 5 } \multicolumn{1}{c|}{} & \multicolumn{3}{c|}{ Element Ductility, $\mu_{\text {element }}$} \\
\hline \multirow{3}{*}{ Limit State } & LS-A & LS-B & LS-C \\
\hline \multirow{2}{*}{ Beams } & $(15 \leq \ell / \mathrm{h})$ & 10 & 6.5 & 3.25 \\
\cline { 2 - 5 } & $(\ell / \mathrm{h} \leq 10)$ & 5 & 4.25 & 3.25 \\
\hline \multicolumn{2}{|c|}{ Columns } & 2.5 & 2.25 & 1.75 \\
\hline
\end{tabular}

$\lambda_{\mathrm{BH}}$ is the ratio of $\mu_{\mathrm{MDOF}}$ to $\mu_{\mathrm{SDOF}}$ for a beam hinge structure, given by Equation 4-34, and

$\mathrm{F} \mu \mathrm{s}$ is the force reduction factor for a single degree-of-freedom system, given by

Equation 3-6, with a ductility of $\mu_{\text {element }} / \lambda_{\mathrm{BH}}$.

Column hinges in a SMRF will form at the base of the first floor columns. However, these hinges are not sufficient to concentrate the structure's ductility into a single story and the beam hinge mechanism is valid to describe the SMRF's behavior.

Frequency dependent $F \mu$ for beams with low shear $(15 \leq / / \mathrm{h})$ are shown in Figure 5.13 while the values for high shear $(\ell / \mathrm{h} \leq 10)$ are shown in Figure 5.14. F $\mu$ for intermediate values of shear may be obtained by interpolation between Figures 5.13 and 5.14. Frequency dependent F $\mu$ for columns are shown in Figure 5.15. Recall that columns are assumed to have high shear, as discussed in Section 2.4.1. More liberal F $\mu$ could be developed for columns with low shear by using the appropriate element ductility.

The $F \mu$ in Figures 5.13 through 5.15 can be simplified by assuming that the frequency range for R/C SMRF in nuclear facilities is below 3 hertz, yielding the conservative frequency independent $F \mu$ in Table 5.1. Also shown in the table are the F $\mu$ from DOESTD-1020, which are based on a limit state similar to LS-C. The proposed F $\mu$ are consistent with DOE-STD-1020.

Table 5.1 Simplified F $\mu$ for R/C SMRF

\begin{tabular}{|c|c|c|c|c|c|}
\hline & & \multicolumn{3}{|c|}{$\mathbf{F} \mu$} & \multirow{2}{*}{$\begin{array}{l}\text { DOE-STD } \\
1020 \mathrm{~F} \mu\end{array}$} \\
\hline \multicolumn{2}{|c|}{ Limit State } & LS-A & LS-B & LS-C & \\
\hline \multirow{2}{*}{ Beams } & $(15 \leq \ell / h)$ & 5.25 & 4 & 2.5 & \multirow{2}{*}{2.75} \\
\hline & $(\ell / h \leq 10)$ & 3.25 & 3 & 2.5 & \\
\hline \multicolumn{2}{|c|}{ Columns } & 2 & 1.75 & 1.5 & 1.5 \\
\hline
\end{tabular}

For $10<1 / \mathrm{h}<15$ Interpolate between the short and long beam values 
Force Reduction Factors for the Structural Design and Evaluation of Facilities Containing Nuclear and Hazardous Materials

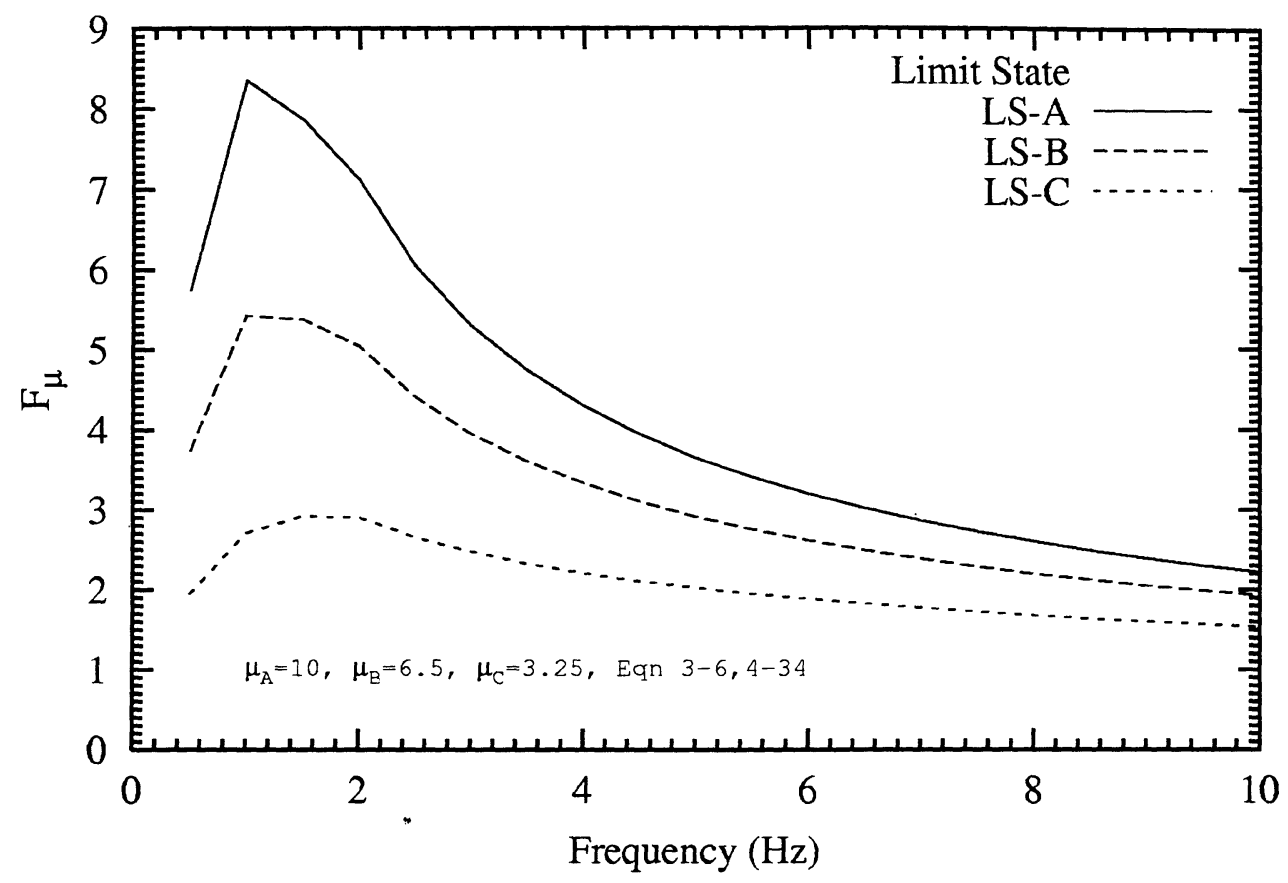

Figure 5.13 R/C SMRF Beams with Low Shear $(15 \leq / /)$

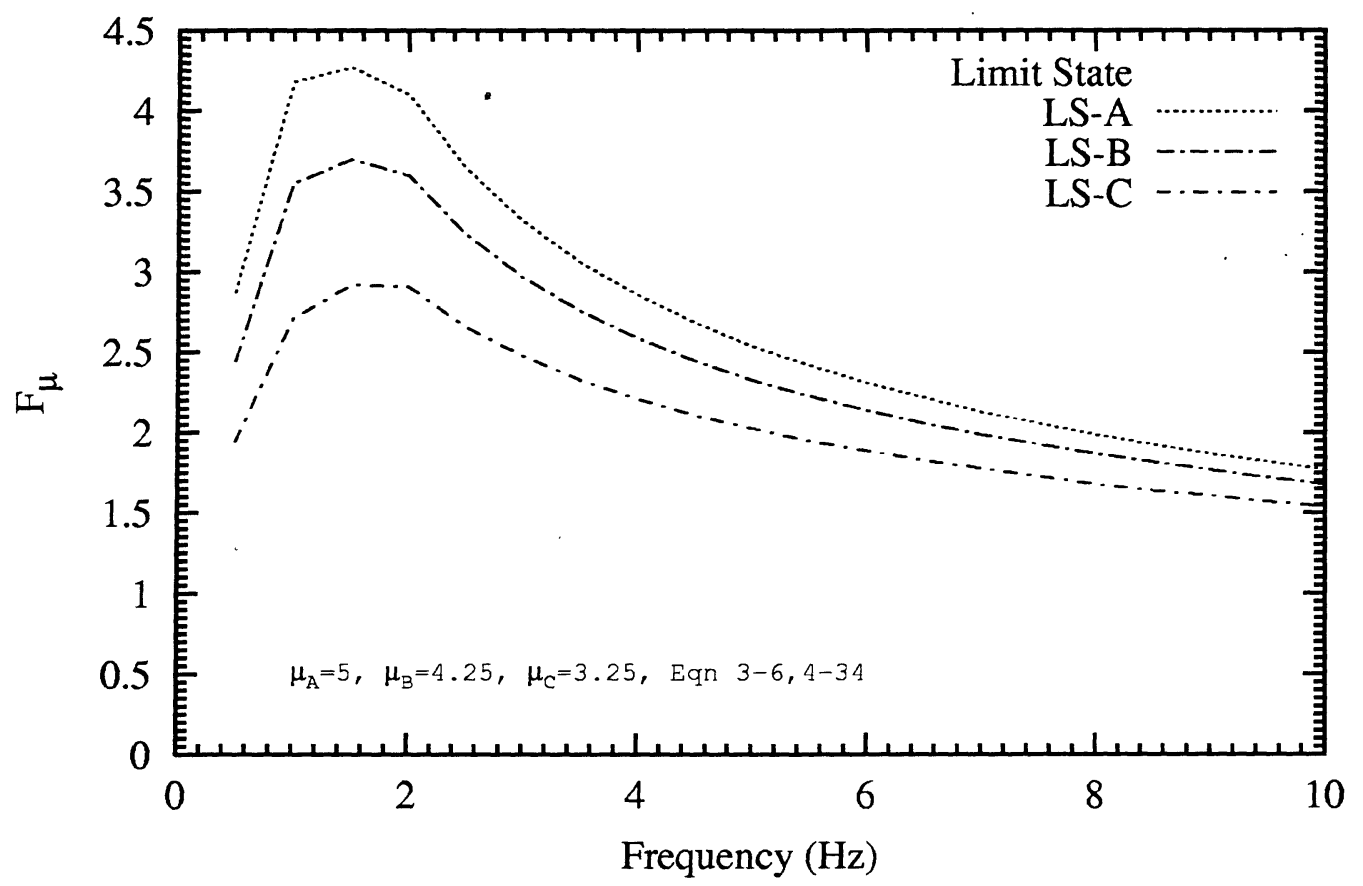

Figure 5.14 R/C SMRF Beams with High Shear $(\ell / \mathrm{h} \leq 10)$ 


\section{Force Reduction Factors for the Structural Design and Evaluation of Facilities Containing Nuclear and Hazardous Materials

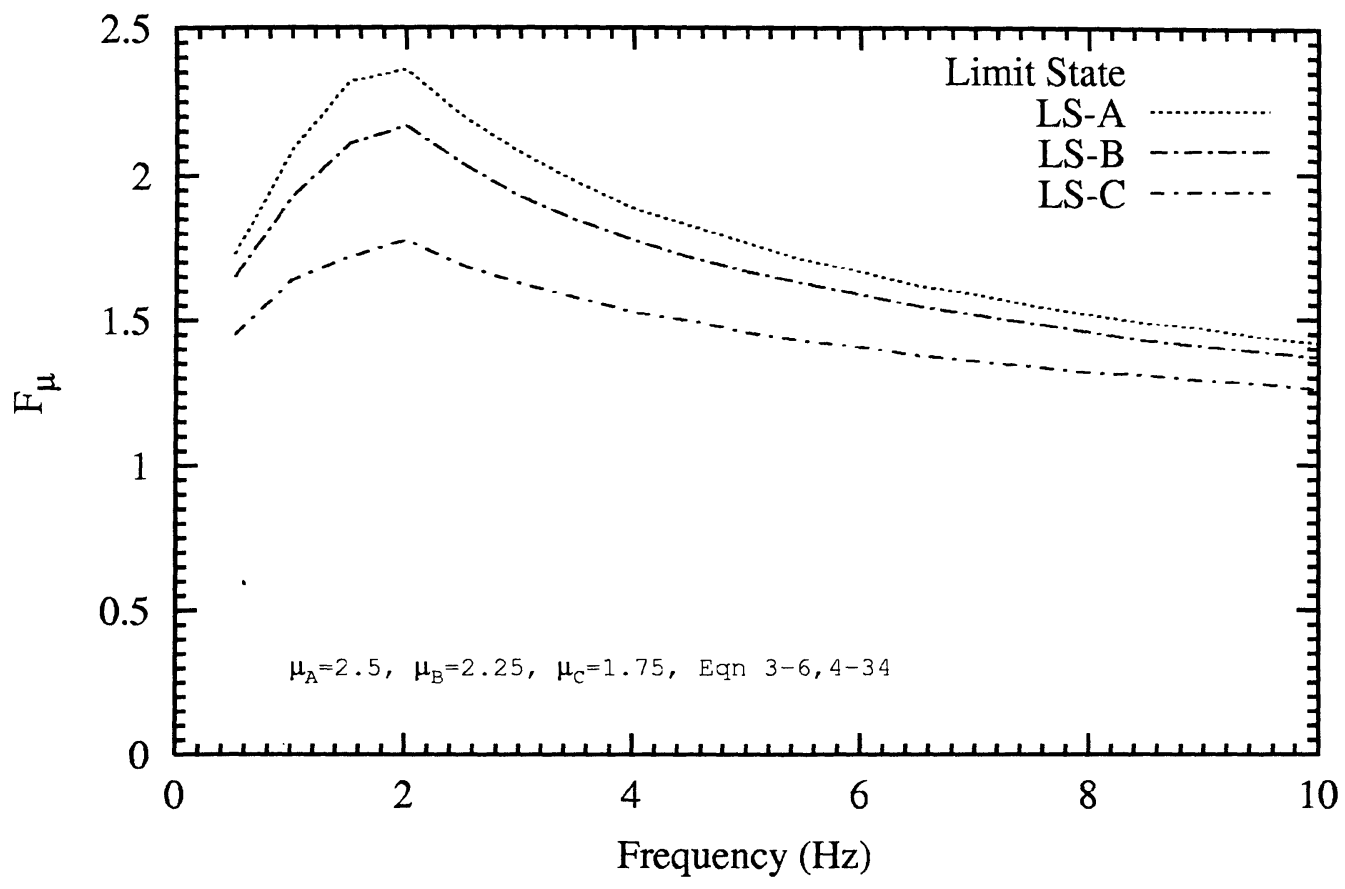

Figure 5.15 R/C SMRF Columns

\subsubsection{Reinforced Concrete Intermediate Moment Resisting Frames (R/C-IMRF)}

ACI 318-99 provides detailing rules for reinforced concrete frames in regions of moderate seismicity. These frames are interpreted to be Intermediate Moment Resisting Frames. Note that ACI 349-97 does not recognize IMRF and states that all moment frames in nuclear structures designed to resist lateral seismic loads should be SMRF. Following this argument, IMRF are included to assist in the evaluation of existing structures and their use in new construction is not anticipated.

The IMRF detailing requirements do not contain provisions that force plastic hinges to form in beams. Thus, either Column Hinges $(\mathrm{CH})$ or a Weak Story (WS) are conservatively postulated for IMRF. If a particular IMRF were proportioned such that the sum of column strengths is greater than the sum of beam strengths, then use of the beam hinge MDOF reduction factor, $\lambda_{\mathrm{BH}}$, would be justified.

In moment frames with Column Hinges the MDOF force reduction factor, $\mathrm{F} \mu$, is related to the SDOF force reduction factor, F $\mu$ s by a form of Equation 4-31 or

$$
\mathrm{F} \mu=\mathrm{F} \mu \mathrm{s}\left(\frac{\mu_{\text {element }}}{\lambda_{\mathrm{CH}}}\right)
$$


Force Reduction Factors for the Structural Design and Evaluation of Facilities Containing Nuclear and Hazardous Materials

where $\mu_{\text {element }}$ is the element ductility for members in a reinforced concrete IMRF given in Table 2.3, or

\begin{tabular}{|c|c|c|c|c|}
\cline { 2 - 5 } \multicolumn{1}{c|}{} & \multicolumn{3}{c|}{ Element Ductility, $\mu_{\text {element }}$} \\
\hline \multirow{2}{*}{ Limit State } & LS-A & LS-B & LS-C \\
\hline \multirow{2}{*}{ Beams } & $(15 \leq \ell / \mathrm{h})$ & 5 & 4 & 3.25 \\
\cline { 2 - 5 } & $(\ell / \mathrm{h} \leq 10)$ & 3.75 & 3.5 & 3.25 \\
\hline \multicolumn{2}{|c|}{ Columns } & 1.75 & 1.5 & 1.25 \\
\hline
\end{tabular}

$\lambda_{\mathrm{CH}}$ is the ratio of $\mu_{\mathrm{MDOF}}$ to $\mu_{\mathrm{SDOF}}$ for a column hinge structure, given by Equation 4-35, and

F $\mu$ s is the force reduction factor for a single degree-of-freedom system, given by

Equation 3-6, with a ductility of $\mu_{\text {element }} / \lambda_{\mathrm{CH}}$.

Frequency dependent $\mathrm{F} \mu$ for both low shear and high shear beams is given in Figures 5.16 and 5.17 for frames which may contain column hinges. If all of the hinges are located in columns then $\mathrm{F} \mu$ for beams would not be required. However, as stated above, the hinges are conservatively assumed to be located in columns because the detailing rules do not prohibit column hinges.

Interpolation between Figures 5.16 and 5.17 may be used to determine F $\mu$ for beams of intermediate shear.

Frequency dependent F $\mu$ for columns are shown in Figure 5.18. Recall that columns are assumed to have high shear, as discussed in Section 2.4.1. More liberal F $\mu$ could be developed for columns with low shear using the approach in Section 5.2. 
Force Reduction Factors for the Structural Design and Evaluation of Facilities Containing Nuclear and Hazardous Materials

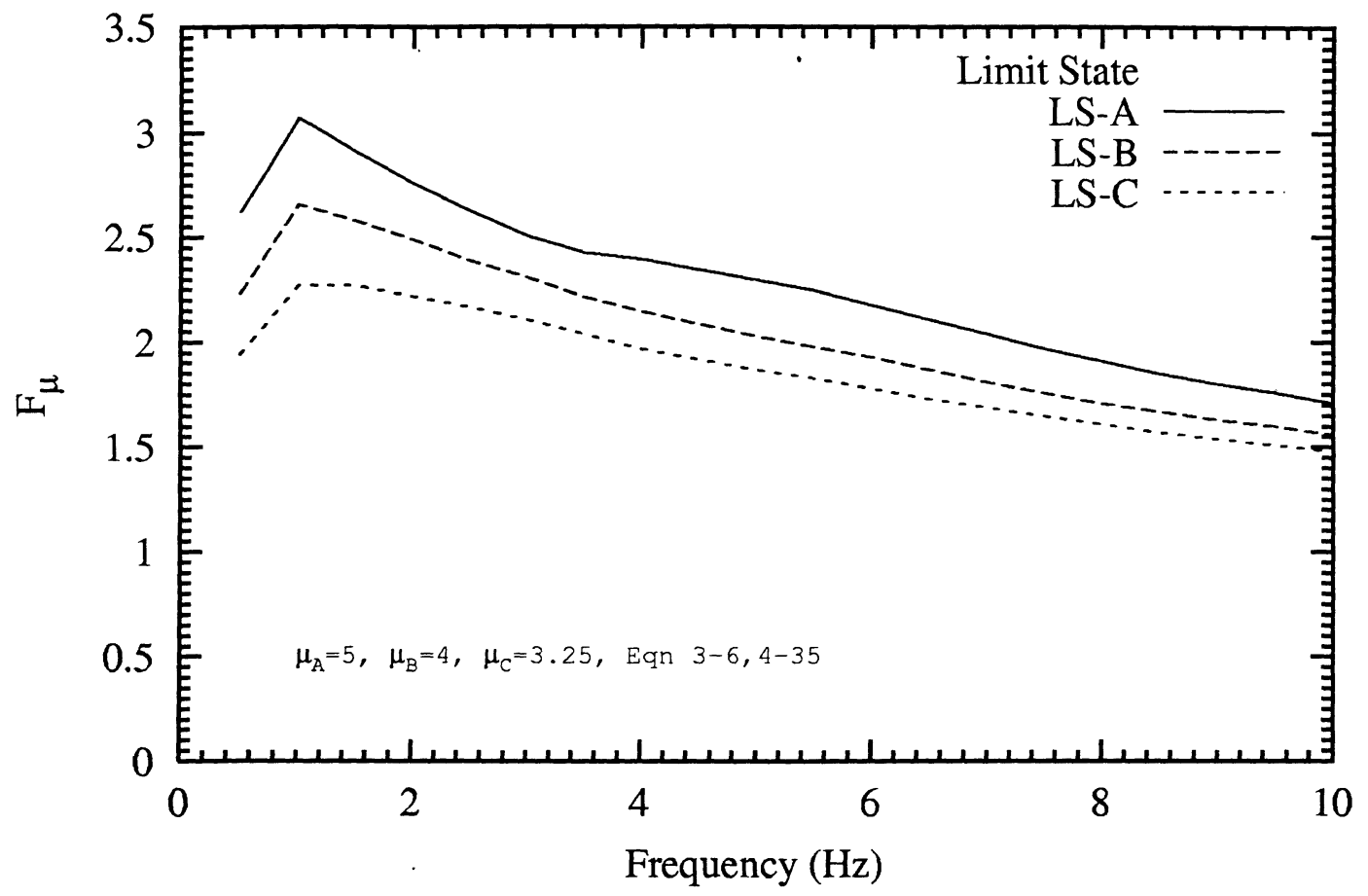

Figure 5.16 R/C IMRF CH Beams with Low Shear $\left(15 \leq \frac{1}{h}\right)$

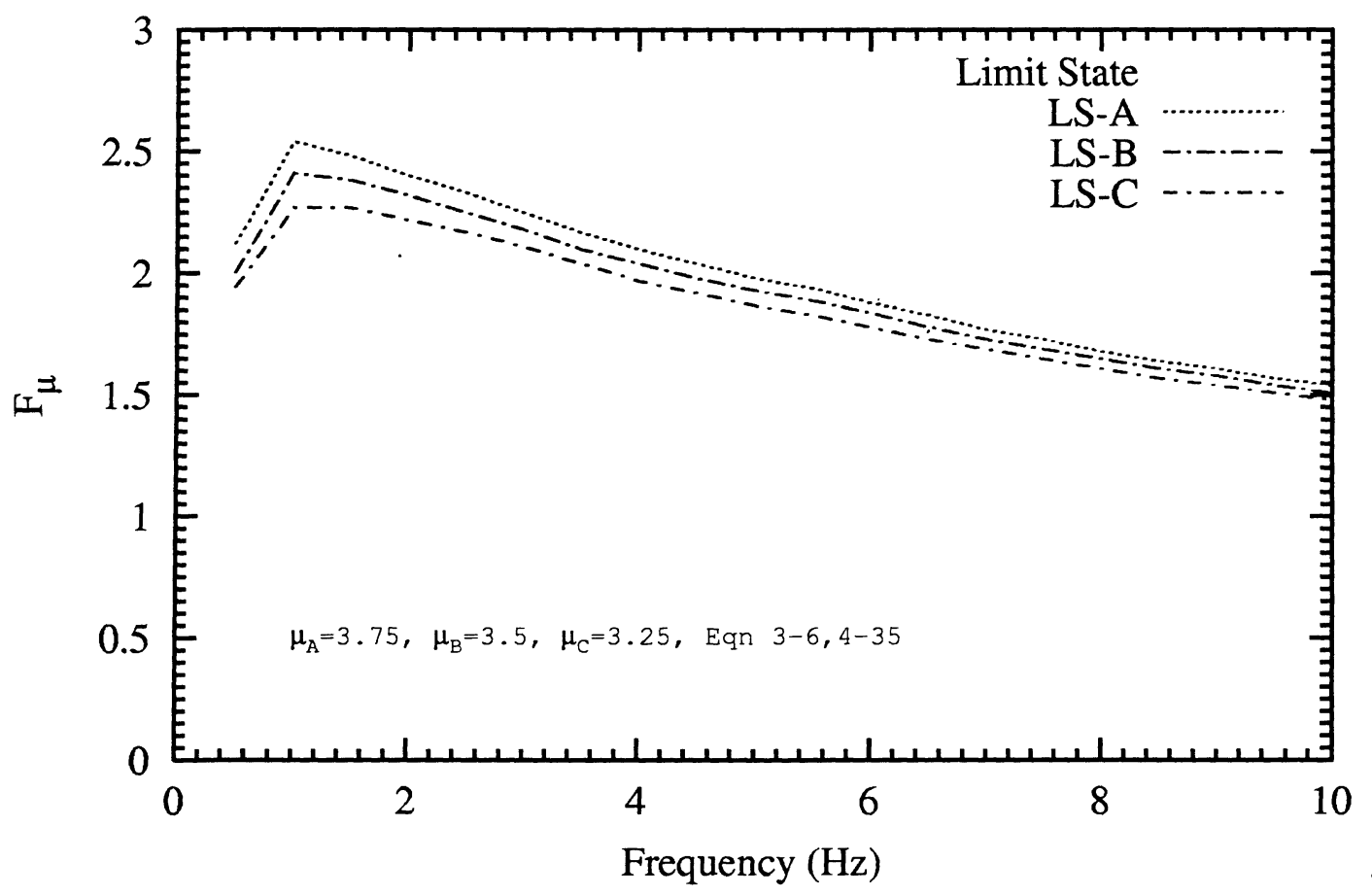

Figure 5.17 R/C IMRF CH Beams with High Shear $(\ell / \mathrm{h} \leq 10)$ 


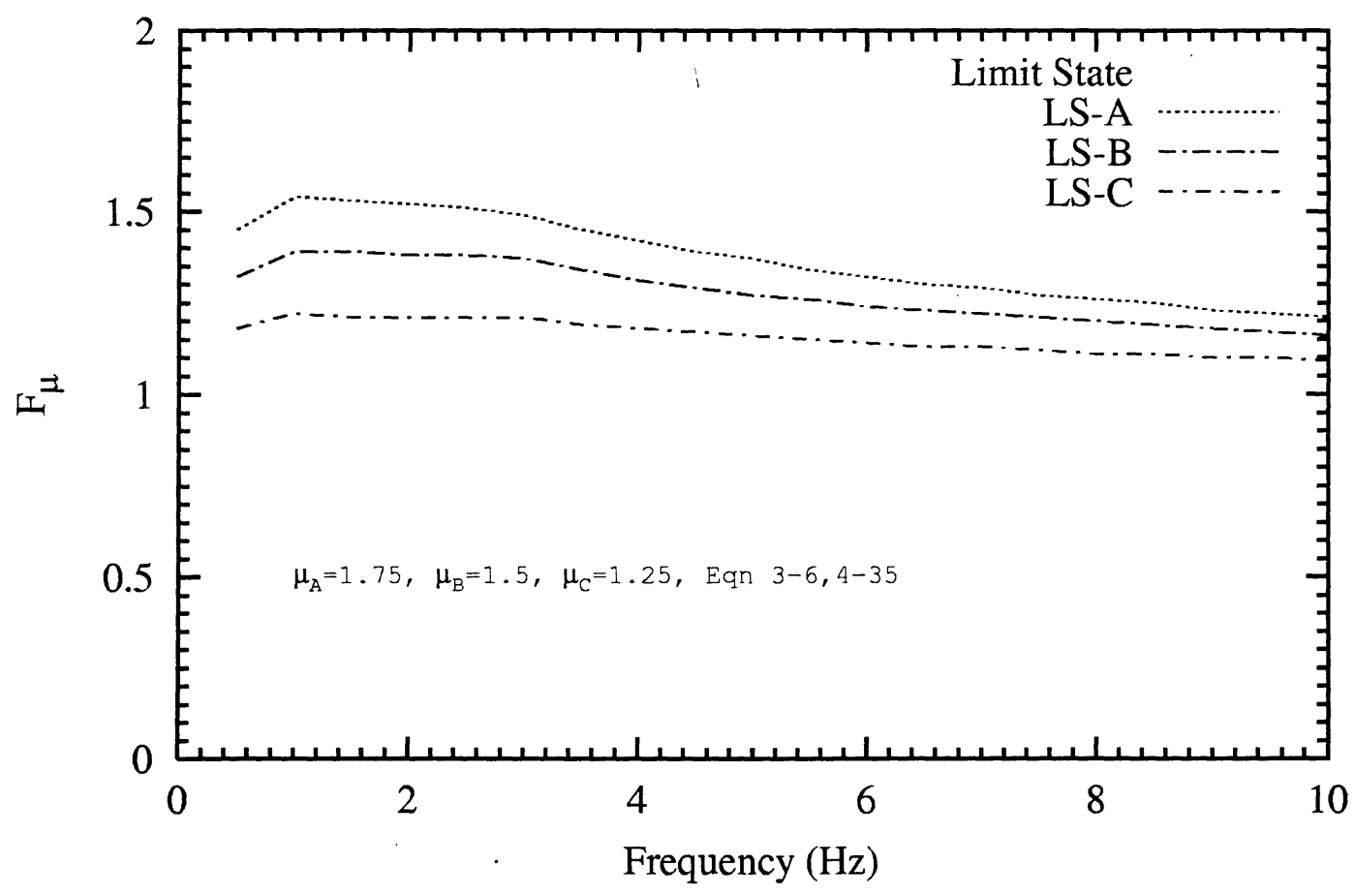

Figure 5.18 R/C IMRF CH Columns

A weak story is typically defined as any story having a lateral load capacity that is less than $80 \%$ of the next higher story's lateral load capacity. In a moment frame governed by column hinges the lateral load capacity of a story is inversely proportional to the column length. Simply varying the column length from 16 feet on the first story to 12 feet on the second story while maintaining the same column section results in

$$
\begin{aligned}
& \mathrm{V}_{1}=\frac{\phi \mathrm{Mn} \mathrm{n}_{\text {Column }}}{16} \text { and } \mathrm{V}_{2}=\frac{\phi \mathrm{Mn}_{\text {Column }}}{12} \\
& \therefore \frac{\mathrm{V}_{1}}{\mathrm{~V}_{2}}=\frac{12 \phi \mathrm{Mn}_{\text {Column }}}{16 \phi \mathrm{Mn}_{\text {Column }}}=0.75
\end{aligned}
$$

Or, a first floor which has a story shear that is only $75 \%$ of the second floor's story shear. Thus, small variations in column height can cause a frame with column hinge mechanisms to behave as a weak story.

In moment frames with a Weak Story the MDOF force reduction factor, F $\mu$, is related to the SDOF force reduction factor, F $\mu$ s by a form of Equation 4-31 or 


\section{Force Reduction Factors for the Structural Design and Evaluation of Facilities}

$F \mu=F \mu s\left(\frac{\mu_{\text {element }}}{\lambda_{\text {ws }}}\right)$

where $\lambda_{\mathrm{WS}}$ is the ratio of $\mu_{\mathrm{MDOF}}$ to $\mu_{\mathrm{SDOF}}$ for a weak story structure, given by

Equation 4-36, and

the remaining terms are defined in Equation 5-2.

Frequency dependent $\mathrm{F} \mu$ for beams with low shear $(15 \leq \mathrm{\ell} / \mathrm{h})$ are shown in Figure 5.19 while the values for high shear $(\ell / \mathrm{h} \leq 10)$ are shown in Figure 5.20. F $\mu$ for intermediate values of shear may be obtained by interpolation. Frequency dependent F $\mu$ for columns are shown in Figure 5.21.

Note that the only difference between the IMRF Column Hinge and IMRF Weak Story $\mathrm{F} \mu$ in Figures 5-16 to 5-18 and 5-19 to 5-21 is MDOF to SDOF conversion, $\lambda_{\mathrm{CH}}$ versus $\lambda_{\text {ws. }}$ As expected, the weak story mechanism has lower F $\mu$ than the column mechanism.

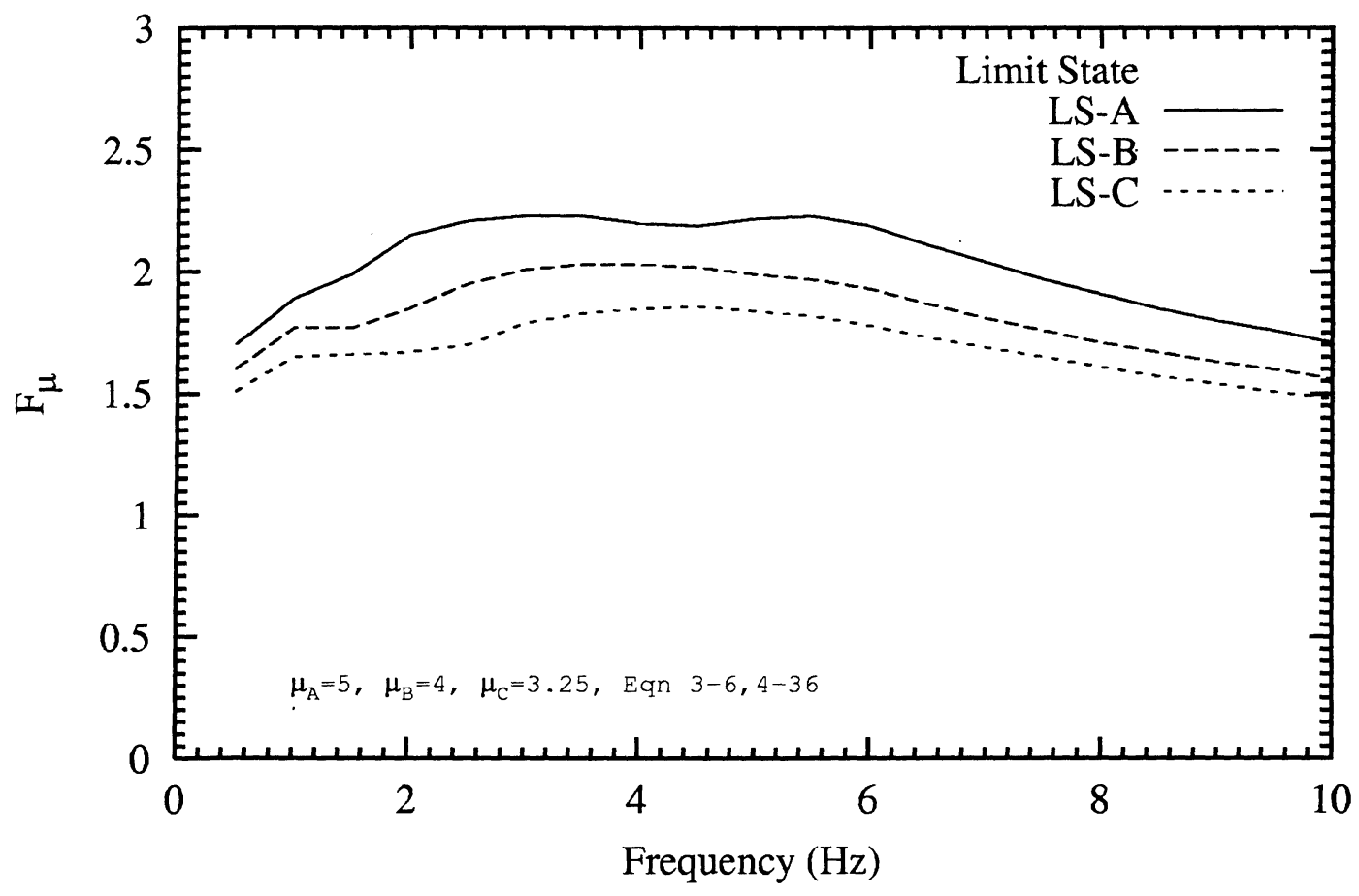

Figure 5.19 R/C IMRF WS Beams with Low Shear $\left(15 \leq \frac{1}{\mathrm{~h}}\right)$ 
Force Reduction Factors for the Structural Design and Evaluation of Facilities Containing Nuclear and Hazardous Materials

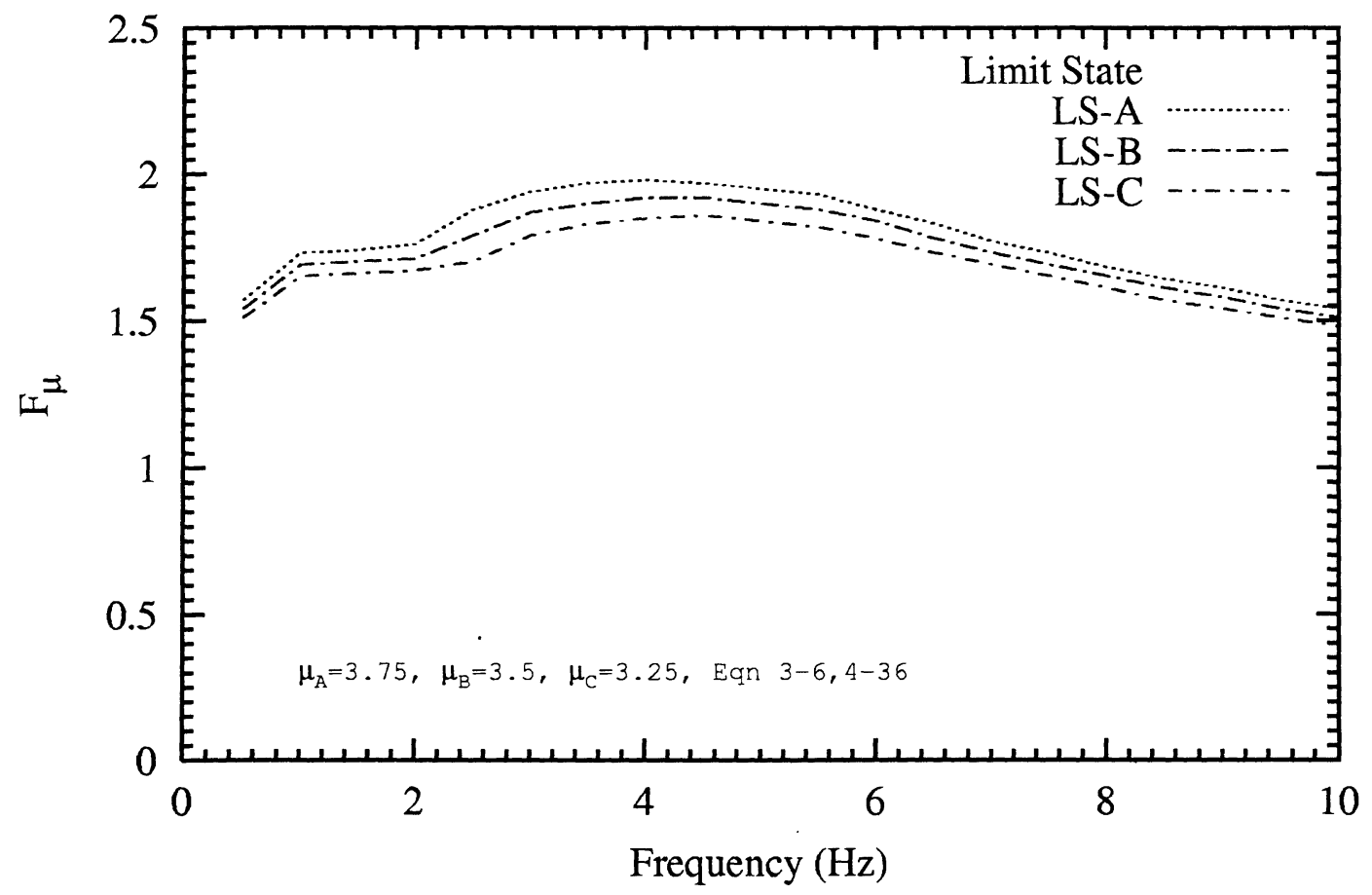

Figure 5.20 R/C IMRF WS Beams with High Shear $(/ / \mathrm{h} \leq 10)$

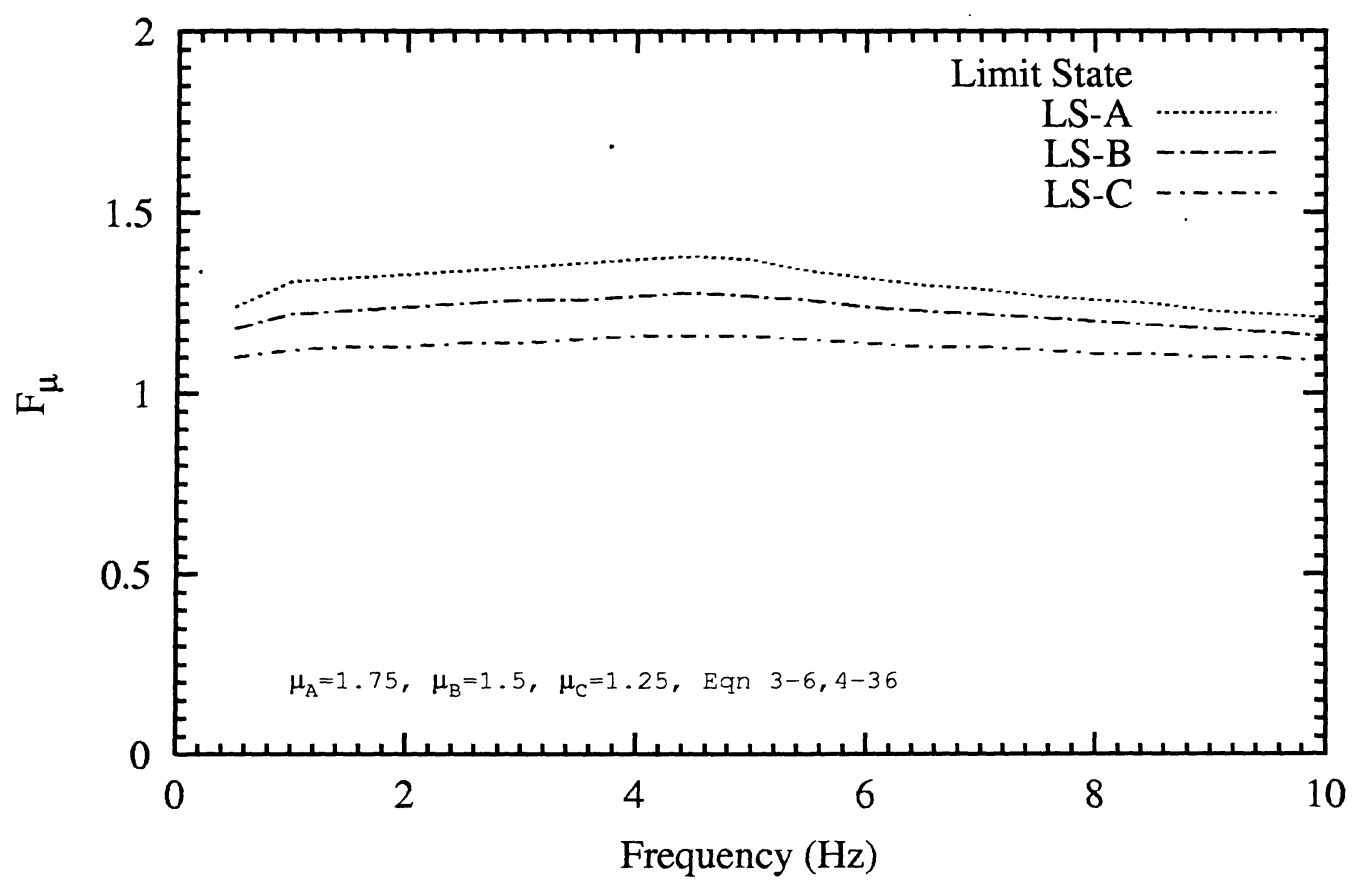

Figure 5.21 R/C IMRF WS Columns 


\section{Force Reduction Factors for the Structural Design and Evaluation of Facilities} Containing Nuclear and Hazardous Materials

The $F \mu$ in Figures 5.16 through 5.21 can be simplified by assuming that the frequency range for R/C IMRF in nuclear facilities is below 3 hertz, yielding the conservative frequency independent $F \mu$ in Table 5.2. Also shown in the table is the $F \mu$ from DOE-STD-1020, which is based on a limit state similar to LS-C. The proposed F $\mu$ values are slightly larger than the DOE-STD-1020 values.

Table 5.2 Simplified F $\mu$ for R/C IMRF

\begin{tabular}{|c|c|c|c|c|c|}
\hline & & \multicolumn{3}{|c|}{$\mathbf{F} \mu$} & \multirow{2}{*}{$\begin{array}{l}\text { DOE-STD- } \\
1020 \mathrm{~F} \mu\end{array}$} \\
\hline \multicolumn{2}{|c|}{ Limit State } & LS-A & LS-B & LS-C & \\
\hline \multicolumn{6}{|c|}{ Column Hinge Frame } \\
\hline \multirow{2}{*}{ Beams } & $(15 \leq / / h)$ & 2.5 & 2.25 & 2 & \multirow{3}{*}{1.5} \\
\hline & $(e / n \leq 10)$ & 2.25 & 2 & 2 & \\
\hline \multicolumn{2}{|c|}{ Columns } & 1.5 & 1.25 & 1.25 & \\
\hline \multicolumn{6}{|c|}{ Weak Story Frame } \\
\hline \multirow{2}{*}{ Beams } & $(15 \leq / / n)$ & 2.25 & 2 & 1.75 & \multirow{3}{*}{1.5} \\
\hline & $(\ell / h \leq 10)$ & 2 & 1.75 & 1.75 & \\
\hline \multicolumn{2}{|c|}{ Columns } & 1.25 & 1.25 & 1 & \\
\hline
\end{tabular}

For $10<1 / \mathrm{k}<15$ Interpolate between the short and long beam values

\subsubsection{Reinforced Concrete Ordinary Moment Resisting Frames (R/C-OMRF)}

Ordinary moment resisting frames are frames designed in accordance with either ACI 318 or 349 but do not meet the requirements of Chapter 21 for frames which resist lateral seismic forces. Note that ACI 349-97 states that all moment frames in nuclear structures designed to resist lateral seismic loads should be SMRF. Recognizing this position, OMRF are included to assist in the evaluation of existing structures and their use in new construction is not anticipated.

The OMRF detailing requirements do not contain provisions that force beam hinges, Thus, like the IMRF, either Column Hinges (CH) or a Weak Story (WS) are conservatively postulated for OMRF. If a particular OMRF were proportioned such that the sum of column strengths is greater than the sum of beam strengths, then use of the beam hinge MDOF reduction factor, $\lambda_{\mathrm{BH}}$, would be justified.

In moment frames with Column Hinges the MDOF force reduction factor, $\mathrm{F} \mu$, is related to the SDOF force reduction factor, F $\mu$ s by a form of Equation 4-31 or

$$
\mathrm{F} \mu=\mathrm{F} \mu \mathrm{s}\left(\frac{\mu_{\text {element }}}{\lambda_{\mathrm{CH}}}\right)
$$


Force Reduction Factors for the Structural Design and Evaluation of Facilities

where $\mu_{\text {element }}$ is the element ductility for members in a reinforced concrete OMRF given in Table 2.3, or

\begin{tabular}{|c|c|c|c|c|}
\cline { 3 - 5 } \multicolumn{1}{c|}{} & \multicolumn{3}{c|}{ Element Ductility, $\mu_{\text {element }}$} \\
\hline \multirow{2}{*}{ Limit State } & LS-A & LS-B & LS-C \\
\hline \multirow{2}{*}{ Beams } & $(15 \leq / / \mathrm{h})$ & 5 & 4 & 3.25 \\
\cline { 2 - 5 } & $(\mathrm{\ell} / \mathrm{h} \leq 10)$ & 3.25 & 2.25 & 1.25 \\
\hline \multicolumn{2}{|c|}{ Columns } & 1.25 & 1 & 1 \\
\hline
\end{tabular}

$\lambda_{\mathrm{CH}}$ is the ratio of $\mu_{\mathrm{MDOF}}$ to $\mu_{\mathrm{SDOF}}$ for a column hinge structure, given by Equation 4-35, and

$\mathrm{F} \mu \mathrm{s}$ is the force reduction factor for a single degree-of-freedom system, given by Equation 3-6, with a ductility of $\mu_{\text {element }} / \lambda_{\mathrm{CH}}$.

Frequency dependent $\mathrm{F} \mu$ for both low shear and high shear beams is given in Figures 5.22 and 5.23 for frames which may contain column hinges. As stated before, if all of the hinges are located in columns then $\mathrm{F} \mu$ for beams would not be required. However, the hinges are conservatively assumed to be located in columns because the detailing rules do not prohibit column hinges.

Interpolation between Figures 5.22 and 5.23 may be used to determine F $\mu$ for beams of intermediate shear.

Frequency dependent F $\mu$ for columns are shown in Figure 5.24. Recall that columns are assumed to have high shear, as discussed in Section 2.4.1. More liberal F $\mu$ could be developed for columns with low shear using appropriate ductilities. 
Force Reduction Factors for the Structural Design and Evaluation of Facilities Containing Nuclear and Hazardous Materials

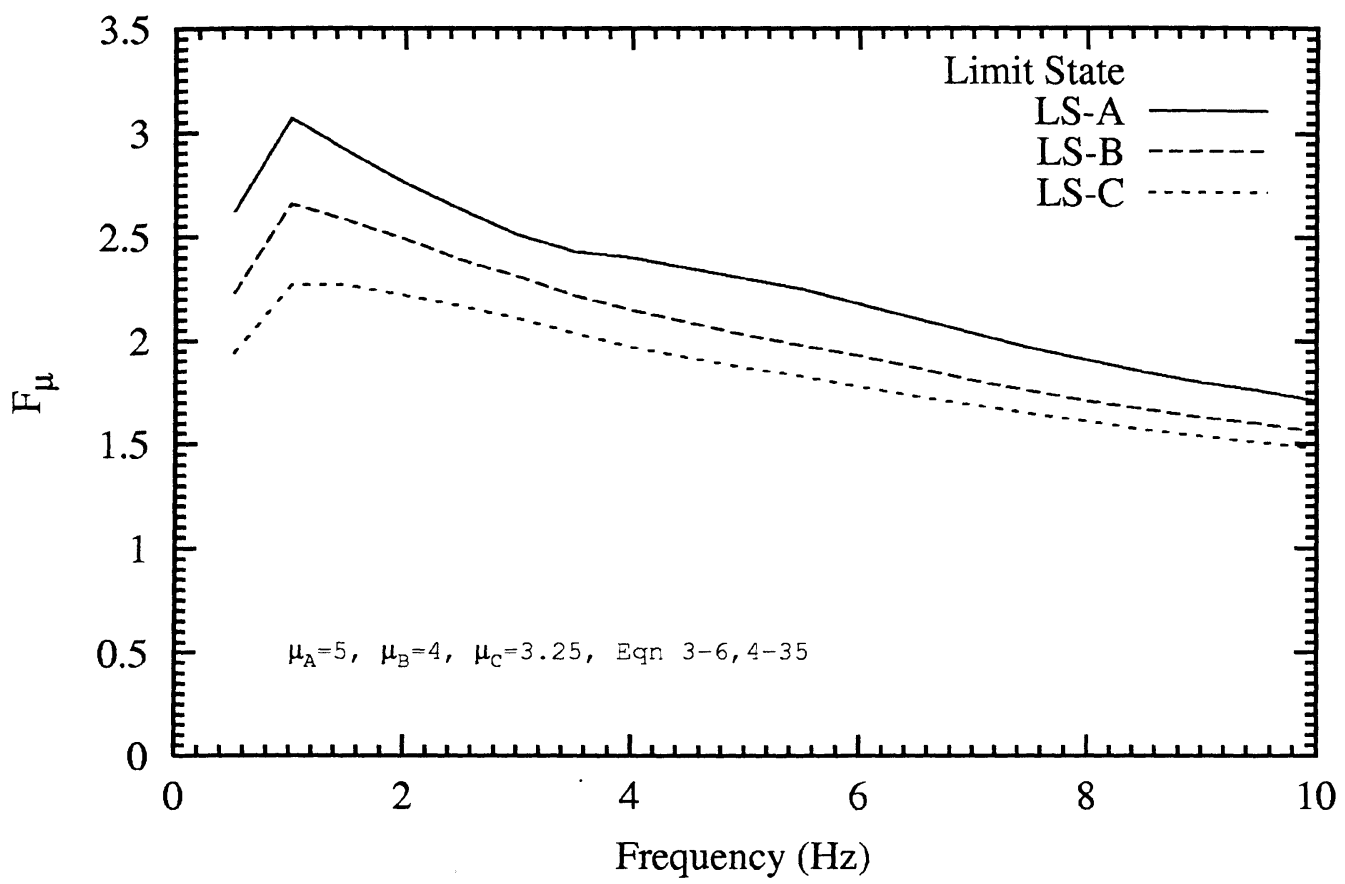

Figure 5.22 R/C OMRF CH Beams with Low Shear $(15 \leq / \mathrm{h})$

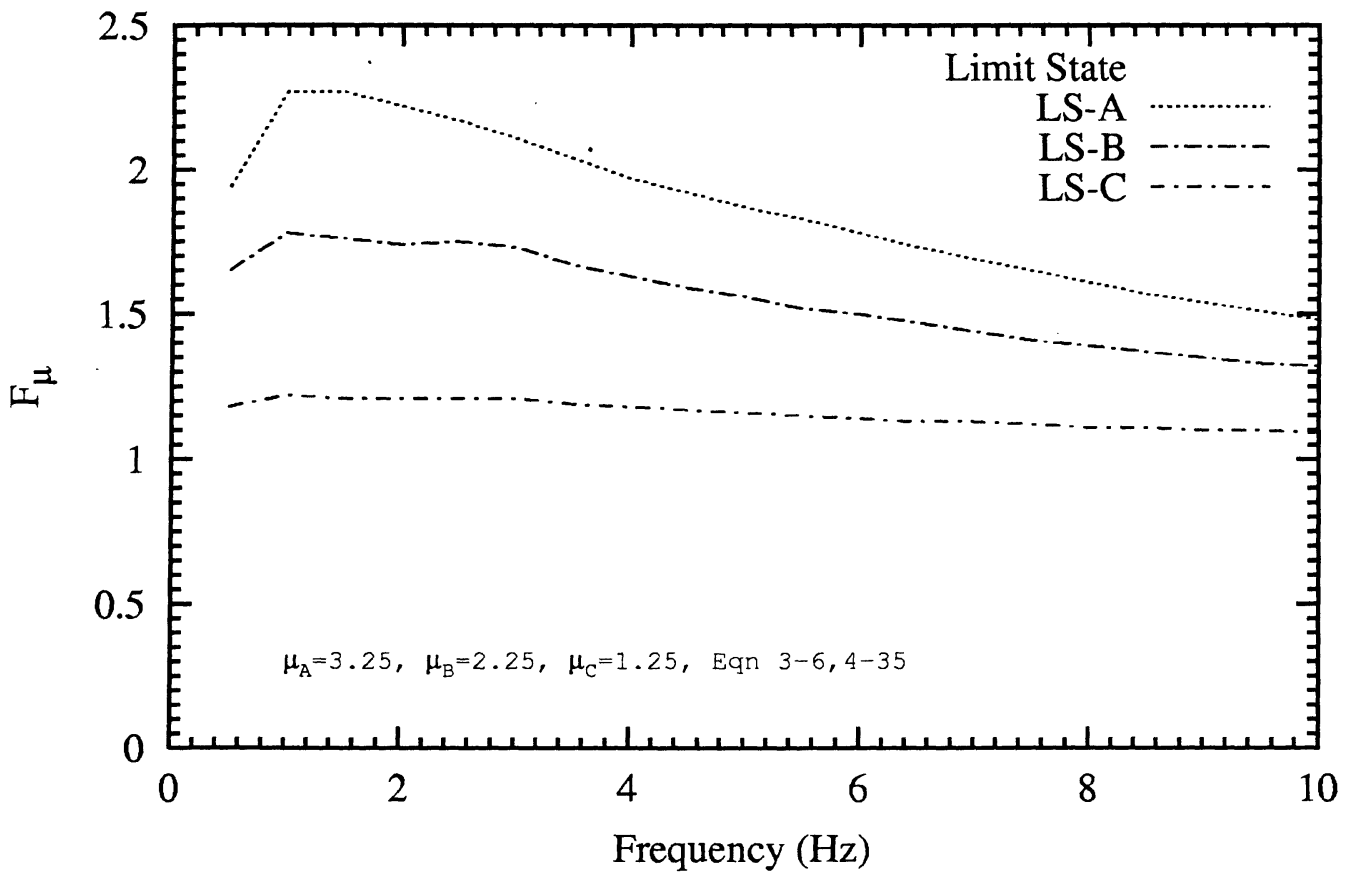

Figure 5.23 R/C OMRF CH Beams with High Shear $(/ / h \leq 10)$ 


\section{Force Reduction Factors for the Structural Design and Evaluation of Facilities Containing Nuclear and Hazardous Materials}

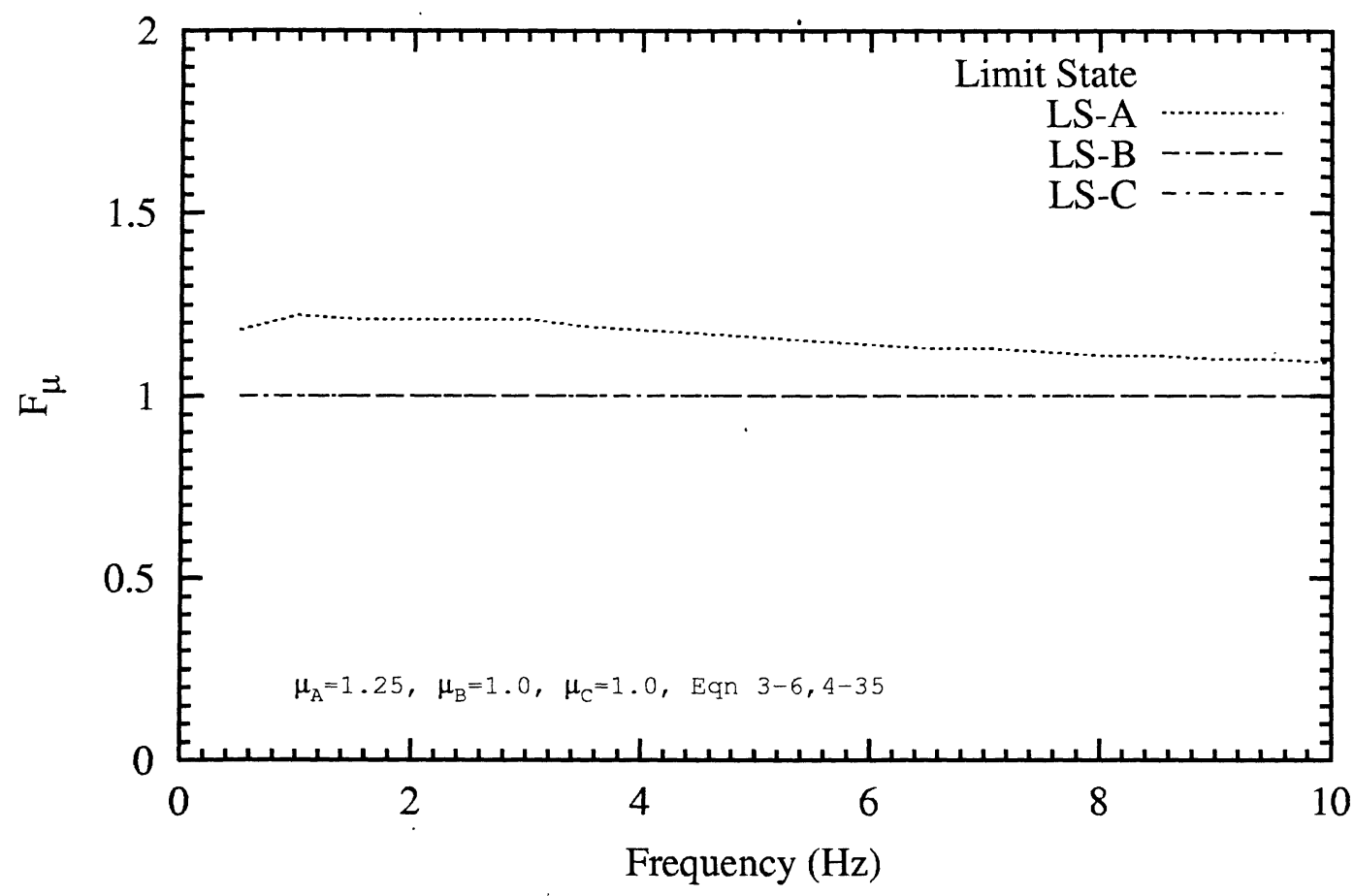

Figure 5.24 R/C OMRF CH Columns

In moment frames with a Weak Story the MDOF force reduction factor, $\mathrm{F} \mu$, is related to the SDOF force reduction factor, F $\mu$ s by a form of Equation 4-31 or

$$
F \mu=F \mu s\left(\frac{\mu_{\text {element }}}{\lambda_{\text {ws }}}\right)
$$

where $\lambda_{\text {WS }}$ is the ratio of $\mu_{\mathrm{MDOF}}$ to $\mu_{\mathrm{SDOF}}$ for a weak story structure, given by Equation 4-36, and the remaining terms are defined in Equation 5-4.

Frequency dependent $\mathrm{F} \mu$ for beams with low shear $(15 \leq \mathrm{\ell} / \mathrm{h})$ are shown in Figure 5.25 while the values for high shear $(\ell / \mathrm{h} \leq 10)$ are shown in Figure 5.26. F $\mu$ for intermediate values of shear may be obtained by interpolation. Frequency dependent $F \mu$ for columns are shown in Figure 5.27.

Note that the only difference between the OMRF Column Hinge and OMRF Weak Story $\mathrm{F} \mu$ in Figures 5-22 to 5-24 and 5-25 to 5-27 is MDOF to SDOF conversion, $\lambda_{\mathrm{CH}}$ versus $\lambda_{\text {ws. }}$ 
Force Reduction Factors for the Structural Design and Evaluation of Facilities Containing Nuclear and Hazardous Materials

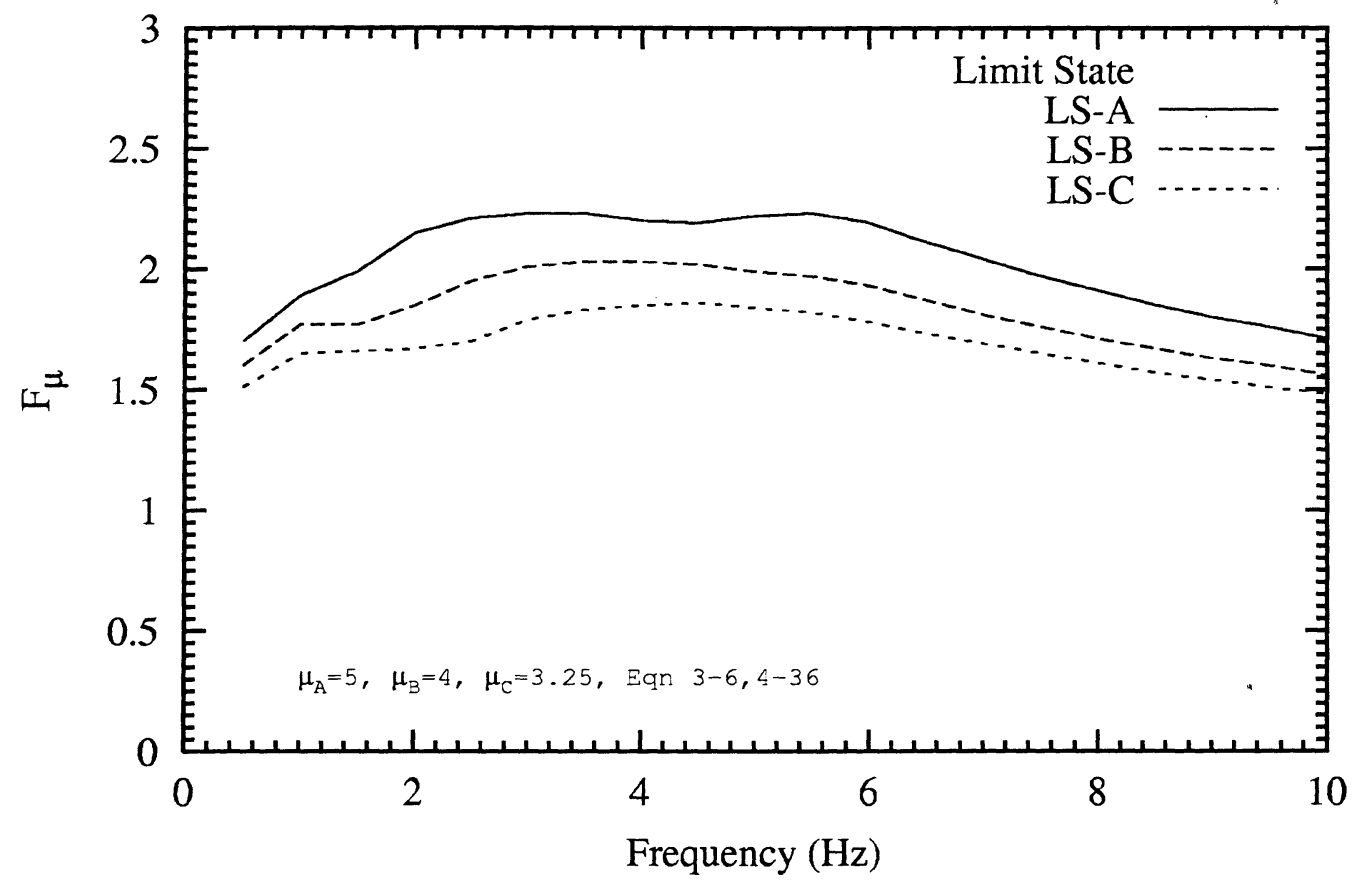

Figure 5.25 R/C OMRF WS Beams with Low Shear $(15 \leq \ell / \mathrm{h})$

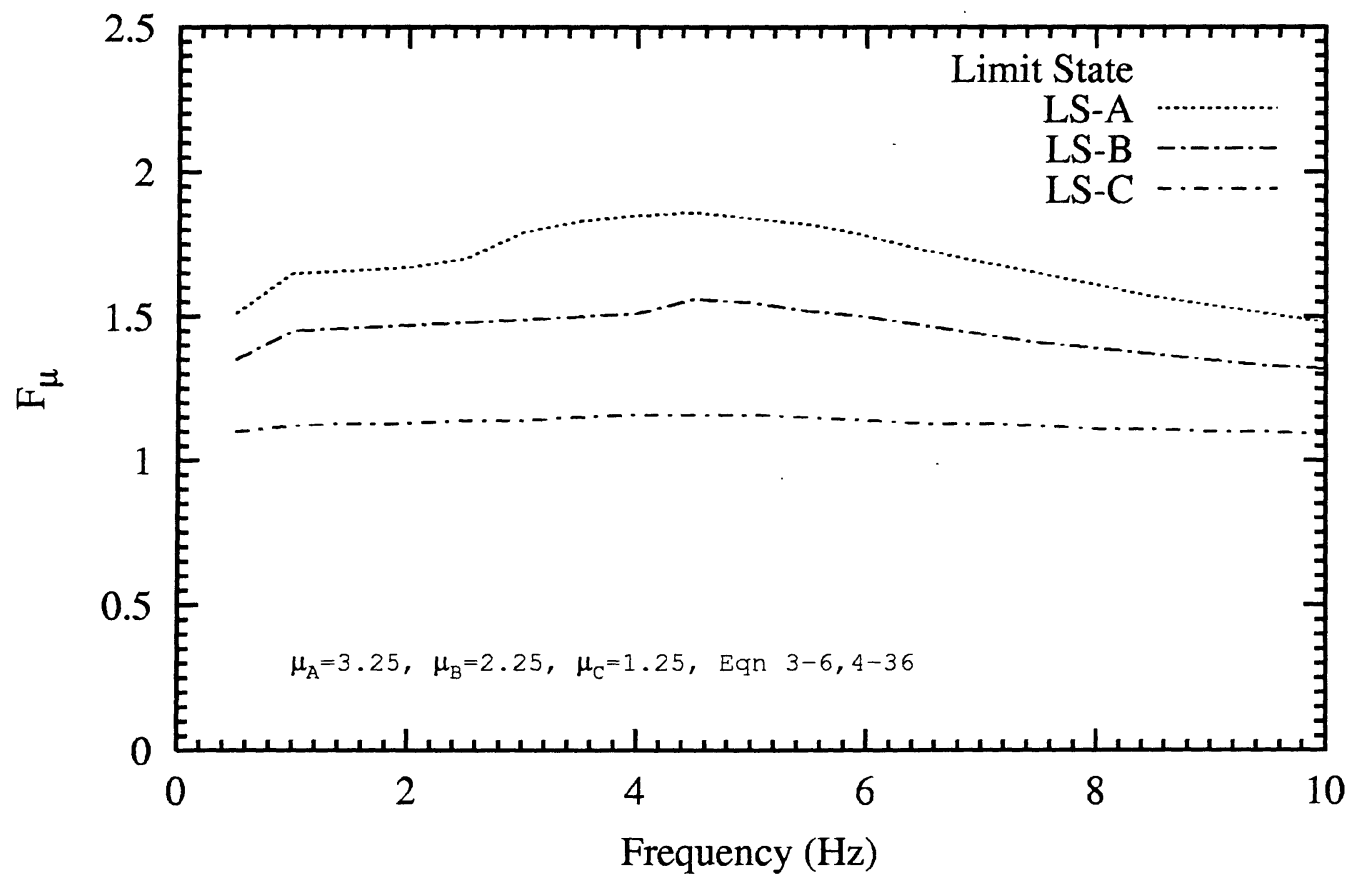

Figure 5.26 R/C OMRF WS Beams with High Shear $(\ell / \mathrm{h} \leq 10)$ 
Force Reduction Factors for the Structural Design and Evaluation of Facilities Containing Nuclear and Hazardous Materials

WSRC-TR-2001-00037

Page 5-25

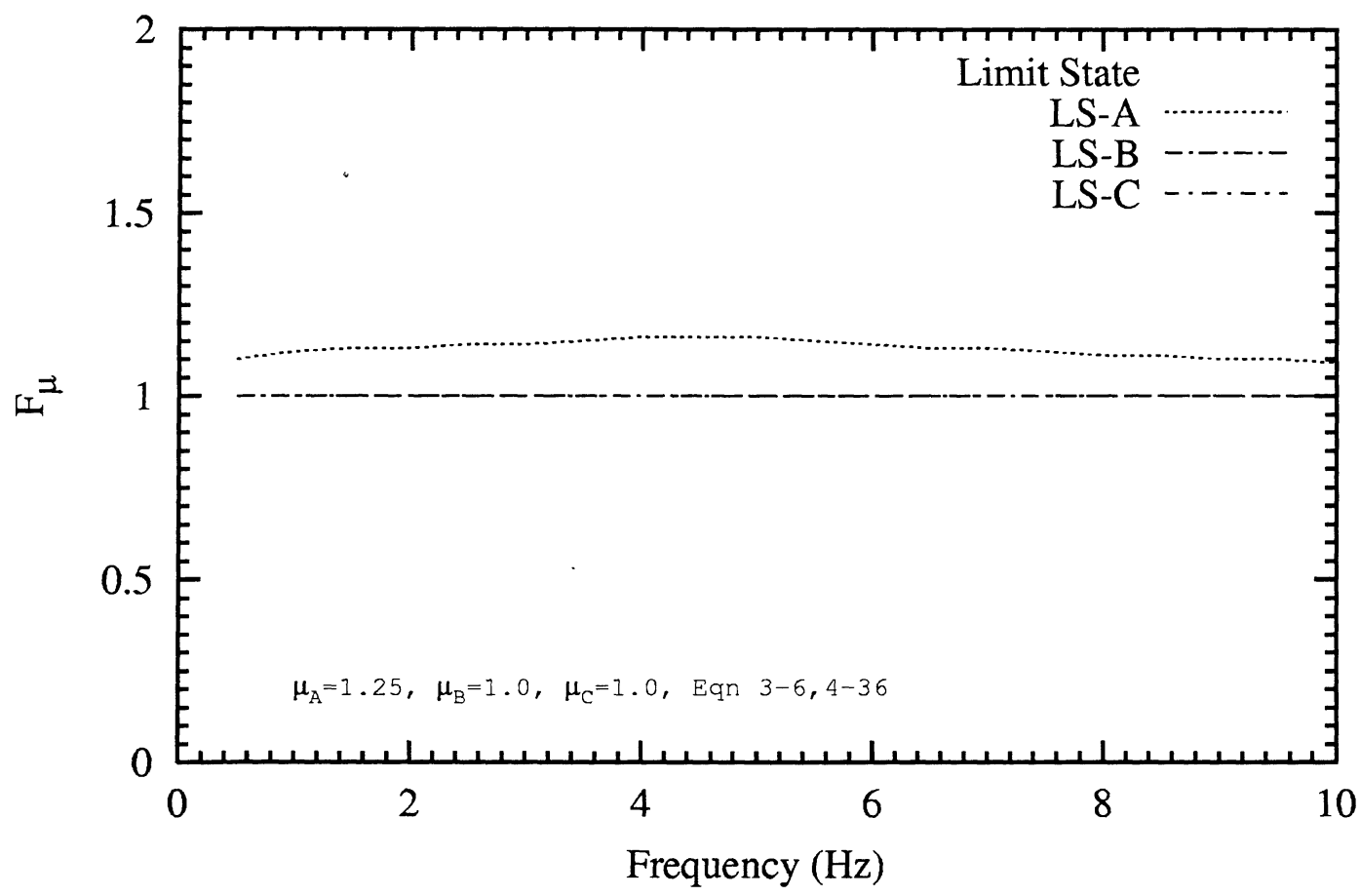

Figure 5.27 R/C OMRF WS Columns

The F $\mu$ in Figures 5.23 through 5.27 can be simplified by assuming that the frequency range for $\mathrm{R} / \mathrm{C}$ IMRF in nuclear facilities is below 3 hertz, yielding the conservative frequency independent $F \mu$ in Table 5.3. Also shown in the table is the F $\mu$ from DOESTD-1020, which are based on a limit state similar to LS-C.

Table 5.3 Simplified F $\mu$ for R/C OMRF

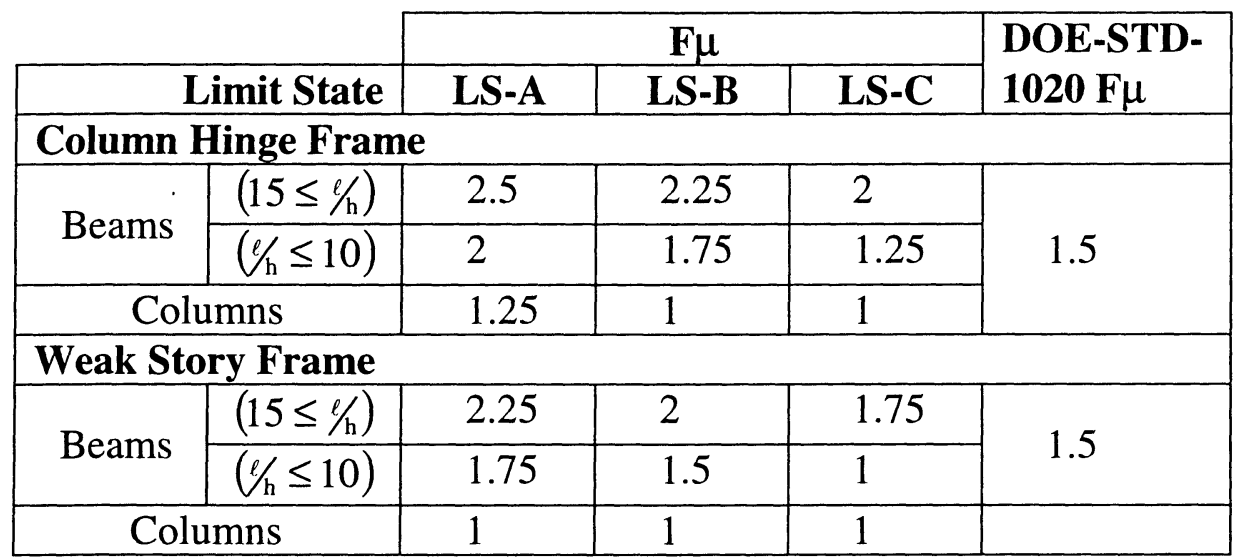

For $10<\frac{1}{\mathrm{~h}}<15$ Interpolate between the short and long beam values. 
Force Reduction Factors for the Structural Design and Evaluation of Facilities Containing Nuclear and Hazardous Materials

\subsubsection{Tall Reinforced Concrete Shear Walls}

The behavior of tall reinforced concrete shear walls is dominated by bending deformation. Chapter 21 of ACI 349-97 observes that walls with a height to width ratio greater than 2 behave as bending dominated shear walls and requires that these walls have boundary elements.

For flexural shear walls the MDOF force reduction factor, F $\mu$, is related to the SDOF force reduction factor, F $\mu$ s by a form of Equation 4-33 or

$$
F \mu=\frac{F \mu s\left(\mu_{\text {element }}\right)}{\kappa_{\text {FSW }}}
$$

where $\mu_{\text {element }}$ is the element ductility for a reinforced concrete flexural shear wall given in Table 2.5 , or

\begin{tabular}{|c|c|c|c|}
\cline { 2 - 4 } \multicolumn{1}{c|}{} & \multicolumn{3}{c|}{ Flexural Shear Wall Ductility, $\mu_{\text {element }}$} \\
\hline Limit State & LS-A & LS-B & LS-C \\
\hline $6 \sqrt{\mathrm{f}^{\prime} \mathrm{c}}<\mathrm{fv}$ & 5 & 4 & 3.25 \\
\hline $\mathrm{fv}<3 \sqrt{\mathrm{f}^{\prime} \mathrm{c}}$ & 6.75 & 5 & 3.25 \\
\hline
\end{tabular}

$\kappa_{\mathrm{FSW}}$ is the ratio of $\mathrm{V}_{\mathrm{MDOF}}$ to $\mathrm{V}_{\mathrm{SDOF}}$ for a flexural shear wall, given by

Equation 4-40, and

$\mathrm{F} \mu \mathrm{s}$ is the force reduction factor for a single degree-of-freedom system, given by

Equation 3-6, with a ductility of $\mu_{\text {element }}$.

Frequency dependent F $\mu$ for both low shear and high shear flexural shear walls is given in Figures 5.28 and 5.29. Interpolation between Figures 5.28 and 5.29 may be used to determine $F \mu$ for intermediate shear values. 
Force Reduction Factors for the Structural Design and Evaluation of Facilities Containing Nuclear and Hazardous Materials

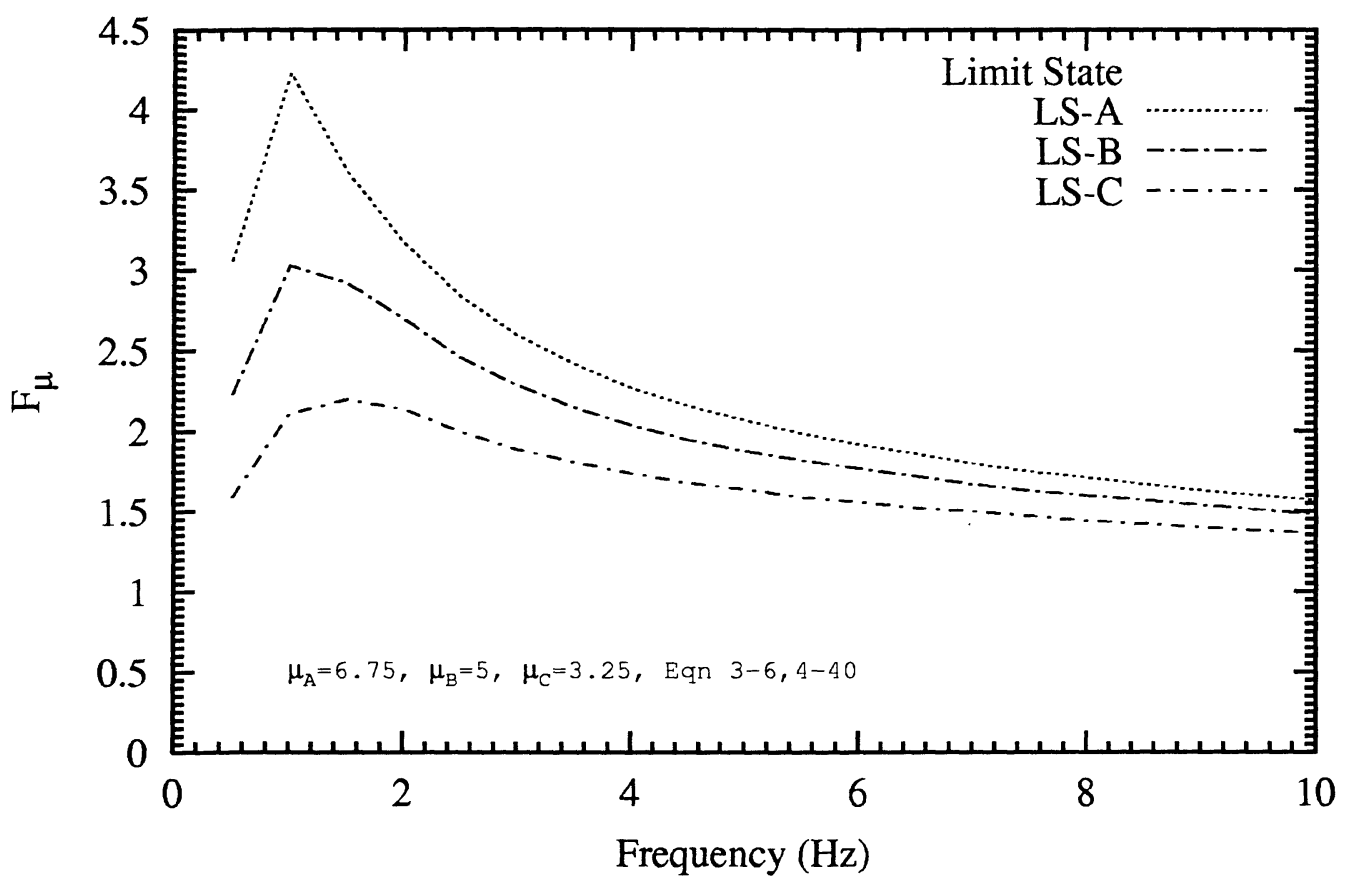

Figure 5.28 R/C Flexural Shear Walls with Low Shear $f v<3 \sqrt{f^{\prime} c}$

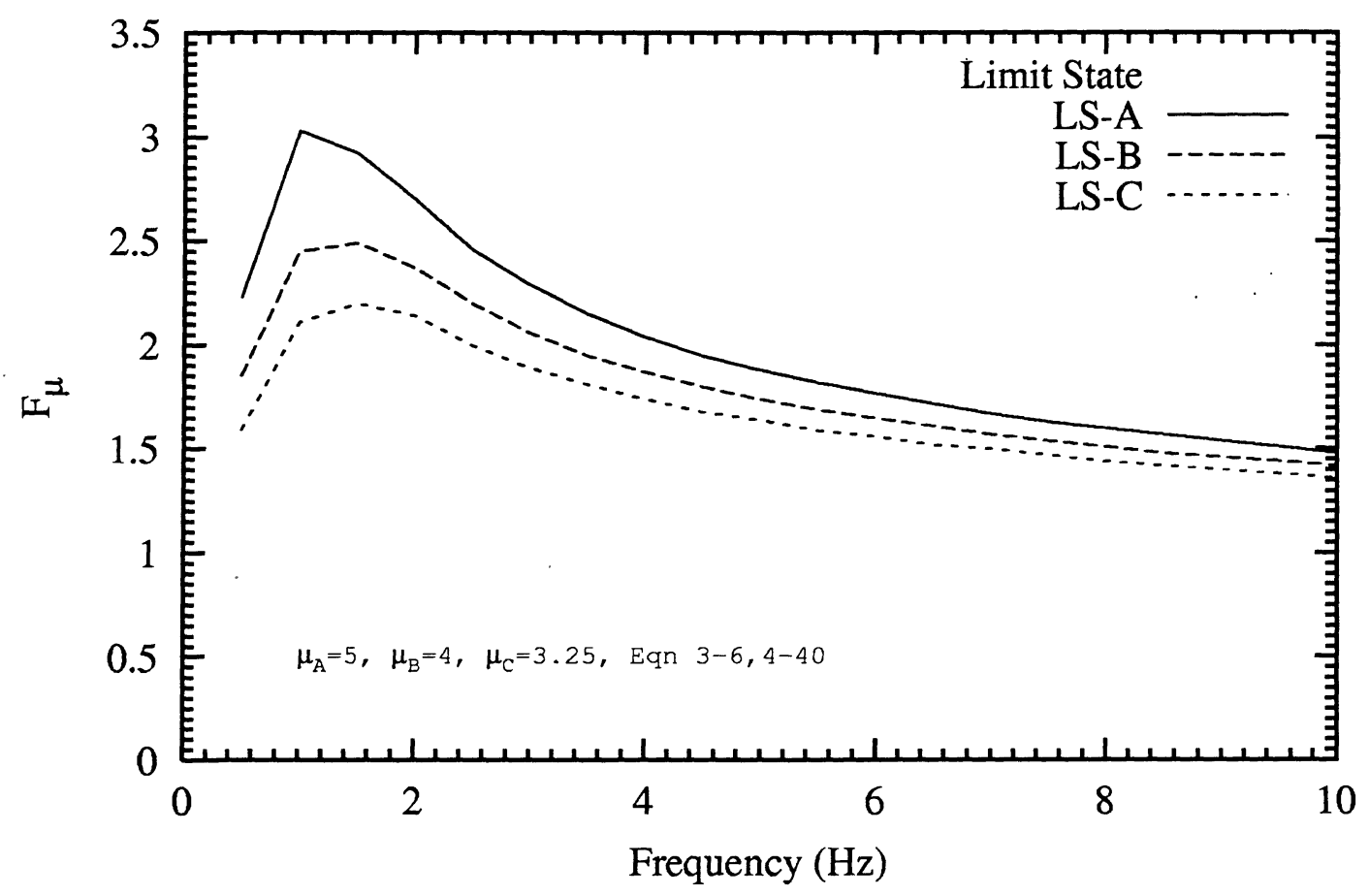

Figure 5.29 R/C OMRF CH Beams with High Shear $6 \sqrt{f^{\prime} \mathrm{c}}<\mathrm{fv}$ 


\section{Force Reduction Factors for the Structural Design and Evaluation of Facilities Containing Nuclear and Hazaràous Materials}

The F $\mu$ in Figures 5.28 and 5.29 can be simplified by assuming that the frequency range for R/C IMRF in nuclear facilities is below 3 hertz, yielding the conservative frequency independent $F \mu$ in Table 5.4. Also shown in the table are the F $\mu$ from DOE-STD-1020 which are based on a limit state similar to LS-C.

Table 5.4 Simplified F $\mu$ for R/C Flexural Shear Walls

\begin{tabular}{|c|c|c|c|c|}
\cline { 2 - 4 } \multicolumn{1}{c|}{} & \multicolumn{3}{c|}{ F $\mu$} & DOE-STD- \\
\hline Limit State & LS-A & LS-B & LS-C & 1020 F $\mu$ \\
\hline $6 \sqrt{f^{\prime} c}<f v$ & 2.25 & 2.0 & 1.75 & \multirow{2}{*}{1.75} \\
\hline$f v<3 \sqrt{f^{\prime} c}$ & 2.5 & 2.25 & 1.75 & \\
\hline
\end{tabular}

For $3 \sqrt{f^{\prime} c}<f v<6 \sqrt{f^{\prime} c}$, interpolate between the low and high shear cases.

\subsubsection{Short Reinforced Concrete Shear Walls}

The behavior of short reinforced concrete shear walls, with a height to width ratio of two or less, are dominated by shear deformation. The first mode of a shear controlled wall is typically above 3 to 5 hertz and the higher modes are seldom important in the seismic response. Thus, the MDOF force reduction factor, $\mathrm{F} \mu$, is related to the SDOF force reduction factor, $F \mu$ s, by a form of Equation 4-31 or

$\mathrm{F} \mu=\mathrm{F} \mu \mathrm{s}\left(\frac{\mu_{\text {element }}}{\lambda}\right)$

where $\mu_{\text {element }}$ is the element ductility for members in a reinforced concrete OMRF given in Table 2.3 , or

\begin{tabular}{|c|c|c|c|}
\cline { 2 - 4 } \multicolumn{1}{c|}{} & \multicolumn{3}{|c|}{ Element Ductility, $\mu_{\text {element }}$} \\
\hline Limit State & LS-A & LS-B & LS-C \\
\hline & 5 & 4 & 3.25 \\
\hline
\end{tabular}

$\lambda=1$, is the ratio of $\mu_{\mathrm{MDOF}}$ to $\mu_{\mathrm{SDOF}}$ for a shear controlled wall, and $\mathrm{F} \mu \mathrm{s}$ is the force reduction factor for a single degree-of-freedom system with a pinched hysteresis loop, given by Equation 3-3, with a ductility of $\mu_{\text {element }} / \lambda$.

Recall that F $\mu$ s for pinched hysteresis loops given by Equation 3-3 is frequency independent in the constant acceleration range and is shown in Figure 3.10. Thus, F $\mu$ for shear controlled shear walls are also frequency independent as shown in Table 5.5. Note that the current values of $F \mu$ for shear controlled shear walls are compatible with the DOE-STD-1020 F $\mu$. 
Force Reduction Factors for the Structural Design and Evaluation of Facilities

Table 5.5 F $\mu$ for R/C Shear Controlled Shear Walls

\begin{tabular}{|c|c|c|c|c|}
\cline { 2 - 4 } \multicolumn{1}{c|}{} & \multicolumn{3}{|c|}{ Element Ductility, $\mu_{\text {element }}$} & DOE-STD- \\
Limit State & LS-A & LS-B & LS-C & F $\mu$ \\
\hline & 2 & 1.75 & 1.5 & 1.5 \\
\hline
\end{tabular}

\subsubsection{Steel Special Moment Resisting Frames (Steel-SMRF)}

The AISC Seismic Provisions for Structural Steel Buildings force Beam Hinges (BH) in SMRF's by proportioning the sum of column strengths to be greater than the sum of beam strengths. In moment frames with beam hinges the MDOF force reduction factor, $F \mu$, is related to the SDOF force reduction factor, $F \mu$ s by a form of Equation 4-31 or

$F \mu=F \mu s\left(\frac{\mu_{\text {element }}}{\lambda_{\text {BH }}}\right)$

where $\mu_{\text {element }}$ is the element ductility for members in a steel SMRF given in Table 2.8 , or

\begin{tabular}{|r|c|c|c|}
\cline { 2 - 4 } \multicolumn{1}{c|}{ Limit State } & \multicolumn{3}{c|}{ Element Ductility, $\mu_{\text {element }}$} \\
\hline Beams, & LS-B & LS-C \\
\hline Columns $\mathrm{P}<0.2 \mathrm{Py}$ & 10 & 5.5 & 3.25 \\
\hline Columns $0.2 \mathrm{Py}<\mathrm{P}<0.5 \mathrm{Py}$ & $15\left(1-1.7^{\mathrm{P}} / \mathrm{Py}\right)$ & $8.1-12.7^{\mathrm{P}} / \mathrm{Py}$ & 1.25 \\
\cline { 2 - 4 } $\mathrm{P}=0.2 \mathrm{Py}$ & 10 & 5.5 & 1.25 \\
\cline { 2 - 4 } $\mathrm{P}=0.3 \mathrm{Py}$ & 7.25 & 4.25 & 1.25 \\
\cline { 2 - 4 } $\mathrm{P}=0.4 \mathrm{Py}$ & 4.8 & 3.0 & 1.25 \\
$\mathrm{P}=0.5 \mathrm{Py}$ & 2.25 & 1.75 & 1.25 \\
\cline { 2 - 4 }
\end{tabular}

$\lambda_{\mathrm{BH}}$ is the ratio of $\mu_{\mathrm{MDOF}}$ to $\mu_{\mathrm{SDOF}}$ for a beam hinge structure, given by Equation 4-34, and

$\mathrm{F} \mu \mathrm{s}$ is the force reduction factor for a single degree-of-freedom system, given by Equation 3-6, with a ductility of $\mu_{\text {element }} / \lambda_{\mathrm{BH}}$.

Column hinges in a SMRF will form at the base of the first floor columns. However, these hinges are not sufficient to concentrate the structure's ductility into a single story and the beam hinge mechanism is valid to describe the structure's overall behavior.

Frequency dependent $\mathrm{F} \mu$ for beams and columns with $\mathrm{P} \leq 0.2 \mathrm{Py}$ are shown in Figure 5.30. $\mathrm{F} \mu$ for columns with $\mathrm{P}=0.3 \mathrm{Py}, 0.4 \mathrm{Py}$ and $0.5 \mathrm{Py}$ are shown in Figure 5.31 to 5.33.

The $\mathrm{F} \mu$ in this figure can be simplified by assuming that the frequency range for steel SMRF in nuclear facilities is below 3 hertz, yielding the conservative frequency independent $\mathrm{F} \mu$ in Table 5.6. Note that column F $\mu$ were developed at several different 
Force Reduction Factors for the Structural Design and Evaluation of Facilities Containing Nuclear and Hazardous Materials

axial load ratio's and the F $\mu$ relationships in Table 5.6 are developed by fitting the calculated F $\mu$. Also shown in the table are the F $\mu$ from DOE-STD-1020 which are based on a limit state similar to LS-C.

Table 5.6 Simplified F $\mu$ for Steel SMRF

\begin{tabular}{|c|c|c|c|c|}
\hline & \multicolumn{3}{|c|}{$\mathbf{F} \mu$} & \multirow{2}{*}{$\begin{array}{c}\text { DOE-STD- } \\
1020 \mathrm{~F} \mu\end{array}$} \\
\hline Limit State & LS-A & LS-B & LS-C & \\
\hline $\begin{array}{c}\text { Beams, } \\
\text { Columns } \mathrm{P}<0.2 \mathrm{Py}\end{array}$ & 5.25 & 3.5 & 2.5 & $r$ \\
\hline Columns $\mathrm{P}=0.3 \mathrm{Py}$ & 4.25 & 3.0 & 1.25 & \multirow{3}{*}{1.5} \\
\hline Columns $\mathrm{P}=0.4 \mathrm{Py}$ & 3.25 & 2.25 & 1.25 & \\
\hline Columns $\mathrm{P}=0.5 \mathrm{Py}$ & 1.75 & 1.5 & 1.25 & \\
\hline Columns 0.2 $\mathrm{Py}<\mathrm{P}<0.5 \mathrm{Py}$ & $7.65-11.5 \frac{\mathrm{P}}{\mathrm{Py}}$ & $4.92-7.65 \frac{\mathrm{P}}{\mathrm{Py}}$ & 1.25 & \\
\hline
\end{tabular}

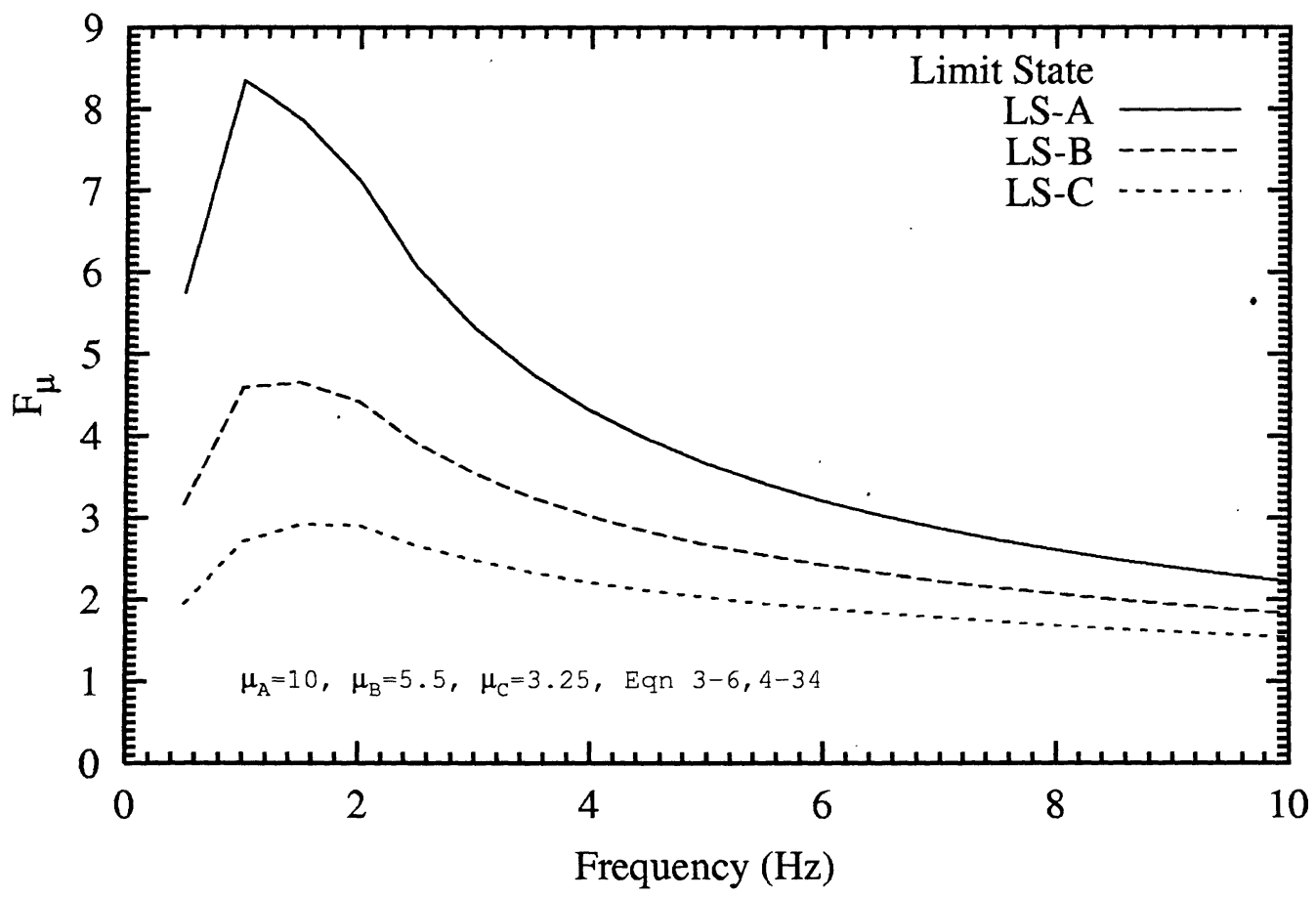

Figure 5.30 Steel SMRF Beams and Columns with $\mathrm{P}<20 \% \mathrm{Py}$ 
Force Reduction Factors for the Structural Design and Evaluation of Facilities Containing Nuclear and Hazardous Materials

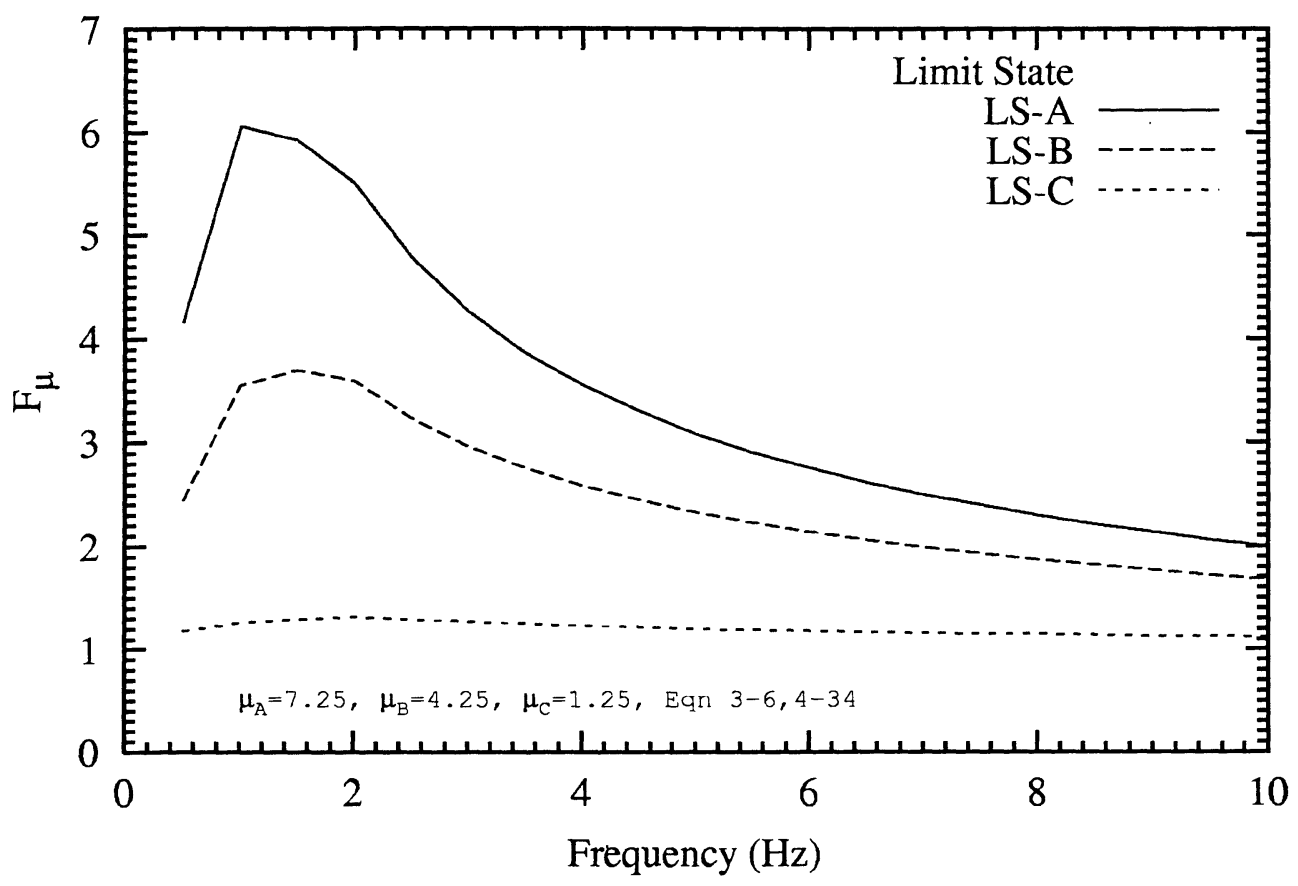

Figure 5.31 Steel SMRF Columns with $P=30 \% P y$

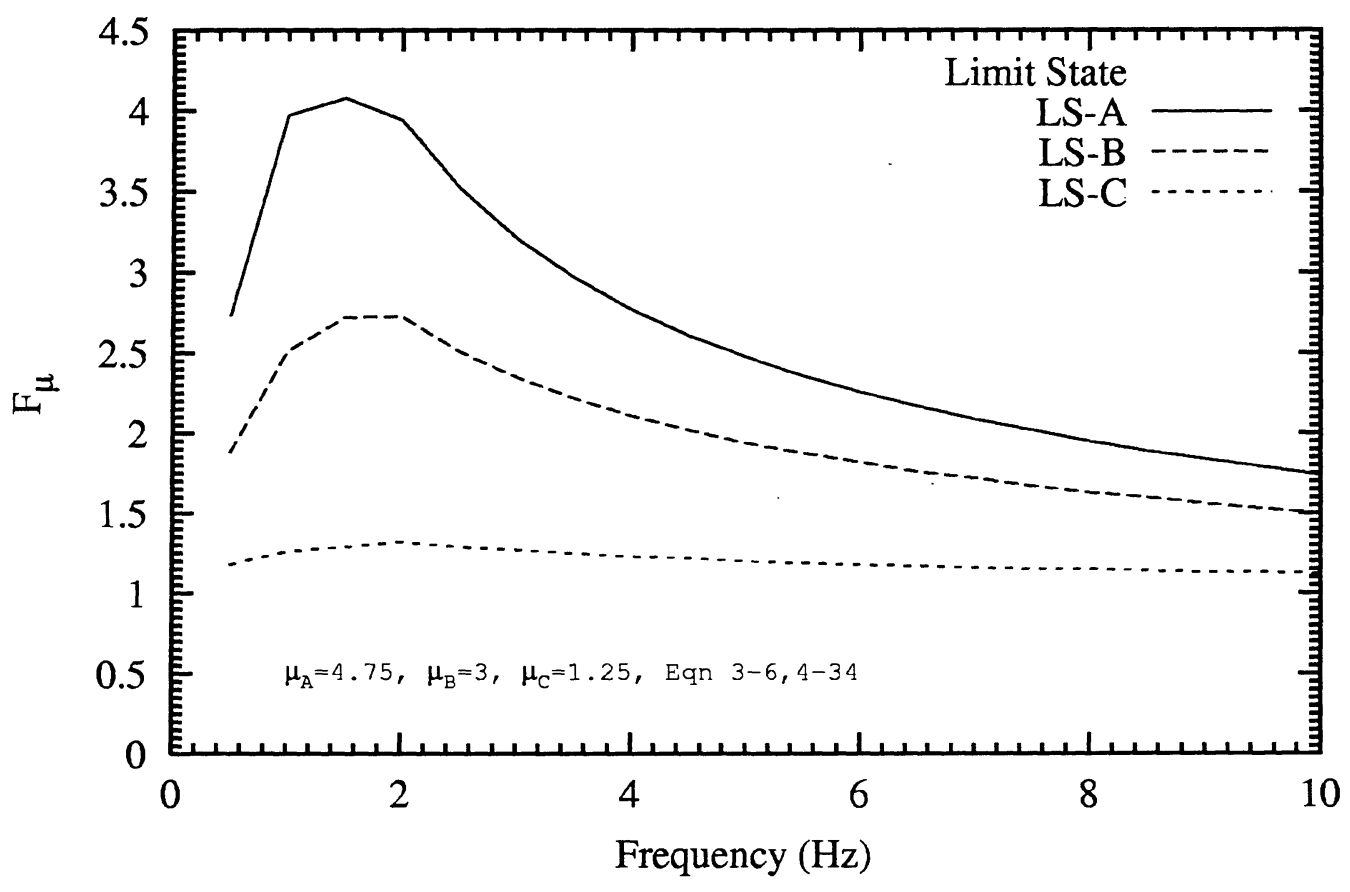

Figure 5.32 Steel SMRF Columns with $P=40 \% P y$ 
Force Reduction Factors for the Structural Design and Evaluation of Facilities Containing Nuclear and Hazardous Materials

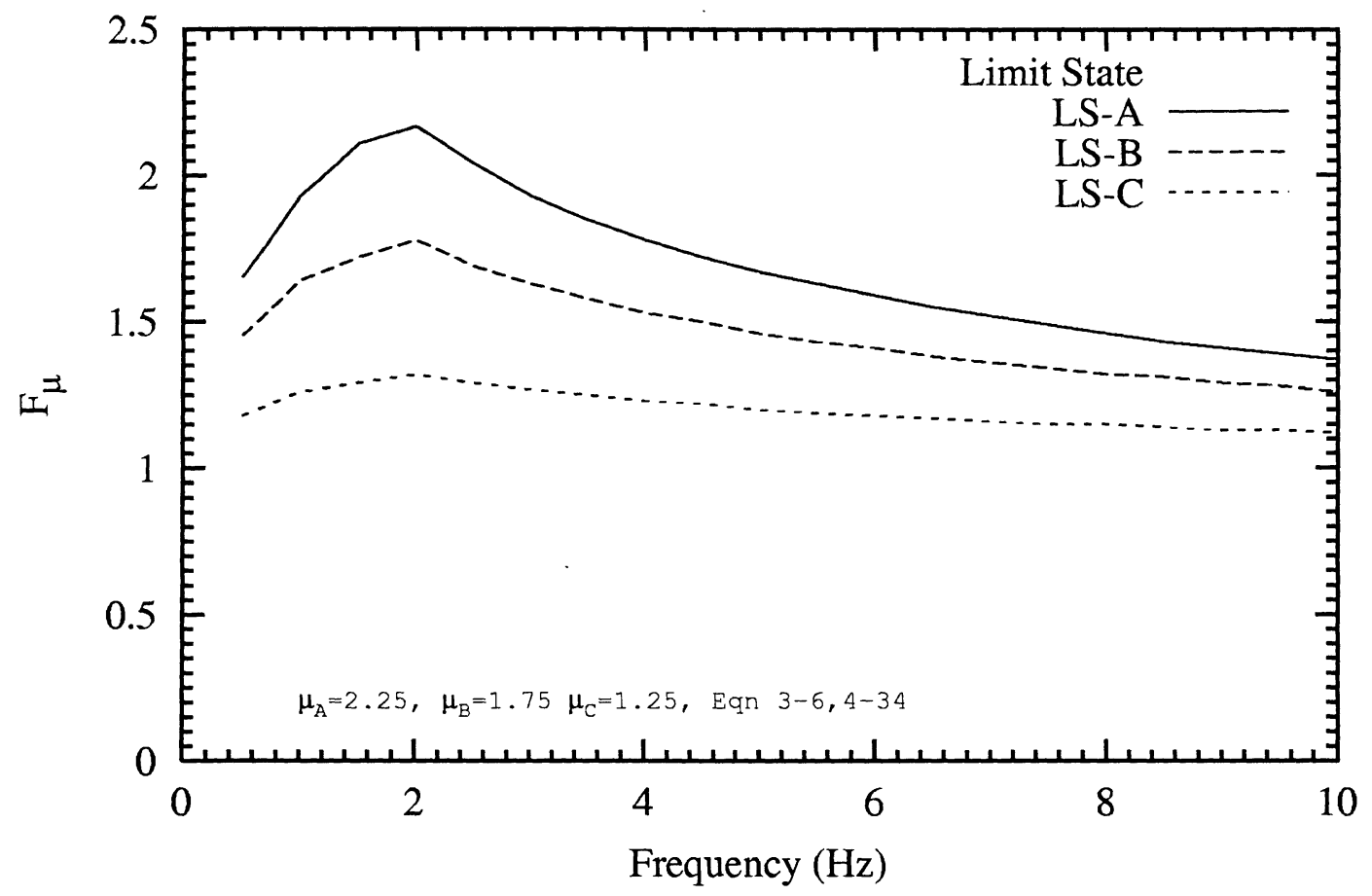

Figure 5.33 Steel SMRF Columns with $\mathbf{P}=50 \%$ Py

\subsubsection{Steel Intermediate Moment Resisting Frames (Steel-IMRF)}

The AISC Seismic Provisions for Structural Steel Buildings forces Beam Hinges (BH) in IMRF's by proportioning the sum of column strengths to be greater than the sum of beam strengths. In moment frames with beam hinges, the MDOF force reduction factor, $\mathrm{F} \mu$, is related to the SDOF force reduction factor, F $\mu$ s by a form of Equation 4-31 or

$$
F \mu=F \mu s\left(\frac{\mu_{\text {element }}}{\lambda_{\mathrm{BH}}}\right)
$$

where $\mu_{\text {element }}$ is the element ductility for members in a steel IMRF given in Table 2.8 , or 
Force Reduction Factors for the Structural Design and Evaluation of Facilities Containing Nuclear and Hazardous Materials

WSRC-TR-2001-00037

Page 5-33

\begin{tabular}{|r|c|c|c|}
\cline { 2 - 4 } \multicolumn{1}{c|}{} & \multicolumn{3}{c|}{ Element Ductility, $\mu_{\text {element }}$} \\
\hline Limit State & LS-A & LS-B & LS-C \\
\hline Beams, & 6.75 & 5 & 3.25 \\
\hline Columns $\mathrm{P}<0.2 \mathrm{Py}$ & & & 1.25 \\
\hline Columns $0.2 \mathrm{Py}<\mathrm{P}<0.5 \mathrm{Py}$ & $10\left(1-1.7^{\mathrm{P}} / \mathrm{Py}\right)$ & $5.6-8.5^{\mathrm{P}} / \mathrm{Py}$ & 1.25 \\
\cline { 2 - 4 } $\mathrm{P}=0.4 \mathrm{Py}$ & 4.9 & 3 & 1.25 \\
\cline { 2 - 4 } $\mathrm{P}=0.5 \mathrm{Py}$ & 3.2 & 2.2 & 1.25 \\
\cline { 2 - 4 } & 1.5 & 1.35 & \\
\end{tabular}

$\lambda_{\mathrm{BH}}$ is the ratio of $\mu_{\mathrm{MDOF}}$ to $\mu_{\mathrm{SDOF}}$ for a beam hinge structure, given by Equation 4-34, and

F $\mu$ s is the force reduction factor for a single degree-of-freedom system, given by

Equation 3-6, with a ductility of $\mu_{\text {element }} / \lambda_{\mathrm{BH}}$.

Column hinges in a IMRF will form at the base of the first floor columns. However, these hinges are not sufficient to concentrate the structure's ductility into a single story and the beam hinge mechanism is valid to describe the structures behavior.

Frequency dependent $F \mu$ for beams and columns with $\mathrm{P} \leq 0.2 \mathrm{Py}$ are shown in Figure 5.34. Fu for columns with $\mathrm{P}=0.3 \mathrm{Py}, 0.4 \mathrm{Py}$ and $0.5 \mathrm{Py}$ are given in Figure 5.35, 5.36 and 5.37.

The $F \mu$ in these figures can be simplified by assuming that the frequency range for steel SMRF in nuclear facilities is below 3 hertz, yielding the conservative frequency independent $F \mu$ in Table 5.7. Note that column F $\mu$ were developed at several different axial load ratio's and the F $\mu$ relationships in Table 5.7 are developed by fitting the calculated F $\mu$. Also shown in the table is the F $\mu$ from DOE-STD-1020, which are based on a limit state similar to LS-C.

Table 5.7 Simplified F $\mu$ for Steel IMRF

\begin{tabular}{|c|c|c|c|c|}
\cline { 2 - 4 } \multicolumn{1}{c|}{ Limit State } & LS-A & LS-B & LS-C & $\begin{array}{l}\text { DOE- } \\
\text { STD- } \\
\text { 1020 F } \mu\end{array}$ \\
\hline $\begin{array}{c}\text { Beams, } \\
\text { Columns P<0.2 Py }\end{array}$ & 4 & 3.25 & 2.5 & 3.0 \\
\hline Columns P=0.3 Py & 3.25 & 2.25 & 1.25 & \multirow{2}{*}{1.5} \\
\hline Columns P=0.4 Py & 2.5 & 2.0 & 1.25 \\
\hline Columns P=0.5 Py & 1.5 & 1.25 & 1.25 & \\
\hline Columns 0.2 Py < P $<0.5 \mathrm{Py}$ & $5.7-8.25 \frac{\mathrm{P}}{\mathrm{Py}}$ & $4.4-6.25 \frac{\mathrm{P}}{\mathrm{Py}}$ & 1.25 & \\
\cline { 1 - 4 } & & &
\end{tabular}




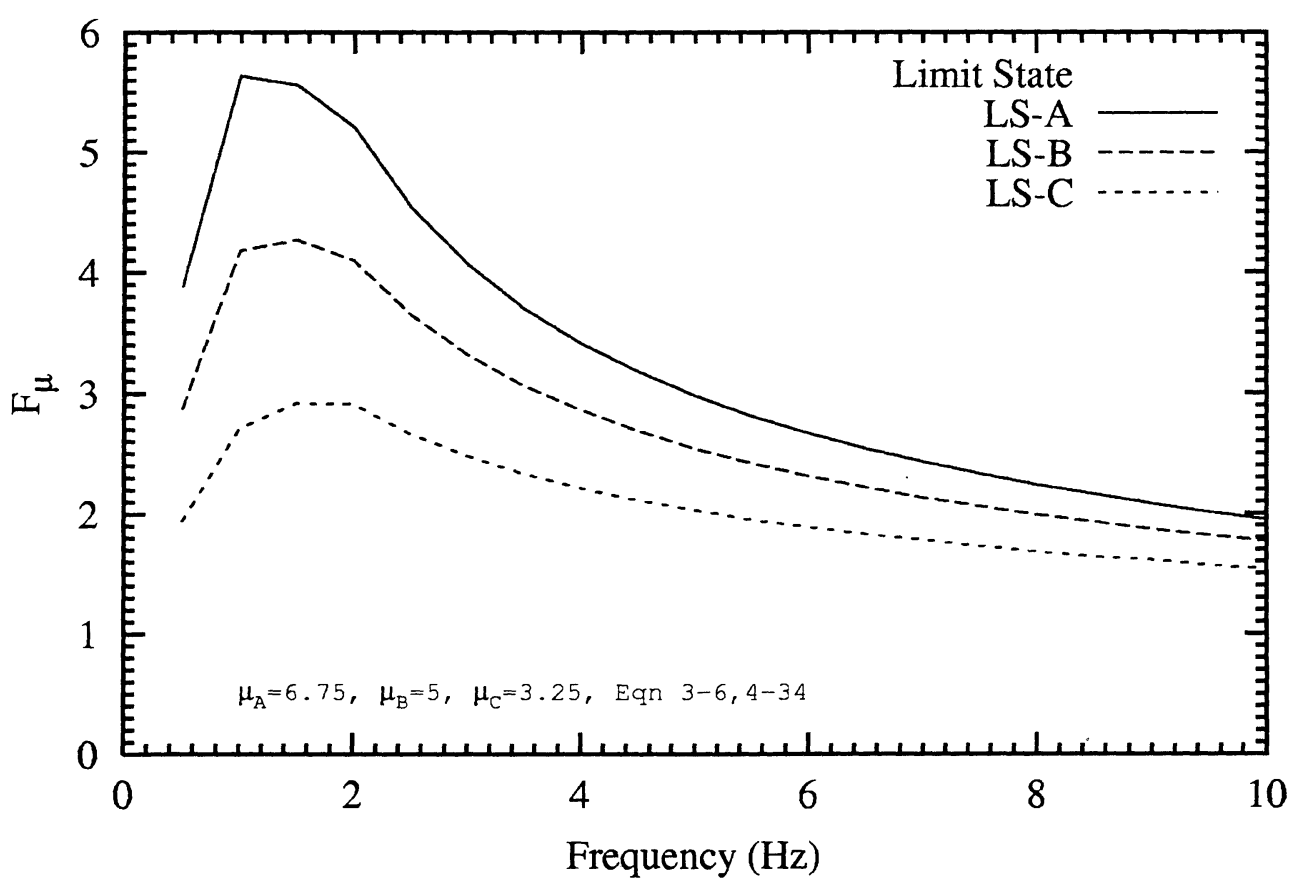

Figure 5.34 Steel IMRF Beams and Columns with $\mathrm{P}<20 \% \mathrm{Py}$

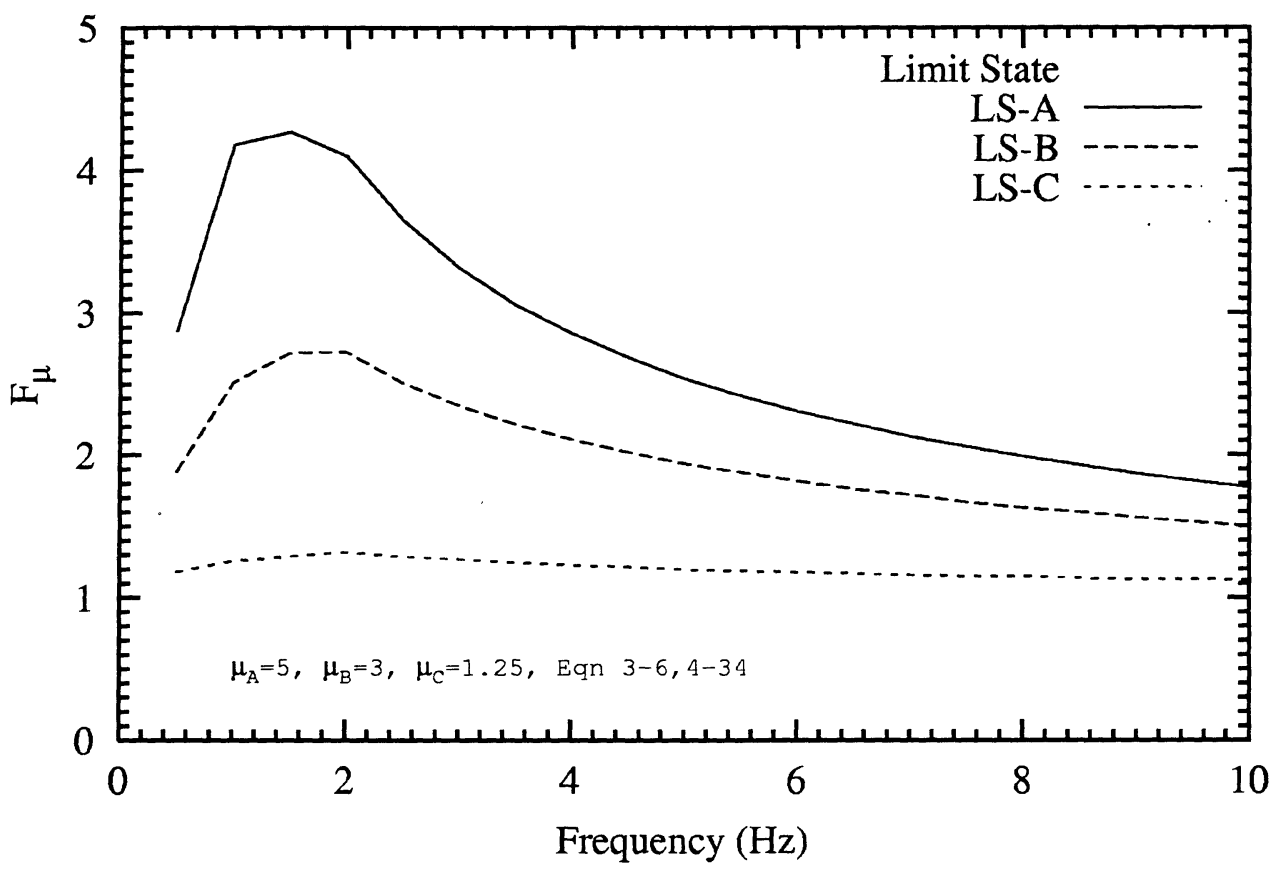

Figure 5.35 Steel IMRF Columns with $P=30 \% P y$ 
Force Reduction Factors for the Structural Design and Evaluation of Facilities Containing Nuclear and Hazardous Materials

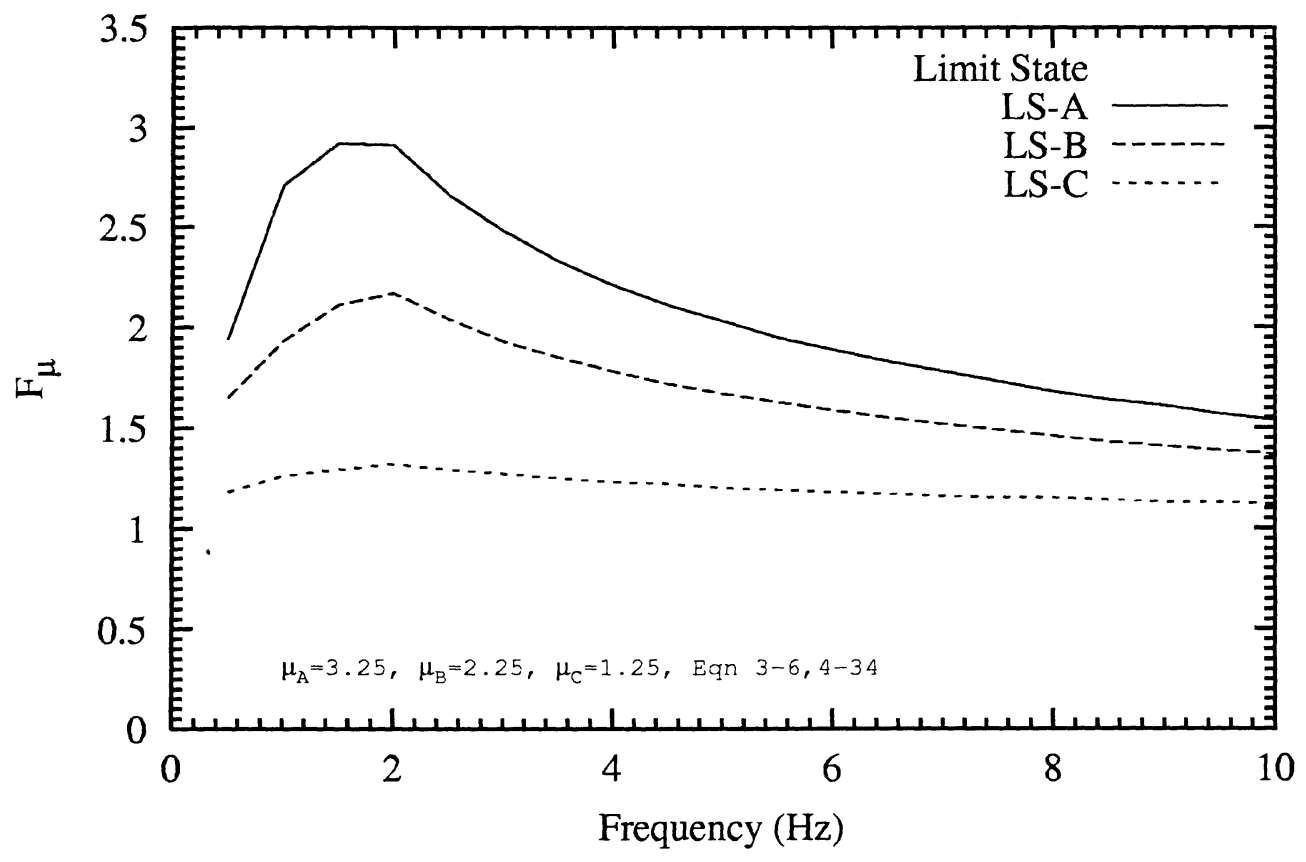

Figure 5.36 Steel IMRF Columns with $P=40 \% P y$

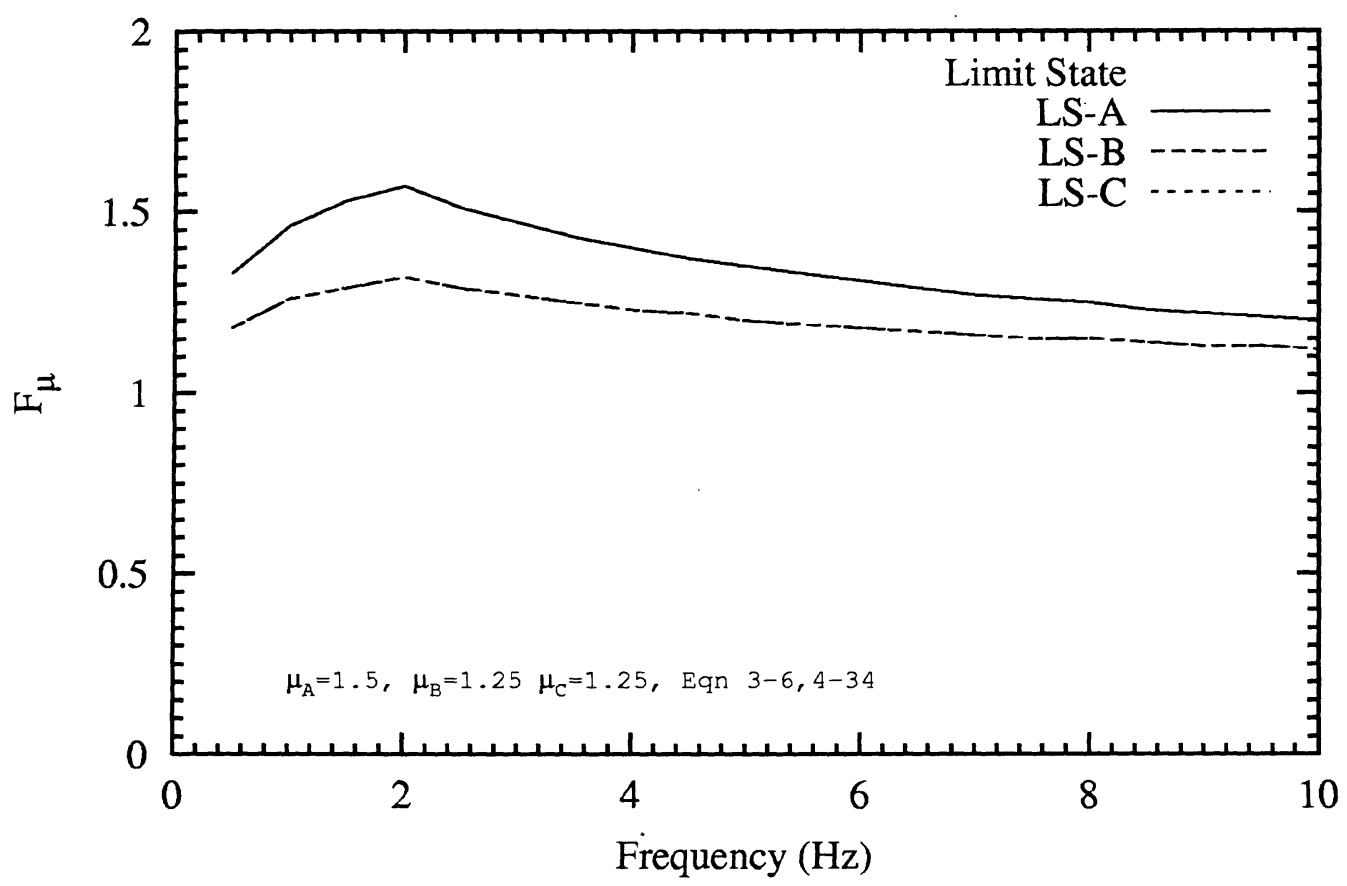

Figure 5.37 Steel IMRF Columns with $P=50 \% P y$ 


\section{Force Reduction Factors for the Structural Design and Evaluation of Facilities} Containing Nuclear and Hazardous Materials

\subsubsection{Steel Ordinary Moment Resisting Frames (Steel-OMRF)}

The AISC Seismic Provisions for Structural Steel Buildings for OMRF's do not contain provisions that force beam hinges. Thus, either Column Hinges $(\mathrm{CH})$ or a Weak Story (WS) are conservatively postulated for OMRF. If a particular OMRF were proportioned such that the sum of column strengths is greater than the sum of beam strengths, then use of the beam hinge MDOF reduction factor, $\lambda_{\mathrm{BH}}$, would be justified.

In moment frames with column hinges the MDOF force reduction factor, $F \mu$, is related to the SDOF force reduction factor, F $\mu$ s by a form of Equation 4-31 or

$$
F \mu=F \mu s\left(\frac{\mu_{\text {element }}}{\lambda_{\mathrm{CH}}}\right)
$$

where $\mu_{\text {element }}$ is the element ductility for members in a steel OMRF given in Table 2.8, or

\begin{tabular}{|c|c|c|c|}
\cline { 2 - 4 } \multicolumn{1}{c|}{} & \multicolumn{3}{c|}{ Element Ductility, $\mu_{\text {element }}$} \\
\hline Limit State & LS-A & LS-B & LS-C \\
\hline $\begin{array}{c}\text { Beams, } \\
\text { Columns P<0.2 Py }\end{array}$ & 3.25 & 2.25 & 1.25 \\
\hline Columns 0.2 Py $<$ P $<0.5$ Py & 1.25 & 1.25 & 1.25 \\
\hline
\end{tabular}

$\lambda_{\mathrm{CH}}$ is the ratio of $\mu_{\mathrm{MDOF}}$ to $\mu_{\mathrm{SDOF}}$ for a column hinge structure, given by Equation 4-35, and

$F \mu s$ is the force reduction factor for a single degree-of-freedom system, given by

Equation 3-6, with a ductility of $\mu_{\text {element }} / \lambda_{\mathrm{BH}}$.

In moment frames with a weak story the MDOF force reduction factor, $F \mu$, is related to the SDOF force reduction factor, F $\mu$ s by a form of Equation 4-31 or

$F \mu=F \mu s\left(\frac{\mu_{\text {element }}}{\lambda_{\text {ws }}}\right)$

where $\lambda_{\mathrm{WS}}$ is the ratio of $\mu_{\mathrm{MDOF}}$ to $\mu_{\mathrm{SDOF}}$ for a weak story structure, given by Equation 4-36, and the remaining terms are as given in Equation 5-10.

Frequency dependent $\mathrm{F} \mu$ for beams and columns in frames with column hinges are shown in Figure 5.38 and 5.39. Similar $\mathrm{F} \mu$ for frames with weak story mechanisms are shown in Figure 5.40 and 5.41. 
Force Reduction Factors for the Structural Design and Evaluation of Facilities Containing Nuclear and Hazardous Materials

WSRC-TR-2001-00037

Page 5-37

The $F \mu$ in this figure can be simplified by assuming that the frequency range for steel SMRF in nuclear facilities is below 3 hertz, yielding the conservative frequency independent $F \mu$ in Table 5.8. Also shown in the table are the F $\mu$ from DOE-STD-1020 which are based on a limit state similar to LS-C. .

Table 5.8 Simplified F $\mu$ for Steel OMRF

\begin{tabular}{|c|c|c|c|c|}
\hline & \multicolumn{3}{|c|}{$\mathbf{F} \mu$} & \multirow{2}{*}{$\begin{array}{l}\text { DOE-STD- } \\
1020 \mathrm{~F} \mu\end{array}$} \\
\hline Limit State & LS-A & LS-B & LS-C & \\
\hline \multicolumn{5}{|l|}{ Column Hinge } \\
\hline $\begin{array}{c}\text { Beams, } \\
\text { Columns } \mathrm{P}<0.2 \mathrm{Py}\end{array}$ & 2 & 1.75 & 1.25 & \multirow[t]{2}{*}{1.5} \\
\hline Columns $0.2 \mathrm{Py}<\mathrm{P}<0.5 \mathrm{Py}$ & 1.25 & 1.25 & 1.25 & \\
\hline \multicolumn{5}{|l|}{ Weak Story } \\
\hline $\begin{array}{c}\text { Beams, } \\
\text { Columns } \mathrm{P}<0.2 \mathrm{Py}\end{array}$ & 1.5 & 1.5 & 1 & \multirow[t]{2}{*}{1.5} \\
\hline Columns $0.2 \mathrm{Py}<\mathrm{P}<0.5 \mathrm{Py}$ & 1.25 & 1 & 1 & \\
\hline
\end{tabular}

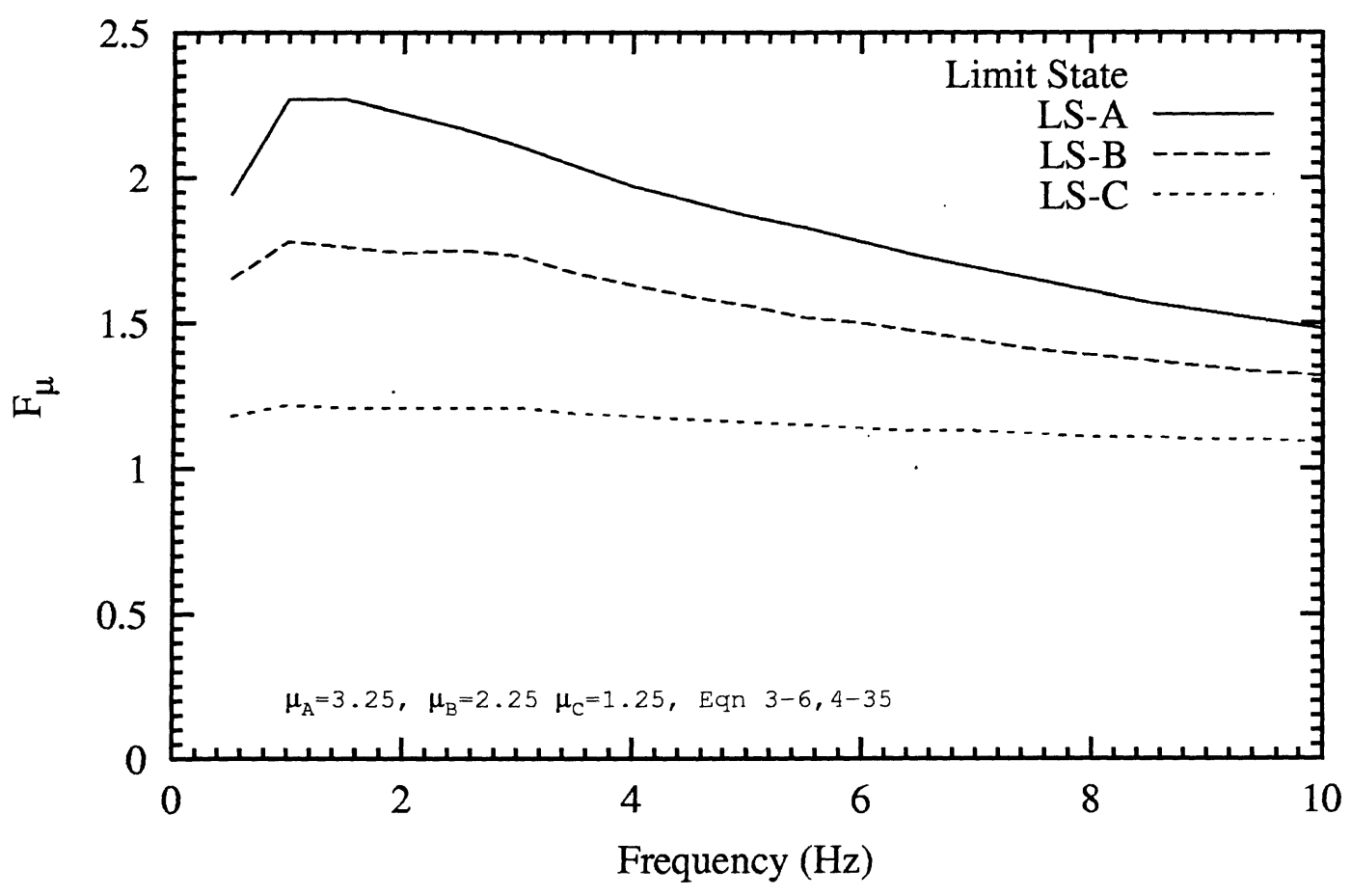

Figure 5.38 Steel OMRF - CH Beams and Columns with $P<20 \% P y$ 
Force Reduction Factors for the Structural Design and Evaluation of Facilities Containing Nuclear and Hazardous Materials

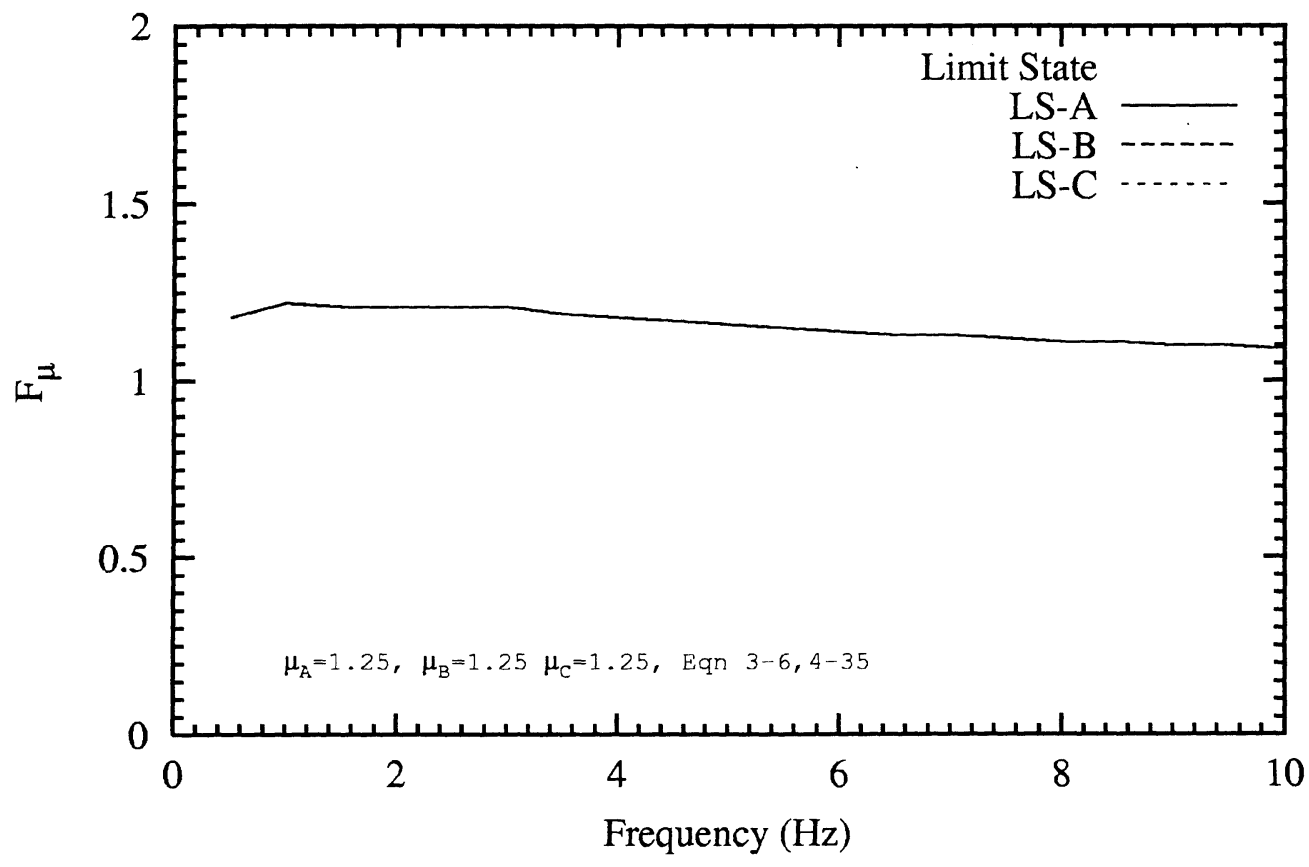

Figure 5.39 Steel OMRF - CH Columns with 20\% Py $<$ P $<50 \%$ Py

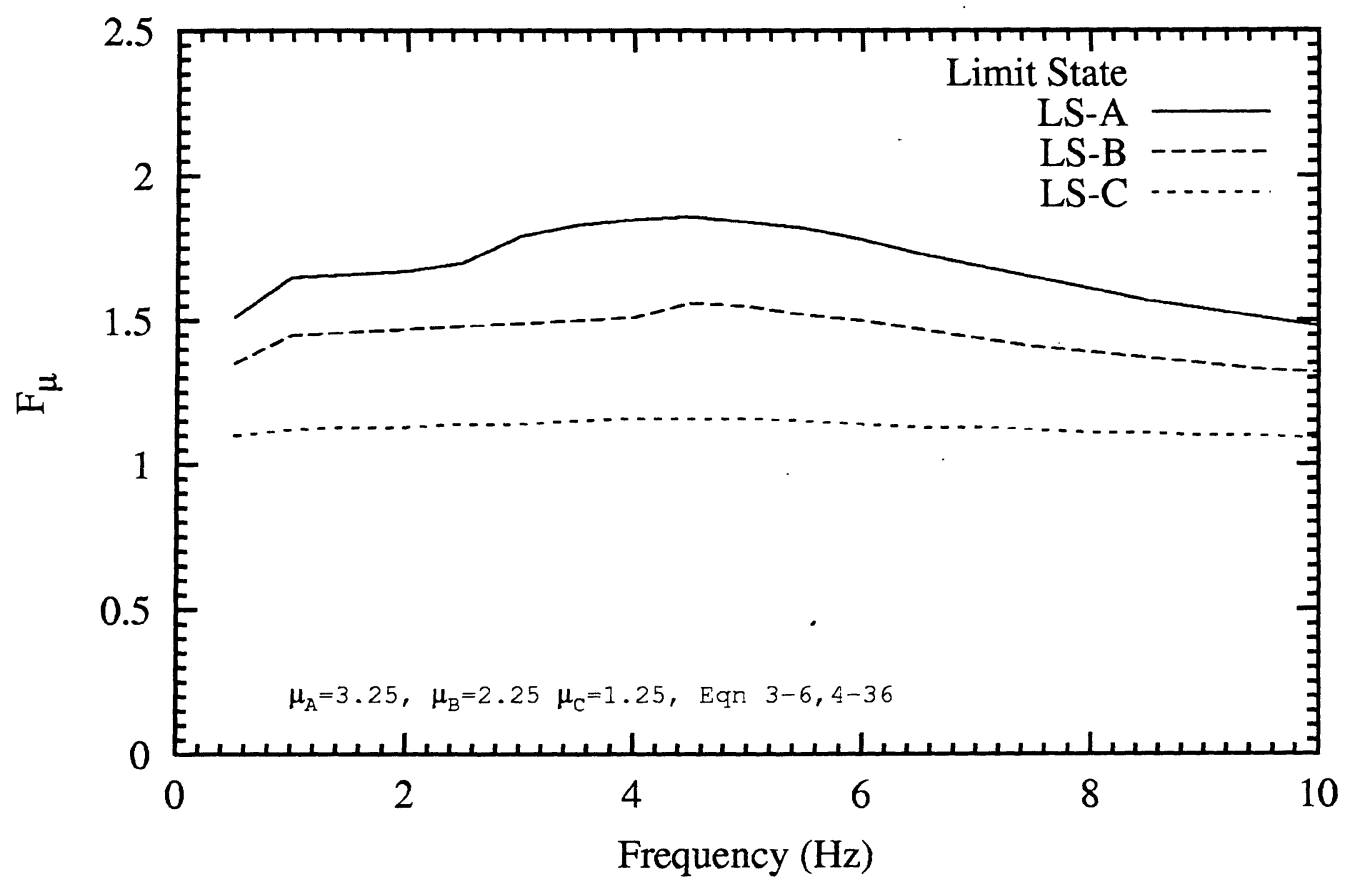

Figure 5.40 Steel OMRF - WS Beams and Columns with $P<20 \% P y$ 
Force Reduction Factors for the Structural Design and Evaluation of Facilities Containing Nuclear and Hazardous Materials

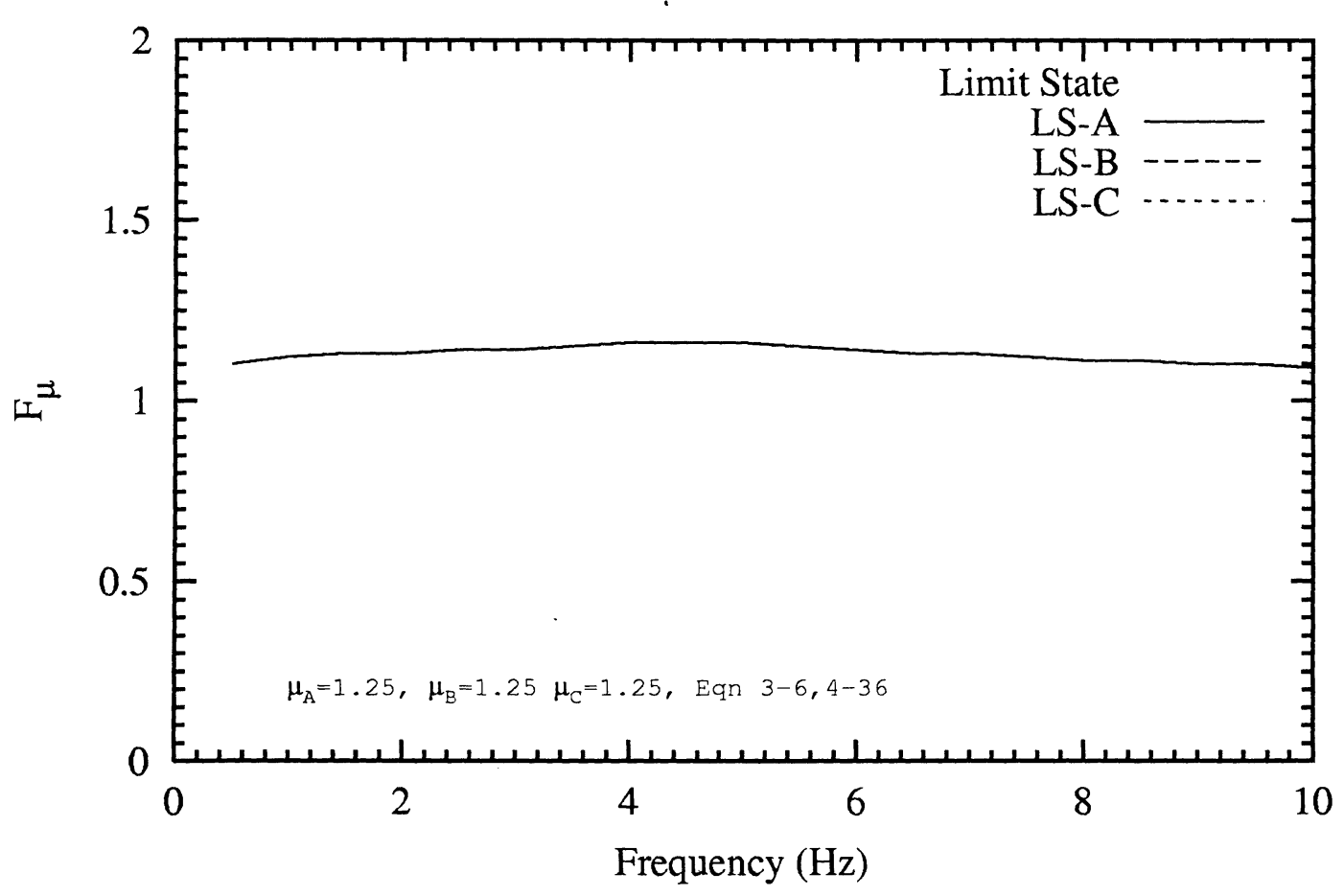

Figure 5.41 Steel OMRF - WS Columns with $20 \%$ Py $<P<50 \%$ Py

\subsubsection{Steel Ordinary Concentric Braced Frames (Steel-OCBF)}

The AISC Seismic Provisions for Structural Steel Buildings for OMRF's allow compression diagonals to buckle and tension diagonals to yield. It is standard building practice to use the same size diagonals bracing elements over several stories and possibly the entire frame in low-rise structures. Since lateral seismic shear is largest near the structure's base, it is highly likely that the lowest story of the frame will buckle or yield while upper stories maintain demands less than the capacity. Thus, Reed's weak story ductility modification factor is used to account for the weak story behavior.

In steel OCBF's the force reduction factor, $\mathrm{F} \mu$, is related to the SDOF force reduction factor, F $\mu$ s by a form of Equation 4-31 or

$F \mu=F \mu s\left(\frac{\mu_{\text {element }}}{\lambda_{\text {Reed }}}\right)$

where $\mu_{\text {element }}$ is the element ductility for members in a steel OCBF given in Table 2.10, or 
Force Reduction Factors for the Structural Design and Evaluation of Facilities Containing Nuclear and Hazardous Materials

\begin{tabular}{|c|c|c|c|}
\cline { 2 - 4 } \multicolumn{1}{c|}{} & \multicolumn{3}{c|}{ Element Ductility, $\mu_{\text {element }}$} \\
\hline Limit State & LS-A & LS-B & LS-C \\
\hline & 8.25 & 5 & 1.75 \\
\hline
\end{tabular}

$\lambda_{\text {Reed }}$ is the ratio of $\mu_{\mathrm{MDOF}}$ to $\mu_{\mathrm{SDOF}}$ for a weak story, given by Equation $4-38$, or conservatively by Equation 4-39 if the weak story is the first level, and

$\mathrm{F} \mu \mathrm{s}$ is the force reduction factor for a single degree-of-freedom system with pinched

hysteresis loops, given by Equation 3-3, with a ductility of $\mu_{\text {element }} / \lambda_{\text {Reed }}$.

Recall that F $\mu$ s, given by Equation 3-3, does not have a frequency dependency in the constant acceleration range. On the other hand, the weak story ductility modification factor, $\lambda_{\text {Reed }}$, is dependent on the number of stories in a building, and, since taller buildings have lower frequencies, then $\mathrm{F} \mu$ has an implicit frequency dependence. F $\mu$ for steel OCBF's are summarized in Table 5.9 as a function of the number of stories. The first floor is conservatively assumed to be the weak story.

Table 5.9 F $\mu$ for Steel Ordinary Concentric Braced Frames

\begin{tabular}{|c|c|c|c|c|}
\hline & & \multicolumn{3}{|c|}{ Element Ductility, $\mu_{\text {element }}$} \\
\hline & Limit State & LS-A & LS-B & LS-C \\
\hline \multirow{6}{*}{ 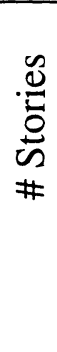 } & 1 & 2.5 & 2.0 & 1.5 \\
\hline & 3 & 2.0 & 1.5 & 1.25 \\
\hline & 5 & 1.75 & 1.4 & 1.2 \\
\hline & 7 & 1.5 & 1.4 & 1.1 \\
\hline & 9 & 1.5 & 1.4 & 1.1 \\
\hline & $\mathrm{N}$ & $1+\frac{3}{N+1}$ & $1+\frac{2}{N+1}$ & $1+\frac{1}{N+1}$ \\
\hline
\end{tabular}

\subsubsection{Steel Eccentric Braced Frames (Steel-EBF)}

The AISC Seismic Provisions for Structural Steel Buildings for EBF's allow the link beam to yield in either shear or bending resulting in large stable hysteresis loops. In contrast the OCBF had pinched hysteresis loops because the diagonals buckle in compression and yield in tension. Thus, the EBF is capable of dissipating more energy than the OCBF at the same ductility level.

As with the OCBF, it is standard building practice to use the same size diagonals and link elements over several stories and possibly the entire frame for low-rise structures. Since lateral seismic shear is largest near the structures base it is highly likely that the lowest story of the frame will yield while upper stories maintain demands less than the capacity. Thus, Reed's weak story ductility modification factor is be used to account for this weak story behavior. 


\section{Force Reduction Factors for the Structural Design and Evaluation of Facilities Containing Nuclear and Hazardous Materials}

In steel OCBF's the force reduction factor, $\mathrm{F} \mu$, is related to the SDOF force reduction factor, F $\mu$ s by a form of Equation 4-31 or

$$
F \mu=F \mu s\left(\frac{\mu_{\text {element }}}{\lambda_{\text {Reed }}}\right)
$$

where $\mu_{\text {element }}$ is the element ductility for members in a steel EBF given in Table 2.10, or

\begin{tabular}{|c|c|c|c|}
\cline { 2 - 4 } \multicolumn{1}{c|}{} & \multicolumn{3}{c|}{ Element Ductility, $\mu_{\text {element }}$} \\
\hline Limit State & LS-A & LS-B & LS-C \\
\hline Short Link & 15 & 8.5 & 2.5 \\
\hline Long Link & Use SMRF Beam \\
\hline Intermediate & \multicolumn{2}{l}{ Interpolate between long and short links } \\
\hline
\end{tabular}

$\lambda_{\text {Reed }}$ is the ratio of $\mu_{\mathrm{MDOF}}$ to $\mu_{\mathrm{SDOF}}$ for a weak story, given by Equation $4-38$, or conservatively by Equation 4-39 if the weak story is the first level,

$\mathrm{F} \mu \mathrm{s}$ is the force reduction factor for a single degree-of-freedom system with stable

hysteresis loops, given by Equation 3-6, with a ductility of $\mu_{\text {element }} / \lambda_{\text {Reed, }}$

Short Link has $1.6 \frac{\mathrm{Z}}{0.6 \mathrm{Aw}} \leq \mathrm{e}$

Long Link has $\mathrm{e} \leq 2.6 \frac{\mathrm{Z}}{0.6 \mathrm{Aw}}$

$\mathrm{e}$ is the eccentricity measured along the link beam,

$\mathrm{Z}$ is the link beam plastic section modulus, and

Aw is the link beam web area.

Frequency dependent F $\mu$ for EBF's with short link beams are shown in Figure 5.42 for Limit States A, B and C. Recall that Reed's weak story ductility modification factor takes accounts for the entire structure's ductility being concentrated into a single story. Thus, the $F \mu$ is repeated for buildings 2, 3, 5, 7 and 9 stories tall in Figures 5.43-5.48. Note that taller structures have more ductility concentrated into a smaller portion of the structure, and $\mathrm{F} \mu$ for these structures is reduced.

The $F \mu$ in this figure can be simplified by assuming that the frequency range for steel EBF in nuclear facilities is below 3 hertz, yielding the conservative frequency independent $\mathrm{F} \mu$ in Table 5.10. 
Force Reduction Factors for the Structural Design and Evaluation of Facilities Containing Nuclear and Hazar dous Materials

Table 5.10 Simplified F $\mu$ for Steel EBF

\begin{tabular}{|l|c|c|c|c|}
\cline { 2 - 4 } \multicolumn{1}{c|}{ Limit State } & LS-A & LS-B & LS-C & DOE-STD- \\
\cline { 2 - 4 } Short Link $\mu$
\end{tabular}

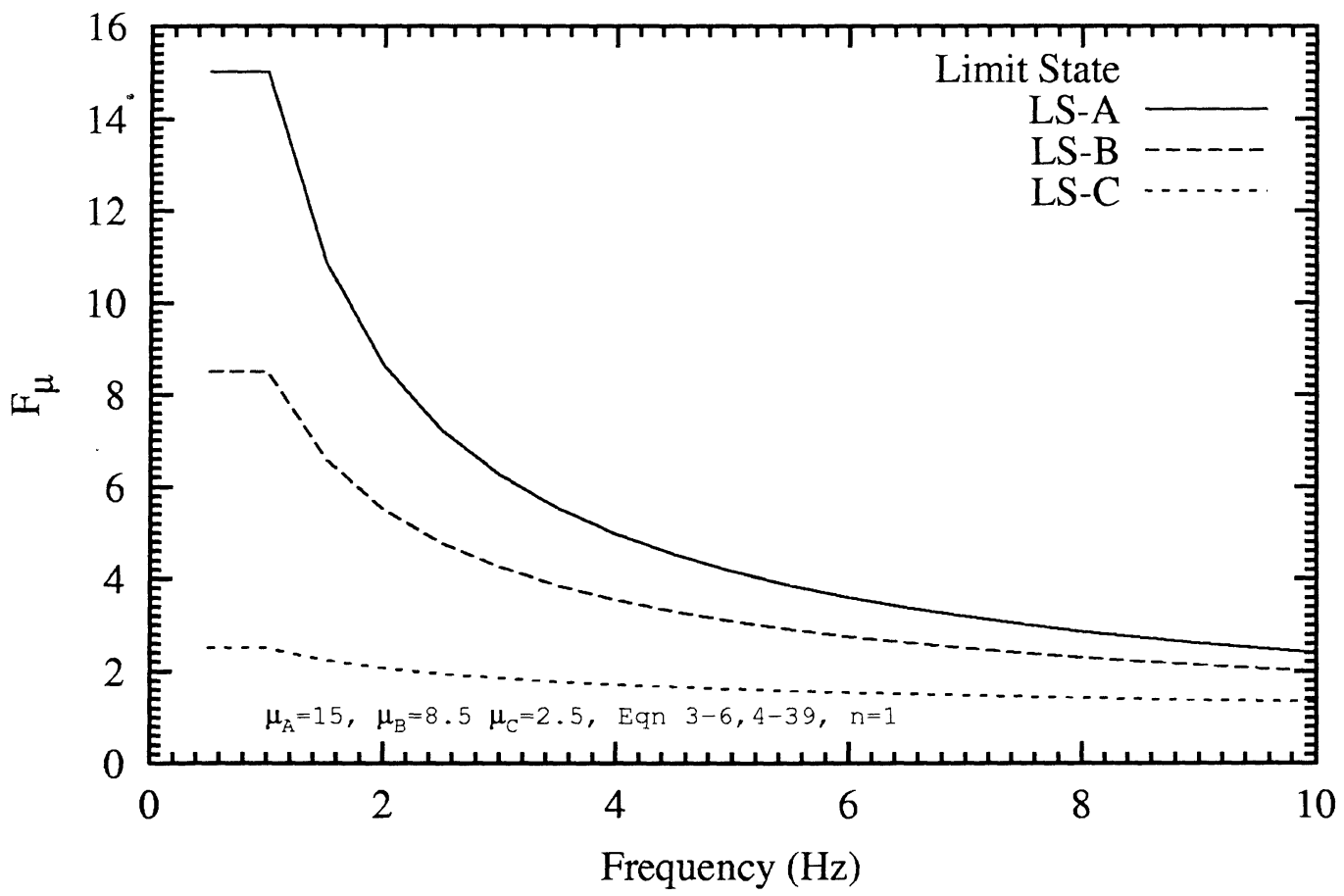

Figure 5.42 Short Link Steel EBF - One Story Tall 
Force Reduction Factors for the Structural Design and Evaluation of Facilities Containing Nuclear and Hazardous Materials

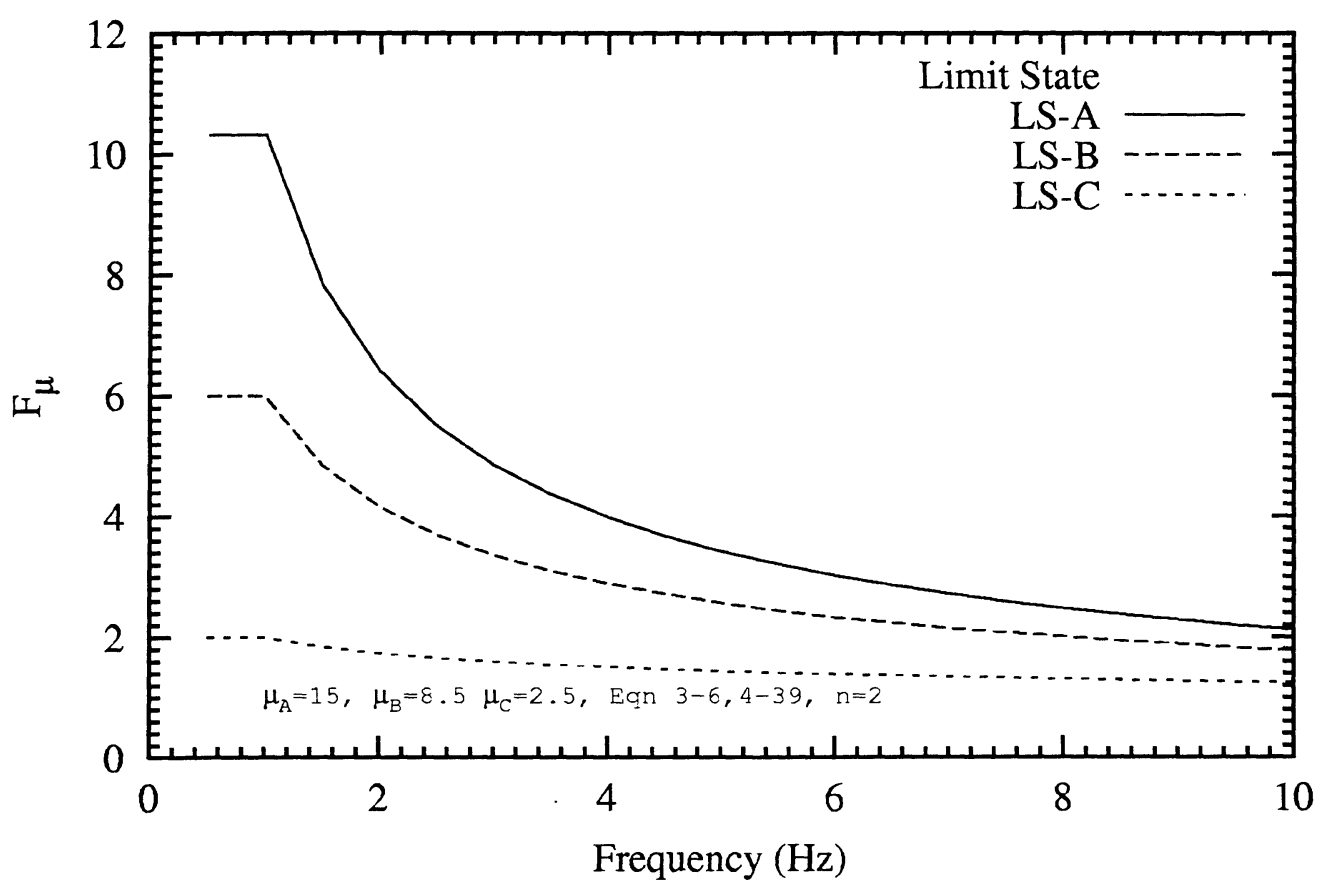

Figure 5.43 Short Link Steel EBF - Two Stories Tall

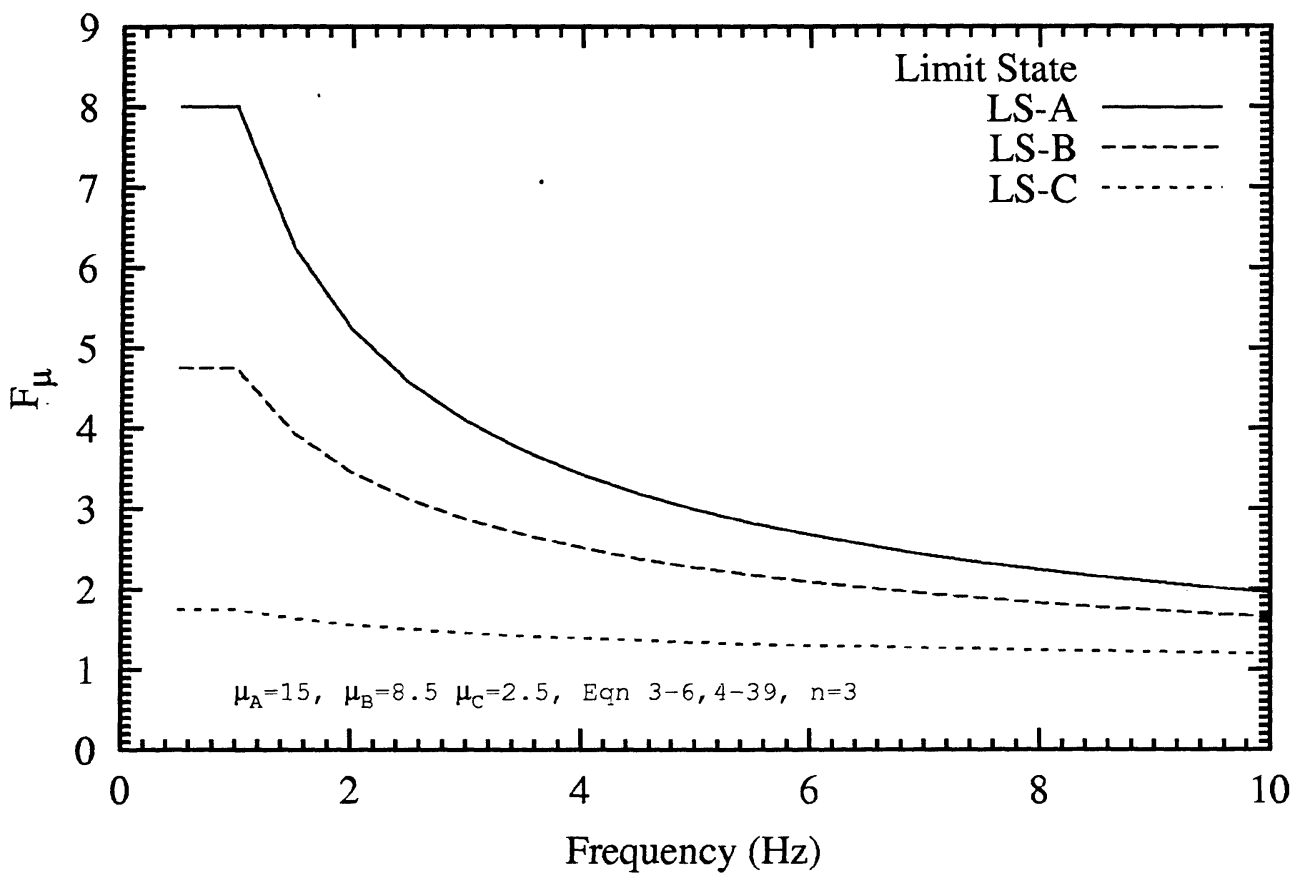

Figure 5.44 Short Link Steel EBF - Three Stories Tall 
Force Reduction Factors for the Structural Design and Evaluation of Facilities Containing Nuclear and Hazardous Materials

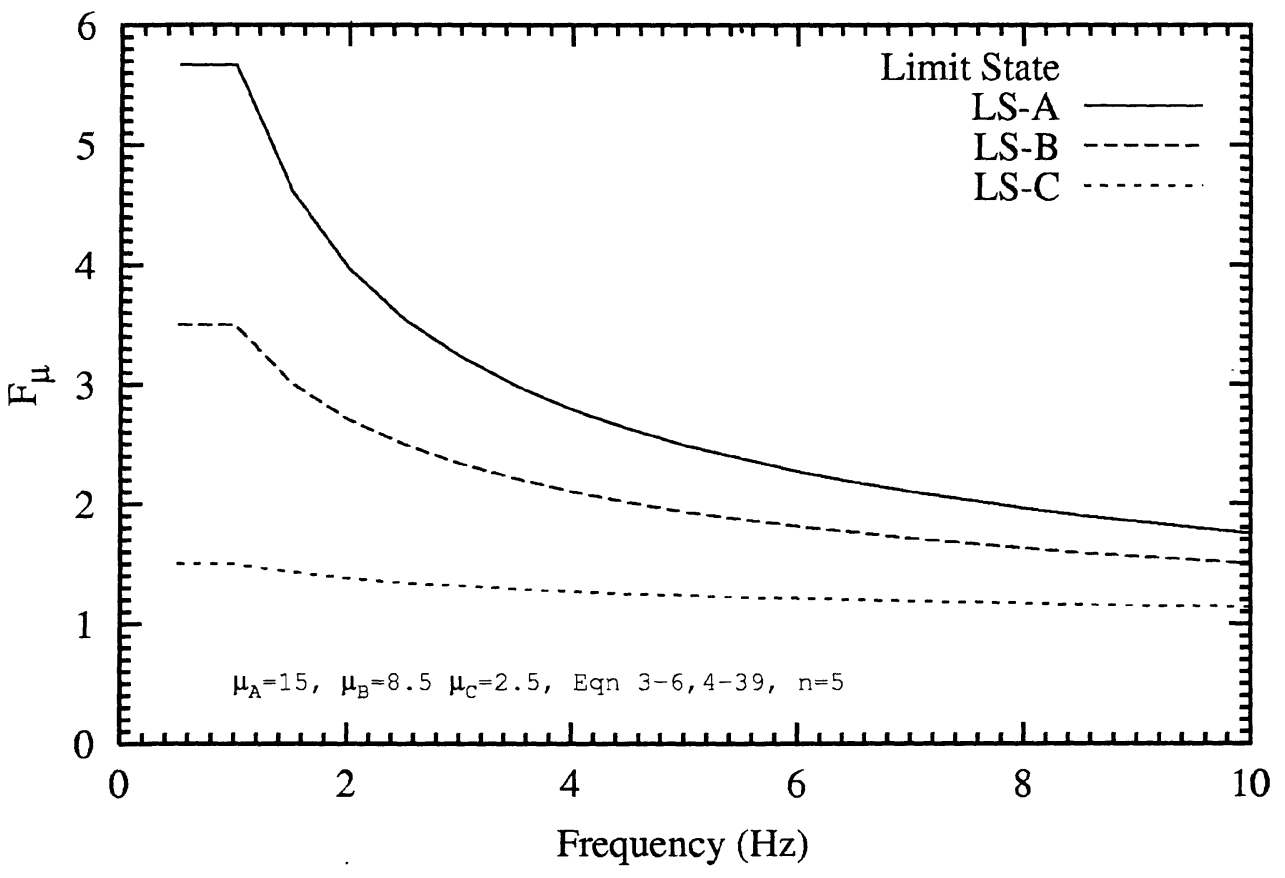

Figure 5.45 Short Link Steel EBF - Five Stories Tall

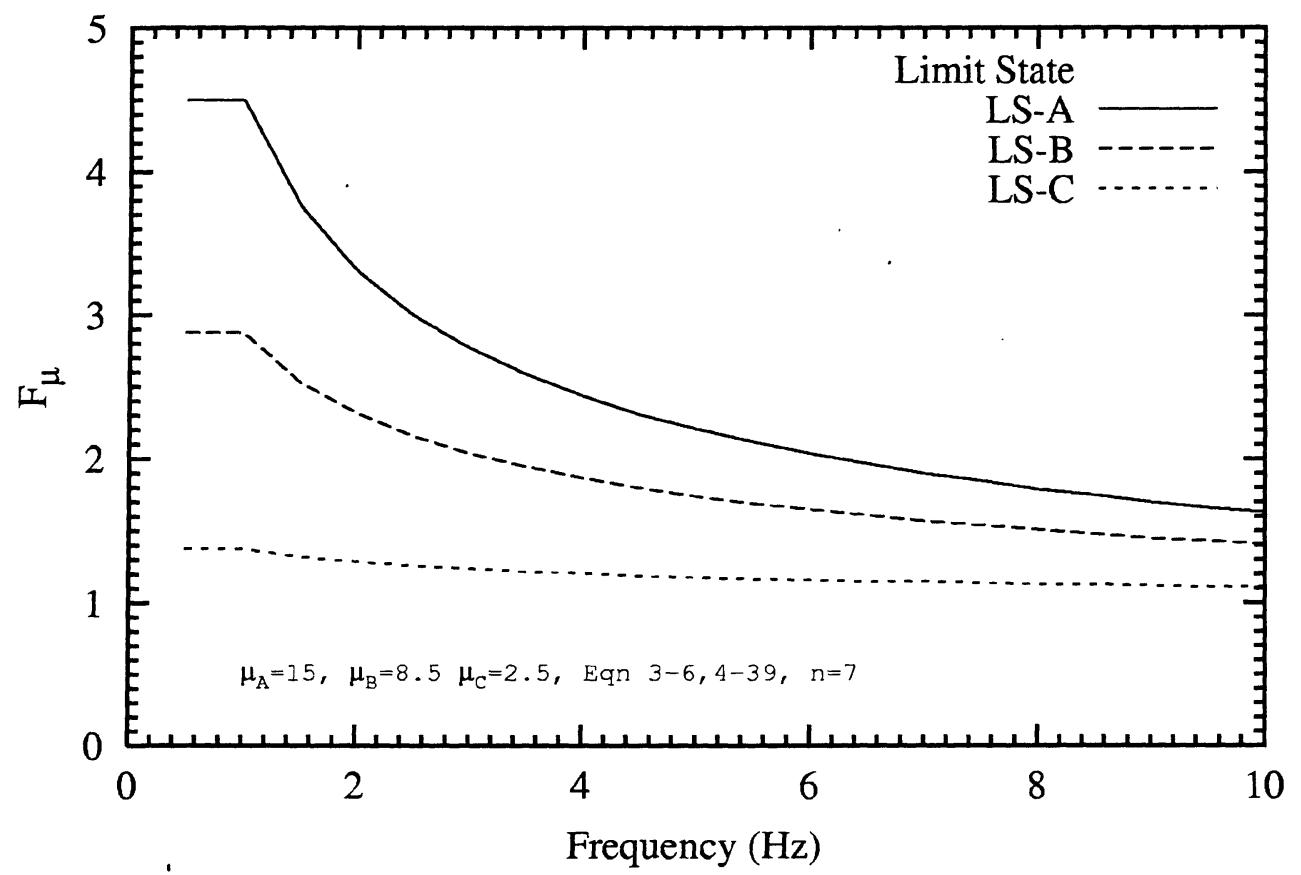

Figure 5.46 Short Link Steel EBF - Seven Stories Tall 
Force Reduction Factors for the Structural Design and Evaluation of Facilities Containing Nuclear and Hazardous Materials

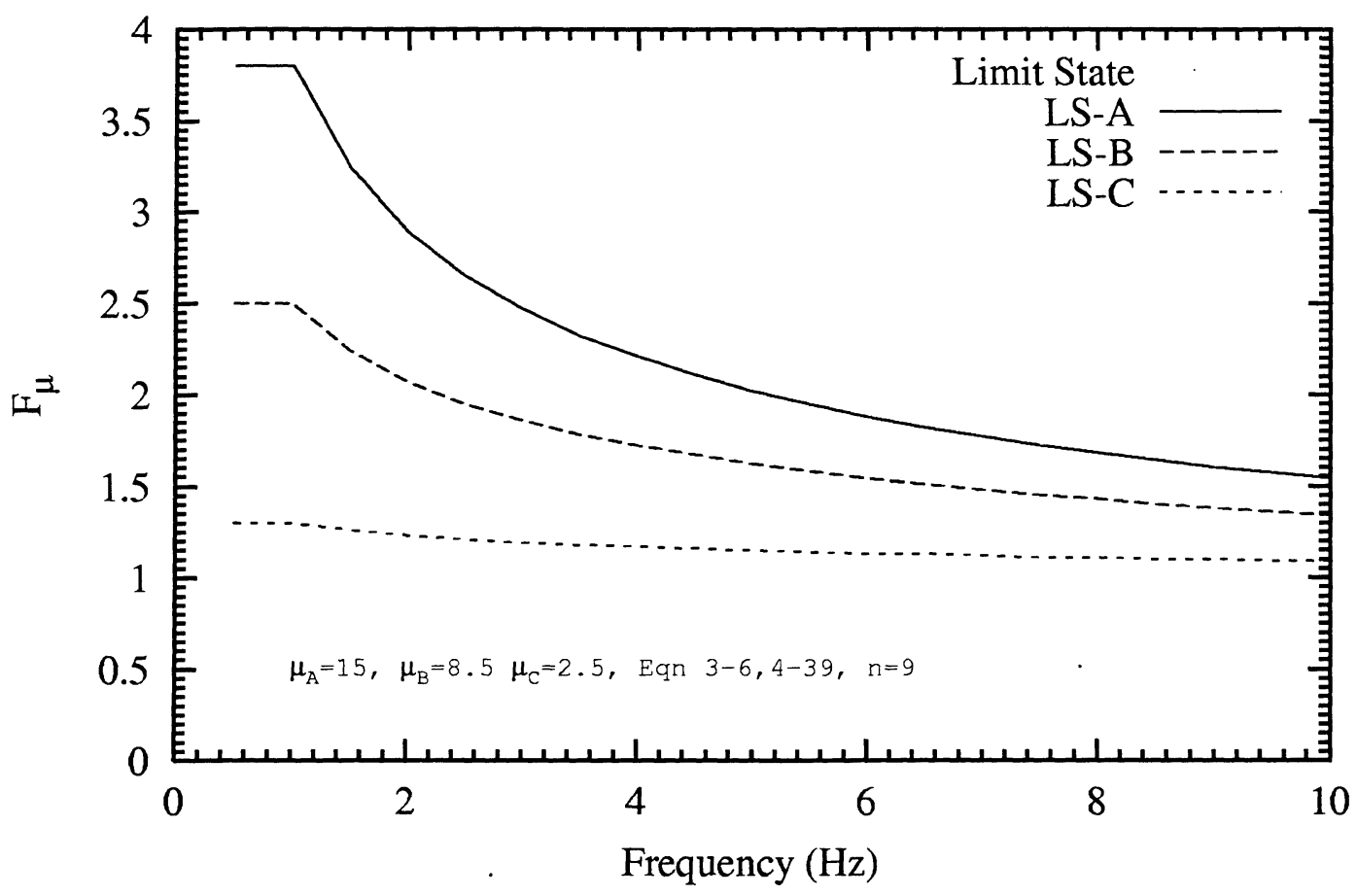

Figure 5.47 Short Link Steel EBF - Nine Stories Tall 
Force Reduction Factors for the Structural Design and Evaluation of Facilities

\subsection{Summary and Conclusion}

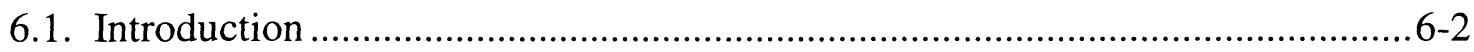

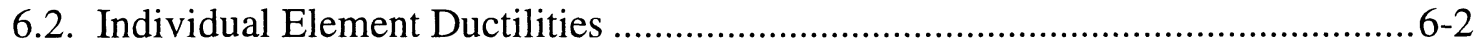

6.3. Dynamic Response of SDOF Systems .................................................... 6-2

6.4. Multiple Element and Multiple Degree-of-Freedom Effects ..........................6-2

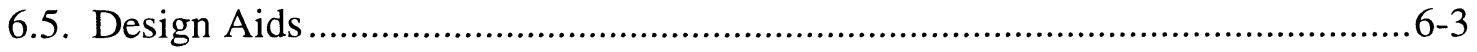




\subsection{Introduction}

This document presents a methodology to derive inelastic force reduction factors, $\mathrm{F} \mu$, for the seismic design of nuclear structures and developed specific $F \mu$ factors for reinforced concrete and structural steel buildings. The F $\mu$ methodology convolves (1) individual element ductilities; (2) the dynamic response of various SDOF systems; and (3) either ductility or base shear adjustment factors to relate SDOF to MDOF effects. This F $\mu$ methodology is applicable to a wide range of structural materials and different structural systems.

\subsection{Individual Element Ductilities}

The F $\mu$ values for reinforced concrete and structural steel buildings developed in this study are generally based member deformation limits and ductilities in FEMA-273. Additional member deformation limits and ductility information from either literature, testing or observed seismic performance can be use to directly generate $F \mu$ using the $F \mu$ versus generic ductility plots in Section 5.2. These plots also include the frequency dependency, which is important at higher ductilities.

Inelastic force reduction factors are developed for limit states representing (1) moderate permanent distortion; (2) minor permanent distortion; and (3) limited permanent distortion. These different limit states allow the user to choose a design that matches the functional requirements of the structure. For example, it is anticipated that limited permanent distortion would be acceptable for a new structure that provides a confinement function, while moderate permanent distortion may be acceptable for Class II structure that is over a Class I structure.

\subsection{Dynamic Response of SDOF Systems}

A simplified method to determine the inelastic force reduction factor for a single degreeof-freedom system, F $\mu$ s, was developed based on literature data. This function conservatively represents the mean of numerous studies of West coast earthquakes. A generalization of $\mathrm{F} \mu \mathrm{s}$ is proposed that addresses the difference in frequency content of East coast earthquakes.

\subsection{Multiple Element and Multiple Degree-of-Freedom Effects}

The effects of stiffness and strength variation on element ductility and system ductility, and the impact of these parameters on the force reduction factor is studied by examining simple structural models. This study indicates that mismatches in element strength and 


\section{Force Reduction Factors for the Structural Design and Evaluation of Facilities Containing Nuclear and Hazardous Materials}

stiffness can result in wide differences between the ductility of a critical element and the ductility of the entire system.

In spite of these differences, the allowable demand acting on the structure is generally the same whether the demand is calculated using (1) an effective system yield with a system ductility; or (2) the individual yield and corresponding ductility for each element in the system. One combination of strength and stiffness mismatch which can cause unconservative allowable demands is identified. Fortunately, this is an atypical case which seldom occurs in building design.

Ductility and base shear adjustment factors are developed from literature data to relate (1) the dynamic influence of higher modes on individual element hinge rotations and ductilities; and (2) the increase in individual element hinge rotations and ductilities due to the concentration of inelastic action in a portion of the structure. These studies addressed moment frames with plastic hinges in the beams, moment frames with plastic hinges in the columns, moment frames with weak stories, and flexural shear walls. An additional ductility adjustment factor, developed by John Reed, that accounts for the behavior of a weak story which can be located anywhere in the structure. These ductility adjustment factors can also be applied to some classes of equipment.

\subsection{Design Aids}

Frequency dependant $\mathrm{F} \mu$ values for reinforced concrete and steel buildings are presented in Section 5.3 to aid in the design of new structures and the evaluation of existing structures. The design charts, Figures 5.13 to 5.47, enable the user to quickly select an appropriate $F \mu$ value for a specific limit state and frequency. These charts address the following types of construction:

\begin{tabular}{cc} 
Reinforced Concrete & Structural Steel \\
\hline Moment Frames & Moment Frames \\
SMRF & SMRF \\
IMRF & IMRF \\
OMRF & OMRF \\
Shear Walls & Braced Frames \\
Short Shear Walls & OCBF \\
Tall Shear Walls & EBF
\end{tabular}

The $F \mu$ values in the design charts are simplified further into $F \mu$ lookup tables based on an assumed frequency range for nuclear structures. The values listed in these tables are in reasonable agreement with the F $\mu$ table in DOE-STD-1020.

It is the author's preference to obtain $F \mu$ values from the design charts. F $\mu$ values for the moderate permanent deformation limit state (LS-A) are typically highly dependant on frequency. The charts include this important frequency effect and also allow the user to visually evaluate $\mathrm{F} \mu$ sensitivity to frequency. 


\subsection{REFERENCES}

"AISC Seismic Provisions for Structural Steel Buildings (1997) Supplement No. 1", February 1999.

ACI 318-99, "Building Code Requirements for Structural Concrete," American Concrete Institute.

ACI 349-97, "Code Requirements for Nuclear Safety Related Concrete Structures," American Concrete Institute.

ATC-19, 1995, “Structural Response Modification Factors,” Applied Technology Council.

ATC-2, 1974, "An Evaluation of A Response Spectrum Approach to Seismic Design of Buildings," Applied Technology Council.

ATC-34, 1995 “A Critical Review of Current Approaches to Earthquake Resistant Design," Applied Technology Council.

Bazzurro, P., Cornell, C. A., Shome, N., Carbello, J. E., 1998, "Three Proposals for Characterizing MDOF Nonlinear Seismic Responses," ASCE Journal of Structural Engineering, Vol. 124, No. 11, November.

Biddah, A. and Heidebrecht, A.C., 1998, "Seismic Performance of Moment-Resisting Steel Frame Structures Designed for Different Levels of Seismic Hazards," Earthquake Spectra, Vol. 14, No. 4, November.

DOE-STD-1020-94, 1996, "Natural Phenomena Hazards Design and Evaluation Criteria for Department of Energy Facilities," including Change Notice \#1, January.

Duffey, T.A., Goldman, A., Farrar, C.R., 1994, "Shear Wall Ultimate Drift Limits," NUREG/CR-6104.

FEMA 273, 1997, "NEHRP Guidelines for the Seismic Rehabilitation of Buildings: Part 1- Provisions," October.

FEMA 273, 1997, "NEHRP Guidelines for the Seismic Rehabilitation of Buildings: Part 2- Commentary," October.

FEMA-xxx "Seismic Design Criteria for New Moment-Resisting Steel Frame Construction, 50\% Draft", SAC Joint Venture, January 1999. 
Force Reduction Factors for the Structural Design and Evaluation of Facilities Containing Nuclear and Hazardous Materials

WSRC-TR-2001-00037

Page 7-2

Gupta, A. and Krawinkler, H., 1998, "Effect of Stiffness Degradation on Deformation Demands for SDOF and MDOF Structures," Proceedings of the $6{ }^{\text {th }}$ U.S. National Conference on Earthquake Engineering, EERI, Seattle, WA.

IBC 2000, "International Building Code”, International Code Council, Inc., March 2000.

Kennedy, R.P., Short, S.A., Merz, K.L., Tokarz, F.J., Idriss, I.M., Power, M.S., Sadigh, K., 1984, NUREG/CR-3805, "Engineering Characterization of Ground Motion: Task 1: Effects of Characteristics of Free-Field Motion on Structural Response," May.

Krawinkler, H. and Gupta, A., 1998, "Story Drift Demands for Steel Moment Frame Structures in Different Seismic Regions," Proceedings of the $6{ }^{\text {th }}$ U.S. National Conference on Earthquake Engineering, EERI, Seattle, WA.

Malley, J. O. Carter, C. J., and Saunders, C. M., 2000, "Seismic Design Guidelines and Provisions for Steel-Framed Buildings: FEMA 267/267A and 1997 AISC Seismic Provisions," Earthquake Spectra, Vol. 16, No. 1, February.

Miranda, E. Bertero, V.V., 1994, "Evaluation of Strength Reduction Factors for Earthquake-Resistant Design,” Earthquake Spectra, Vol 10, No. 2, May.

Nassar, A.A. and Krawinkler, H., , 1991, "Seismic Demands for SDOF and MDOF Systems," Report No. 95, The John A. Blume Earthquake Engineering Center, Stanford University.

Newmark, N.M., Hall, W.J., 1987, “Earthquake Spectra and Design,” Earthquake Engineering Research Institute.

Osteraas, J. D. and Krawinkler, H., , 1990, "Strength and Ductility Considerations in Seismic Demand," Report No. 90, The John A. Blume Earthquake Engineering Center, Stanford University.

Phillips, R. J., 1998, "The Seismic Provisions to the 1997 Uniform Building Code and SEAOC's Recommended Lateral Force Design," 1998 Elsevier Science Ltd., Paper T109-6, Structural Engineering World Wide 1998.

Rojahn, C. and Whittaker, A., 1995, "A Critical Review of Current Approaches to Earthquake Resistant Design," Proceedings of Structures Congress XIII, Boston, MA, April 25.

Seneviratna, G. D. P. K. and Krawinkler, H., 1993, "Effects of Soft Soil and Hysteresis Model on Seismic Demand," Report No. 108, The John A. Blume Earthquake Engineering Center, Stanford University.

Seneviratna, G. D. P. K. and Krawinkler, H., , 1997, "Evaluation of Inelastic MDOF Effects for Seismic Demand," Report No. 120, The John A. Blume Earthquake Engineering Center, Stanford University. 
Force Reduction Factors for the Structural Design and Evaluation of Facilities Containing Nuclear and Hazardous Materials

WSRC-TR-2001-00037

Uang, C-M, 1991, "Establishing $\mathrm{R}$ (or $\mathrm{R}_{\mathrm{w}}$ ) and $\mathrm{C}_{\mathrm{d}}$ Factors for Building Seismic

Page 7-3 Provisions," Journal of Structural Engineering, Vol.117, No. 1, January.

Whittaker, A., Hart, G., Rojahn, C., 1999, "Seismic Response Modification Factors," ASCE, Journal of Structural Engineering, Vol. 125, No. 4, April. 


\section{Appendix A - Span to depth Ratios as an Indicator of Ultimate Reinforced Concrete Beam Shear}

\section{A.1 Introduction}

The shear in a uniform beam govern by bending is developed, parametrically, in this appendix. Parameters studied include material properties, reinforcement ratio, demand to capacity ratio and span to depth ratio. The results of this study indicate that the member's span to depth ratio can be used as a conservative indicator of the maximum shear in a reinforced concrete section. This observation allows the selection of shear sensitive ductility ratios based on member geometry alone instead of assuming a shear level and then verifying that the shear is within that level.

\section{A.2 Shear Demand Due to Gravity Loads, Vug}

The ultimate shear due to uniform gravity loads, Vug, acting on a reinforced concrete beam is

$\operatorname{Vug}=\frac{\mathrm{wu} \ell}{2}$

where wu is the factored gravity load, and

$\ell$ is the span.

The ultimate bending moment due to gravity loads, Mug, acting on a beam in a rigid frame is approximately

$\mathrm{Mu}=\frac{\mathrm{wu} \ell^{2}}{10}$ or $(\mathrm{wu} \ell)=\frac{10 \mathrm{Mug}}{\ell}$

Let the bending demand to capacity ratio for gravity loads be $\Psi$, or $\mathrm{Mug}=\Psi \phi \mathrm{Mn}$, and substitute (wu $\ell$ ) into Equation A-1 to yield the ultimate shear due to gravity loads

$\operatorname{Vug}=\frac{5 \phi \mathrm{Mn} \Psi}{\ell}$ 


\section{A.3 Shear Demand Due to Seismic Loads, Vus}

The ultimate shear on in a beam due to seismic loads, Vus, is

$$
\mathrm{Vus}=\frac{\mathrm{Mus}_{1}+\mathrm{Mus}_{2}}{\ell}
$$

where Mus ${ }_{1}$ and Mus $_{2}$ are the seismic moments at the end of the beam. Assume that Mus is equal to $\mathrm{Mus}_{2}$ and simplify Mus $1=\mathrm{Mus}_{2}=$ Mus. Let the bending demand to capacity ratio for seismic loads be $\chi$, or Mus $=\chi \phi \mathrm{Mn}$. Thus, the ultimate seismic shear due to seismic loads is

Vus $=\frac{2 \chi \phi \mathrm{Mn}}{\ell}$

\section{A.4 Shear Demand for Combined Seismic and Gravity Loads, Vu}

The total shear acting on a beam is the sum of gravity and seismic shears. However, gravity load combinations are calculated with different load factors than seismic load combinations. Let $\varphi$ be the ratio of the gravity load factors to the seismic load factors. Since the seismic load factors are unity and the gravity load factors are between 1.4 and 1.7 then $1.4 \leq \varphi \leq 1.7$.

Thus, the shear due to combined gravity and seismic loads is

$$
\mathrm{Vu}=\frac{\mathrm{Vug}}{\varphi}+\mathrm{Vus}=\frac{5 \phi \mathrm{Mn} \Psi}{\varphi \ell}+\frac{2 \chi \phi \mathrm{Mn}}{\ell}
$$

Similarly, the bending moment due to combined gravity and seismic loads is

$$
\mathrm{Mu}=\frac{\mathrm{Mug}}{\varphi}+\mathrm{Mus}=\left(\frac{\Psi}{\varphi}+\chi\right) \phi \mathrm{Mn}
$$

Recognizing that the bending moment due to combined gravity and shear loads is limited by the members bending capacity, then set $\mathrm{Mu}=\phi \mathrm{Mn}$ and solve for $\chi$

$$
\chi=1-\frac{\Psi}{\varphi}
$$

Or simply stated, the seismic demand to capacity ratio, $\chi$, is equal to unity less the gravity demand to capacity ratio, $\Psi$, divided by the gravity load factor, $\varphi$. Substituting $\chi$ back into $\mathrm{Vu}$ and simplifying yields 


$$
\mathrm{Vu}=\left(\frac{2 \varphi+3 \Psi}{\varphi}\right) \frac{\phi \mathrm{Mn}}{\ell}
$$

\section{A.4 Bending Capacity, $\phi \mathrm{Mn}$}

Neglecting compression reinforcement, the bending capacity of a reinforced concrete beam is

$$
\phi M n=\phi_{b}(\rho b d f y)\left(d-\frac{a}{2}\right)
$$

where $\phi_{\mathrm{b}}$ is the strength reduction factor for bending, $\phi_{\mathrm{b}}=0.9$,

( $\rho$ b d fy) is the tensile force due to the yielding rebar,

$\rho$ is the reinforcing ratio, $\rho=\frac{\mathrm{As}}{\mathrm{bd}}$,

$b$ is the width of the section,

$\mathrm{d}$ is the distance from the compression face to the rebar,

fy is the steel yield strength,

As is the rebar area, and

$\mathrm{a}$ is the depth of the concrete compression block.

The depth of the compression block, a, is determined by setting the bar yield force equal to the concrete compressive force, or for normal strength concrete

$$
\rho b d f y=0.85 f^{\prime} c a b \Rightarrow a=\frac{\rho f y d}{0.85 f^{\prime} c}
$$

where $\mathrm{f}^{\prime} \mathrm{c}$ is the concrete compressive strength.

Substituting a into $\phi \mathrm{Mn}$ yields

$$
\phi M n=\phi_{b}(\rho b d f y)\left(d-\frac{\rho f y d}{1.7 f^{\prime} c}\right)
$$

\section{A.5 Shear Stress}

The nominal shear capacity can be expressed as

$$
\phi \mathrm{Vn}=\phi_{\mathrm{s}} \alpha \sqrt{\mathrm{f}^{\prime} \mathrm{c}} \mathrm{bd}
$$

where $\phi s$ is the strength reduction factor for shear, $\phi s=0.85$, $\alpha$ is a factor defined below, and the remaining terms are previously identified. 
Force Reduction Factors for the Structural Design and Evaluation of Facilities

Containing Nuclear and Hazardous Materials

WSRC-TR-2001-00037

Page A-4

Setting the combined seismic and gravity demand to the capacity and solving for $\alpha$ yields

$\mathrm{Vu}=\phi \mathrm{Vn} \Rightarrow \alpha=\left(\frac{\phi_{\mathrm{b}} \rho \text { fy }\left(1-\frac{\rho \mathrm{fy}}{1.7^{\prime} \mathrm{c}}\right)}{\phi_{\mathrm{s}} \sqrt{\mathrm{f}^{\prime} \mathrm{c}}}\right)\left(\frac{2 \varphi+3 \Psi}{\varphi}\right)\left(\frac{\mathrm{d}}{\ell}\right)$

Note that the first term in Equation A-14 is a function of material properties and reinforcing ratio. As shown in Figure A.1, the value of this term decreases with decreasing yield stress and increasing concrete strength. A concrete strength of $4000 \mathrm{psi}$ and a yield strength of $60 \mathrm{ksi}$ are chosen for this study since these properties represent the minimum concrete strength and maximum steel strength commonly used today. For these material properties $75 \%$ bal corresponds to a reinforcement ratio of 0.021 .

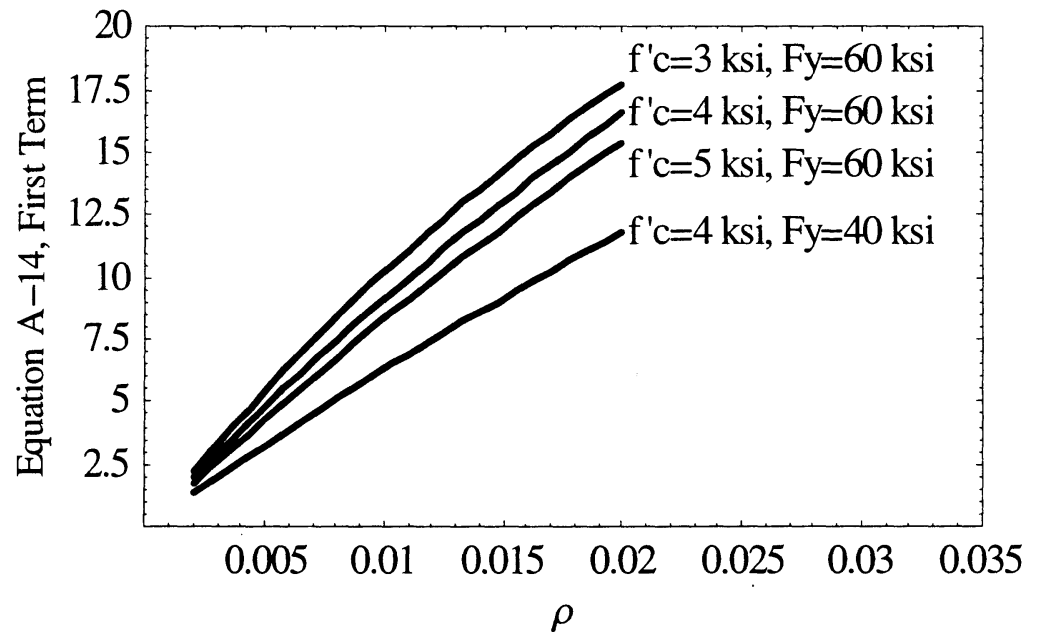

Figure A.1 Material Term in Equation A-14

The second term in Equation A-14 is a function of the demand to capacity ratio and load factors. Recall that $\Psi$ is the bending $\mathrm{D} / \mathrm{C}$ ratio under factored gravity loading. Low values of $\Psi$ correspond to low gravity loads which may be found in elements that are dominated by seismic loads. Note that $\Psi$ varies between 0 and 1.0. A reasonable upper limit on the gravity demand to capacity ratio for a beam in a nuclear facility is about 0.8 . As seen in Equation A-14, all else being equal, $\alpha$ increases as the demand to capacity ratio for gravity loads increases.

Recall that $\varphi$ is the ratio of the dead and live load factors to the seismic load factors and that $1.4 \leq \varphi \leq 1.7$. Assume that the ratio of live to dead load is between 0.5 to 2 , or $\mathrm{L}=0.5 \mathrm{D}$ to $\mathrm{L}=2 \mathrm{D}$. Then the ratio $\varphi$ is

$$
\varphi=\frac{1.4 \mathrm{D}+1.7 \mathrm{~L}}{\mathrm{D}+\mathrm{L}}=\left\{\begin{array}{l}
1.5 \text { when } \mathrm{L}=0.5 \mathrm{D} \\
1.6 \text { when } \mathrm{L}=2 \mathrm{D}
\end{array}\right.
$$




\section{Force Reduction Factors for the Structural Design and Evaluation of Facilities Containing Nuclear and Hazardous Materials \\ WSRC-TR-2001-00037}

Page A-5

Combining the effects of $\varphi$ and $\Psi$ in the second term of Equation A-14 yields values between 2 and 4 .

The third term in Equation A-14 is the span to depth ratio. The span to depth ratio varies from a high of 30 for roof beams to 20 for floor beams to a low of about 5 for very stiff beams. Note that the shear, $\alpha$, increases as the span to depth ratio decreases.

The shear in slender members is shown in Figure A. 2 for different values of $\Psi$ and $\varphi$. The shear is roughly linear with respect to reinforcing ratio. Note that the shear stress in a uniformly loaded slender beam is limited to about $3 \sqrt{f^{\prime} c}$. Beams with a shear capacity larger than the value in these figures are controlled by bending.

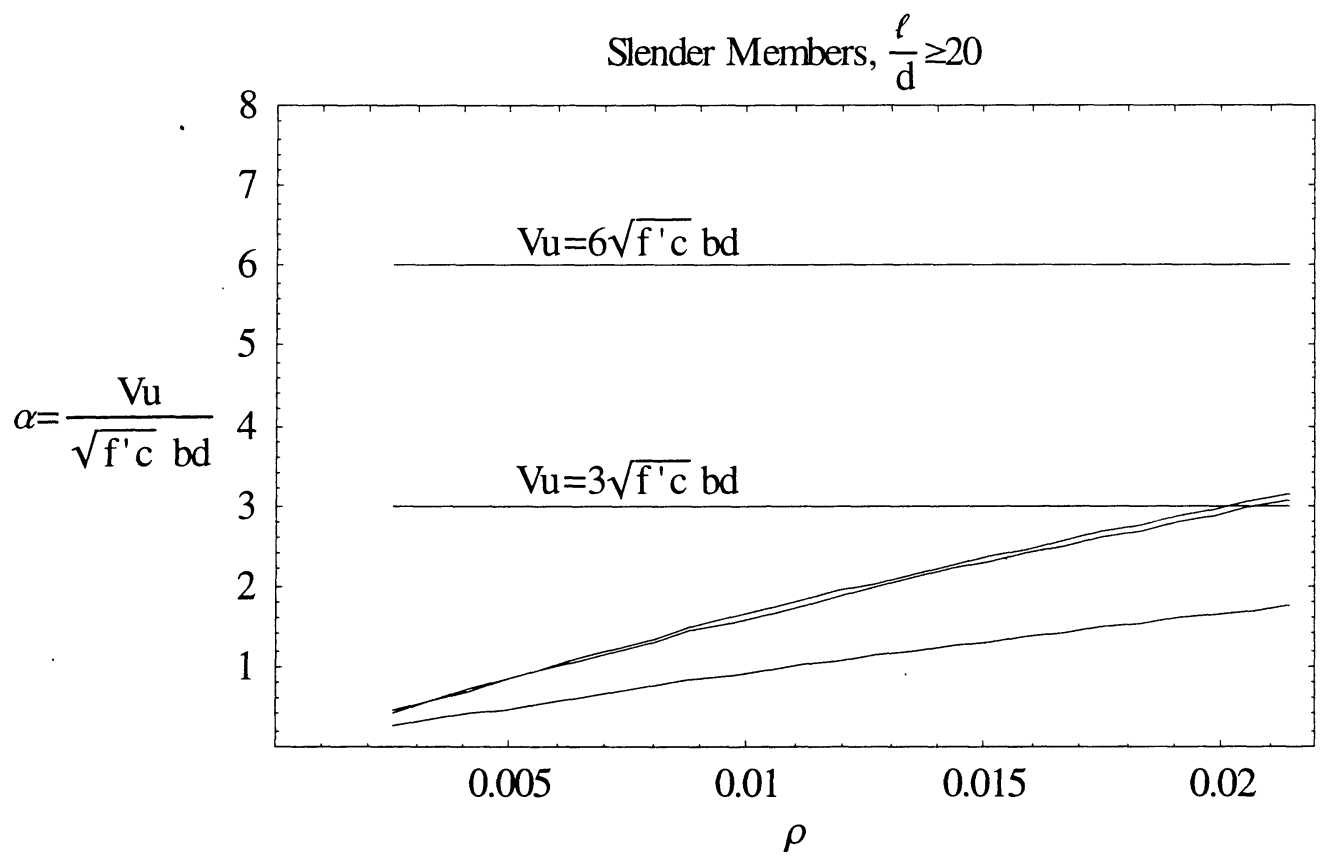

Figure A.2 Shear in Slender Members

The shear is plotted for various beam span to depth ratios in Figures A.3 through A.6 for various reinforcing ratio's. The upper two curves in these figures represent beams with a gravity demand to capacity ratio of 0.8 and various live to dead load ratios. The lower curve represents a beam without gravity loads that only resist lateral seismic loads.

Beams are often reinforced in the 0.005 to 0.01 range and occasionally with reinforcing ratio's of 0.015 . Beams with reinforcing ratios less than 0.015 and span to depth ranges greater than 15 have shear stress less than $3 \sqrt{f^{\prime} c}$. At $\rho=0.015$ the shear stress reaches about $6 \sqrt{f^{\prime} c}$ at a span to depth ratio of about 8 . 
Force Reduction Factors for the Structural Design and Evaluation of Facilities Containing Nuclear and Hazarcious Materials

WSRC-TR-2001-00037

Page A-6

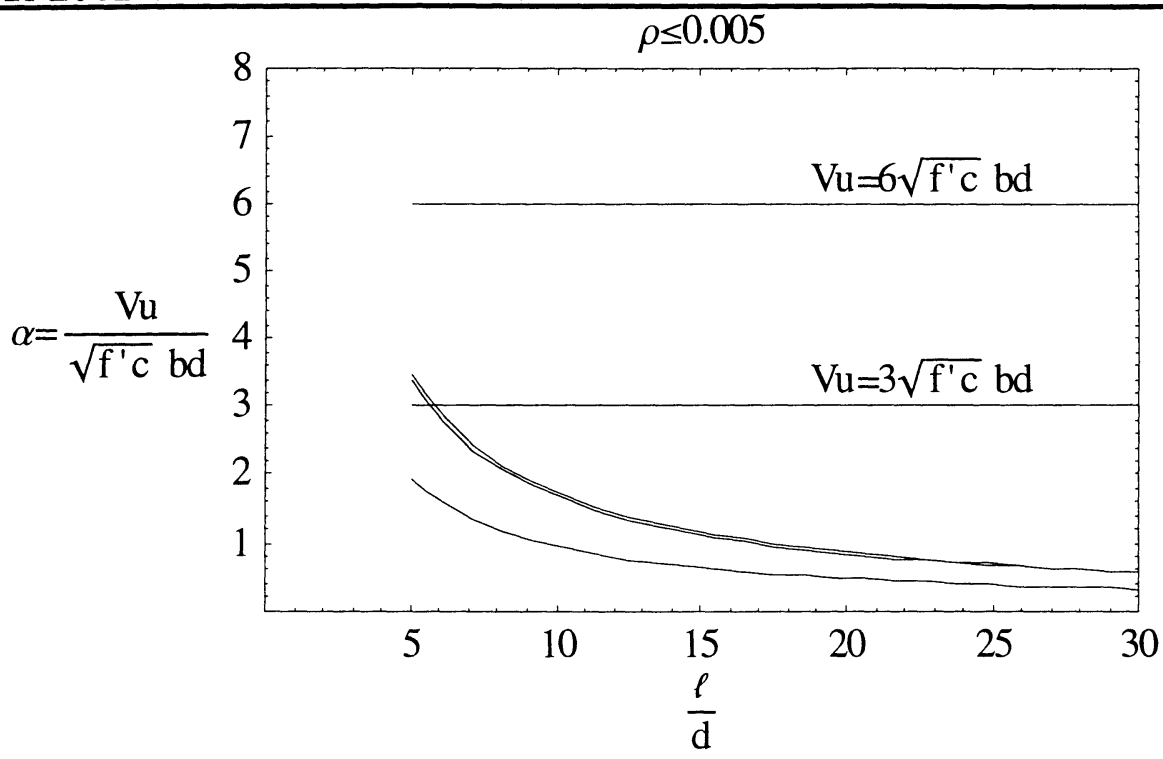

Figure A.3 $\alpha$ versus $\ell / d$ for $\rho=0.005$

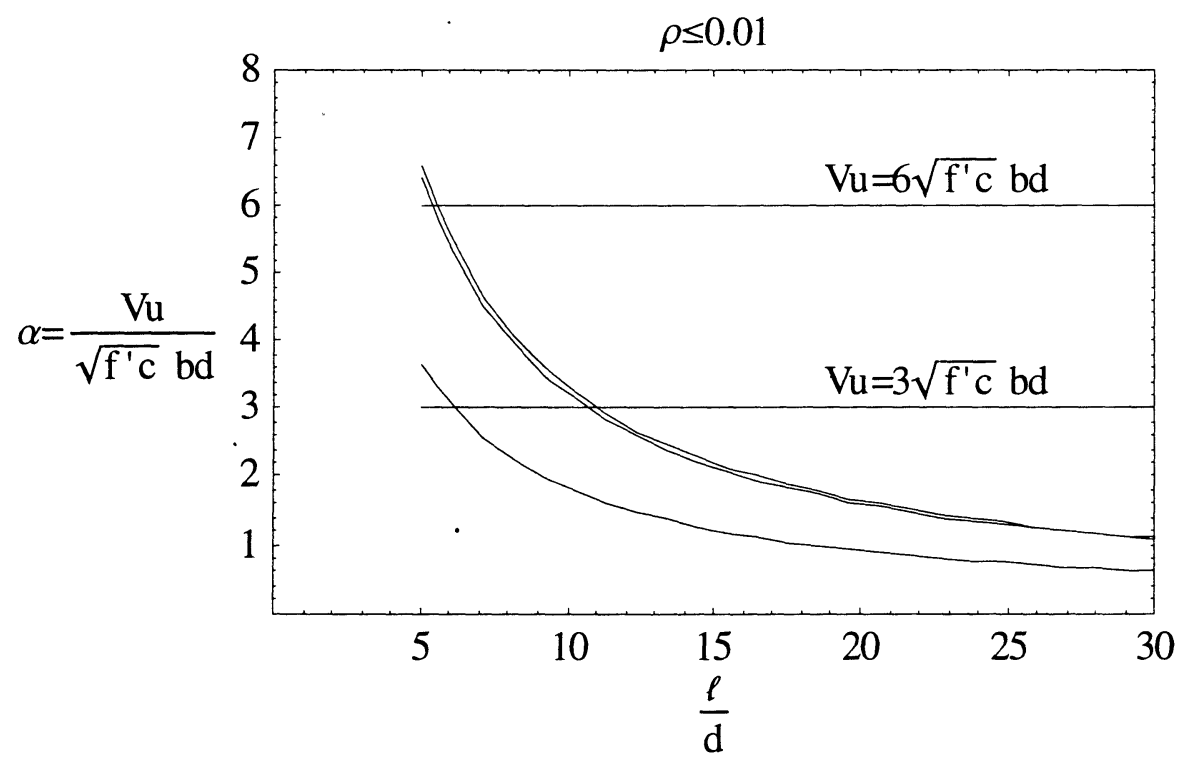

Figure A.4 $\alpha$ versus $\ell / d$ for $\rho=0.010$ 
Force Reduction Factors for the Structural Design and Evaluation of Facilities Containing Nuclear and Hazardous Mattrials

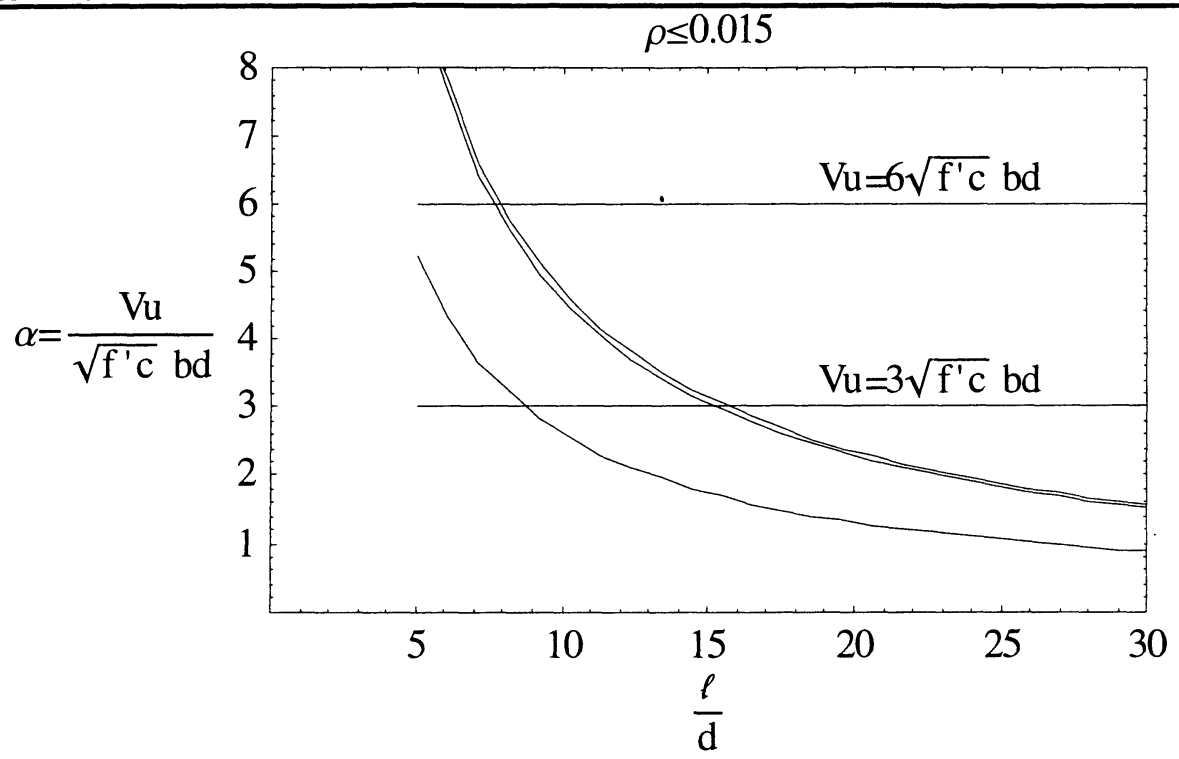

Figure A.5 $\alpha$ versus $\ell / d$ for $\rho=0.015$

Columns usually have low span to depth (width) ratio's and large reinforcing ratio's. Figure A.6 represents the shear in a heavily reinforced column. Note that the column shear for most practical span to depth ratio's is greater than $3 \sqrt{f^{\prime} c}$ and at times greater than $6 \sqrt{f^{\prime} c}$. Column shear can conservatively be assumed to be greater than $6 \sqrt{f^{\prime} c}$.

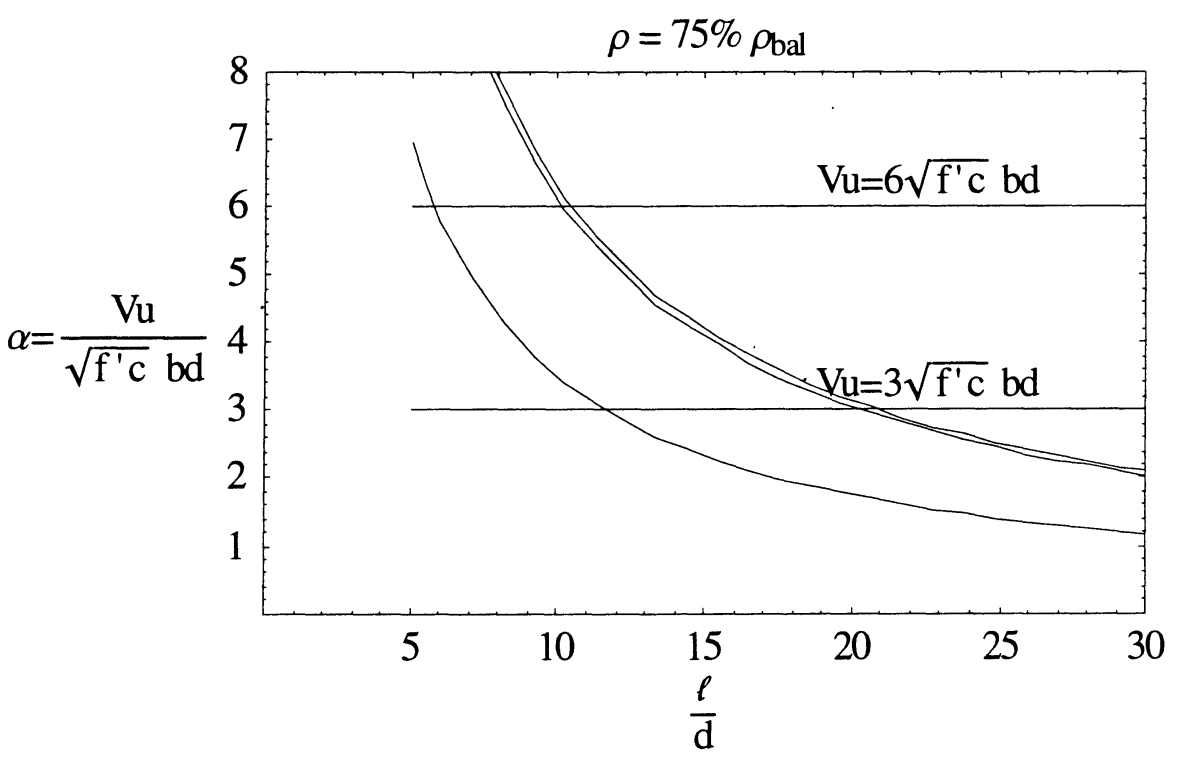

Figure A.6 $\alpha$ versus $\ell / d$ for $\rho=75 \% \rho_{\text {bal }}$ 


\section{Force Reduction Factors for the Structural Design and Evaluation of Facilities Containing Nuclear and Hazardous Materials}

\section{A.6 Conclusion}

The maximum shear in a beam is a function of the reinforcing ratio, $\rho$, the span to depth ratio, $\ell / d$ the normal operating demand to capacity ratio, $\Psi$, and the effective gravity load factor, $\varphi$.

For typical beam reinforcing ratios, $\rho \leq 0.015$, demand to capacity ratio's and load factors:

$\mathrm{fv} \leq 3 \sqrt{\mathrm{f}^{\prime} \mathrm{c}}$ when $\ell / \mathrm{d} \geq 15$, and

$f v \geq 6 \sqrt{f^{\prime} c}$ when $\ell / d \leq 8$

For columns the shear stress may conservatively be assumed to be greater than $6 \sqrt{f^{\prime} \mathrm{c}}$.

Alternately, Figures A.3 through A.6 may be used to determine the maximum shear given other reinforcing ratios or demand to capacity ratios. 


\title{
INELASTIC ENERGY ABSORPTION FACTOR FOR WEAK STORY STRUCTURES
}

\author{
by: John W. Reed \\ December, 2000
}

This white paper describes and investigates the basis for the system inelastic energy absorption factor (i.e., $F_{\mu s}$ ) that is given in Section 3.7.1 of ASCE Standard XXX. This factor appears in the following load combination equation in the Standard for the total demand acting on an element:

Where:

$$
\mathrm{D}=1.0 \mathrm{D}_{\mathrm{ns}}+1.0 \frac{\mathrm{D}_{\mathrm{s}}}{\mathrm{F} \mu_{\mathrm{s}}}
$$

$\mathrm{D}=\quad$ the total demand acting on an element

$D_{\mathrm{ns}}=$ the total non-seismic demand acting on an element

$\mathrm{D}_{s}=$ the calculated seismic response to the DBE using a linear dynamic analysis acting on an element

$$
F_{\mu s}=1+2\left(F_{\mu}-1\right) \frac{n-k+1}{n(n+1)}
$$

$\mathrm{F} \mu=\quad$ the element inelastic energy absorption factor specified in Section 4.4 of ASCE Standard XXX

$\mathrm{n}=\quad$ the number of stories in the structure

$\mathrm{k}=$ the number corresponding to the location of the highest weak story in the structure. The parameter $\mathrm{k}$ is measured upward from the base of the structure

The basis for $\mathrm{F} \mu_{\mathrm{s}}$ comes from the simplified nonlinear analysis procedure for calculating the system inelastic absorption factor for a multidegree of freedom structure given in Section C.4.4.3 in DOE-STD-1020 (Ref. 1). This procedure starts with the following expression for the system ductility, $\mu_{\mathrm{S}}$ : 


$$
\mu_{s}=\frac{\sum_{i=1}^{n} w_{i} \cdot \Delta T_{i}}{\sum_{i=1}^{n} w_{i} \cdot \Delta_{e_{i}}}
$$

Where:

$\mathrm{W}_{\mathrm{i}}=$ the inertial weight applied at the top of story $\mathrm{i}$ in the structure

$\Delta_{\mathrm{T}}=$ the total displacement including elastic and nonlinear distortions at story $\mathrm{i}$

$\Delta_{\mathrm{e}_{\mathrm{i}}}=$ the corresponding elastic displacements at story $\mathrm{i}$ (scaled to the elastic displacement in the weak story reaching yield)

Assuming a single "kth" weak story in the structure, equal story inertial weights, W, and equal elastic story displacements, $\delta_{\mathrm{e}}$, the following expression is found for the system ductility (the assumption of equal $\mathrm{W}$ and $\delta_{e}$ values is investigated below):

$$
\mu_{\mathrm{s}}=1+(\mu-1) \cdot \frac{\left(\sum_{\mathrm{i}=\mathrm{k}}^{\mathrm{n}} \mathrm{w} \cdot \delta_{\mathrm{e}}\right)}{\sum_{\mathrm{i}=1}^{\mathrm{n}} \mathrm{w} \cdot \mathrm{i} \cdot \delta_{\mathrm{e}}}
$$

Where:

$\mu=\quad$ the story ductility in the weak story (i.e., total story displacement/ yield displacement). The total story displacement is the sum of the story yield displacement and the inelastic story displacement. Note the story displacement, $\delta_{\mathrm{e}}$, also corresponds to the yield displacement in the "kth" story

Using the series relationship: $\sum_{i=1}^{n} i=\frac{n \cdot(n+1)}{2}$, the expression for $\mu_{s}$ can be reduced to the following final form:

$$
\mu_{s}=1+2 \cdot(\mu-1) \cdot \frac{n-k+1}{n \cdot(n+1)}
$$

The inelastic energy absorption factor, $F_{\mu s}$, is the seismic demand scaled to reach ductility, $\mu_{\mathrm{s}}$, divided by the seismic demand to reach yield in the weak story. The 


\section{Force Reduction Factors for the Structural Design and Evaluation of Facilities Containing Nuclear and Hazardous Materials}

WSRC-TR-2001-00037

Page B-3

relationship between the system ductility, $\mu_{\mathrm{s}}$, and the system inelastic energy absorption factor is primarily a function of the frequency domain in which the dominant frequency occurs, and other considerations. In developing the $F \mu_{\mathrm{s}}$ factor used in Section 3.7.1 of ASCE Standard XXX the following three cases were considered:

1. $\mathrm{F}_{\mu}=\mu$ (also, $\mathrm{F} \mu_{\mathrm{s}}=\mu_{\mathrm{s}}$ ). This assumption implies that the dominant frequency is in the displacement region of the demand response spectrum.

2. $F_{\mu}=\sqrt{2 \mu-1}$ (also, $F \mu_{s}=\sqrt{2 \mu_{s}-1}$ ). This assumption implies that the dominant frequency is in the acceleration region of the demand response spectrum.

3. The relationship between $\mathrm{F}_{\mu}$ and $\mu$ (also, $\mathrm{F} \mu_{\mathrm{s}}$ and $\mu_{\mathrm{s}}$ ) is in accordance with the simplified procedure in Ref. 2 , which takes into account dominant frequency, damping, and severely pinched hysteric loops (i.e, typical of concrete shear wall structures or braced frames).

It was found in the investigation that the first case produced results that were conservative relative to the other two cases, as will be demonstrated below. Thus, the assumption: $F_{\mu}=\mu$, (also, $\mathrm{F} \mu_{\mathrm{s}}=\mu_{\mathrm{s}}$ ) is used first to develop the relationship for the $\mathrm{F} \mu_{\mathrm{s}}$ factor. It is assumed in this development that the story drift ductility values are equal to the element ductility values that are given in Section 4.4 of ASCE Standard XXX. This is conservative because story drift ductility values are equal to or less than element ductility values Following the assumption in Case $1 \mathrm{~F} \mu_{\mathrm{s}}$ is found directly:

$$
\mathrm{F} \mu_{\mathrm{s}}=1+2 \cdot(\mathrm{F} \mu-1) \cdot \frac{\mathrm{n}-\mathrm{k}+1}{\mathrm{n} \cdot(\mathrm{n}+1)}
$$

The table below shows values of $F_{\mu s}$ for different number of stories, n, and element ductility values, $\mathrm{F} \mu$, for the situation where the first story is the weak story (i.e., $\mathrm{k}=1$ )

\section{WEAK STORY IS FIRST STORY - CASE 1}

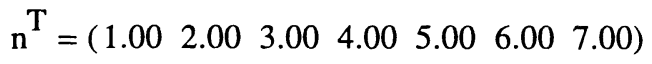

$F \mu_{s_{-} \text {result_1 }}=\left(\begin{array}{lllllll}1.50 & 1.33 & 1.25 & 1.20 & 1.17 & 1.14 & 1.13 \\ 2.00 & 1.67 & 1.50 & 1.40 & 1.33 & 1.29 & 1.25 \\ 2.50 & 2.00 & 1.75 & 1.60 & 1.50 & 1.43 & 1.38 \\ 3.00 & 2.33 & 2.00 & 1.80 & 1.67 & 1.57 & 1.50 \\ 3.50 & 2.67 & 2.25 & 2.00 & 1.83 & 1.71 & 1.63 \\ 4.00 & 3.00 & 2.50 & 2.20 & 2.00 & 1.86 & 1.75 \\ 4.50 & 3.33 & 2.75 & 2.40 & 2.17 & 2.00 & 1.88\end{array}\right)$
Old Equivalent System Ductility Values

$$
\mathrm{F} \mu=\left(\begin{array}{l}
1.5 \\
2.0 \\
2.5 \\
3.0 \\
3.5 \\
4.0 \\
4.5
\end{array}\right)
$$$$
\mathrm{F}_{\text {old }}(\mathrm{F} \mu)=\left(\begin{array}{c}
1.20 \\
1.33 \\
1.43 \\
1.50 \\
1.56 \\
1.60 \\
1.64
\end{array}\right)
$$

Also shown to the right of this table for comparișon are the system ductility values 
Force Reduction Factors for the Structural Design and Evaluation of Facilities Containing Nuclear and Hazardous Materials

WSRC-TR-2001-00037

Page B-4

equivalent to the the Fs factor used in previous versions of Section 3.7.1 of ASCE

Standard XXX. The Fs factor was defined as: $F s=1+\frac{F \mu-1}{2}$, where Fs is independent of the number of stories and the location of the weak story. This factor was used to divide A table in the same format is shown below for the situation where the weak story is at the top story of a structure.

\section{WEAK STORY IS TOP STORY - CASE 1}

$\mathrm{n}^{\mathrm{T}}=\left(\begin{array}{lllllll}1.00 & 2.00 & 3.00 & 4.00 & 5.00 & 6.00 & 7.00\end{array}\right) \quad$ Old Equivalent System Ductility Values
$\mathrm{F} \mu_{\text {s_result_T }}=\left(\begin{array}{lllllll}1.50 & 1.17 & 1.08 & 1.05 & 1.03 & 1.02 & 1.02 \\ 2.00 & 1.33 & 1.17 & 1.10 & 1.07 & 1.05 & 1.04 \\ 2.50 & 1.50 & 1.25 & 1.15 & 1.10 & 1.07 & 1.05 \\ 3.00 & 1.67 & 1.33 & 1.20 & 1.13 & 1.10 & 1.07 \\ 3.50 & 1.83 & 1.42 & 1.25 & 1.17 & 1.12 & 1.09 \\ 4.00 & 2.00 & 1.50 & 1.30 & 1.20 & 1.14 & 1.11 \\ 4.50 & 2.17 & 1.58 & 1.35 & 1.23 & 1.17 & 1.13\end{array}\right) \quad \quad \mathrm{F} \mu=\left(\begin{array}{l}1.5 \\ 2.0 \\ 2.5 \\ 3.0 \\ 3.5 \\ 4.0 \\ 4.5\end{array}\right) \quad \mathrm{F}_{\text {old }}(\mathrm{F} \mu)=\left(\begin{array}{c}1.20 \\ 1.33 \\ 1.43 \\ 1.50 \\ 1.56 \\ 1.60 \\ 1.64\end{array}\right) \quad$

As seen from these tables the system inelastic energy absorption factor, $F_{\mu v}$, decreases as the number of stories increase and as the location of the weak story moves up toward the top of a structure. This trend is not reflected well in the old Fs factor used in previous versions of Section 3.7.1 of ASCE Standard XXX.

The following tables examine Case 2 for defining the relationship between $F_{\mu}$ and $\mu$ (also, $F \mu_{\mathrm{s}}$ and $\mu_{\mathrm{s}}$ ) for the situation where the first story is the weak story (i.e., $\mathrm{k}=1$ ).

\section{WEAK STORY IS FIRST STORY - CASE 2}

$$
\begin{aligned}
\mathrm{n}^{\mathrm{T}} & =\left(\begin{array}{lllllll}
1.00 & 2.00 & 3.00 & 4.00 & 5.00 & 6.00 & 7.00
\end{array}\right) \\
\mathrm{F} \mu_{\text {s_result_2 }} & =\left(\begin{array}{llllllll}
1.50 & 1.35 & 1.27 & 1.22 & 1.19 & 1.16 & 1.15 \\
2.00 & 1.73 & 1.58 & 1.48 & 1.41 & 1.36 & 1.32 \\
2.50 & 2.12 & 1.90 & 1.76 & 1.66 & 1.58 & 1.52 \\
3.00 & 2.52 & 2.24 & 2.05 & 1.91 & 1.81 & 1.73 \\
3.50 & 2.92 & 2.57 & 2.35 & 2.18 & 2.05 & 1.95 \\
4.00 & 3.32 & 2.92 & 2.65 & 2.45 & 2.30 & 2.18 \\
4.50 & 3.72 & 3.26 & 2.95 & 2.72 & 2.55 & 2.41
\end{array}\right) \quad \mathrm{F} \mu=\left(\begin{array}{l}
1.5 \\
2.0 \\
2.5 \\
3.0 \\
3.5 \\
4.0 \\
4.5
\end{array}\right) \quad
\end{aligned}
$$


Force Reduction Factors for the Structural Design and Evaluation of Facilities Containing Nuclear and Hazardous Materials

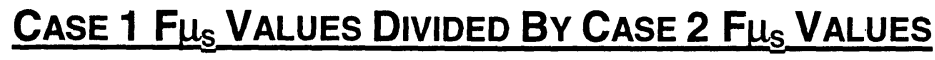

$$
\begin{aligned}
\mathrm{n}^{\mathrm{T}} & =\left(\begin{array}{lllllll}
1.00 & 2.00 & 3.00 & 4.00 & 5.00 & 6.00 & 7.00
\end{array}\right) \\
\text { Ratio1_2 } & =\left(\begin{array}{lllllll}
1.00 & 0.98 & 0.98 & 0.98 & 0.98 & 0.98 & 0.98 \\
1.00 & 0.96 & 0.95 & 0.94 & 0.94 & 0.94 & 0.94 \\
1.00 & 0.94 & 0.92 & 0.91 & 0.90 & 0.90 & 0.90 \\
1.00 & 0.93 & 0.89 & 0.88 & 0.87 & 0.87 & 0.87 \\
1.00 & 0.91 & 0.87 & 0.85 & 0.84 & 0.84 & 0.83 \\
1.00 & 0.90 & 0.86 & 0.83 & 0.82 & 0.81 & 0.80 \\
1.00 & 0.90 & 0.84 & 0.81 & 0.80 & 0.78 & 0.78
\end{array}\right) \quad F \mu=\left(\begin{array}{l}
1.5 \\
2.0 \\
2.5 \\
3.0 \\
3.5 \\
4.0 \\
4.5
\end{array}\right)
\end{aligned}
$$

The following tables examine Case 3 for defining the relationship between $F_{\mu}$ and $\mu$ (also, $F \mu_{\mathrm{s}}$ and $\mu_{\mathrm{s}}$ ) for the situation where the first story is the weak story (i.e., $\mathrm{k}=1$ ). For this example, NUREG/CR-0098 median rock amplification ground response spectra are used with a structure frequency of $6 \mathrm{~Hz}$ and a damping ratio of 0.05 :

\section{WEAK STORY IS FIRST STORY - CASE 3}

(FREQUENCY $=6 \mathrm{HZ}$ AND DAMPING RATIO $=0.05$ )

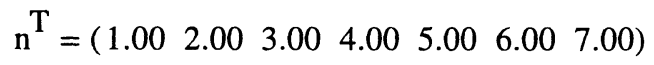

$$
\begin{aligned}
& F_{\mu \text { _result_3 }}=\left[\begin{array}{ccccccc}
1.50 & 1.39 & 1.39 & 1.40 & 1.39 & 1.37 & 1.35 \\
2.00 & 1.81 & 1.70 & 1.62 & 1.57 & 1.52 & 1.48 \\
2.50 & 2.13 & 1.98 & 1.88 & 1.80 & 1.74 & 1.69 \\
3.00 & 2.35 & 2.14 & 2.02 & 1.93 & 1.86 & 1.80 \\
3.50 & 2.73 & 2.31 & 2.16 & 2.06 & 1.98 & 1.91 \\
4.00 & 3.11 & 2.61 & 2.30 & 2.18 & 2.09 & 2.02 \\
4.50 & 3.48 & 2.92 & 2.55 & 2.30 & 2.19 & 2.12
\end{array}\right] \quad F \mu=\left(\begin{array}{l}
1.5 \\
2.0 \\
2.5 \\
3.0 \\
3.5 \\
4.0 \\
4.5
\end{array}\right)
\end{aligned}
$$




\section{CASE 1 Fu $\mu_{S}$ Values Divided By CASE 3 F $\mu_{S}$ VALUes}

$$
\begin{aligned}
\mathrm{n}^{\mathrm{T}} & =\left(\begin{array}{lllllll}
1.00 & 2.00 & 3.00 & 4.00 & 5.00 & 6.00 & 7.00
\end{array}\right) \\
\text { Ratio1_3 } & =\left[\begin{array}{lllllll}
1.00 & 0.93 & 0.90 & 0.86 & 0.84 & 0.89 & 0.83 \\
1.00 & 0.92 & 0.88 & 0.86 & 0.85 & 0.85 & 0.84 \\
1.00 & 0.94 & 0.88 & 0.85 & 0.83 & 0.82 & 0.81 \\
1.00 & 0.99 & 0.93 & 0.89 & 0.86 & 0.84 & 0.83 \\
1.00 & 0.98 & 0.98 & 0.93 & 0.89 & 0.87 & 0.85 \\
1.00 & 0.97 & 0.96 & 0.96 & 0.92 & 0.89 & 0.87 \\
1.00 & 0.96 & 0.94 & 0.94 & 0.94 & 0.91 & 0.89
\end{array}\right] \quad \mathrm{F} \mu=\left(\begin{array}{l}
1.5 \\
2.0 \\
2.5 \\
3.0 \\
3.5 \\
4.0 \\
4.5
\end{array}\right)
\end{aligned}
$$

Finally, the question of whether reasonable differences in the inertial weights, $\mathrm{W}_{\mathrm{i}}$, and elastic displacements, $\delta_{e_{j}}$, up the height of a structure would significantly change $F \mu_{s}$ is addressed. The general equation for $\mu_{\mathrm{s}}$ where $\mathrm{W}$ and $\delta_{e}$ are variable is as follows:

$$
\mu_{\mathrm{s}}=1+(\mu-1) \cdot \frac{\sum_{\mathrm{i}=\mathrm{k}}^{\mathrm{n}} \mathrm{w}_{\mathrm{i}} \cdot \delta_{\mathrm{e}_{\mathrm{k}}}}{\sum_{\mathrm{i}=1}^{\mathrm{n}} \mathrm{w}_{\mathrm{i}} \cdot \sum_{\mathrm{j}=1}^{\mathrm{i}} \delta_{\mathrm{e}_{j}}}
$$

Assuming the distributions on $\mathrm{W}$ and $\delta_{\mathrm{e}}$ are lognormal with median values of 1 and logarithmic standard deviations of 0.2 for each distribution, a random sample of $F \mu_{\mathrm{s}}$ for each pair of number of stories, $\mathrm{n}$, and ductility values $\mathrm{F} \mu$ for Case 1 with weak story at the base (i.e., $\mathrm{k}=1$ ) give the following median and logarithmic standard deviation values for $\mathrm{F} \mu_{\mathrm{s}}$ : 
Force Reduction Factors for the Structural Design and Evaluation of Facilities Containing Nuclear and Hazardous Materials

WEAK STORY IS FIRST STORY - CASE 1

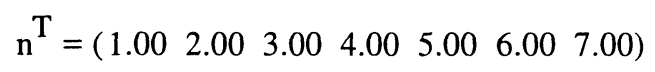

As seen from this table, the variability in $\mathrm{F}_{\mathrm{s}}$ (i.e., BETA $\mathrm{F} \mu_{\mathrm{s}}$ ), is small for reasonable variability in the inertial weights and elastic story displacements (i.e., $\beta=0.20$ for both). Thus, assuming equal values for both variables is a reasonable assumption. Results for ductilities in the range of 4 to 8 yield similar results.

\section{CONCLUSION}

Comparing Cases 2 and 3 to Case 1 it is seen that Case 1 values for $F \mu_{s}$ are conservative for the situation where the weak story is the first story. The same conclusion is also found when the weak story is moved higher up the structure. The formulation for the Case $1 \mathrm{~F}_{\mathrm{s}}$ equation is simpler than for the other two cases. Also, this equation gives a reasonable degree of sensitivity for number of structure stories and the location of the weak story relative to the base. Considering the conservatism and simplifications incorporated into the development of the element $\mathrm{F} \mu$ values given in Section 4.4 of ASCE Standard XXX the expression for $F \mu_{s}$ based on the Case 1 assumptions (i.e., $\mathrm{F}_{\mu}=\mu$ and $\mathrm{F} \mu_{\mathrm{S}}=\mu_{\mathrm{S}}$ ) is consistent and appropriate for the Standard.

\section{REFERENCES}

DOE Standard - Natural phenomena Hazards Design and Evaluation Criteria for Department of Energy Facilities, U.S. Department of Energy, Washington, D.C. 20585, DOE-STD-1020-94, April 1994.

Kennedy, R.P., et. al., Engineering Characterization of Ground Motion - Task 1, Effects of Characteristics of Free-Field Motion on Structural Response, NUREG/CR-3805, Nuclear Regulatory Commission, May 1984. 